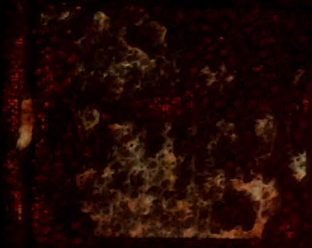




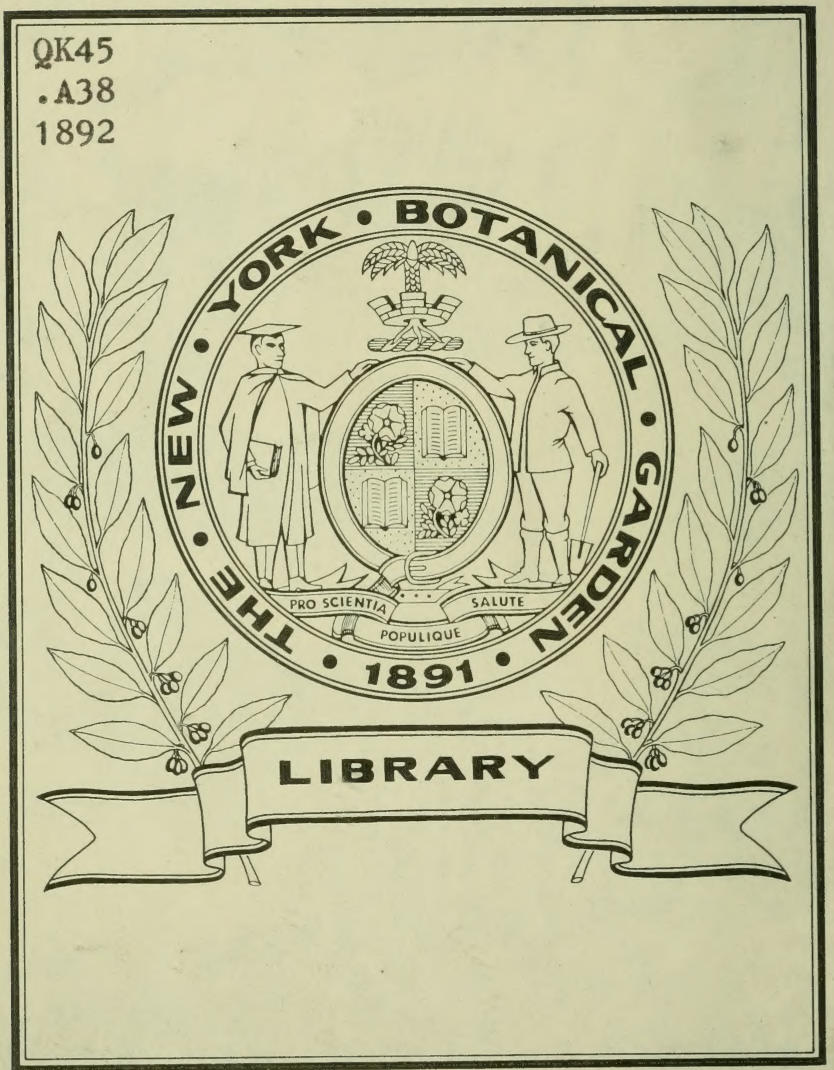






\section{THE FLOWERING PLANT.}




\title{
Liv the same Author.
}

In large crown 8vo, handsome cloth, 12s. $6 \mathrm{~d}$.

\section{AN INTRODUCTION TO BIOLOGY,}

\author{
For the Use of Students.
}

Comprising Vegetable and Animal Morphology and Physiology.

By J. R. A. DAVIS, B.A.,

Lecturer on Biology at the University College of Wales, Aberystwyth.

\section{GENERAL CONTENTS.}

Part I. Vegetable Morphology and Physiology: Fungi; Algæ; The Moss; The Fern; Gymnosperms; Angiosperms.

Comparative Vegetable Morphology and Physiology ; Classification of Plants.

Part II. Animal Morphology and Physiology : Protozoa; Colenterata; Vermes; Arthropoda; Mollusca ; Amphibia; Aves; Mammalia.

Comparative Animal Morphology and Physiology ; Classifition of Animals.

With Bibliography, Examination Questions, Complete Glossary, and 158 Illustrations.

"Furnishes a clear and comprehensive exposition of the subject in a systematic form. For the highest three groups of animals the types described are the frog, the pigeon, and the rabbit. So full are the details of the Morphology, Physiology, and Development of these three types, that 150 pages are occupied in their description, illustration, and comparison. Yet nowhere does there seem to be a single phrase in excess. A valuable Bibliography is appended, besides Index-Glossary."-Saturday Review.

"The volume is literally packed with information." Glasgow Medical Journal.

" As a general work of reference, Mr. Davis' Manual will be highly serviceable to amateur or professional scientists." --British Medical Journal.

LONDON : CHARLES GRIFFIN \& COMPANY, LIMITED Exeter Street, Strand. 


\section{THE FLOWERING PLANT:}

AS ILLUSTRATING THE

\section{FIRST PRINCIPLES OF BOTANY.}

BY

\section{J. R. AINSWORTH DAVIS, B.A.,}

TRINITY COLLEGE, CAMBRIDGE;

PROFESSOR OF BIOLOGT AND GEOLOGY IN THE UNIVERSITY COLLEGE OF ABERYSTWYTH; $\triangle U T H O R$ OF "A TEXT-BOOK OF BIOLOGY."

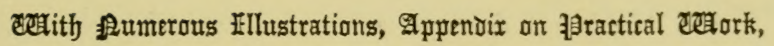
AND EXAMINATION QUESTIONS.

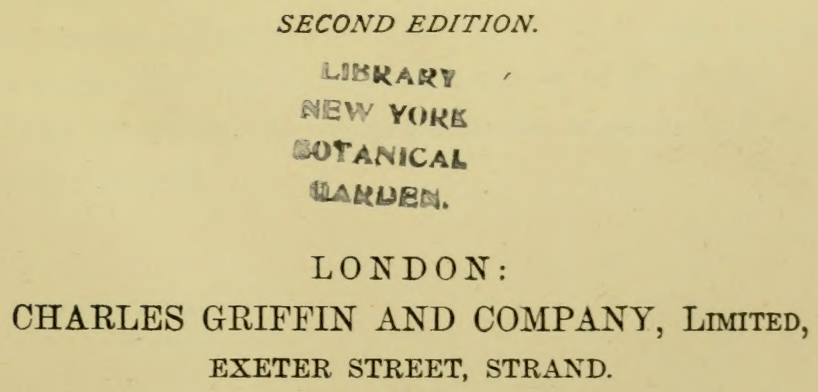


QK45
.$A 38$

1892 


\section{PREFACE.}

THE present work has been written with the intention of illustrating the First Principles of Botany by means of common Flowering Plants. No previous knowledge is assumed, and the style is made as simple as possible, the technical terms necessary being carefully explained as they occur. The paramount importance of Practical Work is insisted on throughout, and, wherever possible, easily obtained objects are described instead of rare ones, so that the student can readily verify most of the facts mentioned. A short Practical Appendix is also added.

No attempt has been made to "write up" (or "down") to any syllabus, but it is believed that the book will meet the requirements of most Elementary Examinations in Botany. A selection of South Kensington and London Questions has been appended.

My best thanks are due to Professor J. von Sachs for permission to use several figures; and also to my friend and former colleague, Mr. John Brill, M.A., who has given me much kind help during the progress of the work.

Any corrections or suggestions for improvement will be gladly received.

J. R. A. D.

ABERYSTWYTH,

December, 1889 . 



\title{
CONTENTS.
}

\section{CHAPTER I.}

\section{INTRODUCTORY.}

PAGE

Scope and Subdivisions of the Subject . . . . . . . I

Differences between Plants and Animals . . . . . . 2

Differexces betweex Living axd Non-Living Matter . . . 4

CHAPTER II.

ELEMENTARY MORPHOLOGY AND PHYSIOLOGY.

Members and Organs

Structure of Plants . . . . .

Life under Simple Conditions . . . . . . . . . 8

CHAPTER III.

THE ROOT.

MoRPhOLOGY .

Physiology

CHAPTER IV.

THE STEM.

MORPHOLOGY . . . . . . . . . . . . 2 I

PHYSIOLOGY . . . . . . . . . . 4 . 4 I

\author{
CHAPTER V. \\ BUDS AND LEAF ARRANGEMENT . . 46
}

CHAPTER VI.

FOLIAGE AND SCALE LEAVES.

MoRPHOLOGY . 
CHAPTER VII.

BRACTS AND FLORAL LEAVES.

General Description .

INFLORESCENCE

Symmetry of Flower

Flokal Receptacle

Relation of Parts

Calyx

Corolla

CHAPTER VIII.

ESSENTIAL FLORAL LEAVES.

Stamens

Carpels

OvUles .

Proof that Flower is a Shoot

\section{CHAP'TER IX. \\ PHYSIOLOGY OF FLOWERS.}

Protection

Respiration .

Reproduction

Pollination .

Cross-Pollination

Self-Pollination .

Fertilization

Motility, Irritability, and Spontaneity

CHAPTER X.

SEEDS AND FRUITS.

MORPHOLOGY . Physiology .

APPENDIX A.

PRACTICAL WORK

APPENDIX B. 


\section{LIST OF ILLUSTRATIONS.}

FIG.

1. Sectional View of a Unicellular Plant (original) . . . . 9

2. Diagram of a Dicotyledon (Sachs) . . . . . . . . I5

3. Seedling of White Mustard (Sachs) . . . . . . . . IS

4. Diagram of a Young Maize Plant (Sachs) . . . . . . 22

5. Diagrams of Anatomy of Vegetative Organs (Prantl) . . . 29

6. Structure of Sunflower Stem $($ Prantl $)$. . . . . . 33

7. Minute Structure of Vegetative Organs (Prantl and original) . . 35

8. Secondary Thickening of Stem (Sachs) . . . . . . 37

9. Phyllotaxis of Cherry . . . . . . . . . . 50

Iо. Part of Grass Leaf . . . . . . . . . 53

I 1. Base of Willow Leaf . . . . . . . . . . . 53

12. Bipinnate Leaf of Acacia . . . . . . . . . 54

13. Oblique Leaf of Elm . . . . . . . . . . 55

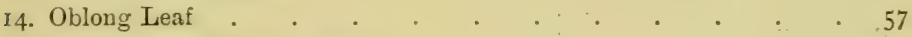

15. Spathulate and Oval Leaves . . . . . . . . . 57

I6. Rounded and Arrow-Shaped Leaves . . . . . . 57

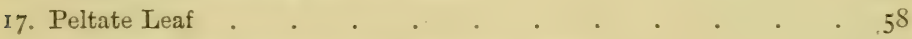

18. Lanceolate, Awl-Shaped, and Whorled Leaves . . . . . . $5^{8}$

I9. Ovate Leaf . . . . . . . . . . . . 58

20. Cordate Leaf . . . . . . . . . . . . . $5^{8}$

2I. Kidney-Shaped, Elliptical, and Abrupt Leaves $\quad . \quad \ldots \quad 5^{8}$

22. Oak Leaf . . . . . . . . . . . 59

23. Poppy Leaf : . . . . . . . . . . 59

24. Pinuate Leaf . . . . . . . . . . . . 60

25. Strawberry Leaf . . . . . . . . . . . 60

26. Horse-Chestnut Leaf . . . . . . . . . 6c

27. Pitcher of Nepenthes . . . . . . . . 62

28. Leaf of Knot-Grass . . . . . . . . . . 64

29. Leaf of Scarlet Runner . . . . . . . . . 72

30. Flower of Buttercup . . . . . . 675 
FIG.

31. Raceme of Barberry

32. Spike of Verbena

77

33. Spadix of Arum

34. Section of Fig .

78

35. Forked Cyme . . . . . . . . . . . . . 79

36. Helicoid Cyme of Forget-me-Not . . . . . . . . 79

37. Relation of Parts of Flower (Prantl) . . . . . . $8 \mathrm{I}$

38. Floral Diagram of White Lily (original) . . . . . . . 82

39. Floral Leaves of White Water-Lily . . . . . . . . 87

40. Flower of Rose . . . . . . . . . . . . . . . 87

41. Petal of Pink . . . . . . . . . . . . . 88

42. Sweet Pea . . . . . . . . . . . . . . . . 88

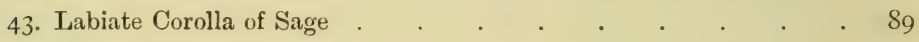

44. Ligulate Floret . . . . . . . . . . 90

45. Flowers of Scotch Fir (original) . . . . . . . . 93

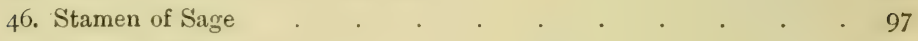

47. Pollinia of Orchid . . . . . . . . . . . . 97

48. Placentation and Ovules $($ Prantl) . . . . . . . . . 104

49. Diagram of a Flower . . . . . . . . . . IoS

50. Flower of Grass . . . . . . . . . . . . . II7

5I. Structure of Pansy (Sachs) . . . . . . . . . 128

52. Early Purple Orchis (original) . . . . . . . . . 129

53. Section of Albuminous Seed . . . . . . . . . . I33

54. Section of a Maize Fruit (Sachs) . . . . . . . . 134

55. Fruit of Mulberry . . . . . . . . . . 135

56. Achene of Buttercup . . . . . . . . . . . . . . 136

57. Splitting Fruit of Geranium . . . . . . . . . . 137

58. Samaras of Sycamore . . . . . . . . . 137

59. Diagrams of Capsules (original) . . . . . . . . . 138

6o. Pyxidium of Henbane . . . . . . . . . . ${ }_{13} \mathrm{~S}$

6r. Browning's Field Microscope . . . . . . . . . I58 


\section{THE FLOWERING PLANT.}

\section{CHAPTER I.}

\section{INTRODUCTORY.}

Scope and Subdivisions of the Subject.-The science of Botary endeavours to answer all questions relating to plants. It is subdivided into numerous branches, which share these questions between them.

The query, "What is its shape, and why is it so ?" is answered by Vegetable Morphology. This deals not only with outward form (Descriptive Botany), but also with inward form or structure, the larger details of which can be made out by the unaided eye or by means of a lens (Vegetable Anatomy), while the finer points cannot be cleared up without the help of a compound microscope (Vegctable Histology). Another primary question is, "How does it act?" and this time the answer is given by Vegetable Physiology. But plants may also be considered in relation to one another. Resemblances and differences are apparent even to the most casual observer. Such a word as "lily" is the expression of a popular conviction that certain flowers (white lily, tiger lily, \&c.) have a general resemblance to one another, and are at the same time different from other plants, such as "grasses," for example. Arrangement into groups according to resemblances and differences is Classification, and the question, "How are plants arranged, or how relaterl?" is answered by Systematic Botany, which is the application of classification to the regetable rorld. Any merely popular classification, as into "lilies," "grasses," dcc., is of necessity unsatisfactory, for resemblances and differences must be noted with a critical eye. An "arum lily," for example. is quite different from other lilies, and the name is incorrect. Systematic Botany has two chief uses. It enables us, in the first place, to remember a far greater number of facts than would he possible without a methodical arrangement. And, again, the 
resemblances which connect plants into groups are not the result of mere chance, but express actual relationship, what, in animals, would be called "blood"-relationship. The different groups of plants do not form a "linear series," i.e., they cannot, as regards affinity, be placed in a line, the most complex members of one group coming just below the least complex of the next group, and so on ; but they naturally fall into a tree-like arrangement. This is now believed to represent, in a general sort of way, a genealogical tree. The second great use of Systematic Botany is, therefore, to help in the construction of plant-genealogies. Apart from the great theoretical interest attaching to this kind of work, there is a very practical application affecting medicine and many manufactures. Broadly speaking, closely related plants have similar. properties, and a classification which represents affinities with fair accuracy will be of the greatest service in the search for new drugs, dyes, fibres, \&c., \&c. 'The uses, if any, of a newly-discorered plant can also be judged of with some accuracy even without experiment. The branch Economic Botany, which deals with the question, "Of what use to man?" is therefore an appendix to Systematic Botany. The present volume, however, has little or nothing to do with this branch, nor is it concerned with Geographical and Fossil Botany, which endearour to answer the questions, "Where found?" and "When found?" that is to say, try to elucidate problems regarding distribution in space and time.

Differences between Plants and Animals. - It might at first be thought that plants, with which Botany deals, could easily be distinguished from animals, which form the sulject-matter of the sister science, Zoology. No one is in danger of confounding a cow with a cabbage, and, as a matter of fact, ordinary plants are marked off with sufficient distinctness. But when we come to lower forms, often of minute size, it is frequently rlfficult to say for certain whether a given form be plint or animal. The recognition of this fact has emphasized the close connection between the two divisions of the organic world, and called into existence the science of Biology, which deals with life generally, and includes both Botany and Zoology.

The largest subdivisions of the vegetalble kingdom are those of Flowerless Plants (Cryptogams) and Flowering Plants (Phanerogams), without and with conspicuous flowers respectively. What flowers exactly are will be seen in the sequel. We shall here deal, from an elementary point of view, with Flowering Plants only. These differ from animals in several important particulars :-

(г.) A typical member of the group is dependent upon gaseous 
food, contained in the air, and liquid food, present in the earth. These are sucked in or absorbed by the general surface of the body, the area of which is much increased by the freely-branched or diffuse form so characteristic of plants. Animals, on the other hand, utilize a great deal of solid food, which is usually taken in by a mouth, and received into a digestive cavity, where it is, to a greater or less extent, brought into a state of solution, or else of fine division. The shape of animals is compact, in accordance with the solid nature of their food.

(2.) Again, plants, at any rate green plants, live on very simple food, namely, the carbon dioxide or carbonic acid $\left(\mathrm{CO}_{2}\right)$ of the air, and watery solutions of mineral substances (salts) contained in the soil. These they can build up into the complex substances composing their own bodies. Animals require complex food, derived from plants or other animals.

(3.) The nature of the food also exerts an influence upon the plant or animal in another direction. The air and earth are full of plant-food, and, by extending branches of the stem and root into them, a tree or herb can obtain an abundant supply. Hence powers of spontaneous locomotion are not possessed by plant. The complex food of animals is less uniformly distributed, and conspicuous powers of locomotion are generally possessed by them, one main aim being to find and secure suitable food.

(4.) Higher animals are also characterized by the possession of a nervous system, i.e., organs for regulating the body generally and rendering it sensitive to external influences. There are central organs (brain and the like) exerting control, and these are placed in communication with all parts of the body by definite strands or nerves, along which impulses pass, and the sole use of which is to convey such impulses. No such arrangement is found in any known plant, although a local sensitiveness is sometimes exhibited (e.g., sensitive plant).

(5.) It may be mentioned as a further point, that plant-hair's and membranes are largely composed of a complex substance, cellulose, allied to starch and composed of carbon, oxygen, and hydrogen. Cotton is a very pure form of this body. In the animal kingdom cellulose is mainly conspicuous by its absence.

Exceptions. - The preceding tests are not absolute, even among the higher plants. Some few are not green (e.g., clover-dodder), and these, like animals, require complex food, though this is not taken into the borly as solid particles. Such forms are termed parasites when they prey upon living organisms, saprophytes when they subsist on complex compounds derived from the deal bodies of plants or animals. The "insectivorous" or "carnivorous" plants, again, partly live on flies and the like, parts of 
which they reduce to solution, often in a kind of external stomach (e.g., pitchers of the pitcher plant). On the other hand, some animals, all rather low in the scale, contain chlorophyll, and by its means utilize the carbon dioxide of the air and simple salts dissolved in the water around them; and it is not unlikely that animals exist which contain so much chlorophyll as to obviate altogether the necessity for solid food. Some comparatively high animals, such as the tapeworm, which are not green, can dispense with such food in another way. They live as endo-parasites, i.e., within other animals, and feed at their expense on the soluble products of digestion, which, however, are by no means simple in composition. This mode of life may, and often dloes, do away with the necessity for an internal digestive cavity, as in the example quoted.

The branching form and absence of locomotor powers cease to be plant-tests among many microscopic forms, which may be oval or spherical, and capable of the most active locomotion. And many comparatively high animals (oyster, \&c.) are sedentary, though their embryos swim actively about. There is no trace of a nervous system in the lowest animals; and, lastly, cellulose is not exclusively a vegetable product. It is found in some few animals, as, e.g., the sea-squirts (Ascidians).

But in spite of these partial exceptions, there is no difficulty whatever in distinguishing plants from animals, except in the very lowest forms. These are believed to be nearer a common stock from which all organisms have sprung; and are, therefore, more alike than are the higher plants and animals, which have diverged more or less in different directions from that stock.

Differences between Living and Non-Living Matter.-At this point the question naturally arises, "How does organic living matter differ from inorganic non-living matter?" Here, so far as we yet know, sharp boundary-lines can be drawn.

(г. $)^{1}$ The elementary chemical substances, some seventy in number, are supposed to be ultimately made up of infinitely minute particles, atoms. Even in an element, these are built up into small aggregates or molecules, while the molecules forming chemical compounds are built up from more than one kind of atom, and are the smallest quantities in which a compound can exist as such. When a very large number of atoms enter into a molecule, it is said to be complex, and this is characteristic of the compounds of which organisms are composed. All plants and animals are essentially made up of a jelly-like substance, known as protoplasm, the molecule of which is undoubtedly of extreme complexity.

1 Students who have read no chemistry are strongly advised to work through such a book as Roscoe's Primer. 
Protoplasm has been called the "physical basis of life," because life, whatever that may be, is always associated with it. In fact, some very simple organisms are entirely (or mainly) composed of protoplasm. The Amoba, for example, one of the lowest of animals, is a minute speck of semifluid protoplasm, which, notwithstanding its simplicity, can and does perform all the functions of life. Generally, however, the existence of protoplasm is more or less hidden by the presence of other substances, formed by or from it, or taken in from the outside. Take, for example, a peeled potato. This is mostly made up of an immense number of microscopic comprartments (cells or units of structure), each of which contains its modicum of protoplasm. The walls of the compartments are made of cellulose, which forms a firm framework, and each of them contains a large number of minute granules of starch. Both cellulose and starch, which form the obrious parts of the potato, are formed from protoplasm. This itself is far less evident, but makes up part of the slime that may be observed on the peeled surface. The vital substance of which we are speaking is, like most very complex compounds, very unstable. After death it breaks down at once, not into elements, but into other simpler compounds, which enter into the composition of its molecule. These simpler compounds are, however, very complex themselves. The most important of them are proteids, composed of a great many atoms of carbon, hydrogen, oxygen, nitrogen, sulphur, and perhaps, in some cases, phosphorus. If, then, the composition of the proteid molecules is so complex, it is obvious that the molecule of protoplasm must be far more so.

It must not be imagined, from what has just been sail, that we know enough of protoplasm to regard it as a chemical compound of definite composition. Nor is to be supposed that all the substances found in protoplasm by chemical analysis necessarily help to build up its living molecules. For "protoplasm" appears to consist of an excessively fine network of living organized matter, the meshes of which enclose other substances that are unorganized and not living.

(2.) Organisms are also characterized by the nature of their external form, which is definite, and bounded by more or less curved surfaces. Non-living matter either has no very particular form (i.e., is amorphous), or else assumes a regular crystalline shape. Crystals are geometrical forms, which are almost always bounded by flat surfaces meeting in sharp edges.

(3.) Furthermore, organisms exert a great deal of kinetic energy, and this is gained by the breaking-down of the protoplasm into simpler substances. A complex chemical molecule is a store of potential energy, and this is changed into the kinetic form by 
the breaking-down of the molecule. The instability of organic matter is due, not only to its complexity, but also to the presence of nitrogen as a component. This element does not readily combine with other elements, and the union, when effected, is a very weak one. The continual wasting of organisms must be made up for by the taking in of food from the exterior, which is built up into new protoplasm. All the protoplasmic parts of an organism are continually breaking down, and new molecules are, therefore, formed in all parts of the body. In brief, an organism undergoes constant waste and as constant renewal.

(4.) If more food is taken in than is necessary to make up for waste, growth may result to a certain extent, and this is effected by formation of new molecules in all parts of the body (intussus(eption). A plant or animal is, then, only constant as regards form, and not as regards the substance of which it is composed. This has been illustrated by comparison with a whirlpool, which may remain for a long time constant in shape, though new particles of water are constantly entering it to replace those passing out.

Inorganic matter does not undergo the constant breaking-down and renewal just described, and though it may exhibit a sort of growth, as seen in a crystal or a stalactite, this is not by intussusception, but by the addition of new layers to the outside (accretion). 'Thus the inner part of such a growing body is always older than the outer. Further, there is no fixed limit to this kind of growth, provided the external conditions are favourable.

(5.) Lastly, organisms have what may be called a definite lifelistory. ${ }^{1}$ They come into existence, carry on certain functions, attain a maximum size, and lastly die, when their bodies break lown into the simpler compounds from which they were originally derived.

Having defined Botany and indicated the boundary-lines which mark off organisms from inorganic matter and plants from animals, the importance of practical work must next be insisted on. The great use of all branches of Natural Science is to teach the habit of accurate and careful observation, and afterwards to build up theories on the facts thus obtained. Botany is extremely well suited to beginners in science, since abundant material is easily obtainable, and the instruments necessary in the early stages are comparatively few. Details will be found in the Appendix on Practical Work.

1 This term has recently been employed in a wider sense. 


\section{CHAPTER · II.}

\section{ELEMENTARY MORPHOLOGY AND PHYSIOLOGY.}

Members of a Plant.-An ordinary plant, e.g., sunflower, regarded from a morphological point of view, is composed of parts which, though they present a great variety of shapes, can all be classified under four main categories-Hair-structure, Root, Stem, and Leaf. By repetition of these members a plant is built up, and they have even been regarded by some as individuals collectively forming a colony. All structures which come under one of these four headings, as say that of hair-structure or "Trichome," are homologues, and are said to be homologous, or to display homology. This signifies an agreement in relative position and manner of origin. It does not mean that they are necessarily similar in shape or perform the same office in the economy, although this may be and often is the case. All hairstructures agree in being superficial nembers, developed from a skin-like coating, the epidermis, with which plants are clothed. Anything which agrees with this definition is a hair-structure, whether it be a thread, simple or branched, a scale, or what not. And again, some hair-structures keep off unwelcome visitors, others (as in horse-chestnut leaf-buds) form a kind of glue to protect the young leaves from cold, while still others assist in processes which lead to the formation and scattering of the seed, and so on.

Organs of a Plant.-If, on the other hand, a plant is regarded from a physiological standpoint, it is found to be made up of migans, i.e., structures fitted to perform special kinds of work. Thus we have organs of nutrition, organs of respiration, concerned with breathing, \&c., \&c. Organs belonging to any one of these categories are analogues, and are said to be analogous, or to display analogy. Relative position and mode of development are here of no moment, the essential agreement being solely in the nature of the work performed. Now, although all hairstructures, roots, stems, and leaves are respectively analogous to a large extent, they are by no means entirely so. Hair-structures, for example, may (as mentioned above) perform very different 
functions. And again, different members may be similar organs, and hence display analogy. Thus, among climbing plants, the ivy climbs by its roots, the convolvulus by its stem, the pea by modified leaves, and the hop by both stem and hair-structures

Structure of Plants. - Careful examination of plant-members shows that they are not homogeneous in structure. A thin skin can be peeled from the upper and lower surfaces of most leaves, and theu comes a green pulp, traversed by firmer strands, popularly called nerves or veins. They are the parts which make up "skeleton" leaves, the softer structures having rotted away. These different components of leaves, dc., are called tissues, and it can be shown by the microscope that they, in their turn, are made up of smaller parts known as cells and cell-derivates. These cells, which are the units of plant-structure, just as bricks and stones are in architecture, are for the must part microscopic, though sometimes of large size. The pulp of an orange, for example, is made up of such large cells, resembling in this case spindle-shaped bags, and containing a good deal of fluid. Botanical knowledge is based on the structure and physiological powers of cells, and the very simplest plants known (anil simplest animals too) are single cells, in other words, they are unicellular.

Life under Simple Conditions. - Without reference to any special example, we will consider the structure and conditions of life in one of these simplest forms, and then see what modifications exist in multicellular plants, i.e., those marle up of many cells.

The general form of the body in our ideal example is spherical, and this appears to be a common result of uniformly distributed external influences. The shape is distinct and permanent, owing to the presence of a firm elastic membrane, the cell-wall, which forms a kind of superficial skin. Within the wall, and forming a lining to it, comes a slimy layer, the protoplasm, and part of this is of different texture to the rest, and forms a firmer round or oval nucleus, which again contains a nucleolus. There are also present a number of granules of dense protoplasm, permeaterl with chlorophyll, a green colouring matter: These are chlorophyll granules. The larger internal space or vacuole is full of fluid, the cell-sap, which consists of water holding various substances in solution. It is also supposed to permeate the protoplasm and cellwall. A cell from the pulp of an orange corresponds fairly well with this description, but a slight modification of shape has taken place. So much for the morphology. The most essential physiological fact with which to start is that the protoplasm is the only living part of the cell. Very young cells contain no vacuole, which is produced later on, owing to the fact that growth in 
volume outstrips growth in mass. Cells are also known which possess no cell-wall, and this in all cases appears to be formed by the protoplasm, probably from transformation of a surface layer. Another important point is that the active vegetable cell is in a turgid state, i.e., the cell-wall is kept on the stretch by pressure from within. This turgidity, which causes the firmness of freshly-cut flowers, and the want of which makes them flaccid when faded, is a phenomenon largely independent of life in the plant. It is a wellknown physical fact that if two different liquids are separated by a membrane which both can moisten, diffusion currents will pass through the membrane in both directions, but not to an equal extent. The gain in volume

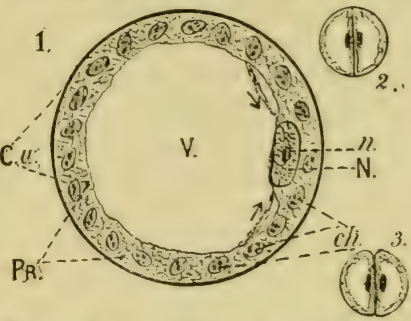

FIG. x.-Sectional View of a Unicellular Plant, much magnified. [Original.] I. C.w. cell-wall; $P r$. protoplasm; $N$. nucleus; $n$. nucleolus; $c h$. chlo. rophyll bodies (granules), the black dots in which represent starch; $V$. central vacuole, full of cell-sap; the arrows on right indicate direction of streaming movements in two protoplasmic threads. 2,3 . Stages in division; in 2 , the nucleus and protoplasm have divided, and a cellulose partition has been formed; in 3 , the two halves are beginning to separate. will be on the part of the liquid, usually the denser one, which can wet the membrane more readily. The phenomenon is called osmosis, the passage inwards being enclosmosis, that outwards exosmosis. These processes can be conveniently studied in an artificial cell, constructed in the following way :-A short piece of fairly wide glass-tubing, filled with a solution of sugar, is closed at both ends by vegetable parchment, and placed in water. Osmotic currents are set up, but more water passes into the denser sugar solution than vice versa, and the result is that the elastic parchment ends bulge out and are placed on the stretch. Some sugar, however, does diffuse out, and slightly sweetens the water outside. The natural cell turgesces in a similar way, but, of course, is bounded by an extensible membrane on all sides. If, at the end of this experiment, the external fluid is made denser than the internal, a flattening of the membranes takes place. Such flattening might also be caused by evaporation through the membranes. We now see in what way the ideal plant can feed, i.e., by taking in osmotically water that contains various salts and carbon dioxide in solution. The chemical nature of the liquids largely affects the rapidity of the osmotic currents, and the cell contains in its sap osmotically-active substances (e.g., organic acids), which increase endosmosis to a large extent.

Having considered the reception of food, the next point to be dealt with is the exact nature of that food. Information on this 
head is obtained in two ways-(I) by chemical analysis of plants ; (2) by cultivating them in various solutions, and determining which are most suitable.

The essential elements (always found on analysis, and compounds of which form a suitable food-solution) are the following :-Carbon, hydrogen, oxygen, nitrogen, sulphur, phosphorus, potassium, calcium, magnesium, and iron. The first six actually make up the plant-body, while the remaining four have a beneficial influence upon the vital processes. For example, chlorophyll cannot be formed when iron is absent. Carbon is obtained from carbon dioxide; hydrogen from water and ammonia or its compounds; oxygen from water and numerous salts; nitrogen from either ammonia and its salts, or else nitrates; sulphur from sulphates; phosplıorus from phosphates; potassium from various compounds, especially chloride; calcium and magnesium as sulphate, phosphate, nitrate, and carbonate; iron from numerous compounds.

Reception of food is followed by assimilation. That is to say, the simple food-substances are built up step by step into the complex compounds which constitute the plant-body. The first step consists in the formation of non-nitrogenous organic matter from carbon dioxide and water, with liberation of oxygen. The equation

$$
\mathrm{CO}_{2}+\mathrm{H}_{2} \mathrm{O}=\mathrm{CH}_{2} \mathrm{O}+\mathrm{O}_{2}
$$

carbon dioxide and water give non-nitrogenous matter and oxygen

roughly represents this. It must not, however, be supposed that the liberated oxygen is all derived from the carbon dioxide, though half must be, while the other half comes from the water: The oxygen in question passes off, at any rate to a large extent, into the surrounding medium. It is most esisential to remember that this process has nothing whatever to do with the breathing of plants.

This first step in assimilation, which bridges the gap between inorganic and organic compounds, can only be effected by the agency of chlorophyll in the presence of light. It has been already mentioned that kinetic energy is liberated when chemical compounds break down. Conversely, kinetic energy is converted into potential when chemical compounds are built up. The necessary kinetic energy appear's to be obtained by the chlorophyll from light-rays.

When organisms contain no chlorophyll, they cannot live on simple inorganic compounds only; hence the complex nature of animal food. There is also no evolution of oxygen.

The first visille product of assimilation is starch, which has a chemical composition closely allied to that of cellulose. 'The ultimate product of assimilation is protoplasm. 
The expenditure of energy on the part of plants involves, as previously mentioned, a constant decomposition of protoplasm. This has been termed Katabolism. Such products of breakingdown may be passed out of the organism or excreted. Carbon dioxide is such a vaste product, and the passage out of this (and water), with concomitant passage in of oxygen, is known as Respiration. The oxygen effects the decomposition, which is a process of oxidation. It is most important to remember that all organisms, plant and animal, with very few exceptions, respire or breathe, and in the same way, i.e., by taking in oxygen and giving out carbon dioxide. It is popularly, but rery erroneously, stated that "plants breathe in carbon dioxide and breathe out oxygen." Green plants do, in the presence of light, give off oxygen, as seen above, but this is simply a part of their food which they do not utilize. The amount of oxygen is so large as to disguise the fact that carbon dioxide is also being evolved, though in much smaller quantities. The true state of things becomes apparent at night, when, since the chlorophyll is not at work, the evolution of carbon dioxicle is not masked. This is why plants help to ritiate the air at night, and are therefore best excluded from a sleeping-room.

If a plant receires and assimilates abundant fool, it will grow to a certain extent, and also reproctuce or give rise to new individuals. Reproduction, in a simple unicellular form, such as we are considering, takes place most simply by division or fission into two equal parts (fig. I). The nucleus divides into two-a cellulose partition is formed across the cell, and the two halves gradually round off and separate.

Our example may also exhibit movements, and such Motility is most commonly seen in the form of currents in the protoplasm, which are renclered erident by the presence of granules (fig. I). These are swept along from place to place.

The last physiological heading is that of Irritability and Spontaneity. In other words, the organism is sensitive to agents or stimuli (mechanical, chemical, thermal, \&c.), which act upon it from without or within. Irritability means sensitiveness to external stimuli. The protoplasmic currents, for example, mentioned in the last paragraph, can, to a certain extent, be altered in rapidity by raising or lowering the temperature of the external medium. On the other hand, spontaneity is sensitiveness to internal stimuli. Movements of protoplasm, to take the same instance, are often so constant that it is scarcely possible to suppose them entirely the direct result of external influences. They must be regarded as spontaneous, or the result of internal stimuli, as chemical change, \&c., \&c. It must be borne in mind that 
movements and their modifications are only one result of spontaneity and irritability.

Multicellular plants carry on precisely the same functions as unicellular ones, namely :-

I. Nutrition (i.e., Reception and Assimilation of food).

2. Katabolism (including Respiration).

3. Reproduction.

4. Motility.

5. Irritability and Spontaneity.

Here, however, different cells undertake different functions, and are specially modified for the performance of those functions. In other words, physiological division of labour is accompanied by morphological differentiation. This principle is most strikingly exemplified in the highest, i.e., the flowering, plants; but all gradations of complexity are found in the vegetable kingdom, from the simple cell upwards.

In the following chapters, Root, Stem, and Leaf will be treaterl of ; and as Hair-structures may occur on any or all of these, they will not be dealt with in a separate chapter, but be mentionerl where necessary. 


\section{CHAPTER III.}

THE ROOT.

\section{MORPHOLOGY.}

A scxfloter or bean-plant may be regarded as consisting of two slender cones placed base to base (fig. 2). One of these, the primary stem, grows upwards ; the other, the primary root, downwards. When such a main axis forms the most prominent part of the root, it is said to be a tap-root, and this is rery strikingly seen in the carrot, turnip, and radish. The primary root generally possesses numerous branches, and these may be regarded as so many slender cones attached by their bases to the main one. These secondary roots are commonly in the form of tibres. But the primary root is very often extremely short, and in that case (e.y., grasses) the plant is fixed in the ground by means of arlientitious roots (fig. 4), which usually grow from the stem, but may also arise from the leaf-stalks or leaves. Such roots may also be present in aclition to the primary and secondary ones, as, for example, in the iry, where they are used for climbing. The "striking" of cuttings means the development of adventitious roots from the end of a piece of stem pushed into the soil. The majority of ronts are underground, but aquatic plants possess vater-roots, and air-roots are also known. These last may be the only ones present, as in many tropical orchids; or, as in the iry, they may exist in addition to roots of the ordinary kind. The orchids in question are epiphytes, that is to say, they simply live on other plants, but not at their expense. Plants exist, however, such as the clover-dodder, and mistletoe, in which the roots are parasitic, penetrating and deriving nourishment from the tissues of other plants.

Young roots are white or pale in colour, old ones generally hrown. Under no circumstances is the green colouring matter, chlorophyll, present. Leaves are never found upon the root.

The external form of a root system depends mainly on three things: ( $\mathrm{I}$ ) the presence or absence of a tap-root; (2) the nature 
and amount of branching; (3) the thickness. The branching is always monopodial, that is to say, the branches are not formed by forking, but arise as outgrowths from the side of a pre-existing axis. The thiclness partly depends upon the duration of life. In annuals, which live for one year only, the parts of the root system are usually of no great thickness. Biennials, which live for two years, develop in many cases a greatly dilated tap-root, which contains a store of reserve material that is used up the seconc? year, when flowering takes place, as in the carrot, turnip, and radish. Perennials, which live for more than two years, frequently have thickened roots, e.g., dahlia, where there is a bunch of secondary roots swollen into spindle-shaped bodies.

The structure of roots is somewhat complex, and can only be very briefly dealt with here. Just as (see p. S) a leaf is divisible into three systems of tissue, so also is a root. This may be conveniently illustrated by the main root of a young bean-seedling grown in damp sawdust. The younger part of this, i.e. the part near the tip, will be covered by a thin ill-defined skin, the epidermis, composed of a single layer of flattened cells, from which numerous delicate unicellular root-hairs grow out (cf. tig. $7, \mathbf{H})$. Such hairs are seen much better in the case of mustardseedlings (fig. 3). If the root is cleanly cut across and examinerl with a lens, an outer spongy-looking portion can be distinguisherl from an inner denser portion. These correspond, respectively, to a sort of external jacket, the cortex, and an internal firm vascular cylinder (cf. fig. 2). In roots which, like those of the? bean, increase in thickness, the epidermis and cortex are early thrown off, being replaced by a brown layer of cork formed in the outer part of the vascular cylinder. This may easily be made out in the roots of an old bean-plant. Suitable crosssections through the young root show that the secondary roots run in to the vascular cylinder. If the cortex is peeled off, which can be readily done, the secondary roots remain behind, attached to the cylinder. These roots then arise endogenously, i.e., from the internal tissue, and break their way through the cortex to the exterior (figs. 5, B, and $7, \mathrm{H}$ ). This way of origin is characteristic of all roots, primary, secondary, and arlventitious.

The cortex is composed of the second kind of tissue, which has received the name of fundamental or ground tissue. This term is a very broad and general one, and it must by no means be supposed that all the component cells are of the same shape or nature. On the contrary, several varieties of tissue may be included under. this system. The commonest and most important is parenchyma (fig. $7, \mathrm{H}$ ), which is made up of cells that are fairly equal in length, breadth, and thickness. The cells in question are not 


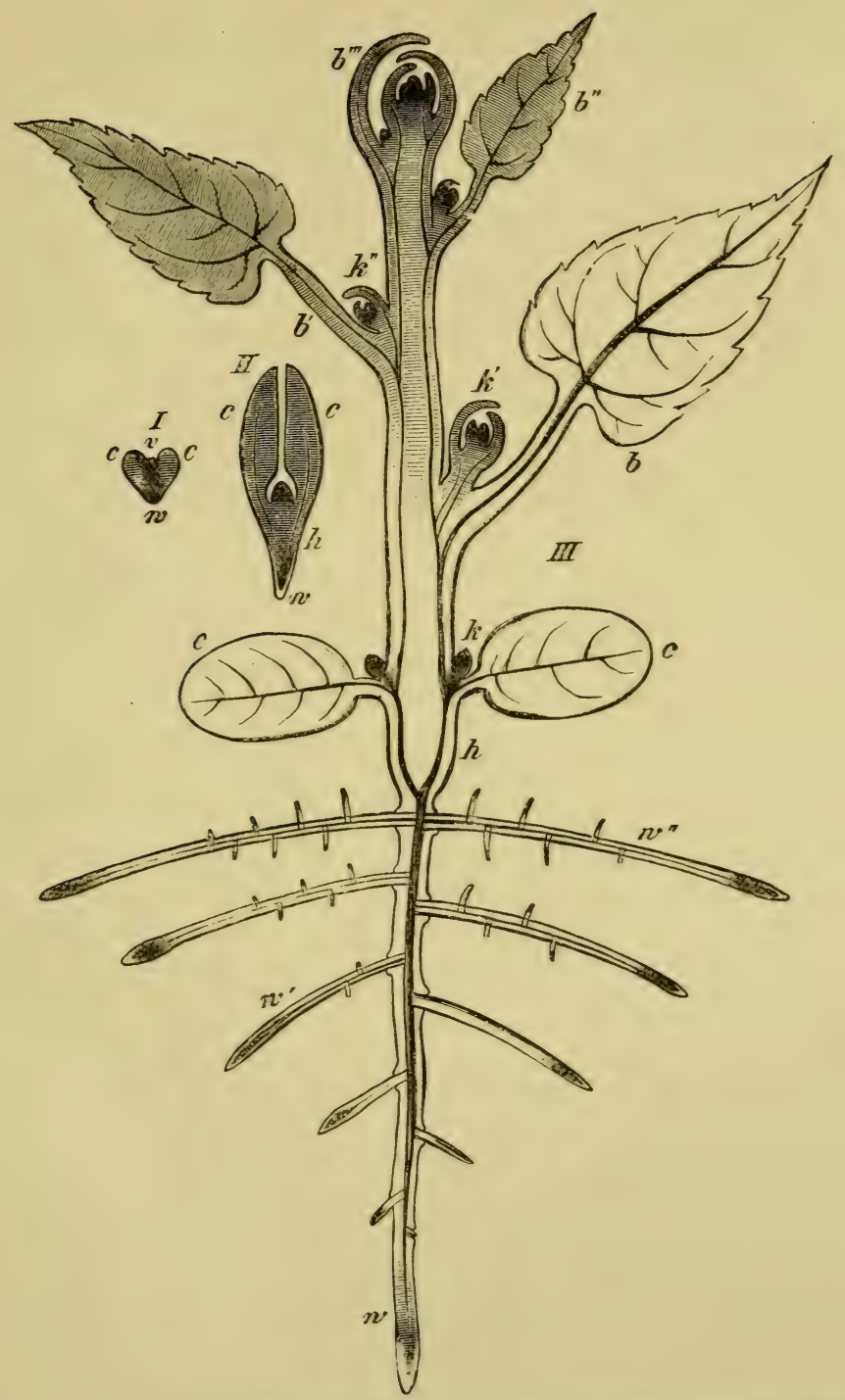

FIG. 2.-Diagram of a Dicotyledon [from Sachs]. I. and II. embryonic stages; III. after secondary roots (developing endogenously and germetally) $; h$, hypocotyl ; $c$, c, cotyledons : $b, b^{\prime}, b^{\prime \prime}, b^{\prime \prime \prime}$, leaves (developing exogenously acropetally); $h$, buck; the parts becoming elongated, grey. Root-caps white. 
spherical, but many-sided (i.e., polyhedral), a natural result of growing together in numbers. This point may be illustrated by pressing together soft clay pellets, when the spaces between them get filled up, and a many-sided form is consequently acquired. Mutual pressure is similarly exerted by growing cells owing to their turgidity (p. 9), and a spherical shape cannot therefore be assumed. In sections of parenchyma the constituent cells of course appear polygonal in outline. The cell-walls are of cellulose, and protoplasm with nucleus is present, with cell-sap in addition.

The vascular cylinder is chiefly made up of the vascular system of tissue, which is the most complex. It is composed not only of cells, but also of cell-derivates, i.e., structures derived from cells. In this case, the most important of them are tubular in nature, and may be broadly spoken of as vessels; hence the term "vascular" tissue. Their structures will be dealt with later on (pp. 3 I and 34). It is only necessary here to emphasize the fact that even in very young roots they are aggregated into a central "cylinder."

All roots are capable of increasing in length. Epidermis, cortex, and vascular cylinder gradually become more indistinct as the apex of the root is reached, and ultimately merge into a minute mass of small cells, which constitute the growing point. Their walls are extremely thin and their protoplasm abundant. New cells are continually being formed by divisions somewhat as described on p. II. Here, however, there is no rounding off, but those cells which are nearest the older parts of the root increase in size and alter in shape, ultimately becoming mature cells of the epidermis, \&c., \&c. The growing-point is not at the actual apex of the root. If it were so, its delicate cells would be exposed to constant injury from the hard particles of earth, against which they would be forced by the growth in length. The extreme end is occupied by a thimble-like sheath, the rootcap, which is made up of numerous layers of flattened cells, and covers over the growing-point, protecting it from injury (figs. 2 and 4). As the outer layers of the root-cap are worn away, new inner layer's are added by the growing-point. All roots are characterized by the presence of a root-cap, and it is present even in water-roots, as may be well seen by examining those of the duck. weed under a low power of the compound microscope. As a root increases in length, branches may arise from it. These are developed in regular order, the youngest being nearest the growingpoint (fig. 2). Technically described, they arise in acropetal succession. Adventitious roots are an exception to this.

Some roots increase not only in length but in thickness as well. This increase is effected by a cambium layer, situated within the 
vascular cylinder, and composeci of cells which differ from those of the growing-point chiefly in their elongated shape. Cambium and increase in thickness will be more fully spoken of on pp. 31 and 36 .

We are now in a position to make a somewhat wider classification of tissues. They may be grouped as follows :-

\section{Formative Tissue or Meristem.}

Composed of actively-dividing cells, with thin cellulose walls and abundant protoplasm.

I. Primary Meristem. Making up growing-points and the whole of very young structures.

2. Secondary Meristem or Cambium. Forming layers bounded internally and externally by permanent tissue.

\section{Permanent Tissue.}

Composed of cells not in a state of active division (though they may retain the power of dividing) and cell-derivates.

I. Epidermis. An external layer of flattened cells, to which hair-structures may be attached.

2. Ground-tissue. Largely composed of parenchyma.

3. Vascular system. Composed of cells and vessels.

\section{PHYSIOLOGY.}

The root of a land plant is protected to a great extent by its position in the soil, the root-caps protecting its delicate growingpoints from injury. The epiclermis at first protects from eraporation, and, in older examples, from which parts external to the vascular cylinder have peeled off, its place is taken by layers of cork (cf. p. 40).

The root serves as an organ of support to the stem and leaves. It is often firmly fixed in the soil by numerous branches, and the nature of the vascular cylinder is such as to give firmness. The root is essentially a regetative organ, i.e., is concerned with maintaining the life of the individual, and consequently plays a very important part in Nutrition, since, in land plants, all the food, with the exception of carbon dioxide, is absorbed by it. The soil is made up of variously-sized particles, with spaces between them, that contain, according to circumstances, more or less water with various substances dissolved in it, the part not thus occupied being filled with air. Part of this water is readily drained off, and has been termed free water, while the remainder is in the form of films that surround the particles. These films, constituting the hygroscopic water, are the part which furnishes the plant with nutriment, and may be looked upon as a natural food solution. The absorption is effected by the young epidermic cells 
and root-hairs, by means of osmosis, much as described on p. 9 . The particles of soil are also more or less corroded by the acid sap of the root-hairs, \&c., to which they closely adhere (fig. 3). This

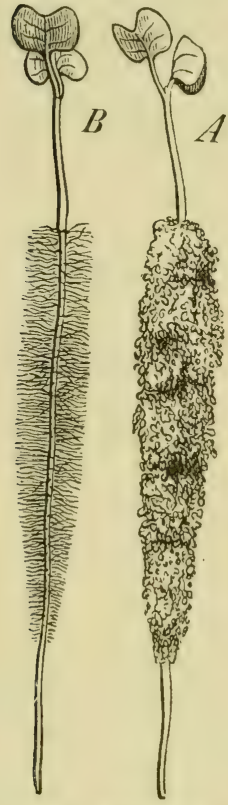

Ií. 3.- Seedling of White Mustard [from Sachs]. A. as taken out of the soil with particles of earth clinging to the roothairs; in B these have been removed by washing in water. Above are seen the two green expanded cotyledons; between these and the roothairs, the hypocotyl. permeates the cell-walls with which the particles come into close connection. If the roots of a plant are allowed to grow over a polished slab of marble, this will be corroded at the points of contact, and a kind of rough etching of the root system produced. Roots thus help in the preparation of the solutions which they absorb. This solvent action is aided by the carbon dioxide excreted in respiration. The roots of water plants can easily avail themselves of the surrounding medium with the substances dissolved in it. Parasitic roots come into such close relation with the tissues of the plant preyed upon, that they form a physiological part of it, and can by its means receive not only simple food, but also material that can at once be built up into protoplasm.

Circulation of Liquids. - The substances absorbed by the root ultimately reach the leaves by various routes and in various ways. Just as they can enter the root-hairs and young epidermal cells by means of osmosis, so can they in the same way reach cells that are more deeply situated, and so on. We also know that liquids travel very largely by means of certain vessels ( $f$. p. 4r), chiefly, as one would expect, in their interior. This has been noticed for a very long time in the case of vines. When these are pruner in spring, a great deal of sap exudes from the cut surfaces. In popular language, the plant "bleeds," and careful examination shows that the liquid oozes out from the cavities of the vessels. This phenomenon was formerly ascribed to a mysterious force called root pressure, operating before the leaves unfold. It was erroneously supposed that at other times liquids travel only in the walls of the vessels, and not within them.

Roots may perform another important office in nutrition, i.e., the storage of reserve materials, which are supplies of nutriment destined for use at some future time. The matter is chiefly stored as starch, but it may assume other forms, e.g., cane-sugar, as in the beet-root. 
Like all other parts of the plants, roots carry on Respiration. A supply of free oxygen is therefore necessary. In the case of aquatic plants this is dissolved in the surrounding water, while in land plants air is present in the interstices between the particles of soil, and enters the plant dissolved in the cell-sap. It is evident, therefore, that if these interstices get completely fillerl with water, the roots cannot respire properly (since, unlike water roots, they are not adapted for utilizing oxygen dissolved in water); hence the sickliness of orerwatered pot-plants. Carbon dioxide, of course, diffuses out of roots in respiration, and, as mentioned previously, helps to bring the food into solution.

Circulation of Gases. - Within the root gases can circulate as well as liquids. In fact, the cell-sap contains gases clissolved in it, which, of course, participate in its movements. There are, however, special channels for the circulation of gases, riz., (r.) the cavities of certain vessels, which, except in spring, contain no liquid, and (2.) intercellular spaces, which are chinks or crerices that exist between the cells of parenchyma and some other tissues, and which form a set of irregular but communicating channels.

It is comparatively seldom that Reproduction is effected by the root, and when this is the case, it is always regetative ( $c . f \cdot p \cdot 43)$, i.e., by development of ordinary leafy shoots; and not of special reproductive organs. One of the best examples is the common acacia (Robinia pseudacacia) of gardens, the roots of which spread horizontally and send up shoots that become new trees. Another case is that of the dahlia, which can be propagated from its roottubers.

Improbable though it may seem, the root exhibits a considerable amount of Motility. Protoplasmic morements occur in some root-hairs, and young growing root-tips are in constant slow movement from side to side, forcing their way between the particles of soil. The older parts of the root move in a different manner, i.e., they shorten, and this causes the plant to be anchored rery firmly in the ground. Rosettes of leaves like those of dandelion are thus prevented from being raised by growth of the stem. It has been remarked that a root burrows in the soil as an earthworm does. The narrow anterior end of this animal makes its way between the particles of earth; the rest of the body then shortens and is pulled up to it.

Irritability of the root is shown by its sensitiveness to various stimuli, such as gravity, light, moisture, and contact. Spontaneity is seen in the persistence of its movements. Geotropism refers to the influence of gravity in determining the direction of growth. Roots are positively geotropic, i.e., grow towards the earth's centre. The primary root takes a vertical direction, and the lateral ones 
a more or less oblique one. If a seedling is placed with its primary root in a horizontal direction, this will very soon curve round and grow downwards, while the stem curves upwards. By keeping seedlings in a state of slow revolution in a vertical plane, the effect of gravity is neutralized. The result is that root and stem do not in this case grow downwards and upwards, but have a tendency towards the horizontal direction. Heliotropism is the ter'm employed to designate the influence of light on direction of growth. Roots are generally negatively heliotropic, i.e., turn away from the light. Hydrotropism refers to the influence of moisture. Roots are positively hydrotropic in that they grow towards moisture. This is commonly the case with trees. If seedlings are placed in a perforated vessel full of damp moss, and the apparatus is then hung up, the primary roots will grow down as a result of positive geotropism, and make their way through the perforations. If the surrounding air is moist, the roots will continue to grow downwards, but if dry, they will bend up towards the damp moss. The tips of roots are also sensitive to contact, which causes them to curve.

It is evident that reaction to all the above stimuli is of such a nature as to fit the root for its share in nutrition. 


\title{
CHAPTER IV.
}

\author{
THE STEM.
}

\section{MORPHOLOGY.}

Just as the well-developed primary root may be regarded as a descending cone with apex below, so may the primary stem be looked upon as an ascending cone with apex above. This doublyconical shape is characteristic of gymnosperms and dicotyledons (fig. 2). In monocotyledons, where there is no tap-root, the stem is typically in the shape of a cone with apex downwards, which is fastened in the soil by adventitious roots which proceed from it (fig. 4). ${ }^{1}$

The stem must be looked upon as the most important part of the plant, since it is the only one always present. Hair-structures are by no means constant, leaves may be absent, as in duckweed, where the little flat green expansions are stem structures, and lastly, roots, in rare cases, are non-existent, as, for example, in a kind of duckweed (Wolffiu arrhiza), the body of which consists solely of a minute cellular green disc.

A stem not only bears, as a rule, secondary stems or brancher, which are similar to it in shape and structure, but also other

1 This is a convenient place to remark that plants are classified into sereral large groups, which are again subdivided, and so on, till at last we reach species. These include individuals which differ only in slight features, such as size, and are evidently descended from a common ancestor. The subdivisions of plants in order of size are: group, division, class, subclass, series, cohort, order (or family), genus, species. Flowering Plants form a group with two divisions : (r.) Gymnosperms, including pine, fir, yew, juniper, larch, cypress, \&c. ; (2.) Angiosperms, embracing most flowering plants, as, e.g., all those with coloured flowers. This division has two classes: $(a$.$) Nonocotyledons (the$ smaller division), taking in palm, arum, lily, tulip, onion, snowdrop, iris, sedges, grasses, \&c.; (b.) Dicotyledons, to which most British forms may be relegated, e.g., the majority of trees and shrubs, buttercup, wallfower, pink, poppy, violet, waterlily, geranium, gorse, rose, daisy, dead nettle, primrose, \&c., \&c.

Every plant has, for the sake of identification, a double scientific name, compounded of the names of its genus and species. For example, daisy is Bellis perennis. Bellis = genus, perennis = species. 
members, leaves, which usually differ considerably from it. This,

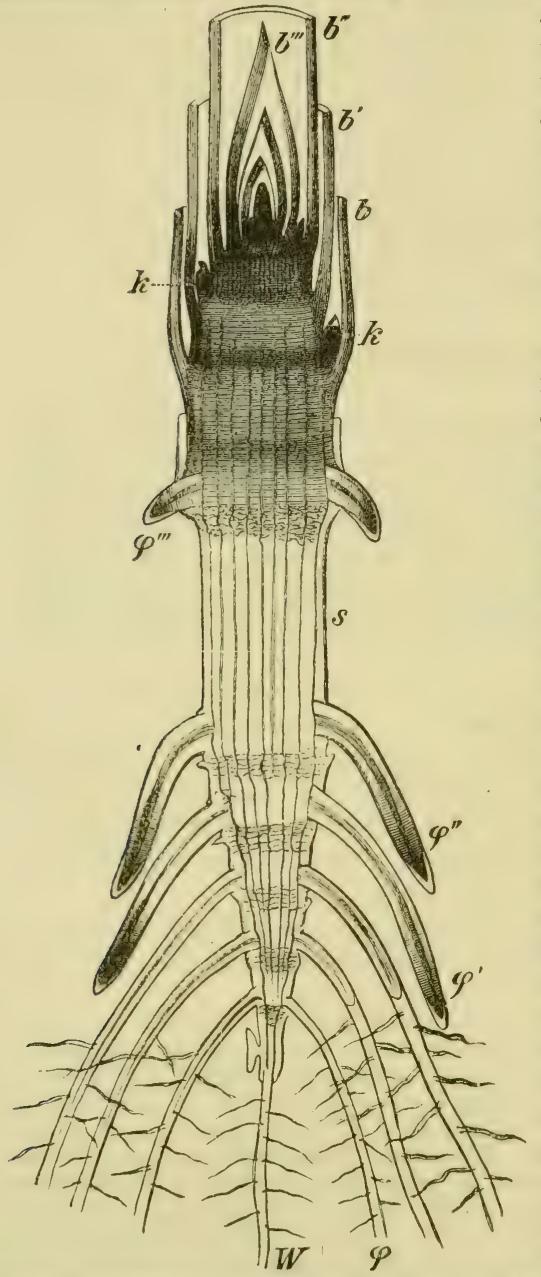
among other points, distinguishes the stem from the root. We have also seen that stems often bear adventitious roots (fig. 4), but this is not of primary importance, at least from a morphological point of view.

Stem and leaf are so constantly associated that it is impossible to treat of one without reference to the other. A collective name, that of shoot, has therefore been given to the stem with its leaves. The broadest grouping that can be made of plant members divides them into only two sets, viz., roots and shoots.

The regions of the stem to which leaves are attached receive the name of nodes, while the intervening portions are known as inter-nodes. Nodes are often thickenerl, and adventitious roots generally arise from them. Where a leaf joins the stem there is an upper. angle formed (usually acute), and a lower angle (usually obtuse). The former is known as the axil of the leaf. This

FIg. 4.- Diagrammatic Longitudinal Section through a point is mentioned here Young Iraize Plant (Zea mais) [from Sachs]. W. pri- because it is the rule
mary root; $\phi, \phi^{\prime}, \phi^{\prime \prime}, \phi^{\prime \prime \prime}$. adventitious roots springing endogenously from the stem $(s) ; b, b^{\prime}, b^{\prime}$. older in flowering plants for leaves, cut off short; $b^{\prime \prime \prime}$. young leaves of the terminal branch stems to arise
lud $k, k$. axillary buds. The growing points are represented black, the elongating parts grey; the in leaf-axils (figs. 2, 4, parts left white are fully grown. The white tips of and 35 ). Such branches,
the root are root-caps. 
as in the casse of the root, may be regarded as slender cones attached to the side of the primary one. Here, too, their succession is regular and acropetal. Adventitious stems may also he formed, and this is the nature of most of the slencler twigs which often sprout from old tree stumps.

The majority of stems are aririal, but water stems, partly or entirely submerged, are naturally present in marsh and water plants. Aërial stems are sometimes parasitic, as in clover-dodder, which possesses suckers on its stem that become intimately united with the stem of the clover: It is commonly imagined that all underyround structures are roots. This, however, is a mistake, since a great many stems are more or less subterranean.

The external form of a stem is influenced by a number of factors. The most obvious is that of sire and duration. Upon this depends the old and somewhat vague classification into herbs, shrubs, and trees, as well as the division already mentioned into annuals, biennials, and perennials.

Herls are plants, usually of no great size, in which either the whole plant dies after a year's growth (amnual herbs), or else the sulaërial portions die away every year (biennial and peremnial herbs). The stem is not at all or scarcely woody. Shrubs are perennials, mostly less than twenty feet high, with woody stems that branch from or near the ground. Trees are perennials, generally more than twenty feet high, with a distinct woody primary stem or trunt: There are, however, no sharp boundaries between these livisions. Herbs pass into shrubs, the intermediate small woody perennials being called undershiruls; and shrubs, again, are connected by all possible gradations with trees. The names herb, \&c., refer to the shape of the overground parts of the plants taken as a whole. The jorim of the inclividual stem is, in the majority of cases, cylindrical and solid. Some herbs, however, possess square or triangular stems, while ribbed and flattened forms are not uncommon. It may happen that the last kind are ringred, or produced at the sides into thin green expansions. Hollow or fistulur stems are often found among herbs, growth in thickness having exceeded increase in substance, the result being that the internal tissues have heen ruptured. This is very typically seen in grasses, where the tubular internodes are separated by swollen notes. Bamboo and any kind of straw will serve as examples. These stems are called culms. Not only may the size of the whole stem system be considered, but also the size of the individual jarts as regards length and thickness. The maximum length is attainer in the trunks of trees, where, as in all long stems, the internodes are well developed. Great development of the internodes maly cause the stem to be thin and weak, as in 
many climbing and creeping plants. On the other hand, the internodes may be so extremely short as to make the stem a scarcely recognisable stump, the leaves being at the same time crowded into a tuft or rosette. Good examples are daisy, dandelion, and house-leek. Such an abbreviated stem is sometimes termed a root-stock, while the leaves growing from it are radical, the old (but erroneous) idea being that they grew from the root. It may also happen, as in the buttercup, that the internodes are very short in the lower part of the stem only. The leaves borne by that part are then also called radical.

The thickness of a stem is dependent on other conditions besides the state of the internodes. Perennial gymnosperms and dicotyledons (rarely monocotyledons) undergo an annual increase in thickness, and many stems and branches, particularly underground ones, are thickened in connection with the storage of reserve materials.

The chief factor determining the general shape of a stem system is the nature of the branching. This is monopodial, as in the case of the root, and two kinds may be distinguished: (I.) Racemose, where, as in most cases, the main axis continues to grow, and is larger and longer than its branches, which, in their turn, bear a similar relation to its subordinates. The pyramilal outline of many trees, e.g., firs, is due to this cause. (2.) Cymose, where the main and other axes cease growing after a time, and are outstripped by their branches. This may result in false dichotomy, i.e., apparent forking, as in the mistletoe; or a pseucaxis or symportium may be formed, where the direction of an axis is continued by one of its branches, which after a certain time is supplanted by one of its branches, and so on (cf. p. 48). The name pseud-axis is given because, at first sight, we have to deal with a case of racemose branching. Examples are found in the twigs of elm and beech. The main branching of these trees is, however, racemose. Special branch systems or inflorescences are often developed, upon which the flowers are borne. These will be dealt with later on in connection with the flower.

The last important point which determines the shape of the stem is its direction, whether vertical, horizontal, or otherwise.

In giving a brief account of various stems, it will be convenient first to speak of aërial forms and then to proceed to subterranean ones.

Aerrial Stems.-As already mentioned, the typical overground main stem is erect and self-supporting. This requires a considerable amount of strength, which may be gained by size and solidity, as in tree-trunks, or where there is comparatively little substance this may be disposed in the most advantageous manner, i.e., on 
the principle of the hollow column, as in the culms of grasses. Overground stems may serve as receptacles for reserve materials, and in this case the internodes may either be of considerable length, as in the trunks of trees, which during winter contain large quantities of starch, \&c., or they may be much shortened. A familiar example of such a condensed stem is the cabbage, in which plant, however, nutriment is stored not only in the shortened stem, but also in the bases of the leaf-stalks.

Overground stems which are not erect may have a greater or less tendency towards the horizontal position, or, on the other hand, they may compensate their want of strength by climbing. In the former case, the first approach to a horizontal position is found in ascending stems which grow obliquely upwards. When a stem commences by being erect or ascending, and then turns down and runs along the ground, it is said to be recumbent. The opposite of this is seen in decumbent stems, which first run along the ground and then become ascending. Lastly, the horizontal direction may be taken from the first, when the term procumbent or prostrate is employed. Such a stem is creeping if it gives rise to adventitious roots at its nodes. A few terms that are applied to branches which serve for the multiplication of plants may here receive mention. Sucker's are ascending branches of subterranean stems. The green shoots commonly growing up from near the base of standard roses are of this nature, and so are the new "canes" developed each year from raspberry bushes. Stolons are prostrate or reclined branches which take root at the end, where a new shoot then grows upwards, and a fresh plant is thus formed. Slender elongated stolons are runners, as in strawberry, while short thick ones are offsets, as in house-leek. Short suckers are also called offisets.

Climbing Stems.-In many climbing forms the main stem itself winds round and round a support. Such twining stems form either right-handed or left-handed spirals. In the former case, which is the commoner, and of which scarlet runner and convolvulus are examples, the coils ascend from left to right, as in a corkscrew. The exact opposite is the case in the hop and certain other stems, which form left-handed spirals. Another large class may be called tendivi-climbers, since they possess irritable clasping organs in the form of tendrils, which are thin, elongated, stem-like structures, capable of turning round and round a support. Tendrils may be either modified parts of the stem, or flower-stalks, or parts of leaves. In the cucumber and vegetable marrow the tendrils are branches, while in the vine they take origin opposite the leaves (p. 27). The same thing is true of the Virginian creeper, where, in addition, there may be 
adhesive dises at the ends of the tendril branches. Leaf-tendrils will be spoken of in another place, as also will leaf-climbers generally, in which the leaves are used for ascending, with or without the development of tendrils. Root-climbers make another class, and ivy is the best-known example. Lastly, we bave hookclimber's, as in the cleaver or goose-grass (Galium), where innumerable minute hooks grow out from the superficial part of the stem.

We now come to subterranean or underground stems. These come under four categories-corm, bulb, rhizome, and tuber. A "orm, like that of the crocus, is a solid, rounded, main axis, full of reserve materials. Adventitious roots grow from its lower surface, and there are a few scaly leaf-bases upon its exterior, in the axils of which young corms may be formed as fleshy buds. From the upper surface a flowering shoot proceeds, and several internodes at the base of this thicken into the main corm of the following year, to which a shrivelled remnant of the main corm of the previous year may allhere. In the sowbreal (Cyclamen) a vertically-flattened corm is present. A bull resembles a corm in heing a conclensed stem, but differs from it by being mainly composerl of thickened leaves or bases of leaves, surrounding a flattenerl disc-like stem. A rhizome differ's from the two precerling in direction and form. Instearl of being vertical, it is oblique or horizontal, while its internodes are often of consiclerable length, and its shape more or less cylindrical. It may either be thin, as in mint and serlges, or else thick, as in the iris and Solomon's seal. Tuber's resemble corms in structure, but differ from them in being thickened branches. The Jerusalem artichoke and potato are good examples, and in both these cases several internodes are dilated, while the leaves borne upon the noiles are scale-like, and axillary buds, popularly known as "eyes," are developed in their axils. Some tuhers, however, consist of only one internorle thickened. In a potato plant grown from an eye only adventitious roots are present, but in examples raised from seed there is a well-developed branching main root. By heaping earth around a tuberous plant, branches with tulers upon them can be formed higher up than would otherwise le the case. Bulbs, thickened rhizomes, and tubers all (like corms) serve as stores of nutriment, chiefly starch. Other reserve materials may also be present. For example, in potatoes many of the cells immediately within the rind contain uninute cubes or crystalloids composed of proteid matter. The term crystalloid is used because, although the form is crystalline, yet the bodies in question are not hard, but possess the power of absorbing water with consequent swelling up. It is obvious from the above that the ordinary method of peeling potatoes, instead of cooking them 
in their skins, reserves the most nutritive parts for the pigs. All the swollen underground stems just spoken of are especially characteristic of dry climates, for which they are well suited, as the condensed form offers comparatively little surface from which evaporation can take place.

Modified Stems.-Hitherto we have had to do with typical undeniable stems, easily recognizable as such to the ordinary observer, except perhaps stem-tendrils. There are, however, numerous cases where stems are so modified, for the purpose of performing special functions, that they can only be recognized by homology. In other words, relative position and mode of development must be taken as criteria, and not the functions performed. This has already been spoken of on p. 7. Let us apply this to stem-tenulrils. A direct continuation of an organ is eridently of the same nature as that organ. In the vine the youngest tericlril is a continuation of the stem, and may therefore be regarded as part of it. This was previously the case with the youngest tendril but one, which, however, has been pushed on one side, its place being taken by a new stem borne in the axil of the youngest leaf. And so on for the next tendril. Thus, in any branch, the tendrils taken in succession, commencing with the oldest, have in turn occupied the end of that branch. TTe have therefore to deal with a sympodium (see p. 24). Another reason for not regarding the axis of a vine branch as a simple stem bearing branches in the usual way, is the fact that the tenclrils do not grow from the axils of leaves. Examination of passion-flower tendrils shows that these do grow from leaf-axils, and we are therefore justified in considering them to be branches. Vine tendrils are further regarded as modified flower-stalks, because all possible gradations are found between the two. Stems may also bear branches modified into spines and thorns for protective purposes. These are known to be of stem nature from their axillary development and the presence of leaves upon many of them. It sometimes happens that stems undergo modification owing to the fact that the leaves are very small or absent. This means that some of the functions of the ordinary leaves have to be carried on by the stem, which in this case may be called a pluylloclacle. In cacti, for example, apart from the flowers, the leares are recluced to minute spines, and the green stem assumes the most remarkable forms, globular, jointed, prismatic, \&c., all of them very compact, and suited for dry climates (see alove). In other cases, as asparagus and hutcher's broom (Ruscus), branches assume a flattened, leaf-like form, and are liable to be mistaken for leaves. Such phylloclades are termed cladopluylls or clartocles. The stem of duckweed may perhaps best be placed in this category. 
The last heading to be mentioned regarding the external form of stems is that of surface. Not only may a stem be more or less ridged, grooved, \&c., but also it may possess a more or less complete clothing of hair-structures, and different names are employed, such as silliy, hirsute, \&c., to indicate the kind of surface produced by them. ${ }^{1}$ Absence of hairs is denoted by the term glabrous. Hairs on the stem (and leaf) are rarely so simple as root-hairs. They are sometimes, however, unicellular, but in this case often assume more or less complicated forms. The stems (and leaves) of the wallflower, for example, are covered by spindle-shaped hairs, attached by their centres, and upon the stems (and leaves) of the stock and shepherd's purse much-branched unicellular hairs are present. It is more common, however, to find the hairs upon the stem (and leaf) multicellular, and they may then either be simple or branched threarls, or else more or less complex scales, with or without stalks. Glandular hairs are also common, and these usually consist of a rounded hearl, supported upon a short stalk. The protoplasm of the hearl is capable of producing or excreting a sticky or oily substance, often of fragrant nature. A thin cross-section of a young pelargonium flower-stalk or regetable marrow stem will, when placed under a low power of the microscope, be seen to possess numerous multicellular hairs, glandular and non-glandular.

The surface of the stem may be more or less corered by prickly structures, and these are not all of the same nature. Some are true hair-structures, i.e., they are developed from the epiclermis only, as in hop, clearer, and borage. Others again are modified stem or leaf structures, e.g., in the sloe and hawthorn. In this case the terms thorn and spine are best employed. But there still remains a third kind, of which the mickles of the rose and bramble are examples. These are not hair structures, since not only epidermis but ground-tissue as well helps in their formation. Nor are they modified stems or leaves, for they arise in no definite order, nor do they contain vascular bundles. The name emergences has been given to them, but it must be remembered that all possible gradations are found between them and hair structures, on which account some have proposed to group them with these last.

1 The following terms describe the character given to the surface of stem, leaf, \&c., by hairs :- Iloary (canesccnt), whitish, owing to presence of numerous ininute hairs; pubescent, with short or soft downy hairs; pilose, with soft distinct hairs; hirsute, with numerous coarse hairs ; setose (hispid), with bristly hairs; villous, with long soft hairs; tomentose, with matted hairs; silky, with soft straight hairs pressed closely to the surface; uoolly, with long crimped and matted hairs; hairy, a general term, applied when the separate hairs are distinctly visible; ciliate, applied to a leaf-margin fringed with hairs. 
We have now to deal with the structure of the stem, and this may be considered under the two headings of ancutomy, which treats of so much as can be made out with the eye alone or by help of a lens, and histology, which goes into the finer details by employing a compound microscope. We may commence by an examination of sunflower and asparagus stems.

Anatomy.-A good-sized example of a sunflorrer stem will be more or less cylindrical in shape, somewhat ridged, and studded with stiff hairs. If an internode is cut across with a sharp knife, and the surface smoothed by a scalpel or razor, the three systems of tissue can be made out. There is first the hair-bearing epidermis, and some little distance within this a circle of small oval areas, separated by interspaces. These are the cut ends of the vascular bundles, and are best seen with a lens. The rest of the stem is made up of ground-tissue, which is divisible into a large white central part, pith or medulla; another part, cortex, between the epidermis and vascular bundles; and thirdly, medullary rays, stirips of tissue running between the vascular bundles, and connecting pith with cortex. If now a piece of the stem is halved
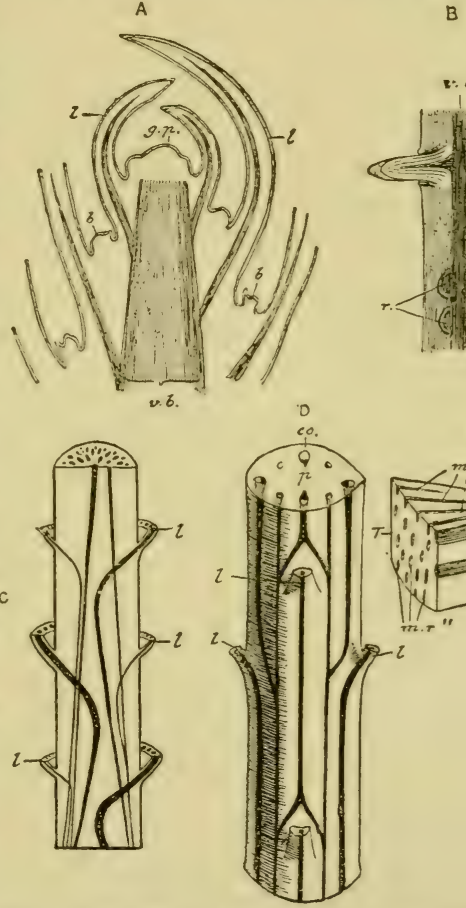

FIG. 5.-Diagrams of Anatomy of Vegetative Organs [after Prantl]. A. relation of stem and leaves; $l$. leaves; $b$. buds; g.p. growing-point; v.b. vascular bundles. The double line on outside represents epidermis. B. origin of lateral roots as seen in longitudinal section of bean; v.c. vascular cylinder ; l.r. lateral roots; r.c. root-caps. C, D. course of vascular bundles in stems of monocotyledon and dicotyledon. $l$. leaves; $p$. pith; $c 0$. cortex, E. piece of wood to show course of medullary rays; m.r. rays ; as seen in a cross-section; $m . x^{\prime}$. rays as seen in a radial section; $m . r^{\prime \prime}$. rays as seen in a tangential section.

longitudinally (taking care to include a node, and to cut through the attachment of a leaf), and the pith carefully scraped away 
with blunt needles, it will be seen that the vascular bundles are firm strands which traverse the ground-tissue in the long direction. With a little care it can be shown that at the node the bundles are more or less united with one another, while fresh bundles rim in from the leaf. All the bundles are common to stem and leaf, since any one of them commences in a leaf and then runs downwards in the outer part of the stem (cf. fig. 5, D). The above description is applicable to most herbaceous gymnosperms and dicotyledons. Similar olservations may with advantage be made on the broad bean (Vicia faba), where, however, the stem is square and glabrous, the bundles follow the external shape, and the pith is traverserl from end to end by a large air cavity ( $f$. p. 23). 'That this has been caused by rupture of the internal tissue may be seen by the presence of ragged fragments on the walls of the cavity. A very young green stem of the Scotch fir may also be examined, but the parts are much smaller and more difficult to see.

The asparagus stem is a typical monocotylerlonous one, and a cross-section shows that the vascular bundles are not arranged in a ring, but scattered through the ground-tissue, so as to forbil the existence of sharply defined cortex, pith, and medullary rays (fig. $7, D$ ). As in the previous case, they are common, but instear of running directly downwards, run inwards and downwards, thickening as they go, and then take an outward and downward course ( $f$ f. fig. 5, C). The bundles are connected together at the nodes by numerous cross branches. Owing to the way in which the bundles thicken, it is clear that those nearest the centre at any point should appear largest in a cross-section taken at that point, and this is actually seen to be the case. The course of the bundles cannot be followed with the same ease as in the sunflower. The hollow stems of grasses bear a similar relation to the asparagus stem that the bean stem does to the sunflower stem. The nodes, however, are solid, as can easily be shown by splitting the stem longitudinally.

We now come to the histology of the two herbaceous stems taken as examples, and it is necessary to explain that longitudinal sections are of two kinds, ractial, corresponding with a radius of the cross-section, and tangential, at right angles to this. The cells of the epidermis in the sunflower stem are flattened, and their cellulose walls thick externally. A very thin membrane, the cuticle, covers the outside of the epiclermis, but though part of this, it is not divided into areas corresponding with the cells, and may perhaps be regarderl as a hardened surface excretion. The substance cutin, of which it is composed, contains the same elements $(\mathrm{C}, \mathrm{O}, \mathrm{H})$ as cellulose, but in different propor- 
tions, and is practically impervious to moisture, though not to gases. Protoplasm and cell-sap occupy the interior of the epidermic cells, and chlorophyll granules are also found there. Most cells of the kind do not contain such granules. The hairs appear as large multicellular structures growing from the epidermis, and small openings, known as stomata are present. These are more abundint in leaves, and will he spoken of in connection with those members (p. 65). They are never found in roots. The groundtissue is mainly composerl, as in the root, of parenchyma (ef. p. I4), with cellulose walls and protoplasmic contents; but the parenchyma of the cortex differs from that of the root in the possession of numerous chlorophyll granules. There is, besides, in the cortex another kind of tissue, collenchyma. forming a band heneath the epidermis. This differs from parenchyma mainly in the fact that the cells are thickened at their angles. Numerous: chlorophyll granules are imberlded in their protoplasm. It is hest to examine the vascular bundles in sections of a rery roung stem, as they are then quite distinct from one another." In a properly stained cross-section (cf. Appendix) we shall be able. with a low power of the microscope, to distinguish the bundles as oval areas, each of which is composed of an outer part, the brast or phtoëm, and an inner part, the wond or xylem, separated by a hand of rery thin-walled cells known as the cambium. As seen with a high power (fig. 6), the bast is macle up of an outer somewhat crescentic portion, the hard hast, the elements of which, bast fibres, have rery thick walls and no protoplasm, and an inner. part, the snft bast, the components of which have thin cellulose walls. Some of these, the sieve tubes, are large, others, making up the bast parenchyma, are much smaller. A number of the sieve tuhes present an appearance reminding one of the perforated top of a pepper-cistor. This appearance is due to the presence of sieve plates pierced with small holes. The most conspicuous components of its wood are the wood ressels, large rounded elements with very thick walls and no protoplasm. The remaining parts are wond purenchyma and wood filies, the latter closely resembling the bast fibres. The cells of the cambium have very thin cellulose walls and abundant deeply-stained protoplasm. Their shape is rectangular, with the long diameter tangential. and they are arranged in radial rows, two or three cells in a row. These features show that division has taken place in a tangential direction. Imagine a cell, square in cross-section, with two sirle: at right angles to a radius of the stem. Then suppose this cell to be bisected by formation of a new wall parallel to the two in

: In buttercup and some other plants the bundles remain distinct through. out life. 
question. Two rectangularly-shaped cells making a radial row would then be formed. Further divisions would give a radial row with more numerous cells, This is the kind of process which goes on in cambium. It is, in fact, a meristem, or actively-dividing formative tissue ( $f f . p$. I 7$)$, with abundant protoplasm and thin cellulose cells, as might be expected. It is secondary meristem, because it abuts externally and internally upon permanent tissues, and the cells formed by its division undergo various changes, finally becoming bast and wood elements. Bundles which contain cambium are termed open, because they are able to increase in size by its means. Such bundles characterize gymnosperms and dicotyledons. The entire ring of bundles is enclosed by a sheath or layer of small starch-containing cells, which crosses over the medullary rays. This is the bundle sheath or staich-layer. By studying a radial longitudinal section we shall get clearer ideas regarding the elements of the bundles. Beginning as before at the outside, we shall find the hard bast composed of thickwalled fibres, bast fibres, with tapering enils, by means of which they dovetail together. A tissue with elements united in this way is said to be prosenchymatous. The bast fibres, moreover, are not cells, but cell-derivates, i.e., they have been derived from cells. The presence or absence of protoplasm is the main test of cell nature or the contrary. What then has been the history of a bast fibre? It was originally a small cell, not specially elongated, with thin cellulose walls, and completely filled with protoplasm. Growth in length then rapidly took place, and at the same time alterations both of the wall and contents went on. The cellulose wall, kept on the stretch by the turgidity of the cell, had layer after layer of wooly matter deposited on its inner side by the agency of the protoplasm. Thin places or pits, in this case resembling canals, were, however, left. The layers in the thickened and lignified cell-wall can be recognized in the cross-section, as well as the original party-walls between the adjacent cells, now known as the middle lamella. The pits appear as streaks running across the thickened wall. They run from the interior of the fibre to the middle lamella, which closes them, so to speak, and forms a pit membrane. It will be seen from the above that woody matter is not limited to the wood or xylem, though mainly characteristic of it. As regards the protoplasmic contents of the original cell, these became vacuolized (cf. p. 8), i.e., small vacuoles were formed which then coalesced so that the protoplasm became limited to a parietal layer. This layer gradually used itself up in the thickening of the wall, and the bast fibre became complete. Such a fibre is not therefore living, and it plays a purely physical part in the organism. The fibres belong 
to a type of tissue known as scleiench!mma, characterized by thickened woody cell-walls and absence of protoplasm. In the soft bast there is nothing very remarkable about the parenchyma, but the sieve tubes are very important. They are the essential part of the bast, and are always present in it, at any rate in phanerogams. The radial section will show, if carefully prepared, that each sieve tube is made up of a series of elongated members or joints, somewhatswollen at their ends, and separated by transverse partitions, the sieve plates perforated (as we have seen in the cross - section) by numerous pores. We have again to cleal, in all probability, with cell-derivates. Each mem-

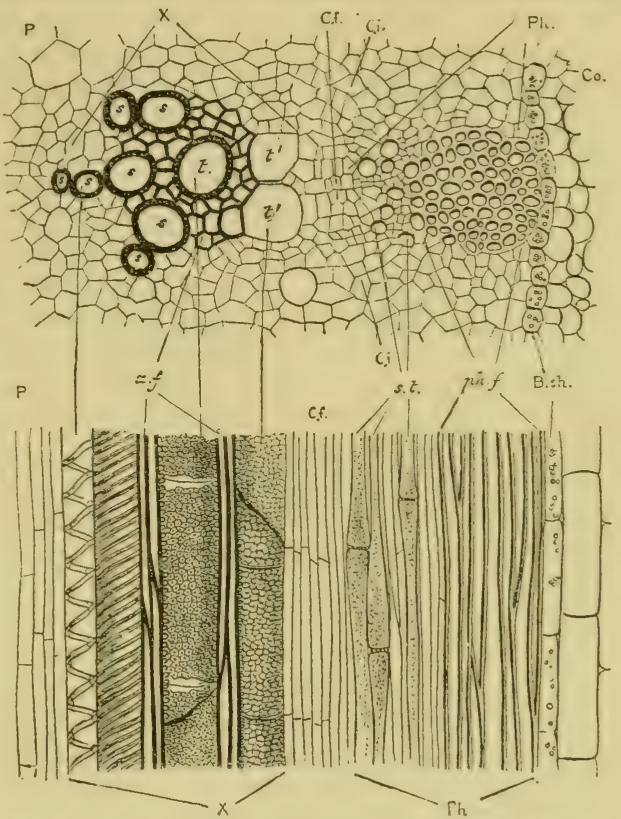

FIG. 6.-Transverse and Radial Sections of Sunflower Stem, to show structure of a Viscular Bundle. [After Prantl.] M[uch magnitied. $B . s h$. humdle sheath; $P$. pith ; co. cortex; $X$. xylem ; $s \varepsilon$. spiral vessels; $t t$. pitted vessels; $x . f$. xylem fibres; $P h$. phloëm ; s.t. sieve tubes; $p h . f$. phloëm filres; C. $f, C . i$. cambium.

ber was originally one of a row of cells. The walls of the mature tubes, although thickened, remain of cellulose, but the protoplasm seems to have disappeared. Each member is lined hy a slimy substance, which is denser, and therefore stains more deeply than the rest. The transverse party-walls between the original row of cells appear to have been thickened, pits, however, having been left, which corresponded on opposite sides. Hence at any spot where these occurred there would be a pit or depression on either side, the two being separated by the pit-membrane, absorption of which would lead to formation of a little canal, piercing the sieve plate. In the sieve tube the slime in one member is connected with that in the adjoining ones by threads of the same material running through the sieve plates. We have here an example of a cell-fusion or vessel, which terms 
are applied to tubular cell-derivates that have been formed by the more or less complete coalescence of adjoining cells. In the wood no special notice need be taken of the wood parenchyma, nor of the wood fibres, which closely correspond to the bast fibres. The essential parts are the wood vessels, which, like the vessels of the bast, are cell fusions made up of numerous joints. Here, however, the cell nature is still more completely lost, for the walls are thickened and lignified, and the protoplasm has completely disappeared, being replaced by air. The transverse partitions have been almost entirely absorbed, so that a continuous tube is formed. The more external ressels are pitted, and obviously made up of joints, while next the pith smaller ressels occur in which the thickening of the wall has taken place in a spiral or ring-like manner. These spiral and annular vessels are the oldest parts of the wood, and therefore termed protoxylem. Having had more time to develop than the other vessels, their members are longer, and the pointed nature is not so obvious. The camlium is not easy to make out in longiturlinal section, but its cells atppear elongated, and are in fact rectangular prisms with rather oblique ends. It has been stated that cells derived from the cambium go to increase the bast and woorl, and before this cam be effected must evidently undergo various changes, according to the nature of the structures formerl. A prismatic cell may become a fibre pretty much as described on p. 32, but of course less elongation is here necessary. Short parenchymatous cells may be derived from such a cell by the formation of transverse walls, while the origin of sieve tubes and woorl vessels will be undlerstood from what has been said above. It must further be adderl that the prismatic cells enlarge and become cylindrical before they can be converted into member's of sieve tubes or wool vessels. The stem, like the root, terminates in a growing-point (cf. p. r6), but there is nothing to correspond to the root-cap.

The above histological description of the sunflower stem will serve pretty well for most herbaceous dicotyledons, but the bast and wood fibres are often absent. When they are present the bundle is fibro-vascular. The most important points may be put in a tabular form :-

1. Bast or Phloëm. $\left\{\begin{array}{c}\text { Hard Bast.-Bast fibres or sclerenchyma. } \\ \text { Soft Bast.-Bast vessels or sieve tubes, } \\ \text { bast parenchyma. }\end{array}\right.$

\section{Cambium.}

III. Wood or Xylem. $\left\{\begin{array}{l}\text { Wood fibres. } \\ \text { Wood vessels. } \\ \text { Wood parenchyma. }\end{array}\right.$ 
Very young stems of most gymnosperms, e.g., Scotch fir and juniper, correspond in their main histological features with those of dicotyledons (fig. 7, A, B). The most important difference is found in the vood. This is almost entirely made up, not of vessels, but of elongated tapering elements, with pitted lignified walls and no protoplasm. These dead skeletons of elongated cells which have lost their living portion are trachëides. Wood vessels and tracheides may collectively be called tracheæ. The pits in the wall are somewhat peculiar. In surface view they present the appearance of two concentric circles, and are therefore called bordered pits (fig. 7, C). The mouth of the pit, i.e., its opening into the cavity of the tracheïle, is narrower than the bottom of the pit, and (the whole section being transparent) it therefore appears as the inner circle, and the latter as the outer. In gymnosperms, again, the
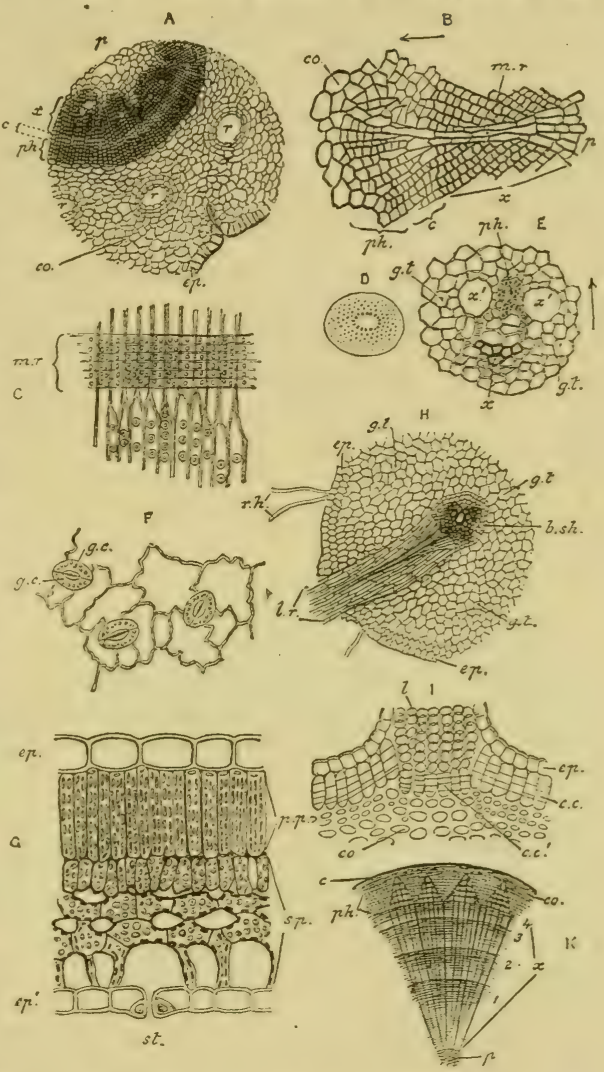

FIG. 7.- Minute Structure of Vegetative Organs [G, I, $\mathrm{K}$, after Prantl]. All more or less magnified. A. cross-section of young shoot of Scotch fir. B. part of same enlarged; $c p$. epidermis ; $p$. pith ; co. cortex; $x$. xylem; $p h$. phloëm; c. cambium ; $m r$. medullary ray. C. small piece of radial section of fir wood, showing tracheïdes with bordered pits; $m r$. medullary ray. D. cross-section of asparagus stem, showing bundles. E. one bundle of same, magnified ; $x$. $x^{\prime}$. xylem; $p h$. phloëm. F. piece of lower epidermis from geranium leaf ; g.c. guard-cells of stomata. G. crosssection of beech leaf; $e p$. upper epidermis; $e p^{\prime}$. lower epidermis; $p p$. palisade parenchyma; $s p$. spongy parenchyma; st. stomata. $H$. part of cross-seetion of buttercup root; $e p$. epiclermis; $l r$. lateral root; $g t$. cortex; $r l$. root-hairs. I. section of elder lenticel; ep. epidermis; co. cork; l. loose cork of lenticel; c.c. cork cambium. $\mathrm{K}$. part of cross-section of four-year-old lime twig; $p$. pith; co. cortex; c. cork; ph. phloëm; $x, 1,2,3,4$. annual rings of xylem. 
sieve tubes are different in structure from those of sunflower, and much more difficult to study. On the other hand, there are dicotyledonous stems which are superior to sunflower for the study of sieve tubes. In the cucumber and vegetable marrow, for example, they are extremely large, and easy to see. These stems are, however, abnormal in some respects, since there is not only bast external to the wood, but also some internal to it. A band of sclerenchinma will also be found in the cortex not far from the epidermis.

We now come to the histology of herhaceous monocotyledons. In the stem of asparagus (fig. 7, D, E) we shall find epidermis of the usual kind, while the ground-tissue is largely composed of parenchyma. Each vascular bundle is macle up of: (г.) Wood, which in cross-section forms a V-shaped or U-shaped mass, with apex pointing inwards. It is chiefly composed of vessels. As in the sunflower, there is protoxylem, composed of spiral and annular vessels, which occupy the apex of the V. (2.) Bast, which is almost all soft, and is situated on the outer side of the lumile, chiefly within the limbs of the V. There is no cambium, and the bundle is therefore closed, since no addition of new elements can take place. Such closed bundles, with woor arranged in a $\mathrm{V}$ or $\mathrm{U}$, characterize monocotyledons generally. Examination of any good-sized grass stem will show these features more clearly than in asparagus. In ardlition, the whole bundle is surrounded hy a sheath of sclerenchyma, and there are also masses of this tissue beneath the epidermis.

Thickening of Stems.-It is the presence of cambium in the stems of gymnosperms and dicotyledons that enables perennials belonging to these groups to increase in thickness, sometimes to a very large extent. This process may commence in herbaceous stems, but has no time to go any great length. The increase is mainly in the wood or xylem, and what are popularly called woody stems owe their nature to this. But it must not he forgotten that all stems contain a certain amount of wood or xylem, so that the term herbaceous is not exactly opposite in meaning to the term woody. If we take such a tree as a Scotch fir or elm, successive examination of older and older stems will enable us to understand how seconclar!l increase of thickness takes place. We will at first mainly consider the vascular bundles. A crosssection through the axis of a bud will present a ring of primary bundles, completely isolated from one another. This condition is retained through life in some herbaceous stems, such as those of the buttercup. The bundles are separated by strips of groundtissue, the primary medullary rays, and each of them consists of primary bast on the outside and primary wood on the inside, the 
two being separated by what may be called fascicular cambium. since it occurs within the bundle. In a rather older stem some of the cells making up the medullary rays have begun to divide actively, giving rise to cambium letueen the primary bundles or interfuscicular cambium. This, together with the fascicular cambium, forms a cambium ring, extending right round the stem. This and even a later stage is reached in the stouter stems of sunflower. Still older examples present a compact mass of vascular tissue, most of which has been formed by the active division of the cambium, producing secondary bast on the outside and secondary wood on the inside, not only in the region of the primary bundles, but also between them. The elements making up the new bast and wood are similar to those already described, but spiral and annular air tubes are limited to the protoxylem. Secondary increase is far greater in the case of the xylem, giving rise to the "wood" of shrubs and trees, while the "bark" is largely composed of

$B$
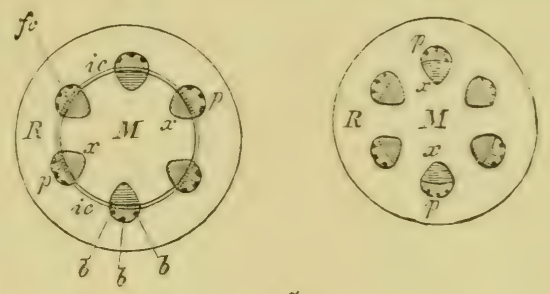

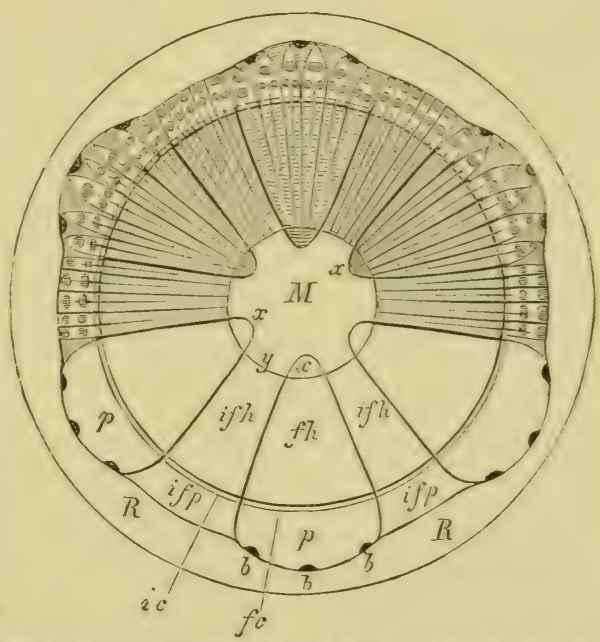

FIr. S.-.Secondary Thickening of Stem. [After Sachs.] A. $B, C$. cross sections of same stem at different ages. A. young bundles quite separate from one another. B. a cambium ring present. C. a cylinder of secondary xylem and phloeim present, formed by activity of cambium rin-; $M$. pith; $R$. cortex; medullary rays in $\mathrm{A}$ and $\mathrm{B}$ are the broad spaces between bundles, in $C^{\prime}$ are represented l.y streaks ; $p$, ifp. phloëm; $x, f h$, ifh. xylen. secondary bast. The primary medullary rays are reduced to exceedingly narrow strips, running through from pith to cortex. Secondary or short medullary rays are also formed, taking origin in the cambium, and only extending part of 
the way from pith to cortex. It must not be supposed that in the thickened stem a medullary ray has a great vertical extent, for it is often only a few cells high. If we imagine a lath-shaped mass of cells running through the vascular tissue in a radial direction, possessing convex sides which face sideways, and edges facing upwards and downwards, we shall have some idea of such a ray. In cross-section (fig. $5, \mathrm{E}$ ) it will look like a narrow streak or " ray" running in a radial direction. A radial section will display it as a broader band running at right angles to the direction of the elongated vascular elements; and, lastly, a tangential section will cut across it, giving an outline resembling in shape the cross-section of a biconvex lens. ${ }^{1}$ The "silver grain " of wood is due to the presence of medullary rays, which are always excessively numerous. In the oak they are of unusually large size, and give the characteristic grained appearance. It is a familiar fact that in a piece of stick, a log, or a tree-trunk the wood presents, as seen in cross-section, a series of concentric layers in "annual rings," surrounding a more or less evident pith, which is generally dead and dry. Generally speaking, one ring is formed per annum, hence the name (fig. $7, \mathrm{~K})$. It is not usual for the pith to occupy the geometrical centre, so that the rings are not exactly circular, nor is any one ring necessarily of uniform thickness all the way round. Since the new layer's are formed by the cambium, it is evident that the inner rings are older than the outer. In many timber trees the internal "heart-wood" or durumen is extremely hard and dry, while the outer "sap-wood" or alburnum is much softer, and, as the name indicates, full of sap. The appearance of annual rings is caused by the difference in texture between wood formed at different seasons of the year. Spring wood is composed of comparatively large, thin-walled elements, but, as growth proceeds, smaller and smaller elements are produced, with thicker and thicker walls, till, in the autumn, growth ceases altogether. Hence the dense autumn wood of one year is abutted upon by the much looser spring wood of the next year, and, as the colour also is generally rather different, the boundary between the two is distinctly seen. Annual rings of different years may vary very considerably in thickness. Owing to this method of increase in the wood, viz., by the addition of layer after layer to the outside, dicotyledons (and gymnosperms too, which were formerly grouped with them) were called exogens, or outside growers. IIonocotyledons received the converse name of endogens. This, however, was founded on mistake. The plants in question rarely side.

1 The very large medullary rays of oak are much flattened from side to 
increase in thickness at all. When they do so, as in some tropical trees akin to lilies, the bundles remain closed, no cambium being formed in them. A ring of cambium is formed in the ground-tissue outside the original bundles, and in the ring ne bundles are developed, so that growth here also is really by external additions. It is therefore best to drop altogether the terms exogen and endogen, but the adjectives exonenous and encomenous may be conveniently retained, as denoting the origin of certain organs or tissues. A ront, for example, is endogenous, being developed from internal tissue layers, while a leaf, as we shall see farther on, is exogenous (fig. 5). Before leaving the secondary wood, it will be useful to examine, in the light of what has been said, the appearances visible in a wooden plank, composed say of fir wood, i.e, deal. The ends will be more or less accurate crosssections of the trunk, and will therefore present small segments of the annual rings. The pith may possibly be seen as a circle, but will be insignificant in size. The medullary rays appear as narrow radial streaks. A plank ruining right through the centre of the annual rings will have a number of more or less parallel lines rumning along its faces in the long rlirection. The pith, if seen, will be a narrow longitudinal streak, and, of course, the stripes immediately bounding this belong to the first anmual ring, the next stripes to the second ring, and so on. The medullary rays appear as streaks rather broader than before, parallel to the ends, and for the most part very discontinuous, since the section is not likely to run very far along any one of them. The edges of the plank clisplay the ends of the rays, and, if rather oblique, may cut through sereral annual rings, the boundaries between which will be irregularly wavy. Most planks are, however, more or less tangential, and either side of such a plank will, near its centre, cut along a single ring for some distance, till in fact the ring curves quite out of the plane of section. There will thus be a central strip, running longways, and bounded by straight lines. Outsile this will be pairs of strips, one of each pair on either side, getting narrower and narrower, till near the elge a practically radial section is seen. Is we pass from the centre, the medullary rays will be first cut right across, and then obliquely, and lastly in the direction of their length. No mention has yet been made of "knots." These are simply dead branches of clifferent age, which in tangential section are cut transversely, when their age can be letermined by counting the rings they possess. Their nature is well seen in radial sections, where they will be olserverl to run out as transverse brown stripes from annual rings of clifferent age. We can therefore tell when they began to grow. The foregoing description will be perfectly useless with- 
out a little thought on the part of the student, and examination of actual specimens.

We may now pass to the consideration of bark. A twig can generally be "peeled" with ease, and this is owing to the delicate nature of the cambium ring, which is broken through in the process of peeling. As the wood receive annual additions on its outside from the cambium, so does the bast receive similar additions, the difference being that they are very much thinner and formed on the inside. There is never such a regular appearance of annual rings as in the wood (fig. $7, \mathrm{~K}$ ). It is evident that the method of increase described must subject the external tissues to a great deal of tension. The epidermis may for some time keep up with the growth in thickness, but sooner or later, in most cases, it bursts and is thrown off. Its place is taken by brown layers of corti cells formed in the following way. A layer of cells in the cortex, i.e., outer part of the ground-tissue, begins to divirle actively and forms a layer of meristem, known as corli camlium (fig. 7, I). Its cells, however, are not elongated like those of ordinary cambium. The cells formed on the outside by division of this layer become cork elements. These, as seen in cross-section, are rectangular iu shape and arranged in radial rows (cf. p. 3I). Their walls are thickened, brown, and composed of a substance, suberin, probably allied to cutin (p. 30). 'They contain no protoplasm. An eximination of elder-shoots of different age will illustrate these points. The youngest are bright green, since the chlorophyll-bearing cells of the cortex ('an be seen through the transparent epidermis, but older ones are brown, owing to the formation of cork. 'This is not very transparent, and so does not permit the green cortical tissue to be clearly seen from the outsile. A cross-section will show the relation of the different parts. If this is made through a branch about half an inch thick, the following points can be easily made out by the eye alone. A large part of the interior will be occupied by the bright, white, spongy pith, the colour of which is due to the fact that the cells are dead and contain air instead of protoplasm. Then follows a whitish-brown band of wood, in which medullary rays are plainly seen. The cambium forms an extremely narrow band, the position of which is shown by the fact that the outer part of the stem can be peeled off at this point. Next comes a narrow greenish-white zone, the bast, and this is succeeded by a narrower dark-green portion, the chlorophyllbearing cortex. This is invested by a thin papery layer of whitish-brown cork, which can easily be detached, owing to the delicate nature of the cork cambium. That it is subjected to tension may be seen by the presence of numerous little fissures, 
taking a longitudinal direction. A number of raised, brown, spongy-looking spots may also be observed on the surface. These are lenticels or porous parts of the cork, where the cells are rounded, with numerous intercellular spaces between them (fig. $7, \mathrm{I}$ ). The bark of trees is mostly made up of hast and cork, which, owing to the increase in size of the wood, are thrown off from time to time in shreds or flakes, and are frequently traversed by numerous cracks and fissures. The rugged nature of many tree-trunks is, therefore, a result of secondary increase in thickness.

\section{PHYSIOLOGY.}

The chief uses of the stem are to display the leares, so that they may best carry on their functions of assimilation and reproduction, and also to serve as a means of communication between them and the roots. Like the root, the stem is a reyetatire organ. An organ of support requires to be more or less firm in texture, and this is effected by means of the hard lignitied tissue making up most of the xylem, as well as by the sclerenchyma that may occur in the bast and cortex. Collenchyma, again, helps to some extent. These supporting or mechanical tisures have collectively been called the stereome, and this is naturally best dereloped in erect perennials. Weaker stems make use of the ground, other plants, \&c., as supports, and attach themselves to these by the means described on pp. 25-26. Stems also present various protective appliances. Spines, thorns, and prickles help to keep off browsing animals, and, when closely set, repel the attaclis of softbodied creeping forms, such as snails and slugs. There may also be viscid substances, excreted by glandular hairs or by the general surface, which prevent wingless insects from reaching the leaves and flowers. In one species of willow the stem. of the flowering shoots are coated by a slippery layer of wax, over which no insects can pass. Again, protection is needed from the weather, and this is afforded by epidermis and cork, which are practically water-tight. Hairs on the stem (and leaf) help to keep off wingless. insects.

Stems assist in nutrition by conveying to the leares the water with substances in solution absorbed by the root, and, on the other hand, carrying the materials formed in the leaves to the plant body generally. The ascencling or crute sap travels chiefly (see p. I8) in the cavities of the lignified wood vessels and tracheides, and an active movement towards the leaves is brought about by the vital activity of the cells of the medullary rays and woodparenchyma, which act alternately as suction-pumps and forcepumps. By means of the pits liquid can filter from one element. 
to another. Some crude sap also passes through the parenchymatous parts of the stem by means of osmosis. The whole of the wood in annual stems can conduct water, but in perennials possessing sap-wood and heart-wood only the former can do so. This is shown by an old experiment, in which a sing of tissue was removed from the stem of an oak, exposing the duramen. The result was that the leaves quickly withered. Since removal of a ring of bark alone did not cause such an effect, it was concluded that the outer or sap-wood conducted water upwards. This is confirmed by the fact that trees can flourish without pith and duramen, as shown by hollow specimens. The leaf-protoplasm, aided by chlorophyll (see p. Io), forms organic matter from the crude sap and the carbon dioxide of the surrounding medium This organic matter, the elaborated sap, travels from the leaves to all parts of the body which contain protoplasm, compensating waste and rendering growth possible. In inany plants it is stored up as reserve materials, e.g., starch, crystalloids, \&c., in thickened roots, stems, and other receptacles. Part of this organic material is in a soluble diffusible form. This can travel through the parenchyma. Another part, consisting of proteids, travels by means of the sieve tuhes, which form a continuous series of canals. Hilaborater san, then, traverses the outer part of the stem. The experiment of removing a ring of burk conclusively proves this, for no growth takes place below the wound, since the supply of nutriment is cut off, while, on the other hand, increase goes on as usual above the wound. Trees are not infrequently seen in country places with the lower part of the trunk comprarively small, and abruptly stucceeded by a considerable bulge. This is generally due to a metal hoop having been placed round the stem year's previously, which, as increase in size took place, first hecame very tight, and then cut through the bark. One or two facts in practical gardening illustrate the same point. It is sometimes required to hasten the ripening of fruit on some special branch of a tree. This is effected by " ringing" the branch, when the elahorated sap formed in its leaves cannot pass lieyond the wound, and is employed in building up the fruit. Again, on a plum tree for eximple, the fruits will not ripen unless they have at least one leafy shoot beyond them. If this were not the case. they would not be in the course of the descending current of elaborated sap.

Where the stem contains chlorophyll, it assists the leares in the formation of organic matter, and this function is mostly or solely carried on by the stem in plants which possess phylloclailes.

As we have seen, thickener stems, such as corms, rhizomes, \&c, serve as stores of reserve materials, and this is also the case with the trunks of trees which shed their leaves in autumn. The 
"fall of the leaf" is not, as might be imaginel, a great waste of protoplasm. All the contents of the leaf cells are, in fact, withlrawn into the stem before this takes place. The fall itself is effected by formation of a layer of cork rumning right across the insertion of the leaf-stalk, i.e., the point where it joins the stem. Separation now readily occurs, leaving, not a raw surface, but a neat "scar" covered by cork.

The protoplasmic parts of the stem carry on respiration, as we have seen to be the case in the root (p. IS). The circulation of gases mainly takes place in the cavities of the tracher, and intercellular spaces of the ground-tissue. In aquatic stems these last form air chambers of consiclerable size. In terrestrial stems communication between the intercellular spaces and the exterior is kept up by the stomata and lenticels (see further p. 65).

The stem, or more correctly speaking the regetative shoot, may subserve the function of reproduction, which in this case is termed regetative. Reproductive organs proper are specially molified for the performance of their function, and are not concernes with nutrition. Vegetative organs, on the other hand, have mainly to lo with nutrition, and, if they reproduce, are either not modified at all for that purpose, or at any rate not so profoundly as to interfere with their chief use. Vegetative reproduction depends. upon the power of the stem to produce adventitious roots. One of the simplest cases is where branches are liberated by the rotting of the main stem, and hecome fresh plants. A notable example is the common aquatic weed, water-thyme (Anculucris or Elortea), found abundantly in all our rivers, canals, \&c. 'This plant is a native of North America, and was introduced into Ireland about ${ }_{1} S_{3} 6$, and into England about I $_{4} \mathrm{I}$. Reproducing solely in the way described, it soon became a serious nuisance, even hindering canal navigation. Attempts were made to destroy it by means of cutting implements, but as every little bit cut off became a new plant, its increase was only augmented. Somewhat similar to this is the case of creeping stems, each node of which can develop roots and send up a shoot. Potting or sererance of the internodes makes the new indiviluals quite independent of the parent plant. The same sort of thing occurs with horizontal underground stems. Stolons and suckers are branches specially allapted for vegetative reproduction, and any strawberry bel will show how well the former are able to produce new plants. Cuttings (see p. I3) form an artificial means of propagation akin to the preceding. "Layering," in which branches are fastened to the ground and induced to form adventitious roots, is of the same nature. Grafting is practically the planting of a shoot in an incision made in another stem insteal of in the ground. Vegeta- 
tive reproduction is often effected by means of buds, i.e., unex tended shoots. Corms and bulbs are modified underground buds developed by annuals for this purpose. At least one of these structures is produced every year, and very frequently the main corm or bulb develops several smaller ones in its leaf-axils. In the tiger-lily small rounded black bodies may be seen during summer in the axils of the leaves. These are small aërial bulbs, which, sooner or later, fall to the ground and grow into fresh individuals. They are known as bulbils or bulblets. The buds or "eyes" occurring upon tubers, as the potato, serve the same enrl, and this fact is largely taken advantage of in cultivation. The operation of "budding" may be mentioned here. It bears a close relation to grafting, and consists in the removal of a burl with a small piece of the tissues external to the cambilim from one tree, and insertion of the same under flaps cut in the back of another tree. Close contact with the cambium of this tree is thus brought about.

Motility is exhibited very conspicuously by the stem uniler various forms. Protoplasmic streamings ( $r f$. p. I I) may sometimes be seen under the microscope in the cells of some of the hairs which clothe it. This point will be spoken of more fully in a later chapter (p. 72). Larger morements are very frequently met with, especially in growing parts, as is strikingly seen in the case of many twining and other climbing stems. The young shoots of a hop plant, for example, exhibit what is termerl circum. mutation, that is to say, they sweep round and round in search of a support, and if they find one, twine round it. Dar'win's experiments show that in the hop a complete revolution is effected in from two hou's to two hours twenty minutes. In a special case noted by him the moving part was about fifteen inches long, and curved in such a way as to describe a circle of nineteen inches in diameter. These data give a maximum rate for the end of the shoot of nearly half an inch per minute. The tip of the minute hand in an ordinary watch, the morement of which can easily be seen, only travels about a quarter as fast as this.

Irritability and Spontaneity are also possessed by the stem, often in a high degree. As in the case of roots (cf. p. 19), gravity exerts an important influence in determining the direction of growth, but the geotropism here is not positive, but negative. The main stem, when strong enough, grows rertically upwards, and its branches have mostly an upward tendency. The experiments with seedlings, lescribed on p. 20 , are as instructive here as in the case of the root. Negative geotropism is as necessary to stems for the suitable display of their leaves as positive geotropism is to roots for bringing them into relation 
"ith the soil. The heliotiopism of the stem is, again, opposed to that of the root, for similar reasons. It is, except in special cases, positive. Light is essential to leaf functions; and many plants which in open localities have comparatively short stems become extremely elongated when surrounded by a dense undergrowth. The excessive development in length of shoots grown in a dark or badly-lighted place may also be interpreted as an effort to reach the light. The sprouting of potatoes in damp cellar's is a familiar example. There is, howerer, another fact to he taken into consideration, namely, that light retards growth. A further instance is that of plants grown in a windor. These curve over towards the light to such an extent as in many cases "to break their backs." The sille turned towards the room here grows more rapidly than the other sicle in it: attempt to reach the light, with the result mentioned. Climbing stems lo not exhibit strong positive heliotropism, as this would often take them away from their supports. They may even be negatively heliotropic. This is seen in the tendrils of the Virginia creeper, which turn away from the light and attach themselves to the wall up which the plint climbs. Again, stems are often very sensitive to mechanical contact, and this is particularly the case with stem (and other) tendrils. The best example is a kind of passion-flower (Passitlora !rucitis), where, according to Darwin, a perceptible curving takes place half a minute after the tip is lightly touched. When, therefore, such a tendril comes into contact with a support, it is enabled to attach itself very quickly. A very interesting case is that of the white bryony (Biyonia clioicu). The long tendrils of this plant coil their ends round supports, and this affects the unattached parts of them near the stem, causing these to coil up like corkscrews. Two ends are served. The plant is pulled upwards and firmly stretched, and the coiled parts in question act like so many springs, which yield in a strong wind, and prevent it from tearing the stems from their support. 


\section{CHAPTER V.}

\section{BUDS AND LEAF ARRANGEMENT.}

IT has already been pointed out that the two parts of the shoot, i.e., stem and leaf, are very closely connected, so that one cannot be defined without reference to the other. Leaves are, in fact, outgrowths from the side of the stem, which generally differ from it in shape, and are developed acropetally (figs. 2, 4, and 5 A). Most leaves are flat, and, in a general sort of way, they may be looked upon as modified pieces of stem. Not unconnmonly the sides of a stem are produced into green wing-like expansions. If these, instead of being continuous, were very much developed at some points and reducerl at others, something very like leaves would result. Curiously enough, some leaves actually do become continuous at their insertions, with wings on the stem, as in the thistle.

There is much more to be said about the leaf than was the case either with the root or stem. Their arrangement will first be considered, and then the various kinds of leaf will be dealt with consecutively.

Leaving the flower out of consideration for the present, immature leaves have a certain arrangement in the bud, which leads up to the arrangement of the mature leaves on the fully-developed stem.

Buds, as previously mentioned, are young shoots, in which all the parts are very small, and the internodes non-elongated. The best examples are to be found in trees, which may be instructively studied in early spring. Every branch typically ends in an apical or terminal bud, within which the year's growth is, so to speak, mapped out, nothing but increase in size being needed to produce a leafy shoot (figs. 2, 4, and 5 A). In racemose branching (p. 24) a branch or twig may grow indefinitely in this way, an apical bud being formed every year ready for the next year's growth. A very good instance is the horse-chestnut. An examination of an apical bud of this tree in spring will show a number of firm over-lapping scales on the outside, which are extremely sticky owing to the secretion of a resinous substance. A longitudinal 
section of the bud brings to view the young leaves, crowded on the stem, and overlapping its growing point. As the bud expands, the protective scales, which must be regarded as the lowest leaves of the shoot, fall off, and, as the internodes between them do not elongate, leave behind narrow scars, which form a band of ridges round the stem, marking the commencement of the year's growth. ${ }^{1}$ Development of these internodes would serve 110 useful purpose, but simply gire a long piece of bare stem. The remaining internodes elongate, and in the summer the shoot will be found bearing about three pairs of large leaves, and terminated by a large bud for next year. It may be noted here that large leaves are always borne in small numbers. Overcrowding would result from the presence of many, and the access of air and light would be hindered. In a well-dereloped branch of horsechestnut the growths of sereral years can be distinguished by noticing the successive bands of scars left by the bud scales of different seasons. After a certain time, horerer, the scars are obliterated by formation of bark, \&c. We may also notice in such a branch the large heart-shaped scars of the ordinary leaves $(p .+3)$. Within each scar are seven small rounded eleva tions, following the lower curve. These are the ends of the vascular bundles that entered the leaf.

Besides terminal buds we have axillary buds, quite similir in structure, and developing into lateral shoots (figs, 2, 4, and $5 \mathrm{~A}$ ). If every leaf-axil gave rise to a shoot which elongated, it is clear that branching would follow the leaf arrangement. This, however, is not the case. Sometimes buds are only developed in some of the axils, and again many buds either die or remain undereloped or dormant. Examine once more the horse-chestnut. Two large axillary buds will be seen near the end of every present or current year's shoot. Other dormant buds will be seen as little brown bodies in the axils of the older leaves. This non-development of many buds is of considerable importance. In the first place, overcrowding is prevented, and then, should the first shoots be blighted from any cause, as by a return of severe weather in the spring, they can be replaced by growth of the dormant buds. It may happen, as a regular thing, that the terminal bud dies. If, as in mistletoe, the leaves are borne in opposite pairs, the axillary buds of the last two grow vigorously, and as the dead end of the parent stem is very small, it appears to have forkerl. This is false rlichotomy (p. 24). It also occur's in many branches of the lilac. A shoot from this plant generally. exhibits at its end a pair of vigorous lateral burls, betreen which is a small terminal bud. This last sometimes grows on, and pro-

1 Such bands are very beautifully seen in the keech. 
duces a weakly terminal shoot, or it may, so to speak, be jostled out of existence, when a false dichotomy results. On the other hand, where the leaves are scattered, i.e., placed singly on the nodes, the terminal bud may be replaced by the axillary bud of the last leaf. Take, for example, a well-grown shoot of elm. The current year's growth may be recognised by its greenish colour and the presence of the ring of scars at its base. The end of the shoot is occupied by a bud, apparently terminal. It is really, however, situated in the axil of the last leaf, and at its base, opposite the leaf, is a small scar, formed by the death of the terminal bud. Similarly, the current year's shoot is itself rleveloped from an axillary but. Just below the ring of scars is a crescentic mark, showing where the corresponding leaf fell off. Opposite this is a little rounderl projection, where last year's terminal bud was attached. The same reasoning applies to still older parts. We have, in fact, to deal with a sympodium (p. 24), though the main branches are developed racemosely. The same remark applies to birch, beech, hazel, and other forms. It must be carefully noted that facts like these are not obvious. Very careful examination of shoots in different phases of growth is necessary to verify them. The lefinite yearly increase described ahove takes place chiefly in trees and shrubs with well-protected scaly buds. Cases like the elm, where the ends of the shoots perish, lead on to the numerous plants in which indefinite growth takes place in the summer, without formation of strong buds near the ends of the shoots, as a provision for the following year. Here (as, for example, in the rose), the later part of the annual growth perishes in autumn, and the axillary buds of the older part expand into leafy shoots the next spring. Owing to this, many shrubs branch very irregularly. A further stage is seen in perennial herbs, where all overground parts die down annually, and are succeeded by outgrowths from buds belonging to the underground portion of the stem.

The statement made on p. 44, that corms and bulbs are thickened underground buds, will now be more clearly understood. The main corm or tuber produced yearly (as well as the smaller ones) is an axillary bud. It may be taken as a general rule that where one of two correlated organs is much and rapidly enlarged, the other will be correspondingly reduced. Thus, in a corm, the stem is very much thickened, while the leaves are very small, and conversely for a bulb. Bulbils (p. 44) are axillary buds with small thickened leaves.

Lateral buds, as we have seen, are typically axillary, and it sometimes happens that more than one bud is produced in an axil. These accessory buds may be placed side by side or one 
above another. If, in the latter case, the upper one develops, an extra-axillary branch is the result. Adventitious buds may also occur, which observe no regularity in their place or time of development. Most of the shoots on old tree-trunks belong to this category, and they may also be produced on some roots, or even on leaves. An example of the last is seen in begonias. A leaf of one of these plants if fixed in the earth will develop roots from the end of its stalk, and buds in various places.

The terms prefuliation and vernation are applied to the ways in which leaves are packed in the buds. The individual leaves are disposed in various manners, and their mutual relation is different in different cases. ${ }^{1}$ We now come to the arrangement of mature leaves on the stem. This partly depends on the length of the internodes (p. 24) and partly on the size of the leaves. But apart from this, it is found that, in a given plant, the leaves are always attached or inserted at points which bear a definite relation to one another, which relation may be expressed numerically. Arrangement of the leaves, in this sense, is known as phyllotaci. A nolle may bear two or more leaves, when the term uhorler is used, or else only one, which fact is denoted by the words seattered or alternate. In the simplest case a whorl consists of two member's, as in dear nettle, pink, horse-chestnut, and lilac. Such opposite leaves are generally decussate, i.e., successive pairs alternate with one another. This is very well seen in the dead nettle, and even a cursory examination will show that the leaves here form four lines, rantis or orthustichies, along the stem, one orthostichy corresponding to each of its four Hat sides. Angled and ridged stems frequently exhibit a relation of this kind. A whorl in other cases may consist of three or more members, and here also the leaves are respectively above and below the spaces between the members of the whorl below and the whorl above. Transitions between the whorled and alternate arrangement are commonly met with. For example, the rapidly-growing stems of the Jerusalem artichoke (Hetianthus tuberosus) bear opposite leaves below and alternate ones above, the two ways of arrangement gradually passing into each other. And in all, or nearly all

1 The following are the chief terms applied to the ways in which individual leaves are folded or rolled in leaf (and flower) buds :-

(1.) When folded: plaitcd (in some palmately-veined leaves), when folded like a fan ; conduplicate, doubled up longitudinally, the upper surface internal; inflexed, the upper part bent down on lower.

(2.) When rolled: convolute, in a continuous roll, upper side being internal, and one margin forming centre of roll ; involute, both margins rolled inwards; revolute, both margins rolled outwards; circinate, rolled from the tip downwards, like a crozier; crumpled, explains itself. Compare also footnote, p. 84 . 
dicotyledons, the two first leaves (the cotylerlons or seerl-leaves) are opposite, however the following leaves may be disposed (fig. 2). Seedlings of mustard and cress show this very well (fig. 3 ).

When the leaves are alternate, they are arranged so that their angular distance from one another is constant. That is to say, if the stem were telescoped so as to bring any two successive leaves to the same level, and if two radii were drawn from the centre of the stem at that level through the insertions of the two leaves, the angle enclosed by the radii would be constant, generally speaking, for the same plant. Diagrams of phyllotaxis represent the stem as being extremely conical, and looked at from above, the leaf insertions being markel by thick curves. The simplest case is that of grasses, \&c., where any particular leaf is succeeded by one placed on the opposite side of the stem. The divergence is evidently $180^{\circ}$, and this may be expressed by the fraction $\frac{1}{2}$, i.e., half of the entire circumference of the stem, or $360^{\circ}$. If a line is drawn round and round the stem in the same direction, cutting the insertions of the leaves, it will form what is called the genctic spiral. Of course a spiral line might be drawn according to pleasure in either direction, right to left, or the opposite. It is agreed, however, always to take the shorter course. Starting from any leaf and proceeding upwards, the spiral will wind once or more round the stem, till a leaf is reached immediately above the first, i.e, in the same rank or orthostichy. Such a portion

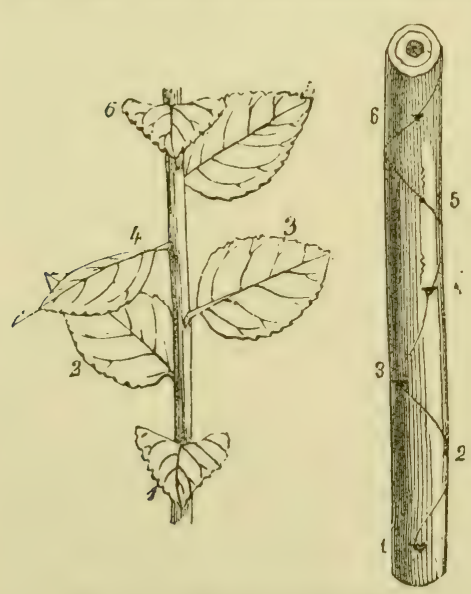

FIG. 9. $-\frac{2}{6}$ Phyllotaxis of Cherry. of the spiral is called a cycle. The numerator of the fraction $\frac{1}{2}$ shows us that the cycle takes one turn round the stem, while the denominator signifies that the cycle contains two leaves, and that there are two orthostichies. The series $\frac{1}{2}, \frac{1}{3}, \frac{2}{5}$, $\frac{3}{8}, \frac{5}{13}$, \&c., includes the commonest divergences. From onwards the numerator and denominator of any fraction are respectively the sums of the numerators and denominators of the two preceding fractions. 'The two-ranked ( $\left.\frac{1}{2}\right)$ arrangement not only occurs in grasses, but also in many other monocotyledons, and in twigs of the lime, elm, beech, \&c. 'The three-ranked $\left(\frac{1}{3}\right)$ distribution is characteristic of sedges, and the alder and aspen. Most 
dicotyledons, e./., willow, oak, rose, apple, and cherry, display five-ranked or quincuncial ( $\left.\frac{2}{5}\right)$ phyllotaxis (fig. 9). Here there are five orthostichies and five leaves in the cycle, which makes two turns round the stem. An eight-ranked ( $\left.\frac{3}{5}\right)$ case may be seen in the holly, while the other divergences chiefly occur in cases where the leaves are much crowded. The house-leek, for example, presents the thirteen-ranked $\left(\frac{5}{13}\right)$ arrangement. It frequently happens that irregularities are brought about from twisting of the stem and other causes. In the elm and beech, for instance, the two ranks of leaves are not exactly opposite each other, but are nearer together on the under than on the upper side of the branch. Here also we get a bilateral arrangement, i.e., the leares are all approximately in the same plane; hence it becomes possible to distinguish between upper and lower surfaces in the branch. This also is caused by displacement of parts.

We now come to a consideration of the kinds of leaf. These are generally taken to be four in number:-

I. Fotiage (euphyllary) leaves.

2. Scale (cataphyllary) leaves.

3. Bracts (hypsophyllary) leaves.

4. Floral leaves.

These will be described in the following chapter. 


\section{CHAP'TER VI.}

\section{FOLIAGE AND SCALE LEAVES.}

\section{MORPHOLOGY.}

The ordinary green leaves of a plant are known as Foliage Leaves. They vary very greatly in shape, but in all of them certain parts can be recognized, which are known by distinctive names. Examine, for instance, a shoot of a garden geranium. Each leaf will be seen to present two distinct parts, the leaf stalli or petiole, and the expanded blacte or lamina supported by this. The leaf is horizontally directed, with upper surface (back) facing the stem, and lower surface (front) turned away from it. A vertical plane passing through the stem will bisect the leaf into two corresponding halves. This plane is called the mectian or anteropusterior plane, and the leaf is said to be bilaterally symmetrical. In other words, it can only be divided by one plane so as to give corresponding halves, which in this case may be termed right and left. Each of them is, so to speak, the reflection of the other, i.e., if one half of the leaf is placed with its cut edge against a mirror, the reflection will resemble the missing half. Optically speaking, each half resembles the other half laterally inverted. The typical stem, on the other hand, is ructially symmetrical, in that a number of planes can divide it into corresponding halves. 'There is consequently no distinction between surfaces and sides, right and left. ${ }^{1}$ In a three-sided stem there are three such planes, in a four-sided one four, and in a smooth cylindrical stem an infinite number. The lamina, being the important part of the leaf, is rarely absent (see p. 53), but the petiole is frequently so, and the leaf is then said to be sessile, as in the majority of monocotyledlons, and in many dicotyledons. 'This is probably a more primitive condition, and all gradations are found between it and cases where a stalk is present. That is to say, the boundary between lamina and petiole is not always sharp. The latter may he ringed, there being a thin green strip on either side of it, directly continuous with the lamina. And if this strip is fairly broad, we no longer speak of a winged petiole, but of a narrow region of the lamina. There are, however, still other regions in certain leaves. A blade of grass will be found at its base to be

${ }^{1}$ Horizontally-directed stems are bilaterally symmetrical. 
continuous with a sheath that closely surrounds the stem (fig. io). It can, however, easily be removed, since it is not a complete tube, there being a longitudinal split traversing it on the side opposite to the lamina. In a sedge the sheath is a complete tube. This structure is especially common among monocotyledons, though by no means confined to them. The sheath is often present in a very rudimentary way, as, e.g., in the leaves of the common groundsel, which, by the way, illustrate the difficulty of distinguishing between a winged petiole and a narrowed region of the lamina. Here we, perhaps, have to do with the latter condition. Again, many leaves possess stipules, which are nembranous or leaf-like outgrowths situated on either side of the insertion of the leaf. Examine once more a young shoot of the garden geranium, and note a green expansion or stipule on either side of the point mentioned. In an older shoot they will be withered and brown ( $c f$. fig. II). The different regions enumerated, petiole, lamina, sheath, and stipules, may now be considered in greater detail.

Little need be added to what has already been said about the Periole. Like the leaf as a whole, it is generally bilaterally symmetrical, and its upper surface is very frequently grooved, its lower surface being at the

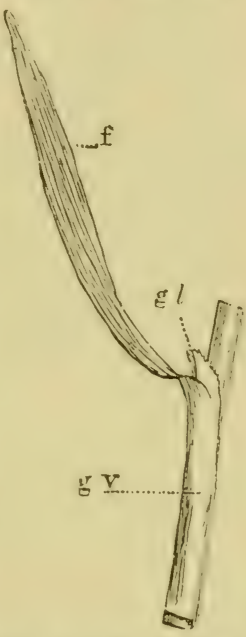

EIG. ro. - Part of a Girisis Leaf. gv. sheath; $t$. blade ; gl. ligule. same time ridged (fig. 29). In some leaves, especially those which possess the power of morement, the petiole presents a swelling at its base, the pulvinus or motile organ (fig. 29). This may be seen in the scarlet runner, sensitive plant, and the common garden acacia (Robinia pseudacacia). The peculiar tremulous movement of the leaves of the aspen is due to the fact that the leaf-stalks are vertically flattened, thus presenting a considerable surface to the wind. Examples are known, but not among British plants, where climbing is effected by means of

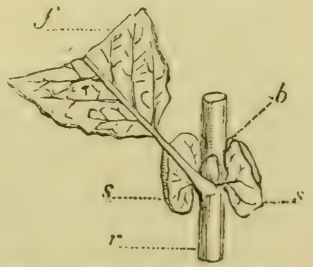

FIG. Ir.-Base of Willow Leaf, showing stipules, $s, s$, and axillary bud, $b$. the leaf-stalks, which are capable of twisting round a support. Just as the stem may become flattened and assume the functions of the leaf, so also may the petiole make up for the small size or absence of the lamina. Such flattened phyllodes are especially characteristic of the Australian eucalypti and acacias. These 
trees cast no shadow, for the phyllodes are vertically expanded. Several considerations show that the structures in question are actually petioles. An ordinary acacia leaf is complex in shape, and there is one species, Acacia melanoxylon, which possesses both phyllodes and ordinaryleaves. Not only so, but upon the

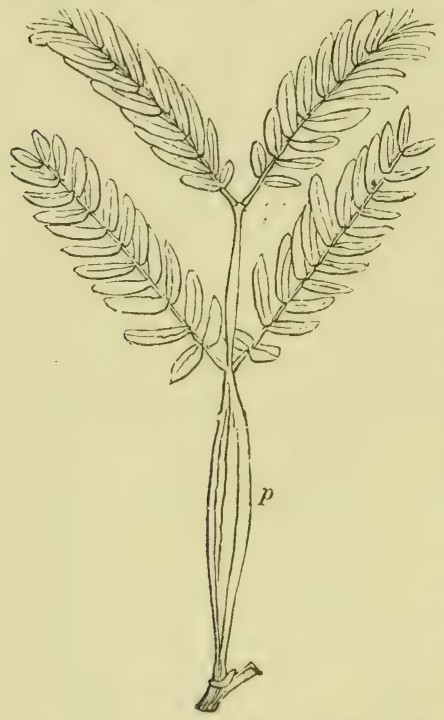

Fr'. 12.-Bipinnate Leaf of Acacia, with flattened petiole.

same tree numerous gradations are found between the two, from examples with well-developed laminæ and slightly flattened stalks, down to others with much reduced laminæ and phyllodelike stalks. Again, although a mature acacia may possess nothing but phyllodes, yet the early leaves of the seedling are normal. These are succeeded by others which are more and more phyllode-like, till, finally, only phyllodes are produced ( $c f$. fig. I2).

A number of plants are now known which are carnivorous or insectivorous, that is, they attract insects by various devices, and make use of them as food. The pitcher-plants are well-known examples. The "pitchers" are hollow leaf structures, and, in the North American Sarracenias, belong mainly to the petiole, though a small hood-like lamina is present which overhangs the mouth of the pitcher.

The surface of the petiole may be glabrous, or else provided with hairs or emergences.

We now come to the Lasins. This is generally expanded horizontally, so that in shoots which grow upwards the upper side is turned towards the stem. The twigs of many trees, as, e.g., the beech, elm, and yew, are more or less horizontally directed, and their leaves are twisted upwards so as to retain their normal position with regard to the light. Bilateral shoots are the result. The same thing occurs in many creeping, trailing, and climbing forms, of which periwinkle (Vinca) and ivy may be taken as examples. The bilateral arrangement is generally limited to alternate leaves. Opposite leaves under the same circumstances would overlap. The horizontal position is not, however, assumed by all leaves. Some of them are vertical, like the phyllodes of acacias, and in this case the same end, i.e., protection from a 
strong sun, may be served, as in most of the Australian myrtles, \&c. A very interesting example is the compass-plant (Silphium laciniatum) of Yorth America, in which the vertical leaves are lirected with their edges north and south. All these cases are only apparent exceptions, for careful examination shows that the rertical position is the result of a twist at the base of the leaf. $A$ very curious case is presented by the leaves of the iris and its allies. The internodes of the stem are here extremely short, so that the two-ranked leaves are closely crowded together. They vould orerlap one another by expanding horizontally, and the lensely packed sheathing bases put a twisting into the vertical position out of the question. No attempt is therefore made to expose the upper surface to the light, but the leaf doubles inwards, so that the under side is so exposed. This folding together causes the bases of the older leaves to overlap or stride over those of the younger ones, on which account the term epritcunt has been applied. But this is not all. In the free part of the leaf more or less union has taken place between the two halves, the edges of which can be easily recognized by their whitish membranous appearance. It will also be easily seen that in this free part there is present, in addition to the obviously doubled portion, an outer thinner region. This is a vertical outgrowth from the under side of the leaf, by which a large amount of leaf-surface is gained.

The lamina is usually bilaterally symmetrical, but radial symmetry is exhibited in some cases, as in the tubular leares of onion and the cylindrical leaves of rushes. In these cases, as in iris and many other monocotyledons, it may perhaps be best to regard the leaves not as laminæ, but as examples of undifferentiated leaf-structures, i.e., showing no distinction of parts ( $c f$. p. 52). Not only are there some instances where the symmetry is greater than usual, but also others where it is less. The common begonias of greenhouses are the best example of such unsymmetrical leaves. Here the base of the lamina bulges out on either side into a lobe, one of which is much larger than the other. No plane will divide such a leaf into two exactly corresponding halves. The same peculiarity is exhibited, to a less extent, by the elm (fig. I 3 ).

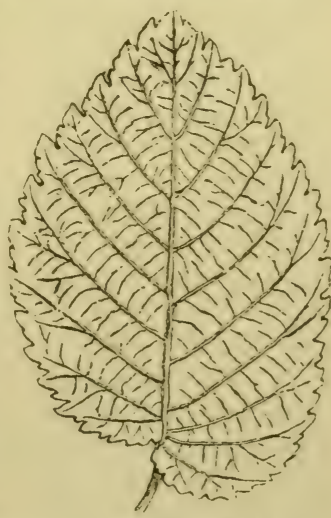

FIG. 13.-Oblique Leaf of Elm, with serrate margin.

Consilerable importance is attached to the cenction of leares, 
i.e., the manner in which the vascular bundles, popularly known as veins, nerves, or ribs, are distributed. These are generally visible externally, especially on the under side, where they may project considerably. It may happen, particularly in fleshy leaves, like those of the stonecrop, that this is not the case. Dissection shows, however, that they are present, though not obvious externally, so that the term hidden-veined may conveniently be applied. Two principal kinds of venation are distinguished, parallel and reticulated. In the former, which is characteristic of monocotyledons, the chief veins, without undergoing division, run more or less parallel with one another, either from base to apex, or from a central midrib to the margin. Their course is either straight or curved. Most of our common monocotyledons are basal-veinel, i.e., possess no midrib, as may be seen, for instance, in grass leaves (fig. Io), iris, lily of the valley, \&c. Many exotics, such as the banana, illustrate the costal-reined arrangement, in which a midrib is present. 'There is, however, no sharp line of demarcation between these two methods of distribution. If in a costal-veined leaf we suppose the midrib to be telescoped, then the lateral veins would radiate from the base of the leaf in a fan-like manner, their parallelism being lost. The leaves of fan-palms are veined in this way. Parallel-veined leaves, as a rule, do not exhibit anything like a network in the arrangement of their vascular bundles, but very small veins or veinlets can often be seen running straight across the interspaces between adjacent veins, and connecting these together. In four British monocotyledons, of which the two commonest are the black bryony and the wild arum, the venation resembles that of the second type, i.f., the reticulated or netter, which is characteristic of dicotyledons. The lamina is here traversed by a complicated and irregular network of small veins (fig. 13). The leaves of dock and apple furnish good examples, respectively coarse and fine. This sort of venation presents two chief varieties. Compare the leaves of beech, Spanish chestnut, or lilac with those of ivy, sycamore, or garden geranium. On the one hand, the lamina will be seen to be traversed by a central midrib, giving off branches in a featherlike manner (fig. I3); on the other, several strong veins will be noticed, radiating from the attachment of the petiole. In both cases a great deal of branching may be observed, the ultimate branchlets uniting or anastomosing into a network. The leaves described, and others like them, are pinnately or featherveined and palmately or radiately-veined. The relation between these two kinds of veining is similar to that existing between the costal and radiate types in monocotyledons, and numerous grada- 
tions exist. In the sunflower, for example, there is a wellmarked midrib, but the pair of lateral veins next the base are much stronger than the remainder. Exceptional dicotylerlons are known in which the venation is more or less parallel. The wild plantains (Plantago) illustrate this. In them a number of strong reins take a curred course from base to apex, having between them, however, a typical network formed by small veins.

The general shape or form of the lamina is correlated with the venation. Monocotyledons have generally leares with simple outlines, which are longest when basal-veined. In dicotyledons long and short forms are associated respectively with pinnate and palmate venation. Details will be given below.

It may be noted, as a general rule, that the most complicated outlines occur in small herbs, especially when these occur in crowded situations. The largest leaves are also, in many cases, found nearest the ground. The leaves of the same plant are by no means uniform either in shape or size. This is especially noticeable in herbs. 'Take, for example, a tall buttercup plant. The lowest, so-called radical leaves, are here the largest and most complicated. They gradually pass into smaller and less complirated upper leaves. Nuch greater uniformity is found among the leaves of trees.

It is not possible to make any exact classification of the innumerable kinds of general outline found among leaf-blades. We may, however, distinguish between forms of fairly equal breadth, or broadest in the middle, and those with broader base or apex.

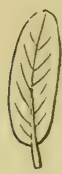

FIG. 14.--Oblong
Leaf.

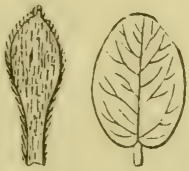

FIG. 15.-Spathulate and Oval Leaves.

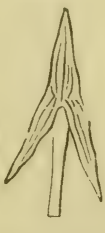

FIG. 16.--Rounded and Arrow-shaped Leaves.

In the first case, we can gradually pass from the needles of the fir to broader grass leaves, and so through oblong (fig. I4), oval (fig. I5), and rounded (fig. I6) forms to circular ones (fig. I 7). Where the blade is broader at the base, the form may distantly resemble that of a lance-head, an egg, \&c., hence receiving the name of lanceolate (fig. I8), orate (fig. I9), \&c. Very commonly the base is notched, and projects on either side of the leaf-stalk as a more or less prominent lobe of various form. Heart-shaped 
(corlate), arrow-shaped (scryittate), kidney-shaped (reniform) leaves, icc., exemplify this (figs. 20, 16, 2 I). The lobes of a sessile lamina of this kind may clasp the stem more or less closely. The leaf is then amplexicaul. Or they may from the first be united together on the opposite side of the stem, which then appears to pierce the perfoliate leaf. A similar origin (i.e., union of lobes) accounts for peltate leaves (tig. I7), and two opposite leaves may be continuous or connate. When the lamina passes into a wing on the stem $\left(* . p .5^{2}\right)$, the leaf is decument. When the blade is broader at the apex, the outline is often similar to that of lanceolate, ovate, cordate, dc., leaves, but reversed. This is expressed by

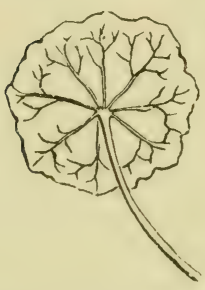

FIG. 17.--Peltate Leaf, seen from below.

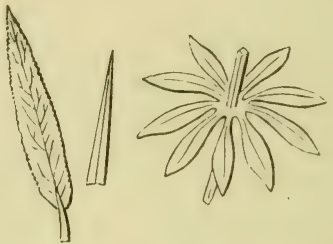

FIG. 18.-Lanceolate, Awl-shaped, and whorled Leaves.

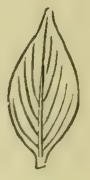

IIG. rg.--Ovate Leaf.

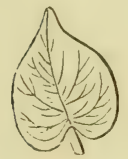

IIIG. 20.-Cordate
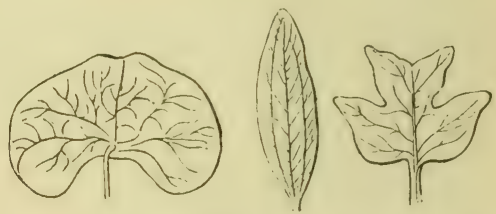

FIG. 21.-Kidney-shaped, Elliptical, and Abrupt Leaves.

prefixing ol, as ollanceolate, obovate. Special regions of the lamina, as extremity and margin, are also very varied in character, and numerous terms are employed in describing. Either extremity, i.e., base or apex, may be more or less pointed, rounded, or notched, and the latter may also be provided with a sharp projection. The maryin may be entire, that is, devoid of marked projections and indentations, or it may possess them. In the latter case, the edge may be either undulating or provided with small tecth of various shape. ${ }^{1}$ From leaves of this sort we can pass, by intermediate gradations, to lobed or segmented leaves,

1 Leaves are serrate (fig. 13), with sharp teeth pointing to apex; crenate (fig. 17), with rounded teeth ; dentate, with sharp irregular ones. 
in which the margin is more deeply excarated. Projections, whether small, as teeth, or large, as lubes, generally correspond to smaller or larger veins. Lobes and the like which follow the latter are therefore arranged either pinnately or palmately. A listinction is clrawn betreen lobed, cleft, and parted leaves, where the excavations extend, respectively, not more than half way, half way or more, and almost the whole way to the miclrib or base. In the first case, either the lobes or interspaces are rouncled, and in the second, sharply cut. Thus we get pinnately and palmately lobed, cleft, and parted leaves (figs. 22 and 23). The lobes may be of very unequal size and shape (as in potato), their margins varying like those of

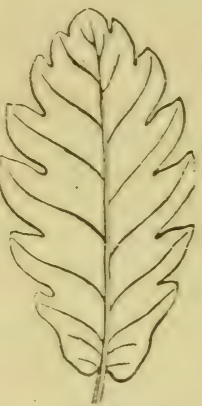

FrG. 22.-Pinnatelylobed Leaf of Oak.

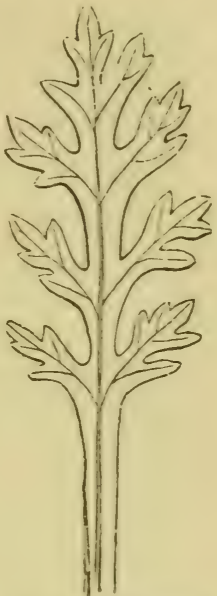

FIG. 23.-Pinnatelycleft Leaf of Poppy. complete leares. Secondary lobes are thus produced in many cases, and still smaller subdivisions may also occur. Examine in this connection the thrice pinnately-parted leares of the yarrow or millefoil.

In a large number of leares division actually extends to the midrib or base, giving pinnately or jalmately-divided forms. The lobes are then termed leaflets, and the leares are compound, as opposed to simple leares, such as those described up to this point. Leaflets may be either sessile or stalked, and their general outline. drc, are described in the same terms as simple leares. Pinnately and palmately-divided compound leares are termed pimute or ficlinute. Examples of the former condition are seen in elder, ash, and rose (ci. fig. 24). The axis upon which the leaflets are borne clearly answers to the midrib of a simple leaf, and cases are not infrequent in which the end of a pinnate leaf is not completely divided. This may be seen rery well in the jessamine. The strawberry (fig. 25) and horse-chestnut (fig. 26) furnish typical instances of palmate leares, where the leaflets are attached together at the tip of the petiole. Leaflets, like leaves, are often attached by means of a joint or articulation, where separation readily takes place. This enables us to distinguish between pinnate and palmate leares with only three leaflets. Compare these structures, for example, in scarlet runner (fig. 29) and clorer. 
In the former case, the petiole is continued into what is evidently the common leaf-stalk, at the base of which are jointed a pair of

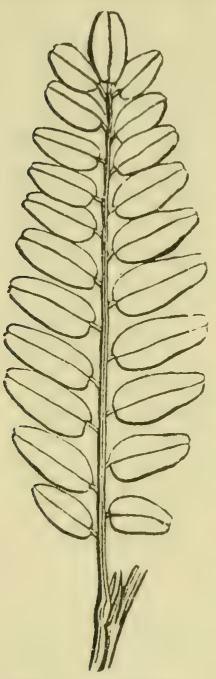

FIG. 24.-Pinnate Leaf. leaflets, while it is terminated by an odd leaflet jointed in the same manner. This, then, is a pinnate leaf. The three leaflets in the clover are all attached to the end of the petiole, which is the only common leaf-stalk. We have here, therefore, a palmate leaf. The general appearance, however, is usually a sufficient guide. The leaflets of the palmate leaf are either all sessile or with stalks of equal length, while in the abbreviated pinnate leaf the terminal leaflet appears to be stalked even when the other two are sessile, for the common leaf-stalk seems to belong to it. Similarly, when the lateral leaflets are stalked, the terminal one apparently has a longer stalk. The lower part of this apparent stalk is, however, common leaf-stalk. A compound leaf may even be reduced to one leaflet, and is then liable to be mistaken for a simple leaf. In the barberry, for example, the small leaves are jointed on short stalks. A simple leaf is not jointed in this way upon its petiole. The inference that it is a reduced compound leaf is borne out by comparison with the closely allied yellow-flowered mahonias frequently found in gardens. Here

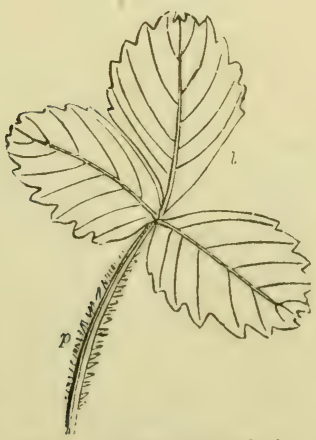

FrG. 25.-Ternate Leaf of

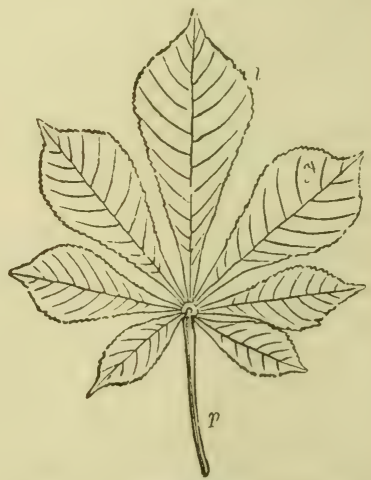

FIG. 26.-Palmate Leaf of HorseChestnut.

the leaves are normally pinnate, with a terminal and two to four pairs of lateral leaflets. The ash presents a similar case. The 
ordinary form (Frainus eicelsior) has well-marked pinnate leaves, but in an allied species (Fiaximus heterophylla) others, reduced to one leaflet, are found in addition. The remarks previously made about the variations in size and shape of the lobes in simple leaves apply with equal force to leaflets. Many leaves are much divided or decompound, the primary leaflets being split up into secondary, and these in some cases into tertiary, dc. Thus we have dipinnate (fig. 12), tripinnate, \&c.. leares. Palmate examples when thus compounded are usually of ternate type (fig. 25), i.e., with successive trifurcations, and may be biternate, triternate, dc. The lamina, like the petiole, may be absent, as in phyllodes, or it may undergo special modifications. Many tentirils are leafstructures, and the best examples are found in the pinnate leaves of peas, retches, and the like. Compare in this respect the common field vetch or tare, the edible pea, and the sweet pea. The leaves of the first possess seven pairs of normal leaflets, but one or more pairs at the end are transformed into tendrils, and the axis also ends in a tendril. The leaf of the edible pea is similar, but there are five tendrils, one being terminal, and only two pairs of green leaflets. In the sweet pea there are an odd and two to four pairs of tendrils, and only one pair of leaflets, as a rule. Sometimes, however, a third leaflet occurs with a tendril opposite to it, the nature of which is thus clearly proved.

Protecting spines are often formed by the modification of the lamina. Sometimes only part is thus modified, as in the holly, but the transformation may be complete, as in gorse. Here we get branch spines bearing leni spines. The nature of the latter may be well observed in seedlings, the early leaves of which are ternate. In succeeding leaves the leaflets gradually become narrower and more spiny. The barberry is another instructive example, presenting, as it does, in the same shoot all gradations between leaves with spiny erlges and three to seven-branched leaf spines.

The leaf blades of insectivorous plants ( $f .1 \% 54)$ are often modified for the purpose of securing prey. In the round-leaved sunder (Dioseic rotuntifolia), which is not uncommon in marshy places, the flower-l)earing stems rise from the centre of a rosette of leaves, each of which possesses a short stalk and a rounded blade, the upper side and margin of which bear a large number of socalled " tentacles." These are emergences, resembling minute pins in shape, the hearls being glandular. In fresh leaves each gland is tipped by a drop of the riscid clear excretion, the appearance of which has given rise to the popular name. Tenus' fly-trap is a plant closely related to the preceding, and is found in North Carolina. The petiole is here broadly winged, 
and separated by a constriction from the lamina, which is composed of two oval halves, the margins of which are provided with bristles, while the upper surface of each bears about three slender

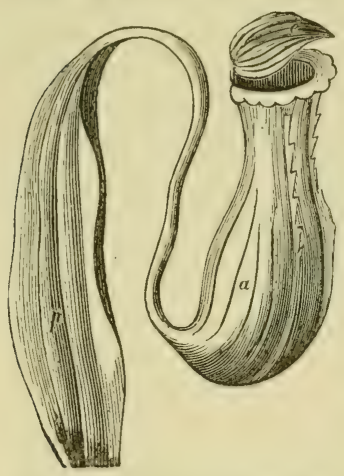

FIG. 27.-Pitcher of Nepenthes. highly sensitive hairs. In one of the pitcher-plants, Nepenthes (fig. 27), species of which occur in Madagascar, Ceylon, and the East Indies, the midrib of the simple leaf extends beyond the apex of the lamina as a tendril, which terminates in a lidded pitcher resembling a hot-water jug in shape. The bladder-wort (Utricularia) is an aquatic herb, sparsely distributed in British ponds and ditches. Its leaves are pinnately parted into numerous narrow lobes, some of which bear small-stalked bladder-like structures, each of which possesses an inwardlyopening valve-like aperture.

The texture of the lamina may be either herbacents, leathery, or succulent. The first characterizes most of our common leaves, which are deciduous, i.e., shed annually (p. 43). Leathery leaves, capable of greater endurance, are found in evergreens, which owe their name to the fact that the foliage is sherl grarlually, so that the branches are never bare. Succulent leaves, such as those of the aloe, are especially characteristic of arid climates (cf. p. 27).

The colour of the lamina is not uniform. Not to mention spotted, mottled, and variegated leaves, it usually happens that the upper side is of a darker green than the lower. This is principally due, as we shall see, to the way in which the internal green tissue is arranged. But the colour is also rlependent on the nature of the surface. This may be glabrous, especially in evergreens, or more or less hairy, and in the latter case it is usual for the hairs to be more numerous on the under sile, giving this a whitish hue. Silverweed (Potentilla anserina) is a beautiful example, and the same thing is seen to a less extent in wallflower, buttercup, dc. Some leaves are of a bluish-green colour, and this may be due to the presence of wax, as in the garden poppy. Glandular hairs are frequently found on the lamina, and these very often secrete a fragrant oil, as in lavender, where short glandular hairs are mixed with larger branched non-glandular ones. The perfume patchouli is obtained from a similar source, and the odour of sweet-briar is also due to such hairs. Stinging hairs may be present on the lamina (petiole and stem) as in the 
nettle. Emergences are also found in many cases, especially where the veins project on the lower sile. (For Sireatr, ef. p. I 54.)

TVe next come to the consideration of Stipules (cf. p. 53). These are not always of the same nature. In the pansy, for eximple, they are extremely large and foliaceous or leaf-like, and very likely correspond to the lateral lobes of a ternatelyparted sessile leaf. The same, or something similar, appear's to be true of many foliaceons stipules, as perhaps in the case of the bean, pear. Sc., where they look like a basal pair of leaflet.s. In fact, they may he the sole organs for performance of the leaf functions, as far as nutrition is concerned. The wild-peas, belonging to the genus Lath!!rus, illustrate in a very interesting way the mutations to which the regions of the leaf are liable. There are several British species. In one of these, the black pea (Lathyjics niyer), the millrih of the pinnate leaf ends in a point; there are fair-sized stipules, and several pairs of leaflets. Another species, the blue marsh-pea (L. palustris), has leaves: tendrilled at the ends, larger stipules, and fewer leaflets. The leaves of the meadow-pea (L. pratensis) possess only one pair of leaflets and more tendrils. Lastly, in the rellow pea (L. Apliaca). the whole leaf is converted into a tenclril, with the exception of the stipules, which are extremely large. Curiously enough, there is one species of Lathyrus, the grass-pea (L. Nissolia), in which neither leaflets nor tendrils are present, and the stipules are very small. The leaf-axes are here converted into phyllodes shaperl like grass leaves. This condition is led up to by one or two other species where the petiole is winged.

Many stipules are membiranous, and very unlike the foliaceous examples alrealy mentioned; and also they are not necessarily in the form of two free expansions, but may be united in various. ways. Examine, for instance, a rose leaf, in illustration of the latter point. The petiole is sheathing at the base and bordered by a green wing on either side, which encls in a pointed lobe some distance from the first pair of leaflets. These two wing-like pieces are called arlnate stipules, from the idea that they represent two of these structures adherent to the petiole. Such stipules are probably simply surviving bits of a once more extended wing. In many roses the adnate stipules are much smaller and not green. This is also the case in clover. A pair of stipules may unite in the leaf-axil to form an arillary stipule. Something akin to this is found in a membranous ligule, which in grasses projects from the upper side at the junction of sheath and lamina (fig. Io). Indeed, this and many undoubted stipular structures appear to belong to the leaf-sheath. Two stipules may also be united into an opyosite stipule, placed on the opposite side of the 
stem from the leaf insertion. Adhesions in this direction form transitions to sheathing or ochreate stipules, which, as in dock,

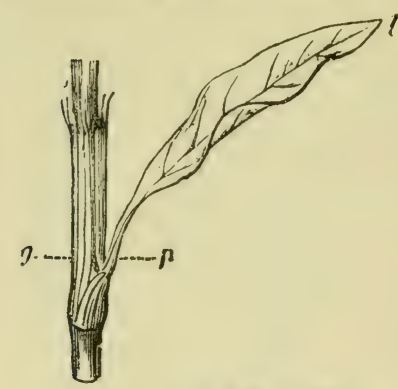

FIG. 28.-Leaf of Knot-Grass.

l. lamina; 2 . petiole; $g$. sheathing stipules. sorrel, and knot-grass (fig. 28), or bistort, form a membranous sheath surrounding the stem for some distance above the leaf insertion. The stipules of opposite leaves may unite on either side into an interfoliar stipule. Tendrils rarely and spines more frequently (garden acacia) result from modifications of this part of the leaf. The leaflets of compound leaves may possess single stipels, as in scarlet runner (fig. 29). As in the lamina, we can distinguish different textures and varieties of surface. Membranous stipules often fall off early, and are then said to be deciduous, as in beech and lilac.

Scale Leaves are much simpler in character than foliage leaves, and in fact may be regarded as reduced representatives of these. 'They alone occur on subterranean stems, and in this case appear to represent leaf-sheaths. In this situation they may be insignificant scales, like those in the axils of which potato-eyes are developed, or else, as in bulbs, they may be considerably thickened in connection with the storage of reserve materials. Scale-leaves are also found on underground stems, and in some forms which are parasitic or saprophytic they entirely supplant the ordinary leaves. The broom rape (Orobanche) and yellow bird's-nest (Monotropa) are examples of this. Most frequently, however, overground scale leaves are found as bud scales, either for storage, as in bulbils, or for protection, as in the buds of trees (p. 46). In the latter case they often grade insensibly into the ordinary leaves of the bud, when their leaf nature becomes evident. They may correspond to leaf-sheaths (fir and horse-chestnut), laminæ (lilac), or stipules (beech). The sticky substance bud-glue or blastocolla, found in horse-chestnut and many other cases, is excreted by special glandular hairs known as colleters.

Structure of the Leaf.- It is not necessary to give any details regarding the structure of the leaf-stalk, since this is constructed almost precisely like a young stem, the chief difference being that the bilateral symmetry usually perceptible externally extends also to the interior.

The lamina of an ordinary foliage leaf (fig. 7, G) consists of upper and lower layers of epidermis, between which is the green pulpy ground-tissue, here called mesophryll, traversed by the 
vascular bundles or veins, which, as we have seen, may be distributed in various ways.

The epidermis, which can be conveniently examined both in sections and by peeling off pieces, is composel, as seen uncler the microscope, of flattened cells, the boundaries between which may be straight or curved (fig. 7, F). The outer walls of the cells are covered by a cuticle, and besides this, especially in leathery leaves like those of the holly, are often much thickened and cuticulari:ed, i.e., their cellulose is more or less completely converterl into cutin (ct. p. 30). The prickles upon many leaves owe their firmness to the thickness of the epidermic cell-walls. Protoplasm and cell-sap are contained in the cells, but, as a general rule, chlorophyll granules are absent. In the under epidermis of a leaf, and often to a less extent in the upper epiclermis as well, a large number of minute openings are found. These stomata (fig. $7, \mathrm{G}$ ) are intercellular spaces formed as small splits between adjacent cells. ${ }^{1}$ Each of them is bounded by two kidney-shaped fucril-cells, the concavities of which face one another. These two cells not only differ in shape from the ordinary epidermic cells, but also in the possession of chlorophyll granules. In many cases some of the neighbouring cells are of different character from those making up most of the epidermis. Stomata are not confined to the foliage leaves, but occur with more or less frequency in the epidermis of all organs except roots. They are also absent in entirely submerged leaves and stems, while the stomata of floating leaves only occur in the upper epidermis.

The hair structures, developed from the epidermis of many leaves, present the same variety as in the case of the stem (p. 2S). The structure of the stinging hairs of the nettle will be described further on (p. 72 ).

The ground-tissue (fig. $7, \mathrm{G}$ ) or mesophyll, like the epidermis, is not constructed in exactly the same manner above and below. An ordinary horizontal foliage leaf is, in fact, bifacial in structure. The upper part of the mesophyll is composed of one or more layers of cells elongated at right angles to the surface, and termed from their appearance palisade parenchyma. Their cellulose walls are thin, and they contain a great many chlorophyll granules. The lower part of the mesophyll is made up of cells differing from the preceding in their very irregular shape. This spongy parencliyna is traversed in all directions by intercellular spaces which communicate with one another, and, by means of the stomata, with the exterior. Under each stoma there is a specially large intercellular space known as a respirct-

1 The stumata of the white lily are favourable objects for study. They are large enough to be seen with a lens. 
tory cavity. The ccrtinuity of this system of cavities and its connection with the exterior can be proved by a simple experiment. Take a large stalked leaf and immerse the lamina in water. Now apply the mouth to the cut end of the stalk and blow vigorously, when numerous small air-bubbles will escape from the surface of the part under water. The vascular bundles mostly run between the two regions of the mesophyll, and they are generally surrounded by parenchyma made up of small colourless cells. The ground-tissue may also contain solerenchyma, especially in the leaves of grasses, and intercellular spaces containing secretions. These spaces are formed by the breaking down of cells, and they contain ethereal oils, which are often odorous. The fragrance of crushed myrtle leaves arises from this cause, and other examples of such secretory reservoirs are found in rue and in the common St. John's wort (Hypericum perforatum). The leaves of the latter present from this cause numerous transparent spots, which appear like perforations, whence the specific name.

The vascular bundles of the leaf, in dicotyledons as well as monocotyledons, are devoid of cambium. 'The wood is above, and its tubular elements are always tracheïles, never vessels. The bast presents the same structure as in the stem, but its elements are small and difficult to make out. It underlies the wood. The respective upper and lower positions of wood and bast, which also obtain in the petiole, may be understood by turning up the leaf into a vertical position, when what were upper and lower now become inner and outer. The mature leaf differs from root and stem in possessing no !rowing-point, and since cambium is absent, its growth is limited. This accords with its comparatively transitory character. It is interesting to note that when the petiole is used for climbing, it often thickens and persists.

It must not be imagined that all leaves possess the bifacial structure described in the preceding paragraph. When the general form is radially symmetrical, so also is the structure. Such leaves are said to be centric, like those of the stonecrop. Here there is no palisade parenchyma, but this may also be absent in flat leaves, e.g., those of grasses. On the other hand, vertical leaves have palisade parenchyma on both sides, which also are equally rich in stomata.

\section{PHYSIOLOGY.}

As in the stem (p. 4I), so also in the foliage leaf support is afforded by the firmer part of the vascular bundles, by scleren- 
chyma and by collenchyma. The larger vascular bundles keep the lamina stretched and extended, acting like the ribs of an umbrella. They and the rest of the stereome (p. 4I) are also arranged so as to prevent the delicate mesophyll from being crushed between the two layers of epidermis. Tearing is largely prevented by thickening of the epidermic walls, as especially in leathery leaves. This takes place to a greater extent at the edge, which is, of course, the place most likely to tear, than elsewhere. Additional firmness is given where a wavy course is taken by the lateral cell-walls of the epidermis, as an increase in amount of supporting substance is thereby gained. The epidermis of some plants (grasses, \&c.) is strengthened by sitica. The remarks made on p. $4 \mathrm{r}$ about protection of stems by thorns, dic., and hair structures apply to the leaf also. The presence of distasteful substances also prevents animals from eating many leaves. Protection from the weather is effected as in stems (p. 4I), with the exception that cork is never present. The glossy leaves of evergreens are peculiarly adapted for preventing the accumulation of snow upon them. Protection from the sun has been mentioned already (p. 54). Buds are often protected by means of scale-leaves, and when these secrete blastocolla the protection is still more complete. It also often happens that young foliage leaves in the bud have a warm covering of woolly hairs, which afterwards fall off.

The main function of foliage leaves is that of nutrition. By means of their chlorophyll they are able (cf.p. ro) to build up organic compounds from the carbon dioxide of the surrounding medium, and the crude sap brought to them by the wood of the vascular bundles. This building up or assimilation is effected in the chlorophyll granules. The first easily recognizable product is starch, and this can readily be detected in leaves which have been in strong sunlight for some time. They are bleached with spirit, then made transparent with chloral hydrate, and, lastly, soaked in a solution of iodine, when they turn a bluish-black. This is a well-known colour-test for the substance in question.

The starch and other organic substances formed in the leaf are largely converted into a soluble form (generally sugar in the case of starch), and travel osmotically in the parenchyma all over the plant, compensating waste and rendering growth possible. Non-diffusible proteid matters can travel by means of the sieve tubes. It may also happen that the various substances composing the elaborated sap are reconverted into the solid form within thickenerl roots, stems, leares, or, as we shall see farther on, seeds. They then become reserve materials.

Chlorophyll is absolutely dependent on light for the performance 
of its constructive function. A plant placed in darkness soon gets pale and unhealthy, and though it may grow considerably in length, gradually becomes less in weight, ultimately dying. Such a plant is said to be etiolated. Celery, and some other garden plants, are purposely reduced to this condition by heaping earth around them. They thus become very sickly, and the tissues not being vigorously developed, are very tender. Also, in the case of celery, the characteristic essential oil is too strong and too abundant under normal conditions to let the shoots be eaten. Chlorophyll cannot be formed, in most cases, unless light is present. If a bean-seed is germinated in the dark, a yellowish etiolated seedling is produced, which grows to a certain extent at the expense of the reserve materials stored up in the seed. The yellow colour is due to the development of etiolin, which is closely related to chlorophyll, and exists, like it, diffused throughout the substance of protoplasmic granules ( $c f . p .8)$. It is also to be noticed that the seedling weighs less than the seed from which it grew. A very feeble light suffices to convert the etiolin into chlorophyll, so that the granules in which it occurs become chlorophyll granules. If the now green seedling is placed in a fairly strong light, it will rapidly increase in size and weight, since its chlorophyll is able to build up organic compounds. The roots of the seedling must of course be placed in a suitable soil or food solution, but this alone is useless if light is excluded.

Since carbon dioxide is one principal item of food, it is obvious that chlorophyll cannot work unless supplied with it. This is readily proved by growing plants under a bell-jar to which air is freely admitted which has been deprived of its carbon dioxide by means of caustic potash. Under these circumstances the plant does not increase in weight, and starch cannot be detected in its leaves. The palisade parenchyma is the most important part of the leaf for the purposes of assimilation, and therefore, as we have seen, is developed on the side turned towards the light. Where, as in vertical leaves, the conditions of illumination are equalized, there may be such tissue on both sides. It is also interesting to notice that, in plants with dense foliage, such as trees, the leaves most exposed to light are thicker than the others, owing to the formation of extra palisade layers.

As already explained (p. Io), the assimilatory process carried on by chlorophyll involves the liberation of a large quantity of oxygen, which passes off into the surrounding medium. This is easily proved by experiments, one of which consists in cutting off a vigorous shoot from a water plant, and, by means of a sunall weight, keeping this submerged, cut end up, in a vessel of fresh 
spring water. If now the apparatus is placed in bright sunlight, bubbles of gas will escape from the cut end. These are ensily collected in a test-tube, and can then be proved to consist of oxygen by the usual methods, e.r., re-ignition of a glowing matchend plunged into the tube. The leaves (and other parts to a less extent) of a land plant are constantly giving off a large amount of aqueous vapour into the air; in other words, they tiansivire. This transpiration is made up for by the active powers of absorption that the root possesses. Numerous familiar facts receive their explanation in this, such as the fading of cut leaves and flowers (p. 9). The loss of water experienced by these malies their cells lose turgidity, and this causes limpness. That water is actually given off on the one hand and taken up on the other is easily demonstrated. A plant growing in a food solution, the surface of which is guarded from evaporation, is covered with at bell-jar, and placed under ordinary conditions of light and heat. Two things soon become evident-aqueous rapour is given off from the plant and condenses on the inner side of the glass, and the food solution gradually diminishes in quantity. The amount of transpiration depends upon a number of conditions. It is naturally greater in dry than in damp air, and in the sun than in the shade. The latter point is shown by a simple experiment. A number of vigorous stalked leaves are collected. Half of these are placed with their stalks in one glass of water and the other half similarly disposed in another glass. It is convenient to employ perforated cards, through the holes in which the stalks are passed. If dry glasses are now inverted over the two lots of leaves, and these are placed in the sun and shade respectively, transpiration will proceed vigorously in the former case, but much less so in the latter. This is shown by the fact that, after the lapse of some ten minutes, abundance of moisture will have condensed on the inner side of the glass which corers the sunned leaves, while that covering the shaded ones remains almost or quite clear. The amount of transpired water may be rery considerable. It has been shown that a sunflower plant presenting $5^{6}$ I 6 square inches of leaf-surface loses in this way, on an arerage, twenty ounces by weight of water during a day of twelve hours. The corresponding loss at night is only about three ounces. Transpiration in the mature leaf takes place partly from the general surface and partly by means of the stomata. The former ("cuticulur") transpiration is greatest in herbaceous leares with a thin cuticle, and least in leathery leaves where the outer cellwalls of the epidermis are thickened and cuticularized and corered by a well-developed cuticle. Stomatal transpiration is much more important, and, in fact, the chief use of stomata is to effect this. 
The quantity of water thus lost depends not only upon the number of stomata present, but also upon their condition. That is to say, a stoma is not always open, and when it is, the aperture is not always of the same size. Stomata generally close at night or on wet days, and open in sunny weather. This is due to the guard-cells. Their action is complicated, but the main principle is easily understood. The fact that these cells always contain chlorophyll granules now receives its explanation. In the sun these granules begin active assimilation, and this causes crude sap to diffuse into the guard-cells, which thus become extremely turgid and increase in size. Curvel cells, like the ones we are dealing with, naturally become more curved when they increase in size. In the case of the guard-cells this means that the stoma opens. But this is not all. The parts of the walls of the guardcells which face outwards and inwards (i.e., towards the outside and inside of the leaf) are very much thickened, and at night or in the wet, when the cells are not very turgil, act like springs, which tend to flatten the cells in the plane of the leaf-surface. Since the walls of the guard-cells are very thin and flexible where they face one another, this flattening causes them to bulge into the slit of the stoma, making it smaller, or even closing it. When the guard-cells are very turgid the outer and inner springlike parts of their walls are forced away from one another, while their thin parts are easily pulled into a position more or less vertical to the surface of the leaf, thus opening the stoma. The walls of the intercellular spaces with which the stomata communicate present a very large surface, from which the evaporation of water can take place.

The importance of transpiration to land plants is seen from the fact that where it is checkel by an over-damp atmosphere sickliness invariably ensues. On the other hand, excessive transpiration is harmful. This is often olserved in the case of plants grown in the hot air of a room. Even when abundantly watered, many of them droop and die, because the roots are unable to absorth rapilly enough to keep pace with the evaporation from the leaves. This is particularly the case when the plants are herbaceous in texture. Protection from too vigorous transpiration may be afforded by a condenser form presenting relatively little surface, or by much thickened and cuticularized cellwalls (aloe, \&c.), or again by the assumption of a vertical position, the best example of which is found in the phyllodes mentioned on p. 53. Transpiration is of importance for two chief reasons. In the first place, young shoots contain 90 per cent. or more of water, without an abundant supply of which they cannot be formed. Such a supply would be out of the question if it were 
not for the vigorous ascending currents facilitated by transpiration. Transpiration ciuses the pressure within the trachere to be least nearest the leaves, towards which, therefore, the sap naturally flows. Again, the formation of organic substance, to any extent, means not only a plentiful supply of carbon dioxide and water, but also of the simple salts dissolved in water. Yet the amount of these is so small in the liquid absorbed by the roots from the soil that it has been compared to ordinary drinkingwater. It is necessary, therefore, in order that enough of these compounds may be oltained, for a very large quantity of water to he absorbed by the root, much more, in fact, than is retained in the plant. Where, as in cacti and similar forms, this process is very sluggish, little organic matter can be formed and growth is extremely slow.

Saproplyytes and purctsites, getting, as they do, organic compounds rearly prepared, mary dispense partly or entirely with chlorophyll. In the latter case the leaves are much reduced in size (broom-rape, dcc.), or even entirely absent (dodder).

Insectivorous plants ( $f . p p .54,6$ I) lay themselves out for the capture of animal food, although they are abundantly provided with chlorophyll and can thrive fairly well without it. In the pitcher-plants a sugary sulstance is secreted at or near the orifice, and in some cases, as in Sarracenia variolaris, there is even a sugary track leadling up from near the ground. Insects, especially ants, are thus attracted, and if they venture to set foot on the slippery inner side of the pitcher, no efforts can save them from sliding down into the liquid within, where they are cirowned. In the case of these and the other insectivorous plants the proteid substances of the prey are brought into solution by a digestive excretion poured out from innumerable glandular hairs or emergences. The solution then diffuses into the interior of the leaf. The excretion closely resembles in composition and function the gastric juice of an animal's stomach.

Leaves, like roots and stems, carry on the function of respiration, but it is only easy to detect this in the dark, since in the light the taking up of oxygen and giving out of carbon clioxide are hidden by the exactly opposite process involved in assimilation (cf. p. 68).

Vegetative reproduction by shoots has already been spoken of (p. 43).

The leaf exhibits various forms of motility. Protoplasmic movements may sometimes be observed in the cells of the mesophyll. This is the case, for example, in Vullisneria spiralis, an aquatic form commonly grown in fresh-water aquaria, where the protoplasm, carrying with it the chlorophyll granules, may 
be observed, under the microscope, to move bodily round the cells in the direction of their length. Streaming protoplasmic currents can also be observed in the cells of many hairs. An instructive and common instance is found in the stinging hairs of nettle. If one of these is carefully removed from a young leaf, and examined under a microscope, it will be found to consist of a unicellular hair produced into a hollow brittle spike terminated by a minute knob. The base of the hair is embedded in a dome-shaped emergence. The inner part of the protoplasm

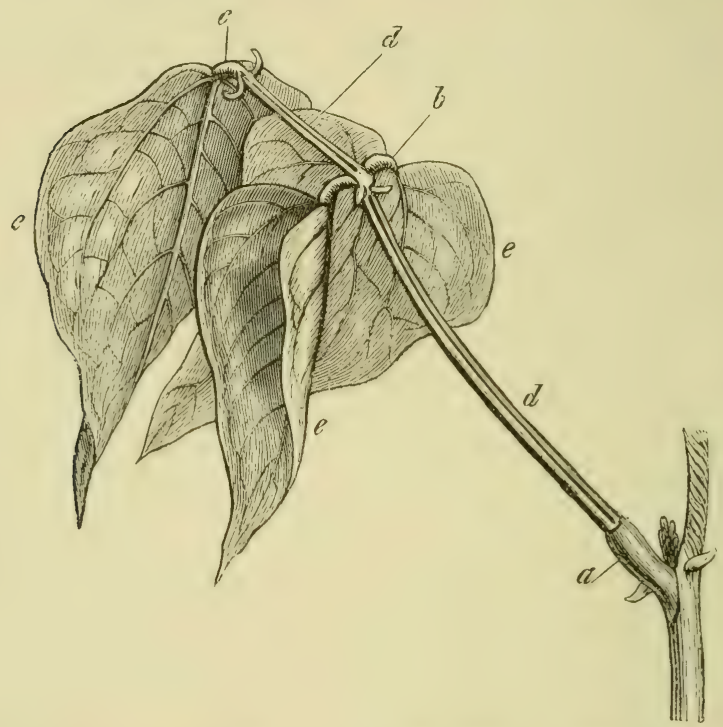

FIG. 29.-Pinnate Leaf of Scarlet Rumner in the position of "Sleep" [after Sachs]. $a$. The large motile organ at base of grooved leaf-stalk and its continuation $d, d ; b, c$. small motile organs of the leaflets, $e, e, e$. Stipules are seen at base of leaf-stalk, also an axillary bud; stipels at the origins of the leatlets.

within the hair is broken up into a network of strands by means of vacuoles. Currents taking various directions can be observed in the strands. It may be noted in passing that the stinging property is due to the presence of formic acid in the cell-sap. The tapering end of the hair readily perforates the skin, when it breaks off and the poison flows into the wound. Movements on a larger scale are also exhibited by leaves, of which the best known example is the sensitive plant. The leaves of wood. sorrel, scarlet runner, and many other plants perform what are krown as "sleep" movements, by which the leaflets sink down 
at night (fig. 29). Among insectivorous plants Venus' fly-trap is a good example of motility. If an insect alights on the upper side of the leaf and happens to touch one of the sensitive hairs on the lamina, the two halres move rapidly upwards, and by the interlocking of the marginal bristles a rery efficient trap is formed.

Leares show a high degree of irritability. They are transversely geotropic and heliotropic, that is to say, under the influence of gravity and light bifacial leares at any rate tend to place themselves horizontally. Sensitiveness to contact is shown by leaf-tendrils as well as stem-tendrils, and other more obrious cases are the sensitive plant and Venus' fly-trap. The tentacles of sundew when a fly alights upon one of them all bend towards the centre of the leaf and entangle it. All the insectivorous plants pour out their digestive excretions as the result of contact, and this often depends on the chemical nature of the touching substance, so that we have sensitiveness to chemical stimuli.

Spontaneity is shown in the protoplasmic morements in hairs, \&c., and on a larger scale in an Indian form, the telegraph plant (Desmortium gyjans:), which possesses ternate leares. The lateral leaflets of these are in a constant state of up and down morement, quite rapid enough to be visible with the unaided eye. 


\section{CHAPTER VII.}

\section{BRACTS AND FLORAL LEAVES. MORṔHOLOGX.}

WE now come to the consideration of the remaining two kinds of leaf, i.e., bracts and floral leaves. The latter make up the greater part of the flower, which may be defined as a shoot specially modified for carrying on the function of reproduction. Bracts are leaves, usually much reduced, which occur near the flower. It will be necessary, in order to understand the various parts which make up a flower, to carefully examine a simple example. It is usual to select a buttercup for this purpose. First, with a sharp penknife or scalpel divide the flower into halves, in which operation it is desirable to commence by splitting the flowerstalk or peduncle. The cut thus made is then continued. If this is done successfully, it will readily be seen (fig. 30) that the continuation of the peduncle within the flower forms a conical structure upon which are crowded numerous parts of different shapes and sizes. This conical body, the floral receptacle or torus, is in reality the stem part of the floral shoot, while the structures situated upon it are the leaf part of the same. The crowding is caused by non-development of internodes, a common occurrence, as we have already seen, in the ordinary vegetative shoot. Now, in another specimen, proceed to examine the various kinds of floral leaf, beginning at the outside. First comes a whorl of five small yellowish-green leaves, the sepals, collectively forming the calyx. Then follows another whorl of five much larger bright-yellow leaves, the petals, which make up the corolla and alternate with the sepals. Now pull off the calyx and corolla, and, before examining the more internal parts, carefully inspect the glossy inner side of a petal. Close to its attached end will found a minute scale covering a spot which excretes honey or nectar, and is known as a honey gland or nectary. Within the perianth (=calyx + corolla) are a very large number of yellow threads arranged spirally, though this is not easily made out. The threads are stamens, and their collective name is androcium. The thin stalk of a stamen is its filament, and the thickened end its anther, within which an immense number of minute pollen 
grainis are developed. These escape, when ripe, as a yellow dust. When the androcium is removed there still remain behind a lot of little spirally arranged green bodies, the carpels, called altogether the pistil or gynacium. Within each carpel is a cavity containing a minute oval body known as an ovule. In overblown specimens all the structures above described fall off except the carpels, which enlarge considerably, and form the buttercup firuit, while the orules become seeds. Sepals, petals, stamens, and carpels are alike floral leaves, though they depart more and more widely from the type presented by the foliage leaf. They will be dealt with in the above order, but it is first desirable to consider some points concerning the flower as a whole, and the receptacle.

The inflorescence or arrangement of flowers upon the plant varies considerably in different cases. Since flower-buds are just as much young shoots as leaf-buds, we may expect to find them developed in corresponding situations, and this is actually the

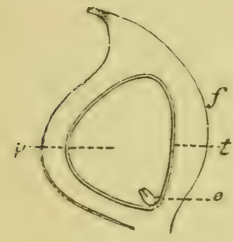

$\mathrm{E}$

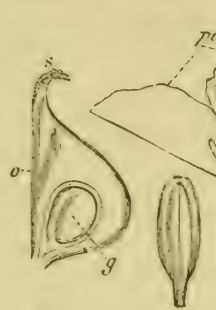

U

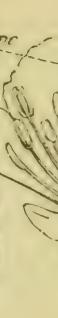

(

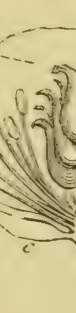

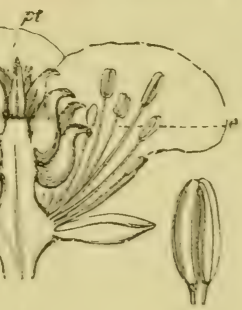

A

$\mathrm{B}$

FIG. 30.-Flower of Buttereup. A. a vertical section; $c$. sepals; pe. petals; $e$. stamens; pi. carpels. B. extrorse anther seen from outside, showing lobes. C. anther seen from inside. D. section of carpel; $o$. ovary ; $s$. stigma; $g$. inverted ovule. E. section of an achene; $f$. pericarp; $t$. seed-coat ; $p$. endosperm; $e$. minute embryo.

case. In very rare cases, e.g., tulip, there is a single flower on the end of the main stem. The plant is then uniaxial. The vast majority of flowers, however, belong to axes of higher order.

The different kinds of inflorescence are classified under two headings, racemose and cymose, corresponding exactly to the methods of monopodial branching described on p. 24. (I.) The rucemose or incletinite type possesses lateral flowers, which, in the simplest cases, e.\%., pansy, spring from the axils of ordinary leaves. The growth in length of a stem ceases when a flowerbud is dereloped at its end, and this type is called "indefinite" because the axis ends in an ordinary leaf-bud, and therefore continues to elongate. The simplest case of (2.) the cymose or d"finite type is seen in the tulip and some other cases, where, as mentioned above, the main axis derelops a flower-bud at its end and ceases to elongate. No other flower is developed. If 
a flower-stalk bearing one or a cluster of flowers grows right up from the ground, it is termed a scape, and may either belong to definite inflorescence, as in tulip, or indefinite, arising in the latter case from a leaf-axil belonging to an underground or abbreviated shoot, as in primrose and corrslip.

It is usual for flowers to occur grouped together into clusters. In other words, they are formed upon special branch-systems, to which the term ${ }^{1}$ inflorescences is usually given. The branches of such a cluster arise from the axils, not of ordinary leaves, but of bracts, which are mostly small, simple, and useless for the purposes of foliage. Many plants, as orchids, show a complete gradation between foliage leaves and bracts. On the other hand, the transition may be very abrupt. In some exceptional cases, e.g., shepherd's purse, the flower clusters possess no bracts, so that the flower-bearing branches are not axillary. The converse of this is not uncommon, i.e., the occurrence of bracts without branches in their axils. 'They then, owing to their small size, receive the name of bractlets or bracteoles, and are situated not far from a flower, as, for instance, in pansy and violet (fig. 5I). Bracts may become large or otherwise conspicuous for special purposes. When brightly coloured, as in hyacinth, they are termed petulvid, because tints other than green are most usually found in the petals. A large sheathlike bract, then known as a spathe, may surround an inflorescence. The large green structure enclosing the central column of arum is of this nature (fig. 33). Another case is seen in the onion. Smaller examples are found in the membranous structures ensheathing the scapes of narcissus, daffodil, and snowdrop. A spathe may be petaloid, as in the arum lily, where it is large and of a brilliant white colour, which makes it look something like a corolla.

When the flowers are in the axils of ordinary leaves, their stalks may be called peduncles, but in the case of a flower cluster they are pedicels, the word peduncle being reserved for the main axis. If the cluster branches more than once, the intermediate stem structures are called partial peduncles.

Ricemose inflorescences are either simple or compound, i.e., the lateral axes either terminate in flowers without branching, or else branch to a greater or less extent. Otherwise expressed, the lateral axes are pedicels in the former case, partial peduncles in the latter. Simple racemose inflorescences are again subdivided according to the state of the internodes in the main axis, which is long or short as these are well or ill developed.

Inflorescence, therefore, may mean :-(r.) Arrangement of flowers; (2.) a special flower-bearing branch system. 
(r.) When the main axis is long or fairly long, it may bear stalked flowers, and is then a raceme (fig. 3I). A good example is the hyacinth, and here, as in all indefinite flower clusters, the blossoms open in acropetal order, so that the lowest flowers have withered before the uppermost ones are even open. Further instances are found in foxglove, snapdragon, wallflower, barberry (fig. 31 ), and currant. The last two racemes are pendulous, owing to the weaknesss of the main axis, while bracts are absent in the wallflower. Where, as in hawthorn and edible cherry, the axis is comparatively short, and the pedicels farther from the apex are larger than those nearer it, so as to bring the flower to about the same level, we have a corymb. This is only a variety of raceme. The flowers here open centripetally, i.e., the outer ones

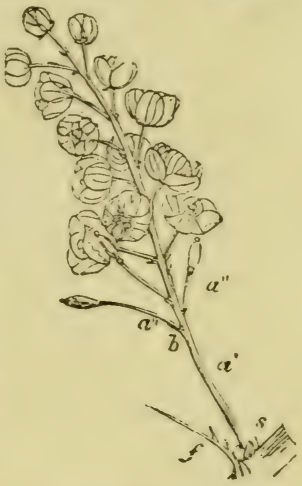

FIG. 3r. - Raceme of Baropen before the inner ones, since they are first dereloped. When

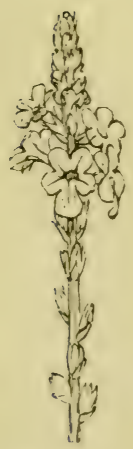

IFIG. 32. Spike of Verbena.

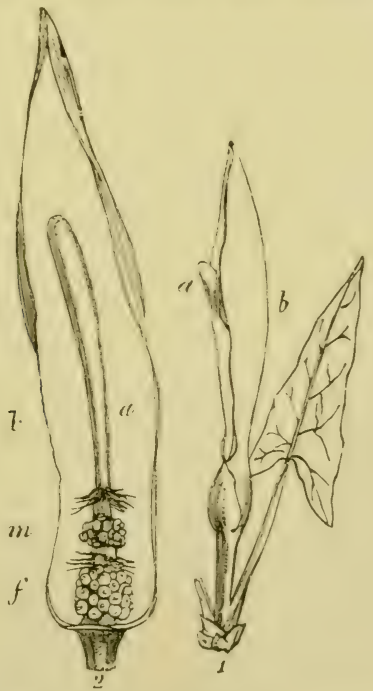

FIG. 33.-. Spadix of Arum. r. Closed; 2 . cut open. $a$. axis; $b$. spathe; $f$. female tlowers; m. male flowers; those above are aborted.

an elongated main axis hears sessile flowers, a spilie (fig. 32) is 
the result, common examples of which are wild plantain and wheat. Varieties of spike are the spadix (fig. 33), with fleshy axis (e.g., arum), and the amentum or cattin, with scaly bracts, as seen in willow and hazel.

(2.) We now come to cases of simple racemose inflorescences, where, by suppression of internodes, the main axis remains extremely short. Imagine a telescoped raceme. The pedicels would all start very close together from the abbreviated axis, looking, so to speak, like the ribs of an umbrella turned inside out. Such an inflorescence is an umbel, as seen in ivy. Its nature may be known by the centripetal way in which the flowers open. In a case like this, the bracts, from the axils of which the pedicels arise, if they do not disappear altogether, are crowded into an involucre or circlet. The capitulum or head is what we should get if a spike were telescoped, or if the flowers of an umbel became sessile or nearly so. The axis is here more or less dilated, and may be rounded, conical, or globular in shape. Common red and white clover are good examples, and the bracts are here readily seen. A further interesting point about clovers is the fact that among the numerous species we find all gradations, from short spikes (crimson clover, a cultivated form) down to well-marked heads. The stumpy axis is often called receptarle, but must not be confounded with the floral receptacle. The extremely large and important family of Composites, including daisy, dandelion, sunflower, thistle, \&c., \&c., is characterized by the possession of heads. Take, for instance, a daisy. A beginner would very likely mistake the white part for a corolla, and a lot

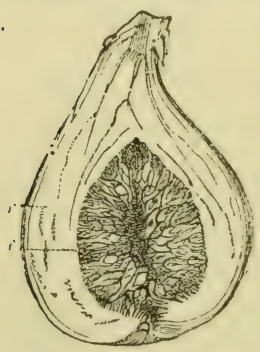

FIa. 34.- Section of Fig. $\because$ succulent common receptacle; $;$ : flowers lining the cavity. of little green leaves outside this for a calyx, but would then be puzzled by the yellow centre. We have, in fact, not a single flower, but a very large number, crowded into a head, and often termed, from their small size, florets. They can easily be picked off the receptacle, and it is not difficult to make out the nature of the central ones which compose the yellow "disk." The white "ray" is made up of somewhat modified florets. The apparent calyx is an involucre made up of the outer bracts. It can easily be seen that the florets open centripetally. In thistle, dandelion, and groundsel the florets are all alike. The fig is a modified head bearing florets on the inner side of a thickened hollow common receptacle (fig. 34). Compound racemose inflorescences have their branches, of secondary or higher order, constructed on one or more of the types 
above described. Thus there are compound racemes and cor? $/ m 7 s$, where the branches of highest order are themselves racemes and corymbs. If the branching is irregular, a panicle is the result. The large group of Umbelliferre is characterized by the occurrence of umbels, usually compouncl. Hence the name. Carrot, parsnip, hemlock, and the like are examples. Bracts may be absent or form a general involucre round the origins of the primary branches, and partial ones where the branch or partial umbels arise. Compound spikes occur in many grasses. It does not always happen that the branching is of the same kind throughout. Thus, in grasses, the spikelets (i.e., small spikes) are not always arranged in compound spikes, but may be in racemes or panicles.

Cymose or definite inflorescences branch in the way already described on p. 24. They are called "definite" because the main axis after producing a flower at its end ceases to elougate, and is overtopped by its branches, which grow in the same manner. Simple and compound cymes may be distinguished. Taking the former first, a subdivision may be made into forms where a psendaris or symportium is (I) absent, (2) present. The false dichotomy of mistletoe (p. 4 ) exemplifies the first kind, and so do the tichotomous or tur-rayed cymmes of campion and stitchrort (cf. fig. 35), where, however, the end of the main axis is of fair

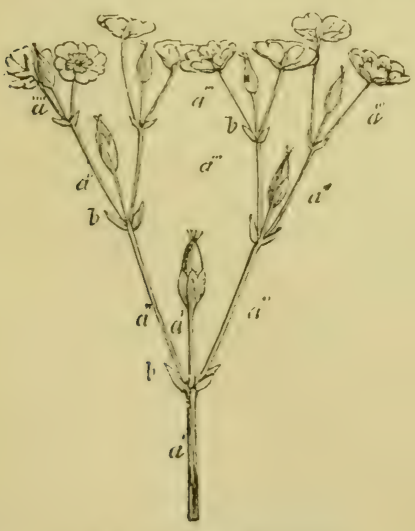

EIG. 35--Forked Cyme.

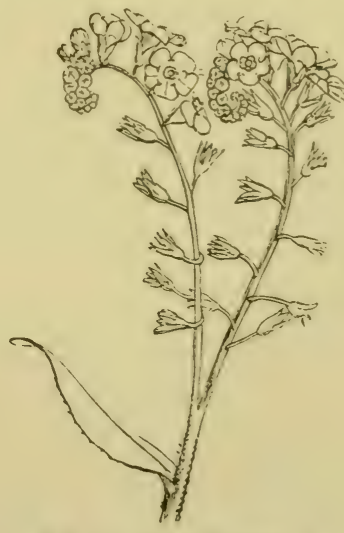

FIG. 36.-Helicoid Cyme of Forget-me-not.

length, and bears a flower, so that the forking is obriously due to lateral branches. The central flower opens first, then those terminating the first pair of branches, and so on. For this reason cymose inflorescences have been called centrifugal. A 
cyme may also be three-rayed, four-rayed, dc., when three, four, ic., lateral branches overtop the main axis. (2.) The nature of a pseudaxis or sympodium has already been fully explained (pp. 24, 48). The pseudaxis may either be formed by branches developed on either side alternately, when it is scorpioid, or by branches belonging to one side only, when it is helicoid. The vegetative shoots of elm, \&c., and flowering shoots of deadly nightshade are instances of the former, while forget-me-not illustrates the latter case, where the pseudaxis naturally curls round in a spiral way (fig. 36 ).

Compound cymes are distinguished by the fact that branches of secondary or higher order themselves bear cymes instead of terminating in flowers. Elder is a common example. A compact cyme is termed a fascicle, and if so condensed as to look like a capitulum, it is a glomerulus.

Mixed inflorescences, which combine more or less the racemose and cymose types, are not uncommon. As might be expected, flower clusters of this nature are usually compound. Comparatively few special names have been given to these cases, since it is easier to describe the general and partial ways of branching separately. The heads of Composites, for example, are often arranged in a cymose manner. Panicles are frequently mixed, and the general name thyirsus has been given to elongated compact forms in which the primary branching is racemose and the secondary cymose, as in the flowering shoots of lilac and horsechestnut. The verticillaster is a variety of thyrsus found in some plants, such as dead nettles, where the leaves are opposite and decussate. At first sight there appears to be a circlet of flowers at each node, the uppermost circles being youngest, so that the general arrangement is racemose or indefinite. Careful examination shows, however, that each apparent circlet is in reality composed of two very short cymose flower clusters in the axils of the opposite leaves.

'The flower, as a whole, generally displays a certain symmetry, as seen on ground-plan. It is usually either radially symmetrical or bilaterally symmetrical (cf. p. $5^{2}$ ). ${ }^{1}$ In the latter case the median or antero-posterior plane is in most cases the one which divides it into similar halves.

Lastly, a flower may be asymmetrical, when it is not divisible by any plane into similar halves. Flowers coming under the second and third cases may conveniently be called irregular. Tn determining the irregularity or otherwise of a flower, calyx and

1 Radially symmetrical flowers are also termed regular, polysymmetrical, or actinomorphic, and bilaterally symmetrical ones zygomorphic or monosymmetrical. 
corolla only are as a rule considered, e.f., the andrœcium and grnœcium of a radially symmetrical flower may or may not agree with the general symmetry.

The floral receptacle, like the receptacle of a shortened flower cluster, may exhibit considerable diversity of form (fig. 37). If it is elongated, conical, or flattened, the flower is said to be hypogynous, i.e., the andrœcium, corolla, and calyx evidently grow from a region below the gynœcium, or at any rate do not start from a higher level (fig. $37, \mathrm{~A}$ ). But the receptacle may cease growing at the centre but not at the edges, when it forms a cuplike structure, on the rim of which andrœcium, corolla, and calyx are situated. Two conditions are here distinguishable. Either the gynœcium remains free, and can readily be dissected away from the receptacle, or else it becomes inseparably fused with this. In the former case (fig. $37, B)$ the flower is termed perigynous, because the floral leaves external to the gynœ-
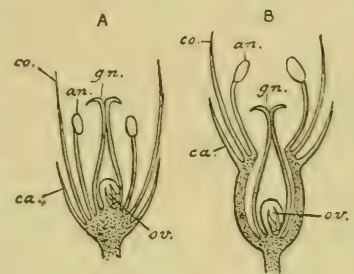

E

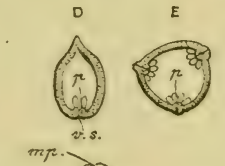

F
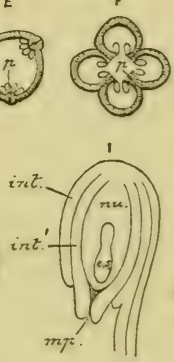

$f$

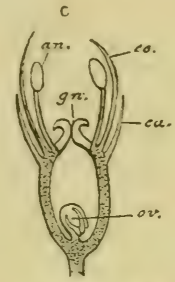

G
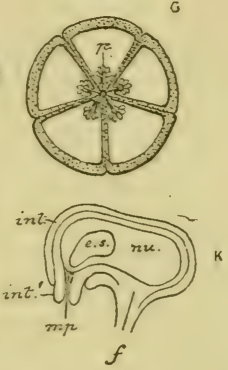

FIG. 37.-Relation of Parts of Flower [after Prantl]. A, $\mathrm{B}$, C. diagrams of longitudinal sections of hypogynous, perigynous, and epigynous flowers. Floral receptacle dotted in $\mathrm{A}$ and $\mathrm{B}$; in $\mathrm{C}$ the inner half of dotted part is wall of ovary, the outer half is receptacle; $c$. calyx; co. corolla ; an. stamens; gn. pistil; 02 . inverted ovule.

cium grow on a ridge round about it; in the latter (fig. $37, \mathrm{C}$ ), epigynous, since they appear to grow upon it. Buttercup, rose, and fuchsia are good examples of hypogynous, perigynous, and epigynous respectively.

In the buttercup, as we have seen, the perianth leaves are arranged in whorts, and the stamens and carpels in a spiral. Such a flower is called hemicyclic, because a part only of its leaves are arranged in whorls (cycles). Departure from this type may take place in two directions. On the one hand, an acyctic flower, like the white waterlily, has all its parts in a spiral; on the other hand, a cyclic flower has all its parts arranged in whorls, as may be seen in stonecrop and white lily (fig. 38 ). 
The relation of parts in a flower to one another and, in a lateral flower, to the main axis is conveniently represented by a floral diagram which may be regarded as a generalized groundplan (fig. 38 ). The position of the axis is shown by a dot; the sepals, petals, and stamens are represented by conventional marks; and the carpels by a rough drawing of their appearance

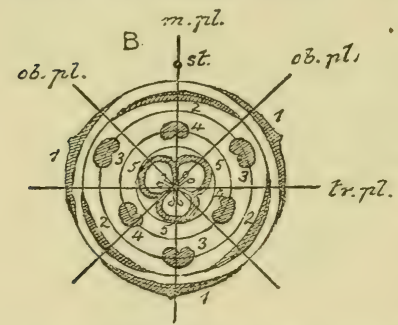

FIG. 38.-Floral Diagram of White Lily. st. stem on posterior side of flower ; 2i. $p l$. mediam plane; $t r \cdot p l$. lateral plane; ol. .1 . olili(que planes; I, I, 1. sepals; 2, 2, 2. petals; $3,3,3$. onter stamens: $4,4,4$. imier stamens : $5,5,5$. carpels : all in alternating whorls. in the diagram. It may seem unnecessary to distinguish so many in cross-section. A line drawn - through the axis dot and the centre of the diagram serves to represent the median or antero-posterior plane, which divides the flower into right and left halves. A line running through the centre of the diagram perpendicalar to the first line therefore represents the lateral plane, a vertical plane at right angles to the median plane, which divides the flower into a posterior half next the axis and an anterior half turned away from it. 'Two oblique vertical planes intersecting the preceding at 45 degrees may also be represented imaginary planes, but it is rery convenient in practice to designate particular parts of the flower as anterior, posterior, or oblique. In the Pea-flower family, for example, there are five sepals, of which one is always anterior. This is, therefore, one of the distinctive features of the family.

A study of the innumerable sorts of flower actually existing shows that for cyclic forms the most typical condition consists in the possession of six whorls, all the whorls having the same number of parts, and the parts of successive whorls alternating, just as in decussate foliage leaves. Such a flower, say, with five members per whorl, can be represented either by a floral diagram, or as follows, the dashes representing the floral leaves, which are supposed to be picked off and laid in straight lines :-

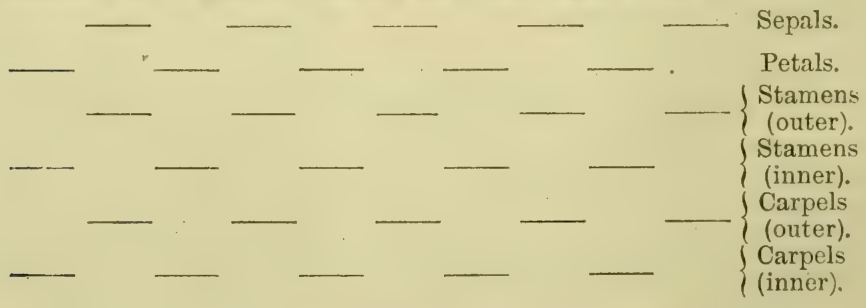


Thus the members of contiguous whorls (e.g., sepals and petals) alternate with one another, while the members of alternate whorls are superposed, i.e., are in the same rank or orthostichy. There are ten ranks in the example supposed. Comparatively few flowers are constructed so regularly as this, but a great many can be explained by supposing alterations to have taken place either in the number of whorls or the number of parts in certain whorls. Very commonly both kinds of change appear to have happened. Abundant examples will be found in the sequel.

We have now to consider in detail calyx, corolla, andrœcium, and gynœcium. Five headings may be conveniently taken in each case, viz., Number and Arrangement, Cohesion (union of like parts), Adhesion (union of unlike parts), External Characters, and Structure.

The CALYX, or outer whorl of the perianth, departs less from the foliage leaves in nature than any other part of the flower, and a gradation may sometimes be traced between sepals and such leaves. In the dog-rose, for example, there are five sepals arranged in a very short spiral. The two or three lowest bear. small leaflets in a pinnate manner, thus resembling the pinnate foliage leaves of the same plant.

Number and Arrangement. - In acyclic flowers, such as those of Cacti, the spirally arranged sepals may be indefinite in number, and pass, on the one hand, into bractlets, on the other, into petals. The cyclic and hemicyclic flowers of dicotyledons are generally characterized by the numbers five and four (or multiples: of the same). The former number very frequently indeed goes with a phyllotaxis of two-fifths. Examine once more the wild rose. The foliage leaves are here arranged with the above divergence ( $f f$. p. 50), which means that each cycle includes five leaves and turns twice round the stem. The fire-leared calyx is here just such a cycle telescoped, but the spiral arrangement can still be made out. A lictle further change would altogether obliterate the spiral, and give us a $x \cdot h o r$ of five members, as in buttercup. The number four is found in wallflower, stock, shepherd's purse, and many other plants. An examination of the calyx in a wallflower will show that the sepals are in two alternating whorls, each containing two sepals. This may perhaps correspond to the opposite decussate arrangement found in foliage leaves (p. 49). In wallflower, however, the foliage leaves are not arranged in this manner, which fact tells against the explanation. Three (or a multiple of it) is by far the commonest number among monocotyledons (fig. 37). The three large white sepals of snowdrop furnish a striking example. This number is associated, as might be expected, with a phyllotaxis of one-third. 
Two sepals are occasionally found, as in the poppy, and this may be here explained as a reduction from a higher number, probably once possessed. In a good many flower's the perianth consists of one whorl only, which is then considered to be, in most cases, a calyx. In cases of doubt it is best simply to use the general word perianth. Here again we see reduction. It is also to be noted that in many small epigynous flowers (composites, umbellifers, \&c.) occurring in dense clusters, the calyx is very much reduced in size, or even absent. Reduction may, lastly, be carried to such an extent that both corolla and calyx are absent, as in certain small inconspicuous flowers, like those of willow. In the great majority of gymnosperms (fir, yew, juniper, \&c.) no perianth is present, but this does not appear to be a case of reduction from a former condition.

Mention has still to be made of arrangement in the bud, which, in the case of flowers, is called cestivation or profforction, ${ }^{1}$ and corresponds to the præfoliation of foliage leaves (p. 49).

Cohesion.-The sepals are often quite free from one another, as in rose, buttercup, and wallflower, when the calyx is polysepalous or aposepalous. This is strikingly seen in poppies, where the sepals are caducous, i.e., fall off very early. In many flowers, on the contrary, the sepals are more or less united into a tube. A gamosepalous or synsepalous calyx of this kind occurs, for instance, in the bean, primrose, and Canterbury bell. We are here reminded of the cup-like or tubular structures formed by connate leaves and sheathing stipules.

Adhesion.-According to the most modern views, the members of other floral whorls adhere but seldom to the calyx. It may not be amiss, however, to explain here some older ideas which caused the invention of certain terms that are still current in many books. The perigynous and epigynous conditions of the flower have been explained ( $p . \delta_{1}$ ) as the result of the growth of the floral receptacle into a cup-like structure, upon the rim of which sepals, petals, and stamens are inserted (fig. 37). This cup was formerly held to be part of a gamosepalous calyx, and was therefore termed the calyx tube, the real sepals being looked

1 The ways in which individual leaves are arranged have been defined in the footnote to p. 49. Sepals and petals (as also foliage leaves) are disposed in the bud with reference to one another as follows:- I. open, the parts separated; II. closed, the parts approximated: (I) valvate, touching at the margins; (2) overlapping at the margin; ( 1 ) imbricate, both margins of one or more leaves covered; $(b)$ obvolute, every leaf with one covered and one uncovered margin.

These points may be determined by cutting through the bud transversely 
upon simply as the free lobes of the calyx. In a perigynous flower, therefore, the petals and stamens were regarded as adherent to the calyx. The union between the hollow receptacle and the gynœcium (p. 8I) in an epigynous flower was similarly taken to be an adhesion between "calyx tube" and gynœcium. In this case the calyx was termed "superior," because its "lobes" had a position obviously above the adhering part of the gynœcium. In other cases it ras called "inferior."

External Characters. - The calyx may be radially or bilaterally. symmetrical. When polysepalous, the individual sepals can be described in the terms used for foliage leaves. They are never stalked, but may possess stipules at their points of attachment These, if large, look like an outer whorl of sepals, which receive: the name epicalyx, as in strawberry and marsh-mallow. An epicalyx may also be formed by bracteoles. The sepals are sometimes diveigent or spreading, as in the tallest form of buttercup' (Ranunculus acris), or again they may be reftered, i.e., bent back, of which another common kind of buttercup (Rannentus bulbusus) is an example. Sepals are frequently more or less swollen or saccate at their base. This is the case with the two lateral sepals of wallflower and shepherd's purse. Such a swelling may be exaggerated into a tubular structure termed a spur, which is then usually a nectary, secreting honey on its inner surface. In the buttercup, as we have seen (p. 74), the nectaries form part of the petal, and indeed these organs vary very much in position according to the kind of plant examined. In some cases they are found away from the flower altogether. Examine the bilaterally symmetrical calyx of a pelargonium, first remoring the petals. Fire sepals will be seen, a large pair on the anterior side, then a smaller pair, and lastly, a much larger unpaired posterior one. By looking down upon the calyx a small hole will be seen between the odd sepal and the pink structures in the centre of the flower. A needle pushed into this will enter a short tube which can be seen as a ridge on the outside of the flower-stalk: A transverse section at this point will show both tube and stalk. We have here a spur, belonging to the posterior sepal, and firmly adherent to the flower-stalk. A spur, however, is not always a nectary. In the larkspur there are five large blue sepals, the posterior one of which is produced into a large spur. This simply serves as a cover to two small spurred petals, parts of which, together with two small unspurred petals, are seen in the centre of the flower. Monkshood is somewhat similar. The "hood" formed by the posterior sepal encloses two small petals (here the only ones), which are entirely changed into nectaries.

When the calyx is gumospalons the united part forms a tube 
of varying extent, and the free parts of the sepals, collectively forming the limb, usually appear in the margin of this as small pointed teeth or larger lobes. The general shape, when radially symmetrical, may be tubular, funnel-shaped, bell-shaped, inflated, sc. (cf. p. 89). The most common form of bilaterally symmetrical calyx is the labiate or lipped, where the free anterior and posterior portions form projecting lips. Dead nettle, sage, and gorse furnish examples. In all three cases there are five sepals, and in the first two the odd sepal is posterior, so that the upper or posterior lip is composed of three sepals, and the lower or anterior of two. Exactly the reverse is true of gorse. The outside of the gamosepalous calyx is often strongly ribbed, the ridges corresponding to the midribs of the united sepals. The gamosepalous calyx of Indian cress (garden nasturtium) possesses a large posterior spur.

The surface of the calyx is very frequently provided with hair structures, especially on the outsile, where prickles may also occur. More will be said about this in the sequel.

Sepals are typically green in colour, but the brightly tinted or petaloid condition is very common, especially among monocotyledons, as snowdrop, tulip, lily, hyacinth, orchis, dre. Many dicotyledons also present examples of the same thing, e.g., many buttercups, larkspur, gorse, barberry.

The texture of sepals varies considerably. They may be delicate, firm, membranous, or scaly. This has an influence on their duration, whether caducous (shed when the flower opens), afecidurims (falling off when the seeds begin to ripen), or persistent (remaining during the ripening of the seeds). The last condition is especially characteristic of gamosepalous examples.

Structure.-It need only be stated under this head that an ordinary green sepal resembles a foliage leaf, while a petaloid one is more or less like a petal.

The Corolla, in most dicotyledons at any rate, is the most brightly coloured part of the flower, and diveiges more from the type of the foliage leaf than the calyx.

Number and Arrangement.-The petals of an acyclic flower are generally indefinite in number, and not sharply marked off in character from the other floral leaves. Thus, in white waterlily, there is a gradual transition from sepals to petals, and from these again to stamens (fig. 39). Hemicyclic and cyclic flowers in dicotyledons generally possess five or four petals, while three is the usual number among monocotyledons. The same reasons may be given for this as in the case of the calyx $\left(p . s_{3}\right)$. Two petals sometimes occur (enchanter's nightshade), and more rarely one. Many flowers possess no corolla at all, and in this case 
there may be a petaloid calyx, as in anemone and marsh-marigold, or no perianth at all, e.g., willow.

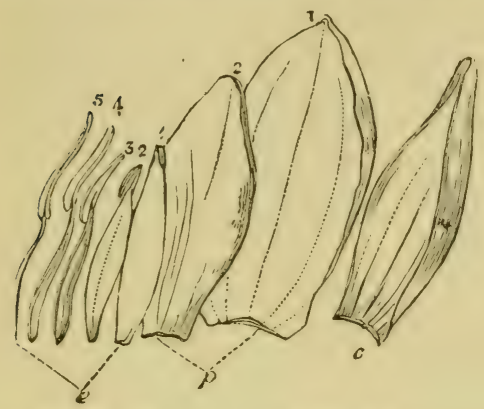

FIG. 39. -Floral Leaves of White Waterlily. $c$. sepal; $p$. petals; $c$. stamens.

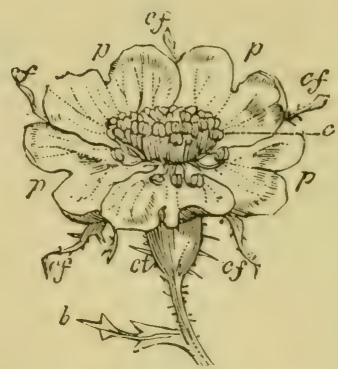

FIG. 40.-llower of Rose. $b$. bract ; ct. cup-like receptacle; $c f$. sepals; $p$. petals ; $\epsilon$. stamens.

The corolla and calyx, when arranged in whorls, are usually isomerous, i.e., they contain an equal number of members, which, in this case, regularly alternate with one another. When petals and sepals are unequal in number, the former are sometimes more numerous (e.g., poppy, petals four, sepals two), sometimes less so (e.g., monkshood, petals two, sepals five).

The terms hypogynous, perigynous, and epigynous ( $\left.f \cdot \mathrm{p} . \mathrm{SI}_{\mathrm{I}}\right)$ are applied to the corolla specially, as well as to the flower as a whole.

Prafloration or arrangement of leaves in the flower-bud equally concerns both divisions of the perianth.

Cohesion. - When the petals are firee and distinct, as in rose, buttercup, and wallflower, the corolla is polypetalous or apopetalous (fig. 40). Frequently, however, there is more or less union, with formation of a tube, cup, or the like, as in the gamopetalous or synpetalous corollas of primrose, Canterbury bell, snapdragon, and convolvulus.

Adhesion.--The commonest union is one between corolla and stamens, which will be mentioned later (p. 95). Compare also p. 84 .

External Characters.-The very greatest variety is developed in the corolla, which, as a whole, may be radially symmetrical, bilaterally symmetrical, or asymmetrical. The individual petals, when free, can, like sepals, be described in the same terms as foliage leaves. They are usually narrowed at their attached end, and, not infrequently, as in the pink (fig. $4 \mathrm{r})$, there is a distinction between stalk and blade, termed in this case clau and limb. There may be, e.g., in ragged-robin and red campion, a small out- 
growth at the junction of the two, which is termed a ligule from its resemblance as regards position to the structure of that name in grasses. The ligules are collectively called the corona. One or more petals of the polypetalous corolla may be saccate or spurred. In the pansy and violet the lower petal is produced

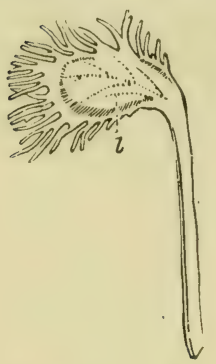

F'IG. 4r. - Petal of Pink. l. limb; 0. claw.

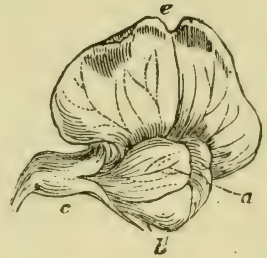

FIG. 42.-Sweet Pea. $c$. calyx; e. standard; $a$. wings; $b$. keel. into a large spur (fig. 5 I). Larkspur and monkshood (p. 85) have two spurred petals, while all five petals have conspicuous spurs in the closely allied columbine, where the corolla is regular. A very common and striking form of irregutar corolla with free petals is seen in gorse, pea, bean, wistaria, clover, \&c. shaped (fig. 42). It has been termed papilionaceous or butterflyrest, a (Ge (vexillum). In front of this come a fairly large pair of petals, the wings $(a l c)$, which orerlap a third smaller pair that are united into a boat-shaped structure, the keel (carina), enclosing the stamens and pistil. The union of the last two petals is not complete, for they have separate stalks, nor is it very close, as they can readily be separated. Petals, like sepals, may lie sprearting or reflexel, and when they are clawed the limb may be bent sharply on the claw. Thus, in the wallflower there are four equal petals, diagonal in position, and with long claws. The limbs spread abruptly ont transversely to the claws, and the corolla is strikingly cross-shapert in consequence, for which reason it is termed cruciferous.

Some of the most remarkable forms of irregular corolla are found in orchids, especially tropical ones. Perhaps the commonest British species is the early purple orchis (Orchis mascula), which flowers from April to June. There are here three petaloid sepals, an upper one, arching over the central structures, and two spreading or reflexerl lateral ones. Alternating with these are three other purple flower leaves, two smaller upper petals, arching like the upper sepal, and a much larger three-lobed one, the luliellum. The central lobe of this last is regarded as the lover petal, and the two side lobes as petaloid stamens fused with it. These conclusions are based upon comparison with allied but less modified plants and the structure of the parts. Details would 
be out of place in an elementary book like this. Two further points may be noted about the purple orchis. The labellum possesses a large spur, and the flower is so twisted round that upper parts are really lower, and vice versî (fig. 52).

The gamopetalous corolla usually presents certain well-marked regions. The united part is termed the tube, while the more or less distinct teeth or lubes which represent the free ends of the petals form the limb. The commencement of the tube is the throat. Sometimes the limb is alsent, and the number of petals is then found by counting the most prominent veins (i.e., midribs of the petals), or is inferred by comparison with the calyx and also with the corollas of closely related plants. The principal shapes found among regular forms are the following, in which the tube becomes of greater relative importance as we proceed in the series. In potato and forget-me-not the tube is extremely short, and the limb flat and spreading, giving a certain resemblance to a wheel, whence the term rotate or uh-el-shapert. A corolla of this kind may be slightly irregular, as in speedwell. The word stellate is applied to cases where the tube is very short and the spreading lobes very pointed, as in clearer, while a sausershaped corolla differs from a rotate ore in being concare instead of flat. If in a wheel-shaped or saucer-shaped corolla the tube were considerably elongated, we should get a salcer-shaper? (hylpwcrateriform) example, is in primrose and plumbago. A lellshaped or camprumulate corolla, like that of harebell, Canterbury bell, \&c., gradually enlirges almost from its heginning, the limi, being small. An irregular example of the same is foxglore. A lell-shaped corolla by contracting at its mouth would become inflated or urn-shaped (ureeolate). The different kinds of heath (but not heather) are good instances. Tulmilar and jumnel-shapel corollas are respectively cylindrical and conical, the limb being very small or absent. Thistle-florets and convolvulus are examples.

The irregular gamopetalous corolla may be slightly or markedly so. The speedwell, mentioned above, is an example of the former condition, while in the latter case a labiate or lipped form is the commonest. The white (or red) dead nettle is a typical illustration ( $c f$. fig. 43 ). Since in this plant (and allied forms) there are five sepals, the odd one posterior, it is

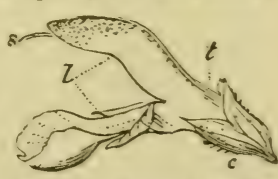

FIG. 43.--Laliate Curvilia of Sage. evident that of the five alternating petals the odd one must be anterior, so that the lower lip consists of three petals, and the upper lip of two. In this particular example the two petals forming the upper lip are so closely united that its double nature cannot easily be recognized, but the union is not 
so close in ground-ivy and some other related forms. The triple nature of the lower lip is more readily seen. It is chiefly made up of a large central lobe, corresponding to the free part of the anterior petal, while a small pointed tooth on either side of this indicates the existence of another petal. In ground-ivy the lower lip is three-lobed, and though the middle one is largest, yet there is not the same disproportion as in the other case. A labiate corolla is said to be helmet-shaped (galeate) when the upper lip forms a curved hood covering the stamens, \&c., as in the white dead nettle, and it is termed gaping (ringent) when, as in the same instance, the throat is freely open. The upper lip may be very much reduced in size, as in blue lobelia, bugle, and wood-sage. Examination of the irregularly bell-shaped corolla of foxglove will show that here too is an instance of the lipped condition. The upper lip is broad, and its double nature is indicated by a slight notch. The lower lip is composed of three lobes well marked off from one another. Two of these are lateral, while the third and largest one projects somewhat, is spotted, and covered inside with soft, rather long hairs. A remarkable modification of the labiate corolla is found in snapdragon. The larger upper lip is deeply cleft, and obviously

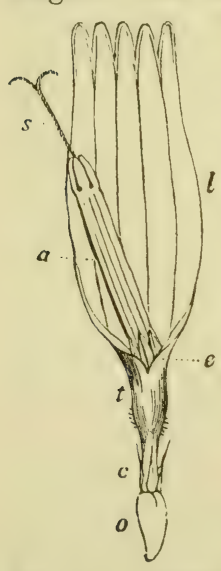

FIG. 44. - Ligulate Floret. $o$. inferior ovary; c. rudimen. tary calyx; $?$. corolla; a. minited anthers; s. style with forked stigma. represents two petals, while the lower lip possesses three lobes, of which the middle one is smallest, just the opposite to the preceding cases. But this is not all. Projecting from the upper side of the lower lip is a large, differently coloured outgrowth, the palate, which blocks up the throat. Such a corolla is masked (per'sonate). It may be noted in addition that the tube is saccate near its attachment, at a part which belongs to the posterior petal. The wild yellow toad-flax agrees generally with the above description, but the posterior petal, instead of being saccate, is produced into a long pointed spur. In all the preceding cases one lip has been composed of three, the other of two lobes. Other groupings are known of the same number of petals. Thus, in honeysuckle there is a narrow tube, a large four-lobed upper lip and a narrow one-lobed lower lip. All the lobes are reflexed.

The strap-shaped (ligulate) corolla is not very removed from the labiate one, e.g., wood-sage, with a reduced upper lip. Take, for example, the cultivated scarlet lobelia. The narrow tube here terminates in a deeply five-lobed limb. The corolla, in fact, looks as if 
it had been partly split open and spread out. The same peculiarity is carried to a greater extent in the florets of dandelion and the ray florets of daisy. The strap-shaped limb in the former case has five teeth at its termination, the latter only three ( $f$. fig. 44). The surface of the corolla may be glabrous or present hair structures or hair-like outgrowths. Its texture is usually delicate, corresponding with its deciduous nature. The colour may be simple, or streakings and mottlings may occur; bright tints are the rule.

Structure.-Petals (and petaloid sepals) are covered on either side by a delicate epidermis. Internally they are made up of one or more layers of spongy parenchyma ( $f f . p .65$ ), traversed by delicate vascular bundles, which, as in the foliage leaf, give a veined appearance. The colours of flowers are due to pigments contained in the epidermal cells. Blue and red are dissolved in the cell-sap, as in larkspur and rose. Yellow and orange are usually contained in variously shaped colour bodies, e.g., in Indiancress (garden nasturtium), where a large number are found in each cell. 


\section{CHAPTER VIII.}

\section{ESSENTIAL FLORAL LEAVES.}

\section{MORPHOLOGY.}

THE androcium and gynœcium may collectively be called the essential organs, since they have to do with the formation of seed.

It is a familiar fact that, at certain times of the year, liown patches appear on the backs of fern leaves. These are made up of minute cases filled with excessively small brown grains. The cases are termed sporangia, and the contained grains spores. Club-mosses, common in mountainous districts, also produce spores, and the yellow powder sold by chemists under the name of lycopodium consists entirely of these. The bodies in question can give rise to new plants under favourable conditions.

Flowering plants also produce spores. Pollen is made up of innumerable small grains which are of this nature, and every ovule, as we shall see further on, contains a cell, the embryo sac, which is also a spore. Since stamens and carpels produce these bodies, they may be termed spore-leaves or sporophylls, and from this point of view the flower may be defined as "a shoot modified for spore-bearing."

The stamens are termed male spore-leaves and the carpels female spore-leaves.

The Sthuevs, as we have seen in the buttercup, differ very much from the typical leaf form. In the white waterlily, however, there are all possible stages between them and petals (fig. 39). On the other hand, no links connecting stamens and carpels are found in normal flowers.

Number and Arrangement.-In acyclic and hemicyclic flowers a large number of spirally arranged stamens are found. An instructive example of the former kind is seen in the Scotch fir. The flowers of this plant (fig. 45) possess no perianth, and are of two kinds-male, with stamens only, and female, with carpels only. The ordinary "cones" are the latter, while the former are much smaller, and crowded together into clusters. They are best examined in June, when the pollen is ripe. Each one consists of 
an axis upon which numerous stamens are crowded in a spiral manner. They are here more flattened and leaf-like than, for example, in the buttercup, which is a good example of the hemicyclic condition. The most typical cyclic flowers possess tuo whorls of stamens (fig. $3 \delta$ ) -an outer, alternating with the petals (and superposed to the sepals), and an inner, alternating with the sepals (and superposed to the petals). As in the case of the perianth, five and four are the typical numbers in a whorl for dicotyledons, and three for monocotyledons. Ten stamens occur in papilionaceous flowers, but the two five-membered whorls are here indistinguishably united together. Fuchsia, willow-herh,

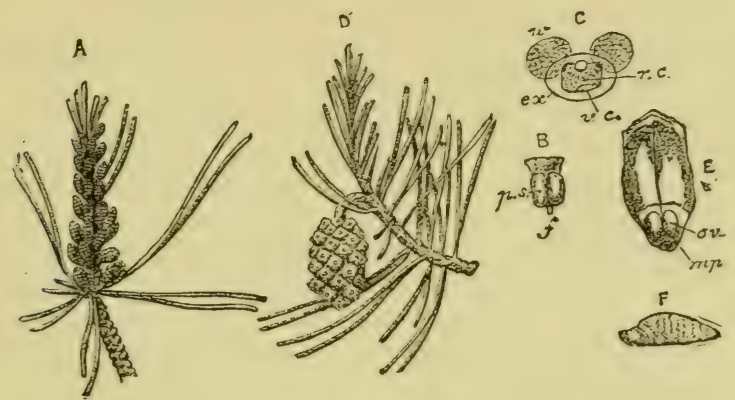

FIG. 45.-Flowers of Scotch Fir [original]. Various scales. A. Group of male cones. B. A stamen; ps. pollen sac; $f$. filament. C. Pollen grain ; $e x$. extine; $w$. wing; r.c., v.c. cells. D. A female cone. E. An ovulebearing scale; ov. ovule; $m p$. micropyle. F. A seed.

and evening primrose possess two whorls of four each, while snowdrops, lilies, and rushes have six stamens in two whorls. Very frequently one whorl is suppressed, usually the inner one. Thus a very large number of dicotyledons are provided with five stamens alternating with the petals, as, for example, in parsnip, disk florets of daisy, potato, violet, convolvulus, and forget-menot. Others have four similarly placed stamens, as in plantain and rerbena. Again, in monocotyledons the outer whorl only may be present, as in iris, where there are three stamens. Far more rarely the outer whorl is suppressed. This is seen in primrose and its allies, which possess five stamens superposed to the lobes of the gamopetalous corolla. That a whorl has been here suppressed is proved by the fact that in brookweed or water-pimpernel, a closely allied plant, rudiments of the outer whorl are actually present. But reduction may go still farther, and leave only part of a whorl. White dead nettle is a case in point. Here there are five sepals and five petals, but only four stamens, two 
long and two short (didynamous). It will be remembered that in this flower the odd petal is anterior, and there should, therefore, be an odd posterior stamen, since the outer whorl of stamens, which alternate with the petals, is retained. This, however, is almost always absent. Very rarely, however, a minute stamen is found in this position. Snapdragon is a similar case. Take one of its flowers, and carefully split open the gamopetalous corolla along one side. Upon spreading it out, you will find in its posterior side (i.e., next the stem and opposite the rounded swelling at the base of the corolla tube), near its attachment to the receptacle, a minute white projection. This is the remains of the lost fifth stamen. The foxglove, a near ally, possesses four stamens and no rudiment, while pentastemon, a common garden flower related to this, possesses a very large fifth stamen, devoid, however, of an anther, which curves down to the lower side of the flower. Finally, mullein, also a relative, has five perfect stamens. The speedwell, which belongs to the same group of flowers, presents still further reduction. The sepals and petals are four, but the stamens only two. In most orchids there is only one perfect stamen, the anterior one of the outer whorl. One orchis, however, ladies'-slipper (Cyprippertium), has two stamens, belonging in this case to the inner whorl. These facts, and the presence of more or less complete rudiments of other stamens ( $f$. p. 88), lead to the conclusion that the onestamened orchis is descended from forms which possessed six perfect stamens, arranged in two alternating three-membered whorls, as, for example, in snowdrop and lily (fig. 38 ). Stamens are absent altogether in female or pistillate flowers, and this often appears to be the result of reduction. Some of the flowers on certain plants are neuter, i.e., deroid altogether of sporophylls, and reduction has undoubtedly taken place in such cases.

Stamens are sometimes increased in number in cyclic flowers, instead of being reduced. In the wallflower, for instance, there are four sepals and four petals, but six stamens-four long and two short (tetradynamous). The petals are diagonally placed, while the short stamens are lateral in position, and the long ones are grouped in two pairs, one anterior and the other posterior. Each pair appears to have arisen by the splitting of a single stamen. This is supported by the fact that in some tetradynamous flowers a partly-split stamen is occasionally found instead of a pair. Branching may also occur. In St. John's wort there are three or five groups of stamens, each group of which has been formed by the branching of a single stamen at an early stage of development. Mallows and hollyhocks, again, possess numerous stamens formed by the branching of five original ones. The terms 
hypogynous, perigynous, and epigynous are applied to stamens (cf. p. 8I).

Cohesion.-Stamens may either be united together by their stalks (filaments) or by their thickened heads (anthers). In the former case they are termed mon-, di-, tri-, or polyaclelphous, forming respectirely one, two, three, or more than three groups. Monadelphous stamens are found in some papilionaceous flowers, as gorse and broom. The lower parts of the ten filaments are here united into a tube which surrounds the gynœcium. A somewhat similar state of things exists in mallow and hollyhock. Many papilionaceous flowers exemplify the diadelphous condition. Examination, for example, of clorer, bird's-foot trefoil, pea, or bean will show that the staminal tube is formed by the bases of nine filaments only, while the remaining upper or posterior stamen is free. The only British examples of more numerous groups of stamens are the St. John's worts. The andrœcium is here commonly said to be triadelphous or polyadelphous, although, as stated above, it is really an example of branching.

The stamens are synantherous or syngenesious when their anthers cohere together into a cylinder. This is the case in the large group of Composites, of which dandelion, daisy, thistle, sunflorrer, dahlia, and groundsel are common examples. Pull off, for instance, one of the disk florets from a single dahlia (double or quilled ones have become abnormal by cultivation), and hold it up to the light. Projecting from the mouth of the five-toothed tubular corolla is a thickened fork. This is the upper part of the grmœcium. Within the upper part of the translucent corolla is a dirk rodlike body, the united anthers, surrounding the middle of the gynœeium, and below this are some wary threads, the filaments (cf. p. 126). By tearing open the corolla with needles these points can be made out more clearly. The same thing can he seen with greater difficulty in the much smaller florets of dandelion, \&c. (fig. 44). In lobelia the stamens are both synantherous and monarlelphous. Something similar takes place in the male flowers of cucumber and vegetable marrow.

Adhesion.-Stamens are sometimes united to the petals of a polypetalous corolla, as is the case with the inner five stamens of bladder-campion, and very frequently to the tube of a gamopetalous corolla, as in foxglove, dead nettle, primrose, speedwell, and snapdragon. In either case they are termed epipetalous. Split open a foxglove bell, and you will find the filaments of the four stamens partly free and partly represented by prominent ridges running down to the attachment of the corolla.

Far more rarely there is adhesion between stamens and carpels. The commonest examples of this are orchids, where the single 
gynandious stamen is fused with the gynocium, upon the top of which it is perched.

External Characters.-Examine carefully a buttercup stamen (fig. 30). It presents two regions, a stalk or filament, and a thickened head or anther. The latter possesses a grooved anther lobe on either side, the two being separated by a continuation of the filament, called the connective. Within the anther lobes a yellow dust is formed, the pollen, which escapes by a longitudinal slit formed on either side in the ripe anther. All the parts described present different forms according to the plant examined.

The filament may be very short or absent, when the anther is sessile, as in the epipetalous stamens of primrose. If they are long, the stamens may be exserted, i.e., project from the corolla. Filarnents are generally more or less slender, but they may be flattened, as in some of the stamens of white waterlily. Appendages or outgrowths are sometimes present. In the violet and pansy; for example, there are five stamens, the anthers of which appear at first sight to be united, though in reality only closely approximated. Carefully slit open the spur of the lower petal, when two little white rods will be seen projecting into it. These, when traced, prove to be outgrowths from the filaments of the two lower stamens, close to their junction with the anthers.

If the connective is a direct prolongation of the filament, the anther is basifixed, and in that case its lobes are either lateral, internal, or external; and the descriptive terms innate, introrse, and extrorse are used. The last two are included in the wider meaning word adnate. It frequently happens that the filament is attached to the back of the anther, which is then basifixed, and if in this case the attachment is very loose, the anther can swing freely about or is versatile, as in grasses (fig. 50) and white lily. When the connective is narrow the anther lobes are parallel, as in buttercup, but it may be broadened so as to make the lobes divergent, e.g., in marjoram, dead nettle, and foxglove. The connective may even form a sort of cross-bar, hinged upon the filament. This state of things is seen in the meadow and garden sages and an ornamental crimson form belonging to the same genus (fig. 46). The andrœcium here consists of four stamens, two of which are aborted or reduced to minute rudiments, like the odd stamen of snapdragon. The connectives of the other two are elongated, and bear a perfect anther lobe at one end and an aborted one at the other. The connective does not usually extend beyond the anther lobes, except in some few cases, as in violet and pansy (fig. 5I), where it forms an orangecoloured triangular expansion in this position. 
The anther lobes present various shapes, linear, oval, kidneyshaped, \&c., and they may possess tail-like appendages, as in heath. One lobe may be aborted, as in sage (fig. 46), while in mallow the anthers produced by branching have also but one lobe, and are, so to speak, half-anthers. 'The surface of the anther may be more or less hairy, as in dead nettle. When the pollen is ripe, the anthers open or dehisce to liberate it. Most commonly each lobe splits longitudinally, and the slit faces to the side, interior, or exterior, according as the anther is innate, introrse, or extrorse. In other cases, as potato and heath, a pore or minute fissure is formed at the tip of each lobe: In barberry the dehiscence is valvular, i.e., part of the wall in each lobe becomes detached and turns up as a kind of flap, which remains united to the tip of the anther.

Pollen is usually in the form of a fine sticky or dry powder, composed of an immense number of minute pollen grains. In heath and rho-

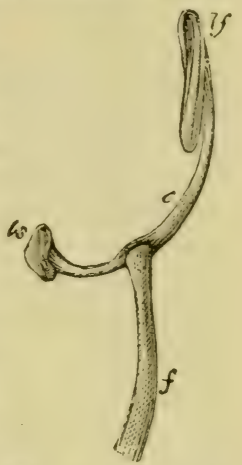

FIG. 46. - Stamen of Sage. $f$. filament; c. connective ; $l f$. fertile anther lobe; ls. aborted anther lobe. dodendron several grains are united together, and in orchids the whole of the pollen in each lobe of the solitary anther is agglutinated into a club-shaped mass termed a pollinium (fig. 47).

Stamens sometimes occur in which the anthers are absent. They are then termed staminorles, and are often leaf-like. Compare the allied forms, mullein, pentastemon, snapdragon, and foxglove ( $c f$. p. 94). These possess, respectively, five stamens, four stamens and a large staminode, four perfect and one aborted stamens, and four stamens. We are justified, therefore, in concluding that an odd fifth stamen has been suppressed or absolutely done away with in foxglove, especially as, so to speak, there is a "vacant chair" left by it. Similarly (cf. p. 93), if we take the closely related water-pimpernel and primrose, we shall find

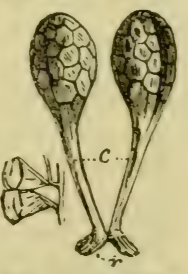

FIG. 47.-Pollinia of Urchid. that one has five perfect stamens superposed to the petals and five staminodes alternating with them, the other five stamens superpose to the petals. Hence the conclusion is reached that a whorl of stamens has been suppressed in primrose. Observations like these, extencled over a large number of cases, have led to the conclusion that tro whorls are typical for the andrœcium.

Fellow is the most common colour for stamens, especially the anthers, but this is by no means an invariable rule.

Structure.-The three systems of tissue can be recognized in 
stamens. Their exterior is corered with epidermis, which frequently produces hairs, and may possess stomata. The filament and connective are traversed by a central vascular bundle, and the ground-tissue is made up of parenchyma. A cross-section of a young buttercup bud will give numerous thin slices of anthers. In these it will be seen that each lobe contains two compartments filled with pollen grains, and hence called pollen sacs (cf. fig. $5 \mathrm{I}$ ). The pollen grains have been formerl by active division of parenchymatous cells belonging to the ground-tissue. Later on the party-wall between the two sacs in each lobe breaks down, and their contents escape to the exterior by formation of a slit.

Pollen grains are mostly spherical. They are invested by two membranes, a firm outer one, the extine, often produced into spines, knobs, or ridges, and in the fir into a pair of little air bladders (fig. $45, \mathrm{C}$ ); and a delicate inner one, the intine. Within the coatings are two or a few small cells in gymnosperms and protoplasm with two nuclei in angiosperms.

The CARPELS depart even more widely from the ordinary leaftype than the stamens. They collectively form the pistil or g!mocium, which occupies the centre of the flower.

Number and Arrangement.-In acyclic and hemicyclic flowers an indefinite number of carpels are frequently present. The ordinary cones of the Scotch fir consist of a large number of spirally arranged woody scales (fig. 45). These are carpels, or, at any rate, outgrowths from them. We have previously seen (p. 75) that a large number of carpels are present in the hemicyclic flowers of the buttercup. It is probable that two alternating whorls of carpels are typical for the cyclic flower. One entire whorl, however, is generally suppressed, and the remaining one is very frequently reduced. Dicotyledons often possess five or four carpels, as in geranium and holly respectively, but a smaller number is extremely common. Thus, pansy (fig. 5I) has three, wallflower, dead nettle and foxglove two, and papilionaccous flowers only one. A few British monocotyledons, as flowering rush and frogbit, retain six carpels in alternating whorls of three each. Far more commonly the inner whorl is suppressed, so that three carpels only are present, as in lily (fig. 38 ), tulip, snowdrop, and orchis. Still further reduction takes place in most grasses, which have only two carpels, while duckweed, wild arum, and maize retain but one. In male flowers carpels are, of course, absent, and in this case they may have been suppresserl or else never have existed. As mentioned previously, neuter flowers contain no essential organs.

Most flowers are bisexucul, i.e., possess both stamens and carpels, some are unisexual; and are then male, with stamens only, 
and female, with carpels only. Sereral terms used in this connection, are given in the following table :--

Plants possessing $\left\{\begin{array}{c}\text { unisexual flowers are }\left\{\begin{array}{c}\text { monøecious, with both kinds } \\ \text { on same plant, e.g., fir, } \\ \text { hazel, arum ; diocious, } \\ \text { with the two kinds on } \\ \text { different plants, e.g., wil- } \\ \text { low, nettle, hop. }\end{array}\right. \\ \text { unisexual flowers + bi- } \begin{array}{l}\text { sexual flowers are } \\ \text { polygamous, e.g., ash. }\end{array}\end{array}\right.$

The instances mentioned may now be briefly described.

Fir (fig. 45).-Male cones small, crowded into a cluster on the sides of a shoot which produces leaves beyond it. Dusty when ripe from yellow pollen. Female cones occur singly for the most part. They take two years to mature their seeds, and in early summer cones in three stages may be found on the same plant. (r.) Small green cones with pink-tipped scales, occurring close to the ends of the youngest shoots, and belonging therefore to the current year. (2.) Larger green cones, belonging to the previous year, and situated on older shoots. (3.) Brown woody cones with ripe seeds, placed on still older parts of the stem, and two years old.

Hazel.-The pendent catkins seen in March are male inflorescences, and consist of a large number of scaly bracts. Each of these bears four stamens on its under side, but, as each of these is forked, there appear to be eight. Their true nature is shown by the fact that they bear but one anther lobe. The female catkins are very small, and being closely surrounded by bracts, look like buds. Each of them consists of five or six flowers, the only parts of which are visible externally resemble a number of smail threads, bright pink in colour.

Arum (fig. 33).-The upper part of the spadix is club-shaped and brightly coloured. Lower down comes a circlet of aborted male flowers, a little distance beneath which is a lot of small male flowers, each of which consists of one stamen. These are crowded into a ring round the stem. A ring of female flowers forms the base of the inflorescence. It is separated by an interspace from the preceding. Each female flower has a single carpel, but, like the male flowers, is devoid of perianth. Those at the upper part of the ring are aborted.

Willox.-Both male and female catkins are here short and upright. The former are readily distinguished by their bright yellow colour, and consist of a large number of male flowers without perianth. Each consists of two long stamens placed in the axil of an oval bract provided with long hairs. At the base of 
the filaments is a glandular projection or nectary. The female catkins are green, and a female flower corresponds to the above description, except that, instead of two stamens, there is a pistil formed by two cohering carpels.

Nettle.-There are two common British forms, the small and the large, which are monœcious and diœcious respectively. The latter kind is easily recognized by its greater size and by its elongated paniculate inflorescences. The small male flowers have a four-lobed calyx, superposed to which is a whorl of four stamens. A minute knob, representing an aborted pistil, is seen in the centre. The female flowers possess a pistil, composed of a single carpel, but no traces of stamens.

Hop.-The minute male flowers are arranged in cymes. Wach consists of a whorl of five sepals, with five superposed stamens. The female inflorescences are short broad catkins, the large overlapping bracts of which give a cone-like appearance. They form the "hops" of commerce. A pair of female flowers are situated in the axil of each bract. Their perianth is rudimentary, and encloses a pistil formed of two united carpels.

Ash. - The small flowers are borne in short racemes, and are without perianth. The bisexual ones are provided with two purplish-black stamens and a pistil of two united carpels. The male and female flowers are similar; but in one case stamens, in the other carpels, only are present. This is a very interesting case of reduction, for in the flowering ash, a South European species, all the flowers are bisexual, and possess four sepals and four petals, as well as stamens and carpels. This is also the case in the flowers of privet and lilac, both allied forms.

Cohesion.-The pistil is siid to be apucaipous when its constituent carpels are free. In buttercup, for example, the small green bodies in the centre of the flower are separate carpels (fig. $30)$; here they are very numerous. Instances of smaller numbers are found in columbine (five), larkspur (generally three), and gorse or pea (one). Much more frequently the pistil is syncarpous, its carpels being united, as already alluded to in willow, ash, and hop. The union may be more or less complete. Examine the flower of a saxifrage, such as London pride. A deeply bilobed pistil will be found, evidently consisting of two carpels. In pink or carnation the seed-containing part (orary) is undivided, but projecting from the top of this are two curved threads (styles), which point to the presence of a pair of carpels. The same thing is indicated by the forked end of the style in dead nettle, sage, and most grasses (fig. 50). In the white lily the existence of three carpels can be recognized by the trilobed stigma, and the three compartinents seen in a cross-section of ovary (fig. 38 ). 
The pistil of primrose, consisting of five united carpels, presents a case of very close union, where the true state of things can only be inferred from analogy.

Adhesion.-Mention has already been made of gynandrous stamens (p. 95). The most important example of union between pistil and other structures is presented by the epigynons flower (p. 8I). Take, for example, a snowdrop, female flower of regetable marrow, or bloom of fuchsia. Immediately beneath the calyx a green swelling will be found, which careful examination shows to be the ovary, containing seed rudiments or ovules. By examining flowers of different ages, it will be seen to become the fruit. The most reasonable explanation supposes an inferinr ovary like this to be formed by an intimate union between it and a cup-shaped floral receptacle (c $\%$. fig. 37). If a Californian poppy (Eschscholtzia), which is an orange-coloured flower commonly cultivated, is cut accurately in half, its ovary will be seen partly embedded in a shallow cup formed by the receptacle. It is, so to speak, becoming inferior.

Where, as in hypogynous and perigynous flowers, the ovary is free, i.e., attached to, but not fused with, the receptacle, it is said to be superior.

External Characters.-The simplest kind of pistil is found in gymnosperms. Examine one of the large green cones found upon the Scotch fir in early summer. With some difficulty the scales crowded upon it can be detached. Look at the upper surface of one of them, and observe, close to the end that was attached, a pair of small oval whitish elevations (tig. 45, E). These are seed rudiments or ovules. That part of a carpel to which orules are attached is termed a placenta, and this rery frequently forms a more or less considerable outgrowth. In this particular case the carpels proper are extremely small, and the scales making up the cone are extremely large placentas. Note that but for the overlapping of adjoining scales the ovules would be quite unprotected. This condition is characteristic of gymnosperms, which owe their name to it.

The ovules of angiosperms (fig. 48), on the contrary, are situated in a closed chamber, the orary. It will be the simplest plan first to consider apocarpous pistils, and afterwards syncarpous ones, which are more complex. An apocarpous pistil is either monocarpellary or polycarpellary, i.e., made up respectively of one and more than one carpel. Papilionaceous flowers are examples of the former class. Take, for example, a pea flower, and strip off the corolla and diadelphous stamens, leaving the pistil behind. It consists of a laterally flattened ovary, from which a curved rod projects. This is the style, and at its tip there is a small sticky 
area, the stigma, to which pollen may often be found adhering. By splitting open the ovary, several little green ovules may be found attached along its upper margin. Now examine a young pea-pod, which is a further developed pistil. At one end the stalk and calyx will be seen, at the other the remains of the style, while the pod is the developed ovary. By holding it up to the light, a row of matured ovules, i.e., seeds, will be observed rumning along one side. Split open the pod on that side and spread it out. It will then look like an ordinary leaf, with wellmarked midrib and thickened edges bearing ovules. Every carpel of an apocarpous pistil is, in fact, regarded as a folded leaf, the thickened edges of which bear ovules, and are united together in a seam or suture, called the ventral suture. The other edge of the carpel may be called the dorsal margin, which corresponds to the midrib. The thickened edges here form the placenta, and the arrangement or placentation of the ovules is here said to be murinal (fig. $48 \mathrm{D}$ ). In order to grasp the idea that a pistil like that of the pea corresponds to a folded leaf, take some simple leaf that tapers gradually to a point, e.g., one from a fuchsia, and fold it upon the midrib; you will then see that the broader part answers to the ovary, and the narrower part to the style. It sometimes happens in abnormal flowers that carpels remain partly or entirely open, thus showing their true nature, and the syncarpous pistil of mignonette never completely closes at the top ( $c f$. also p. I07). In gymnosperms folding has not taken place at all. We may consider that the pea has descended from ancestors somewhat resembling the gymnosperms of the present day, and that the formation of a closed ovary has taken place gradually in the course of innumerable generations. The next question is, "Which surface of the folded leaf is inside, upper or lower?" This query cannot easily be answered by reference to the pea alone, but examination of apocarpous pistils with more than one carpel will readily give a solution. Examine, for instance, a head of ripe fruit in larkspur, columbine, or marsh-marigold, where three, five, and several carpels are respectively present. It will be seen that the ventral sutures face invards, for in the fruit they will have split open, allowing the seeds to be seen attached to their edges. But facing inwards means facing the shortened axis or receptacle, and since folding has taken place in this direction, the upper surface of the leaf must bound the internal cavity. Take a piece of stem with a foliage leaf attached, and fold this up so that the approximated edges face the stem, and the nature of the above process will be seen. In the single carpel of pea the ventral suture fuces upwards, and since there are five sepals, 
five petals, and ten stamens, we may consiler this ould carpel as the remains of an outer whorl of five $(c \% . \mathrm{p} .82)$. The four suppressed member's of this whorl must all have been on the upper side of the one still remaining, for we see from the columbine that the ventral sutures of a whorl are all turned towara's one another. Hence the odd carpel of peir is the surviving lower or anterior member of a whorl of five. We can show in another way that the supposed whorl uould have had its odd member placed anteriorly. The parts of the flower in the pea are placed in fives. It can easily be seen that sepals and petals alternate, and the same is true of the two whorls of stamens, though this is difficult to make out in the mature flower, owing to their diadelphous state. We can observe easily at starting that the odd sepal is anterior. Therefore-

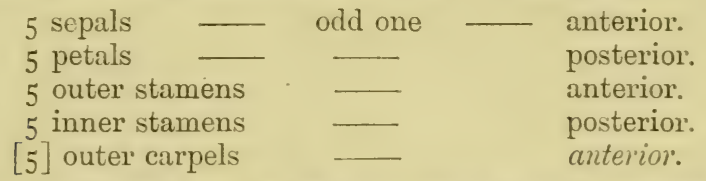

Where, as in larkspur, dr., an apocarpous pistil possesses more than one carpel, each has its orn ovary, style, and stigma. Examine once more the buttercup, and note that the style is a short "beak," upon which the stigma exists as a rough sticky line. The ovary contains but one ovule (fig. 30, D).

Rose, blackberry, raspberry, and strawberry are further examples of apocarpous pistils composed of several or many carpels. Each carpel contains a single orule. The flower of rose (fig. 40) is perigynous, and the carpels are attached to the inner side of the fleshy cup-like receptacle. In strawberry the style is not at the end of the carpel, but attached to the rentral margin of the ovary. It is, therefore, termed ventral. This can readily be seen in any one of the brown "seeds" (really fruits) scattered over a ripe strawberry.

The syncapous pistil ( $c f . p$. Ioo) consists of a complete or reduced whorl of carpels more or less completely united into one. The least constant part of such a pistil is the style. When it is absent, the stigma is scrsite on the ovary. This is the case, for instance, in poppy, where the stigma is represented by a number of roughened lines radiating from the centre. When more than one style is present, each has its orm stigma (fig. 50). Styles generally grow from the apex of the ovary, but they may be lateral or basal, i.e., arising respectively from the side or base of the ovary. Their length varies considerably in different forms. In shape the style is typically cylindrical. It is frequently bent 
or curved, and in many cases its exterior is provided with hairs. The stigma is a roughened and viscid region of the pistil. It may be a mere spot or streak, but often forms a distinct projection. The general shape of the ovary may be described by such terms as globular, ovoid, elongated, flattened, \&c. It often presents a particular number of sides and angles, corresponding to the number of uniterl carpels. The ovaries of tulip and lily, for instance, are three-sided. Prominent ribs or conspicuous veins may correspond to the midribs of the united carpels. The surface of the ovary is often more or less beset with hairs. One or more ovule-containing compartments (loculi) may be found within the ovary, and we will now try to ascertain what this has to do with the folding of the carpels. Imagine the five separate carpels of a columbine to fuse together. An ovary possessing five compartments or loculi would be formed, each of which would have an outer wall formed by the dorsal side of a carpel, and two side-
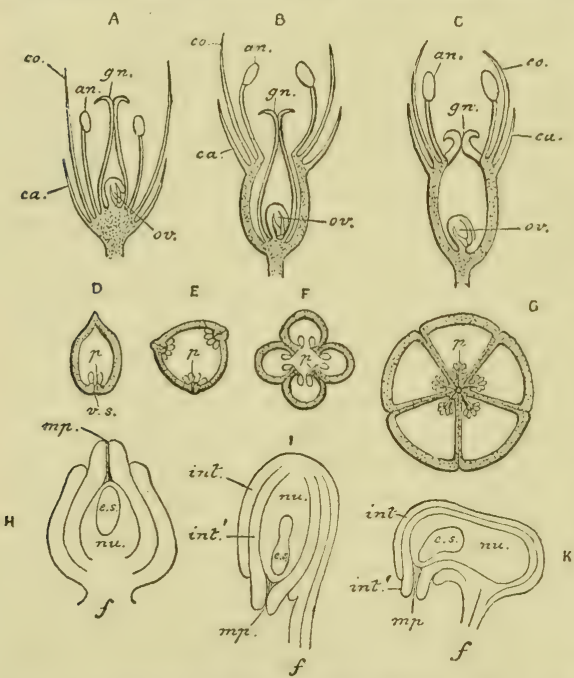

G

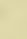

walls or dissepiments separating it from adjacent compartments (fig. 48, G). The sidewalls would evidently be double in nature. Finally, the ventral sutures would become internal, and the ovules would spring from the inner angle of the loculus. This kind of placentation is termed axile. Good examples are found in orange (several carpels), dittany (five), snowberry (four), lily (three), and foxglove (two). It is evident that if two or more carpels become united by their edges without any folding, they would form an unilocular ovary, i.e., an ovary with one compartment. This condition is well exemplified in the three-sided ovary of violet or pansy (fig. 5I). A cross-section shows that the angles corre- 
spond to the united edges, for at each of them is a ridge-like placenta bearing ovules. This kind of placentation is parietal (fig. 48, E). The same term is applied where the united carpels are partly folded, so that the single loculus is divided into chambers at its margin. Thus in poppy there are a great many chambers, and the parietal placentas, which bear an immense number of minute ovules, project into the ovary. This can easily be verified in the dried poppy-heads sold by druggists ( $c f$. fig. $48, \mathrm{~F}$ ).

Some ovaries are divided up by false or spurious dissepiments, so called because they are not partitions formed by union of adjacent carpels, but outgrouths from the wall of the ovary. In yellow corydal and Dielytra, both common garden plants, the syncarpous pistil is formed by the union of two lateral carpels. The ovary is unilocular, and the ovules are borne on two parietal placentas, one anterior, the other posterior. Wallflower, stock, and shepherd's purse, which are not very distantly related, present precisely the same arrangement, with this exception-the ovary is divided by a partition into right and left halves. This evidently does not correspond to the infolded edges of carpels, or the placentation would be axile. It is, however, parietul, and this fact, supported by comparison with the allied dielytra, \&c., prove the partition to be an ingrowth. A study of the development confirms this view. Again, in dead nettle and sage the end of the style forks into anterior and posterior branches, which leads one to suspect the existence of two carpels, one anterior, the other posterior. The ovary, however, is four-lobed, and contains four loculi. This points to four carpels. The evidence given by the style is here really correct. Development show. that two is the actual number, but an ingrowth occurs from the dorsal margin of each carpel, dividing its cavity into two. Borage, forget-me-not, and their allies present the same feature, but are even more misleading, since in them the style is undivided, or at most slightly notched.

The inferior syncarpous orary (fig. 48, C), though its outer wall is partly formed by the cup-like receptacle, corresponds very closely in form and placentation with the superior syncarpous one. Snowdrop and orchis will here serve, respectively, as examples of axile and parietal placentation.

There are still other ways in which ovules may be arranged. Each one of the ten carpels of the flowering rush contains a large number of ovules which are scattered over the walls of the loculus, and not limited to the united margins. This is superficial placentation. It is a rare form, but also occurs in the syncarpous pistils of white and yellow waterlilies.

Transverse and longitudinal sections of the ovary of a pink or 
primrose will show that there is a single cavity into which a knob-like placenta projects, upon which numerous ovules are situated. This kind of placentation is free central. The presence of two styles points to two carpels, but in primrose the pistil is from the first absolutely devoid of branching or lobation. Is it then a single carpel? If so, it would naturally have a ventral suture, and be bilaterally symmetrical, as is the case in the pea. But the pistil of primrose is absolutely terminal and radially symmetrical; and in thrift, a plant belonging to a closely related family, the flowers agree very nearly with those of primrose, excepting only that five styles are present. A great deal of discussion has arisen as to the nature of the knob-like placenta in the primrose and other forms. Some regard it as the dilated end of the axis. If so, the placentation is arial, i.e., the ovules are borne by the axis, and not by the carpels. (N.B.-Do not confound this term with arile.) But the knob may very possibly be more or less formed from the carpels. It is best, for the present, to keep the word free-central, as that simply refers to the way of arrangement. There are other cases in which the ovules are, or appear to be, developed on the axis. In docks, for instance, a single ovule grows straight up from the bottom of the unilocular ovary, apparently forming the end of the axis. The Horets of daisy, dandelion, sunflower, \&c., present a seed-like structure beneath the coloured corolla. 'This is the inferior ovary. Although there are two cohering carpels, as shown (fig. 44) by the forked style (c $f$. p. Ioo), the ovary contains but one cavity, from the base of which a single ovule rises. Just by the side of it is a minute knob. This represents the end of the axis, upon the side of which the ovule appears to be borne.

An ovule may take various directions. When growing up from the bottom of a loculus, it is erect, as in dock. An ovule developed on the side of a loculus is very frequently horizontal, as in lily. Advantage is taken of this fact in procuring longitudinal sections of the ovules, i.e., transverse sections of the ovary are made. Or such an ovule may be directed upwards, ascenting, e.g., buttercup, or hanging downwards, penclutous, as in rose. If it hangs down from the top of the loculus, it is suspended. Anemone is an instance. When one or a few ovules only are present, more attention is paid to their direction than when a large number exist.

Nectaries may be situated on the pistil. The best example of this is found in inferior ovaries, upon the top of which a fleshy honey-secreting cushion, commonly called the disc, is often present. Parsnip, hemilock, and daisy are good examples. The nectary of dead nettle is a fleshy outgrowth from the front of the ovary. 
Structure.-The pistil is made up of the usual three systems of tissue, but only a few of the more important details can be given here. Cross-sections through one of the ovaries of larkspur or columbine will show a well-marked notch on the ventral side, corresponding to the ventral suture. A layer of epidermis is present on the outside, which can be traced right through the wall where the notch occurs, after which it becomes continuous with a layer of epidermis lining the loculus. The carpel being a folded leaf, we might have expected this. The outer and inner epidermis correspond, in fact, to the lower and upper layers of epidermis in a foliage leaf (cf. p. 64), and in a very young ovary of larkspur the margins of the carpel will be found in contact, but not united. It is also interesting to note that the inner epirlermis possesses stomata as well as the outer, though they appear to be useless in such a position. Between the epidermic layers comes the parenchymatous ground-tissue traversed by numerous vascular bundles. Each margin of the carpel is swollen slightly at the ventral structure, so as to form a placenta, upon which a row of ovules is borne, as can be seen in a longitudinal section.

Cross-sections through a syncarpous ovary, such as that of lily, hyacinth, or violet, do not show sharp boundaries between the constituent carpels ( $c f$. tig. 5I). The outside is covered by a continuous layer of epidermis, which does not dip inwards where the carpels unite. Each loculus is lined by its own separate layer of epidermis.

The style is sometimes traversed by a pollen cancl, as in lily and hyacinth. This canal may open to the exterior in the centre of the stigma, as in pansy (fig. $5 \mathrm{I}$ ). More frequently the centre of the style is occupied by a very delicate, loose, conducting tissue, as, e.g., in fuchsia and evening primrose.

The stigma is frequently provicled with delicate hairs, and its cells generally form minute projections or papillæ at the surface. They also secrete a sticky fluid when the stigma is mature.

An Orcle (figs. 48 and 49) is a minute oroid body, in which there is an attached hase or chalum and a free apex. The base is in most cases fixed to the placenta by a slender stalk, the finnicle, which is traversed by a vascular bundle. The ovule is corered by either one or two skins or integuments, within which is a central mass of cells, the nucellus. The integuments do not cover the extreme apex of the ovule, where a short canal, the micropyle, is left, which leads down to the nucellus. One integument only is present in gymmosperms and most gamopetalous dicotyledons, while there are two in nearly all monocotyledons and many dicotyledons. In the latter case the inner coat, being 
first developed, is termed the primine, the other being the secundine. ${ }^{1}$

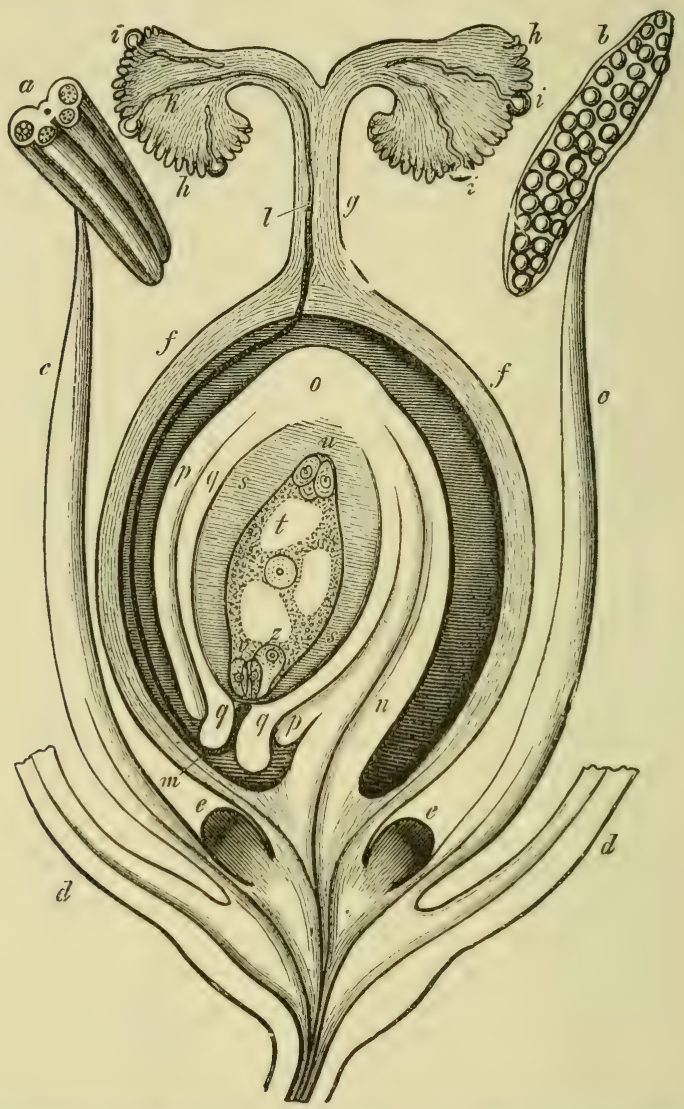

HIG. 49.-Diagram of a very simple flower in longitulinal section [from Sachs]. $d$, $d$. leaves of perianth cut off short; $a$. anther before dehiscence, cut across to show four pollen sacs ; $b$. anther dehiscing longitudinally; $h, h$. lobed stigmas upon which are pollen grains, $i, i, i$, developing pollen tubes; $g$. style traversed by a pollen tube, $l ; f, f$. ovary containing a single inverted ovule; $n$. funicle; $p, p$. outer integument; $q, q$. inner integument; 0 . base of ovule; $s, s$. nucellus containing embryo sac, full of protoplasm with vacuoles, $t$, central nucleus, co-operating cells, $v$, egg-cell, $z$, and antipodal cells, $u$; a pollen tube is seen entering the micropyle at $m ; e, e$. nectaries projecting from the receptacle. Vascular bundles indicated by dark lines.

The ovule is termed (fig. 48) straight or orthotropous when nucellus and funicle (short in this case) are in the same straight

1 These two terms are often employed in exactly the reverse way. 
line. This condition is common among gymnosperms. A female flower of yew, for instance, consists of a single straight ovule terminating a short axis crowded with scale leaves. It is much rarer among angiosperms. The solitary ovules of docks and nettles are examples. Sometimes the nucellus, with its corering, is bent or campylotropous, as in campion and shepherd's purse. The commonest condition, however, is the inverted or anatropous. one. Here the ovule turns sharply down on its stalk, part of which unites with the integuments, and forms a ridge or raphe. Cross-section of larkspur, lily, or hyacinth ovaries will show this well. The ovules of pinus, though without stalks, must be consiclered anatropous, since their micropyles are downwardly directed.

It will be remembered that the flower was defined (p. 92) as a spore-producing organ, and we have seen that a pollen sac is a spore case or sporangium, producing numerous pollen grains or spores. An ovule is another kind of sporangium, which produces only one spore, called in this case an embiyo sac, for reasons that will presently appear. One of the cells of the nucellus in a young ovule very early becomes larger than its neighbours. This is the embryo sac. It does not, like a pollen grain, become free, but is destined, if the conditions are favourable, to originate a rudimentary plant or embryo within it, which, surrounded by other structures developed from the ovule, will ultimately constitute the ripe seed. The embryo sac in the mature ovule of the angiosperm $^{1}$ (fig. 49) is no longer a simple cell; it occupies a considerable part of the nucellus, and its apex directly adjoins the micropyle. In its interior is an abundance of protoplasm, with large vacuoles, and a central nucleus, the embryo sac muclens. Six small cells are also contained within the embryo sac, three at its apex and three at its base. The former are known as the eg! apparatus, the latter (being exactly opposite) as the antipodal cells. Two of the cells composing the egg apparatus are smaller than the third, and situated rather nearer the micropyle. They are known as co-operating cells. The third and larger cell, the ovum or egg-cell, is of greatest importance, since it gives rise to the embryo.

Proofs that the Flower is a Shoot.-I. The floral receptacle is a stem because it bears lateral members, differing from it in shape, and developed acropetally, just as in an ordinary shoot. The internodes are usually suppressed, but this is a common occurrence in ordinary shoots. Sometimes, too, there is a distinct internode between the pistil and other mem. bers, or between essential organs and perianth. It happens in some

I The scope of this work will not allow of reference to gymnosperms in this connection. 
monstrosities (e.g., among roses) that the receptacle keeps on growing for some time, even ending in a second Hower.

II. The sepals, petals, stamens, and cupels are considered to be leaves for the following reasons:-(r.) Like foliage leaves, they are lateral menbers, developed acropetally on an axis from which they differ in shape. (2.) They are arranged like foliage leaves, i.e., spirally or in whorls. (3.) As already stated, certain normal flowers present gradations from ordinary leaves, through bracts to sepals, petals, and stamens. (4.) In abnormal or monstrous flowers, which are especially common in eultivation, the gap between stamens and carpels is bridged over by transitions. It also appears that any one kind of floral leaf is capable of either partial or complete metamorphosis into any other kind. "Double" flowers are the best examples. In them stamens, or stamens and carpels, become transformed into petals. (5.) All the various kinds of floral leaf may, in abnormal specimens, be green in colour, and shaped more or less like foliage leaves. The most interesting cases are those where, as in double-flowering cherry, the carpels are in the form of small green leaves, some quite flat and others partly folded. (6.) Very rarely a bud may make its appearance in the axil of a petal or stamen, giving proof of its leaf nature.

III. Nectaries are not found in flowers alone, but may be "extrafloral" and variously situated. 


\section{CHAPTER IX.}

\section{PHYSIOLOGY OF THE FLOWER.}

THE flower, as a whole, is, of course, supported by the stem, and, as in other cases (but here to a less extent), the various parts are rendered firm by vascular bundles. Flowers need protection (r.) from certain animals, (2.) from the weather.

As regards animals, many insects, especially winged ones, and more rarely birds, are "bidden guests." For them nectar is excreted, and, in many cases, an otherwise unnecessary amount of pollen developed. For these favours, as we shall see, unconscious returns are made (p. is $S$ ). Other animals have been called "unbidden guests." Some, e.g., browsing animals, would devour the flowers altogether, if not deterred in some way; others, of which small wingless insects are the most important, would carry off pollen or nectar without conferring equivalent benefit. Protection against these attacks is secured in various ways, more or less complete, but rarely entirely so. It is here important to point out that one of the chief uses of the perianth is to protect the essential organs, the pollen and the nectar.

Protection fiom Animals.-(a.) Browsing animals, as also softbodierl insects, caterpillars, and snails, are kept off to a large extent by the presence of thorns, spines, prickles, \&c., upon the leaves and stems. Bracts are very often prickly, as, for instance, those making up the involusre of a thistle.

(b.) Flowers always, or nearly always, contain (like some foliage leaves) substances (as more particularly volatile oils) which are distasteful to browsing animals and caterpillars. They thus escape being eaten, and may even help to protect the foliage leaves; for when very small flowers are present in large numbers among ordinary leares, cattle will reject both. Dried flowers mixed up with hay are, however, often eaten at once, as the obnoxious substances are frequently volatile, and therefore disappear in the process of drying.

(c.) In countries where white ants are common, objects such as tables can be protected by placing their legs in vessels of water. Many plants keep off creeping insects in a similar way. 
Such water-holding receptacles are generally formed by rosettes of leaves, but sometimes by connate leaves, as in the teasel, where the cups thus constituted also digest insects that tumble into them. It is superfluous to remark that aquatic plants are protected from creeping land insects by the water surrounding them.

(d.) Sticky excretions may also keep off insects. Slippery wax (cf. p. 4I) sometimes serves this purpose, but most commonly sticky substances, excreted by the general surface of the epidermis or by glandular hairs, play this part. The seat of the secretion may be foliage leaf, stem, bract, or part of the flower. 'The butterwort, for instance, a small plant not uncommon in the marshy parts of mountainous districts, possesses a basal rosette of simple leaves, slippery from the presence of a secretion. From the centre of the rosette rise several scapes terminated by flower's something like small violets. The excretion, to the feel of which the plant owes its name, is poured out from innumerable mushroom-shaped glandular hairs. As in teasel, two purposes are served ; for not only are the flowers protected, but the excretion can digest small insects, and the edges of the leaf are sensitive, curling over such insects and holding them fast. Butterwort, therefore, is an "insectivorous" plant, and, in fact, is closely related to the bladderwort, previously described (p. 62). Again, gooseberry has glandular hairs on the outside of the cupshaped receptacle, and Plumbago upon the calyx. A very interesting example is found in Poly!gmum ampjlibium, a plant which grows with its lower part in litches. When there is plenty of water, the stem is glabrous, but it develops glandular hairs if the water dries up. These disappear again when enough moisture collects to surround the base of the plant.

(e.) Hair structures proper and thin hair-like outgrowths of the corolla, \&c., are often arranged so as to prevent unsuitable insects from reaching the nectar. Instances of this kind are so numerous that only a few can be mentioned. A "weel" of hairs (i.e., a circlet of straight flexible hairs with ends slanting inwards) is often found within the tube of a gamopetalous corolla, as in dead nettle, verbena, and speedwell. In passion-flower the whole corona is split up into narrow threads. The way to the nectar may also be blocked by tangled masses of hairs growing on various parts of the flower.

$(f$.$) It frequently happens that foliage leaves, peduncles, bracts,$ or else parts of the flower are so shaped or arranged as to hinder the access of small insects. Opposite leaves (more rarely stipules or scattered leaves) often form a kind of collar, over which insects cannot climb from below. This is the case in many gentians. 
Pendulous flowers, such as snowdrop, often present an insurmountable barrier in the form of a slippery curved stalk. Reflexed bracts and perianth leaves act in a similar way. We shall see (p. I 2 I) that if an insect is to benefit a flower by its visit, it must, so to speak, go in by the front door. Bees, even such as could get the nectar in a legitimate way, sometimes prefer to bite a hole at the sicle. Certain gamopetalous corollas are frequently found neatly drilled in this way. The calyx, epicalyx, and bracts often check such a proceeding, either by the toughness of their tissue, or, in the last case, by crowding. It also seems likely that an inflated calyx, like that of the bladder-campion, is a special arrangement for protecting the nectar. Parts of the flower are often so arranged or shaped as to entirely or partly block up the way to the nectar (which lies deep down in the blossom), in such a manner that small insects are unable to get at it. Very striking examples are afforded by the personate corollas, e.g., that of snapdragon. Only humble-bees are sufficiently heary and strong to force down the lower lip of this flower. Stamens may also form obstacles. In heath the large anthers serve this end; in harebell and Canterbury bell, the dilated bases of the filaments. Cinquefoil secretes nectar on the inner side of the concave receptacle, and the numerous perigynous stamens slant upwards and inwards, thus forming a roof for it. Narrow or constricted corolla tubes-knobs, ridges, or swellings in the perianth-nectar-containing spurs-crowded petals, stamens, and carpels, all these frequently have to do with the protection of nectar from unbidden guests. Still other devices are found.

(g.) Wingless insects are most active when the dew has evaporated, and this is a signal for the closing of many flowers.

(h.) Some forms again secrete substances in parts away from the flower, which serve to divert the attention of unwelcome insects. Beans and retches, for instance, possess "extra-floral" nectaries on the stipules, while common laurel, almond, and peach develop them at the base of the leaf-stalk.

Equally varied are the means of protection against wet and wind. (a.) Many flowers close in unfavourable weather. (b.) Parts of the perianth often form a kind of roof or penthouse which covers over the internal organs, and the efficiency of which is often enhanced by a covering of hairs. Good examples are seen in the hairy calyx and forwardly directed standard (p. 88) of gorse, and the arched upper lip of the dead nettle. The spathe of arum protects an entire inflorescence (fig. 33). Rain will obviously run off the outside of pendulous flowers, such as harebell and snowdrop, without doing them much injury. (c.) Nectar, again, is so slippery in nature, that rain can only with difficulty wash 
it away. (dl.) Polypetalous flowers are the most likely to be blown open and damaged by wind. The sweet-pea illustrates very well how such flowers are protected. In the first place, the peduncles are extremely strong and at the same time flexible, so that they yield without injury to gusts of wind. Again, the petals are firmly locked together at their bases by means of knobs and corresponding hollows. In this special case of the papilionaceous flower, the most important part is specially strengthened, i.e., the two lowest petals are united into the keel (p. 88). Lastly, the standard serves as a sail, causing the flower always to point away from the wind. Further examples are unnecessary, as many devices are sufficiently obvious on a little consideration.

Flowers are not organs of nutrition, but any chlorophyll they may contain assists in the building up of organic matter ( $c f$. p. 10).

Respiration is carried on very vigorously by flowers, and some crowded inflorescences, such as those of arum, can conveniently bo used for demonstrating this process. Flowers also commonly excrete, or pass out to the exterior, other substances besides carbon dioxide formed by the breaking down of protoplasm ( $c$. p. I I). Such, for example, are nectar and the volatile substances to which the odour of many flowers is due. These excretions are, in a sense, "waste products," lut they are not useless. The same remark applies to blastocolla, the digestive juices of "insectivorous plants," and the viscid substances on stems, leaves, \&c., by which insects are kept off.

We now come to the main function of the flower, that of true reproduction. This differs from vegetative reproduction (p. 43) in that special reproductive cells or spores are formed. The pollen grains, when ripe, are liberated by dehiscence of the anther, and then, by various means, are transferred, in gymnosperms to the micropyle of the ovule, in angiosper'ms to the stigma. This transference of pollen is called pollination. The viscid substance excreted by the stigma stimulates the pollen grains to a sort of growth; that is to say, each of them sends out a delicate pollen tube $^{1}$ (fig. 49), which grows down through the style by forcing its way between the delicate cells of the conducting tissue, or by traversing the slime in the canal, if this is present. Arrived at the ovary, the tube makes its way to the micropyle of an ovule and applies its tip to the apex of the nucellus. The two cooperating cells now absorb some of the protoplasm from the

1 Pollen grains laid in a drop of weak (not more than Io per cent.) sugar solution on a microscopic slide, and placed in the dark for a few hours, will be found to have emitted pollen tubes. 
pollen tube and pass it on to the egg-cell. This is now fertitizent, and is able to produce an embryo plant. The union of protoplasm from the pollen tube with the egg-cell is known as fertilization. This leads to the formation of seed and fruit, which will be considered in Chapter X.

It might be imagined that the pollen of a bisexual flower would generally effect the pollination of that flower. Such self-pollination can and does occur in many cases, but many arrangements exist, often rery elaborate, by which cross-pollination is brought about, i.e., the transference of pollen from one flower to another, either on the same or a different plant. Cross-fertitiwution, ${ }^{1}$ which follows cross-pollination, results in more numerous and healthier seeds.

Cross-Pollination.-(I.) It is obrious that self-pollination is out of the question in uniserual flowers, where stamens and pistil do not occur together. Even, however, in bisexual flowers selfpollination is avoided in rarjous ways. (2.) It frequently hap. pens that flowers are dichoganous, i.e., the stamens and stigma are mature at different times. Dichogamy is exhibited under two different forms-(a.) Proterandi'y, much the commoner, when the stamens mature first; (b.) Proterogyny, when the opposite is the case. (3.) Often again herkogamy is presented. In other words, there are mechanical arrangements by which the pollen of a flower is prevented from falling upon the stigma of the same flower. (4.) The flowers of some plants are even self sterile, i.e., their pollen, if it reaches the stigma, has either no effect at all, or else a baneful one. What then are the agents effecting crosspollination? The answer is simple-water, wind, insects, and birds.

Some aquatic plants are water-pollinated. Perhaps the best example that can be given is Vallisneria spiralis, a plant commonly found in aquaria. This possesses female flowers placed on long spiral stalks, by means of which they can be brought to the surface of the water when mature. The small male flowers, on the contrary, do not possess such stalks, but when their pollen is ripe they become detached, rise to the surface, and pollinate the female flowers.

Wind-pollinated (anemophilous) flowers are characterized by their small size. The perianth is often absent or imperfect; when present, it is regular and devoid of bright coloration. Large size would here simply interfere with the action of the wind and prevent pollen from being blown freely to and from the flowers. Brilliant hues would be thrown away on an inani-

1 This term is often erroneously employed to designate cross-pollination. 
mate agent, and, for the same reason, both scent and nectar are wanting. Stamens and stigmas project well out of the flower when they are mature, so as to catch the wind. Pollen is produced in very large quantities, as it is evident much must be wasted, while at the same time it is dry and powdery, its grains also being generally smooth. In firs and pines each pollen grain is provided with a pair of little air-bladder's (fig. 45), which offer an increased surface. The stigmas, again, are remarkable for their size and the presence of numerous hairs or roughnesses. Frequently, too, they are branched, and, in short, are admirably adapted for catching pollen. It is also to be remarked that the flowers are mostly unisexual. Our native trees are for the most part wind-pollinated, and so inconspicuous are their flowers that many are popularly believed to have none at all. They usually flower in early spring, before the foliage leaves are unfolded, and this evidently has to do with the unimpeded dispersal of pollen. All catkin-bearing trees (except willow) may be cited as examples, the principal kinds being alder, birch, hornbeam, hazel, beech, oak, and poplar. These possess all the above-mentioned characteristics of wind-pollinated flowers. Poplar is diøcious, the others monøcious.

Take, for instance, hazel, the flowers of which have alrealy been described (p. 99). The male catkins are pendulous upon slender stalks, and the slightest breath of air can move them. Their character is well expressed by the popular name of "lambs'tails." The group of pink threads projecting from the bud-like female catkins are the forked stigmas.

The Scotch fir is another excellent example of wind-pollination. It is monœcious, and the smallest female cones (cf. p. 99) are the ones ready for pollination. Vast quantities of pollen are produced in June, and even a gentle breeze blows it away in yellow clouds. The so-called "sulphur showers" of North America are of this nature, and they often form a scum on the surface of water miles distant from fir forests. Such a shower occurred in Inverness-shire in $1 \delta_{5} \delta$, covering the ground to a depth of half an inch. More pollen is necessary in this case, since blooming takes place when abundance of foliage is about, although the evergreen needle-like leaves of the fir do not block up the flowers, as broader ones would do. Between the scales of the female cones ready for pollination a viscid substance is excreted. This catches pollen grains, and then gradually dries up, drawing them down to the micropyles as it does so.

Willow and lime, although their flowers possess no scent, and an inconspicuous perianth respectively, are both insect-pollinated. The former is diccious (cf. p. 99), and every male and 
female flower possesses a nectary at its base. The lime blossoms in summer, is markedly proterandrous, and characterized by fragrance and abundant nectar. Bees are excessively fond of it.

Some smaller plants than those described are wind-pollinated, as docks, sorrels (not wood-sorrel), nettles, rushes, wild plantains, sedges, and grasses.

Docks have numerous small bisexual flowers, arranged in terminal and axillary racemes. Each flower can easily swing about on its slender pedicel. Both calyx and corolla are inconspicuous, each consisting of three members, stamens six. The syncarpous pistil possesses three short styles, each terminating in a fringed stigma.

Sorrels are similar, but the flowers are unisexual.

Rushes possess small brown bisexual flowers, arranged in panicles, and often proterogynous. All the floral leares are in alternating whorls of three, viz, three free sepals, three free sepaloid petals, three outer and three inner stamens, on slender filaments; three carpels, united into a superior ovary, with short style, and three rough spreading stigmas.

Nettles ( $c f$. p. Iоo) are remarkable for the elastic nature of their filaments, which, when the flower-buds open suddenly, scatter the light pollen in the air.

Wheat may serve as an example of a grass. The inflorescence is here a compound spike, the bracts and bractlets of which are overlapping scales, known as glumes. Numerous spikelets are situated on the main axis, in two alternating rows. Each spikelet possesses a short axis, bearing from three to five sessile flowers, also in two alternating rows. These flowers are in axils of glumes, termed lower pales (flowering glumes). Each of these is produced into a short spine or aun (very long in barley). The two lowest flowers are rudimentary, and the large lower pales belonging to them ensheathe the base of the spikelet, and receive the special name of outer glumes. Each flower has an upper pale on its inner side, and consists (fig. $5^{\circ}$ ) of a rudimentary perianth, three stamens, and a syncarpous pistil. The perianth is constituted by two small scales, the lodicules, which expand when the

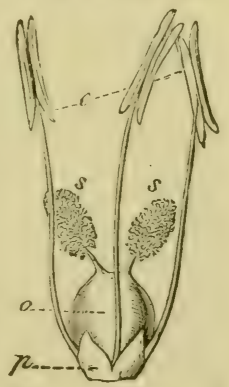

FIG. 50.- Hlower of Gralss, magnitied ; p. lodicules; 0 ovary; $s, s$. feathery stigmas; $e$. versatile anthers. flower is mature, force the glumes apart, and allow the essential organs to project externally. The stamens, when mature, elongate very rapidly. Their delicate filaments and versatile anthers are well adapted for catching the wind. Two feathery stigmas grow from the top of the superior ovary. 
Serlges, again, possess minute flowers, often unisexual. The perianth, when present, is reduced to bristles or scales, the stamens have slender filaments, and there are two or three spreading roughened stigmas.

Wild plantains are all characterized by the following features, which, after what has been said, will speak for themselves. Flower's small, green, bisexual, arranged in spikes (or heads), proterogynous. Sepals four. Corolla salver-shaped, with four small lobes alternating with the sepals. Stamens four, epipetalous, alternating with corolla lobes, possessing long slender filaments and large versatile anthers. Style long, covered with hairs and with two stigmatic lines. As might be expected from such a description all wild plantains are pollinated mainly or entirely by the wind.

Insect-pollinated (entomoplitous) flowers are as conspicuous as wind-pollinated ones are insignificant. They are characterized by some or all of the following features. Perianth brightly coloured, often irregular; pollen grains mostly rough or sticky; odorous and nectar-producing. A modern botanist graphically describes the state of things thus:--"The animate [pollinating] agent . . . as a general rule is an insect. This must be allured to the flower; and this accordingly appeals to either sight or smell by brilliant colours and by attractive scents. These colours and these scents draw the insect to a flower from a distance; but by themselves they would be but empty gratitications, unprofitable to insect and to flower alike. Something more substantial must be afforded, something that will prevent the insect from merely loitering about the flower in idle satisfaction, and that will induce it to probe the recesses of the blossom, and in so doing to transfer the pollen of one flower to the stigma of another. This further allurement is addressed to the palate; and though in some cases it is nothing more than the pollen itself, in most it is supplied by the secretion of a sweet fluid, the so-called nectar.

"Now Nature, who at first sight often appears a prodigal, is always found, on closer examination, to be the most rigid of economists. If no insects are to be allured, she gives . . . no nectar ; she cuts off the bright petals, and suppresses the attractive odours. Nor even when a bait is wanted will she give it one minute sooner than necessary. The brilliancy, the scent, and the nectar are only furnished when the flower is ready for its guests, and requires their presence; just as a thrifty housewife lights her candles when the first guest is at the door. The mature bud is furnished with no such attractions. Still more, even when the flower is mature, when its pollen is ready for transference or its stigma for pollination, when all the allure- 
ments are consequently displayed and insects invited to the feast, she still shows her economy. Guests might come who were not of sufficient importance, and the banquet be wasted on them ; for it is only when insects have a certain shape, size, or weight that she requires their visits, and can use them profitably for her purposes. She requires, moreover, that they should make their entrance by the main portal, which she has specially adapted to suit their and her requirements. All insignificant and unremunerative visitors, all such, moreorer, as would creep in by the back entrance, must be kept out. ...."1

We will now first of all consider, in a general way, the most important features, and then briefly review the arrangements found in certain well-known flowers.

Conspicuousness.-The corolla, calyx, bracts, and eren the flower-stalk, may all display more or less colour. In the simpler flowers yellou's are displayed, which seem attractive to small insects and beetles. White in a great many cases either attracts small insects or night-flying ones. At walk round a flower-garden in the dusk will show how conspicuous white flowers are at this time. Red is found in many of the most complex flowers, and reddish-broun blooms are often visited by wasps and carrion insects. Purple and blue are the rarest colours. They are preferred by bees. Aggregation of flowers of course makes flowers much more conspicuous than they would otherwise be, as a blossoming gorse-bush or bed of foxglores will show. This is one reason for the existence of inflorescences, and the small size or absence of bracts in many of them. Eren rery small flowers may be made striking by aggregation, as especially is parsnip, hemlock, ife, and Coinposites like sunflower and daisy. Flowers may even possess a much enlarged perianth (accompanied by corresponding reduction of the essential organs), by which their efficiency as "flags" is increased. This is the meaning of the ligulate ray-florets of Composites, which are either female or neuter, as in daisy and millefoil on the one hand, dahlia and sunflower on the other. Compare in this connection the compound cymes of the closely allied elder and guelder rose. The former possesses numerous small white flowers, and, though scented, secretes no nectar. It is risited by insects to some extent. In guelder rose the outer flowers are enlarged and neuter, while the inner ones secrete nectar, by which many insects are attracted. ${ }^{2}$ The same tendency is seen in some Umbellifers, as cow-parsnip and carrot. Here all the flowers are small, and the corollas of

1 Ogle, in the preface to his translation of Kerner's "Unbidden Guests."

$2 \mathrm{~A}$ cultivated variety produces neuter flowers only. Hydrangea is a similarly abnormal case. 
the outer ones irregular and much larger than in the inner ones.

The most closely related flowers often differ remarkably in character, and this is correlated with differences in pollination. Compare, for instance, the common mallow (Malva sylvestris) and the dwarf mallow (M. rotundifolia). The flower of the former is much the larger, and the numerous stigmas form a tuft above the ends of the monadelphous stamens (cf. p. 95). It is insectpollinated. The latter has much smaller flowers, and the stigmas and stamens intertwine, favouring self-pollination. A similar pair is found in the large-flowered, proterandrous rose-bay willow herb (Epilobium angustifolium), and the small-flowered willow herb (E. parviflorum), the stamens and stigmas of which mature simultaneously. The following table ${ }^{1}$ compares, in this connection, four of our native wild geraniums.

\begin{tabular}{|c|c|c|c|c|c|}
\hline & & $\begin{array}{l}\text { Blue Meadow } \\
\text { Geranium } \\
\text { (G. pratense). }\end{array}$ & $\begin{array}{c}\text { Mountain } \\
\text { Geranium } \\
\text { (G.pyrenaicum). }\end{array}$ & $\begin{array}{l}\text { Dove's-Foot } \\
\text { Geranium } \\
(G . \text { molle }) \text {. }\end{array}$ & $\begin{array}{l}\text { Small-Flowered } \\
\text { Geranium } \\
\text { (G. pusillum). }\end{array}$ \\
\hline Flower. & & Large. & Small. & Smaller. & Smallest. \\
\hline Proterandry & - & Complete. & Partial. & Partial. & Slight. \\
\hline Pollination & . & Never self- & $\left\{\begin{array}{c}\text { Generally } \\
\text { insect- }\end{array}\right\}$ & Often self- & Generally self- \\
\hline
\end{tabular}

Monocotyledons are remarkable from the fact that, although they include some of the minutest wind-pollinated forms (sedges, grasses, and rushes), yet, on the other hand, many of the most conspicuous flowers are found among them. Not only is the calyx frequently as bright as the corolla, e.g., in lity, tulip, and hyacinth, but also stamens may become petaloid, as in orchids (cf. p. SS), and the three styles of iris are in the same condition. Their bracts also are frequently petaloid, as in many orelide and hyacinth, while in some exotic arums the enlarged spathe plays the part of a corolla. In many arums, too, the fleshy axis of the spadix compensates for the lack of perianth.

Octour.-This varies according to the visitors required. Fragrant flowers attract bees, butterflies, moths, and higher insects generally, while more rarely foetid odours are given out with the view of enticing flies. Many flowers which to us appear scentless are probably not so to insects, which seem to be gifted with unusually keen powers of smell. There can be no doubt, for

\footnotetext{
1 Modified from Lubbock.
} 
instance, that nectar, whenever present, is powerfully odorous from the insect point of view, even when in minute quantities. A jar of honey possesses a well-marked odour, easily perceived by us, but a minute drop of the same appears scentless; yet to an insect such a drop is relatively large. Nectar that is completely hidden from sight will thus be smelt out, just as wasps rapidly find their way through the open window of a room containing sweet stuffs.

A powerful scent is often more attractive to insects than bright colour or large size, as may be well seen by comparing certain closely allied forms. Thus, the sweet violet is visited much more frequently than the larger and brighter, but scentless, pansy. Similarly, the small field bindweed (Convolvulus arvensis) is a much greater favourite with insects, owing no doubt to its fragrance, than the large white odourless form, Calystegia sepium.

The villow and lime (cf. p. I I6) are good examples of inconspicuous but insect-pollinated flowers, which attract by fragrance.

Mignonette also makes up for its insignificant appearance by a fragrant smell and the excretion of abundant nectar on the back of a sort of plate which projects from the floral receptacle. It is a favourite with certain bees.

Flowers pollinated by night-flying insects reserve their fragrance for this time.

The preceding features concern the attraction of insects; the following have to do with their reception.

Irregularity.-This always has reference to insect visitors. By it a landing-stage is generally provided, as in labiate flowers, and it may also have to do with the excretion of nectar, as in the spur of toad-flax, or the storing of nectar, as in pansy (fig. 5I). The landing-stage is always in such a position that the insect is brought into contact with stamens and stigma. If a part of its body gets dusted in one flower, things are so arranged that this part will touch the stigina of some other flower, and so on. It is also to be remembered that irregular flower's lay themselves out to secure the services of special insects, and, in such cases, correlated modifications of structure are found in insect and flower. This may be advantageous, as insects are often kept in this way to the same kind of flower, and therefore effect crosspollination more certainly than they otherwise would; but there is a corresponding disadvantage. Thus, red clover sets no seed in some of our colonies, owing to the absence of humble-bees, by which, in this country, it is usually pollinated. This flower also shows in what a complex way organisms are linked together, for, to use a well-known illustration by Darwin, red clover is dependent on cats for the formation of its seeds. These animals destroy 
field-mice, which, if left to themselves, would cause the extinction of humble-bees (here the pollinating insects) by demolishing their nests.

Some regular flowers, however, also court the visits of special insects, and in these the nectar is excreted at the bottom of a long corolla tube, and is only accessible to the long proboscis of a butterfly or moth.

An instructive comparison has been drawn between regular and irregular flowers in reference to the number of insect visitors. The following conspicuous regular flowers, with nectar easily reached, have the number of useful guests shown by the figures :Meadow buttercup (over 60), blackberry (67), wild strawberry (25), hawthorn (57). In striking contrast to this are larkspur and monkshood (larger bees only), foxglove (3), toad-flax (about 9 bees), early purple orchis (S). All these are conspicuous, irregular, and with nectar difficult to reach.

Honey-Guicles.-Many flowers are spotted or streaked with bright colours in such a way as to indicate the position of the nectar. The petals of geraniums and the lower lips of many labiate corollas show this. Prickles may also serve as "pathpointers." When intended to keep off creeping insects, they are generally directed downwards, while, if turned up, they may have the other function. Both these points are illustrated by the involucres of thistles.

Honey or Nectar:-As already shown, this may be excreted by the most various parts. It is always situated deep down in the flower.

Pollen.-This, as stated above, is either rough or sticky, being thus adapted for clinging to the bodies of insects, and at the same time prevented from being blown away. Where the arrangements for effecting crossing are simple, many stamens and much pollen may be present, while if these are complex the converse is often true.

We will now take a ferw special cases in illustration of the points involved in cross-pollination, commencing with simple regular flowers, and ending with complex irregular ones. Space will only admit of very brief descriptions.

I. Regular Flowers.-Buttercups are as simple here as in structure. Numerous small insects are attracted by the yellow colour, and in obtaining the nectar, are pretty sure to get dusted with pollen, especially as the outer stamens are matured first. Moderately proterandrous.

The poppy is visited for pollen, of which a superabundance is formed by the numerous stamens. The broad flattened top of the pistil is well adapted as an alighting platform, and it also bears the radiating sessile stigmas. 
Raspbermy, blacliberry, strauberiy, apple, and hauthom all agree in the possession of numerous stamens and excretion of honey by the receptacle. In blackberry the stigmas are mature before the inner stamens, which turn outwards as they ripen. The last three display well-marked proterogrny, and, except the strawberry, are sweet-scented.

Roses do not excrete nectar, but are visited for pollen. The styles and stigmas project in the centre, and form a landingplace, so that crossing must often be effected, although many stamens are mature at the same time.

Gooseberry, red currant, and blacti currant possess small greenish flowers, with minute petals, and five stamens. Nectar is excreted, howerer, from the top of the inferior orary, and the first is proterandrous and self-sterile.

Snouclrop excretes honey in groves on the inner surfaces of the small petals, upon which green streaks serve as honey-guicles. The pendulous flower is approached by flying insects from below, when they are sure first to touch the stigma, which is placed on the end of the simple style that projects beyond the six stamens. The anthers dehisce by pores at their pointed ends. so that pollen can readily fall out upon an approaching insect.

Wallflover and stocli do not present many remarkable features. The stamens are tetradynamous, and the shortness of two of them is partly due to the fact that thes have to curve round two of the nectaries, which are here small rounded green projections of the receptacle betreen them and the orary. Two other similar nectaries are also present, one outside either pair of long stamens. The long claws of the petals are held firmly by the calys against the structures within, and an insect alighting upon the platform constituted by the spreading limbs is, if already dusted with pollen, pretty likely to deposit some on the stigma, and to carry off a fresh supply while probing down to the nectar.

Fur:7sia is attractively coloured, and abundant honer is excreted by the top of the inferior ovary. Pollination takes place as in snowdrop, but the stigma is protruded more, and the anthers dehisce by slits. In fuchsia and snowdrop there is no specialized arrangement for causing pollen to fall upon insects.

Heath (not heather) provides for this in a rather elaborate way. The flower is pendant, and the contracted mouth of the urceolate corolla (for the shape of which we shall now see a reason) is almost blocked up by the style and stamens. The former projects somewhat, ready (as in most pendulous flowers) to receire pollen from approaching insects. The stamens, eight in number, arise from a honey-excreting receptacle, and their anthers form a ring round the style. The pollen escapes from 
terminal pores, but, in the undisturbed state, is prevented from falling out by the apposition of adjacent pores. Further, a slender process or "tail" stretches from the base of each anther towards the corolla. A bee, in trying to thrust its tongue up to the nectar, is sure to touch some of these tails, the anther-ring is disarranged, and a shower of pollen falls down.

Barberry possesses irritable stamens. An insect landing on the top of the syncarpous pistil (which possesses a stigmatic margin) is sure to touch them in trying to get nectar, here excreted by paired nectaries on the bases of the six petals. The stamens then spring suddenly inward, not only dusting it with pollen, but often frightening it off to another flower.

We now come to some flowers in which examination of several specimens will show that the same relative position is sometimes occupied by the stamens, sometimes by the stigma.

In the pink, for instance, there is well-marked proterandry, and a young flower presents five stamens projecting in the centre. Later on these wither, and the two stigmas are protruded in the same place. In this case we have successive elongation of organs which are rendered parallel by the enclosing claws of the petals.

A similar end is served by movement of the stamens in the blue meadow-geranium. Here the style rises in the centre of the flower, and (as this is another case of proterandry) the five lobes (stigmatic internally) which terminate it are at first closely pressed together. There are five spreading petals and ten spreading stamens. The outer five of these rise parallel to the style, shed their pollen, and retire, their action being followed by the five inner stamens. Now the stigmas separate, and can be pollinated. Note here that maturity is reached from without inwards, as in a centripetal inflorescence.

The rosebay willow-herl, which, by the way, presents a case of proterandry known since I790, attains the same end by movement of the style. The whole flower is epigynous, with four spreading sepals, four spreading petals, and eight stamens directed downwards. The style, which resembles that of the geranium just described, but possesses four lobes only, at first curves back between the petals. After the pollen is shed it bends forwards, and the four stigmas expand. It is hardly necessary to remark that, in the four cases described, different flowers are in different stages at the same time, so that the expanded stigmas are sure of receiving pollen.

Similar results to the preceding are attained, without proterandry, in primrose and purple loosestrife, by the occurrence of bisexual flowers of different kinds (heteromorphism or heterostyly). 
A bunch of primroses, ${ }^{1}$ examined with a little care, will show that the flowers are of two kinds (dimn'phic)-(г.) long-stylect, with the stigma in the throat of the corolla tube, and anthers deep down in it; (2.) short-styled, with these positions reversed. Imagine now, in a long-styled flower, an insect alighting on the convenient platform afforded by the salver-shaped corolla, and inserting its trunk into the tube to get nectar. A particular part of the trunk will be dusted with pollen, and, if a short-styled flower is next visited, that part will touch the correspondingly placed stigma. A new part will also be dusted, with similar result. Moreover, the pollen from a short-styled flower is made up of larger grains, since the pollen tubes are destined to reach a greater length.

Purple loosestrife is trimorplic, i.e., possesses three kinds of flowers, each of which has a style of certain length, and two sets of stamens different from the style and from another in that respect. Thus there are the following three sorts of flower:(I.) Long-styled, with medium and short stamens; (2.) mediumstyled, with long and short stamens; (3.) short-styled, with long and short stamens. A little consideration will show that pollen from a stamen of particular length will be carried to the stigma of a style of the same length. The best effect will be thus produced, but other combinations are not excluded.

Although the wild arum (fig. 33) has no perianth, yet it is degraded from a condition when a regular one was present, and so may be considered here. The inflorescence has alieady been described (p. 76). The aborted upper male flowers form a circlet of threads radiating downwards and touching the spathe. Small insects, attracted by the bright axis, can enter, but are not able to get out again. The female flowers are first matured, and some of the insects are likely to carry in pollen for their benefit. ${ }^{2}$ After pollination they excrete nectar, no doubt to the great joy of the hungry captives, which remain in durance, however, till the pollen is shed, when they, all dusty, are freed by withering of the chevaux-de-frise. Gladly they sally forth, and perchance falling into a like prison, brush their coats against a new lot of stigmas.

A pretty arrangement for preventing self-pollination is found in iris. This presents three admirable landing-stages for bees in its reflexed petaloid sepals. Facing the alighting insect is a stamen with outwardly dehiscing anther, arching over which is a little shelf borne by a petaloid style. The stigmatic upper side of this shelf is likely to be pollinated as the insect settles. The

1 Chinese primrose, cowslip, oxlip, or polyanthus will serve equally well.

2 As many as a hundred small insects have been found imprisoned. 
nectar is excreted deep down between sepal and style, and the bee, in backing out, rubs its head against the anther. The little shelf is not stigmatic below, and is simply lifted up out of harm's way for a moment.

The most daring way by which self-pollination is avoided by regular flowers is where the style actually assists in the distribution of pollen. This is seen in haretell (and Canterbury bell) and many Composites. In the former case the anthers shed their pollen before the flower opens, and a great deal of it adheres to the hairy outer surface of the style. Later on, the three (or more) lobes in which the style terminates expand and display their stigmatic inner surfaces.

The regular disk florets of a cluisy or sunflower will illustrate the method in many Composites, and show the meaning of syantherous stamens. Take, for example, a half-blown example of the larger form. The youngest inner florets are still shut. Outside these come a large number in which the brown antherrings are very conspicuous. Dehiscence is intemal, and by looking at older and older florets (i.e., passing gradually to the outside), you will find that first a small heap of pollen is seen on the top of the anther, and then the elongating style gradually emerges. It is provided with a little brush of hairs at its end, and, in fact, sweeps the pollen clean out of the tube, afterwards spreading into two lobes, stigmatic, as will be anticipated, internally. The most external disk-florets will be found already pollinated, with stigma and stamens withered. Aggregation not only render's Composites conspicuous, but also makes them favourites with insects, since a great deal of nectar is attainable in a small area. Their visitors alight in what must relatively be a perfect thicket of anthers and stigmas in various stages. Cross-pollination cannot but be extremely frequent.

II. Irregular Flowers.-Larkspur contrasts strongly with the closely related buttercup. Bees alight on the large petaloid sepals ( $c f . p .85$ ), and to reach the nectar contained in the two spurred petals, must pass their tongues through a small opening between the upper leaves of the perianth. Now the principle alluded to on p. $\mathrm{x} 2 \mathrm{I}$ comes into play. The stamens mature first, and successively raise themselves into this opening, retiring afterwards. Lastly, the stigmas are lifted up into the same position.

Indian-cress (so-called garden nasturtium) works on the same lines, but the nectar is here contained in the spur of the gamosepalous calyx.

Papilionaceous flowers present many interesting modifications. In all of them the wings ( $c f . p .88)$ serve as a landing-stage, 
and the weight of the insect effects more or less disarrangement of parts. There are four chief ways of action :-

(I.) In bird's-foot trefoil and lupin the pollen collects in the end of the keel, and when an insect alights, some of it is forced out and the stigma is also protruded.

(2.) Clover presents similar features, but the stamens are protruded as well.

(3.) Sweet and everlasting peas, broad bean, and scarlet runner possess a style which presents a hairy region near its end, the use of which is to sweep out pollen. The stigma is also protected by hairs from self-pollination.

Scarlet runner is the most complicated, and here the keel is drawn out into a narrow spiral "snout," occupied by the similarly curved style and stamens. The pressure of a bee on the wings causes the oblique stigma, protected by a circlet of hairs, to be protruded, and then the hairy part of the style with its attached pollen grains.

The seven flowers just described all recover their normal shape when the insect leaves, but in (4.) froom and gorse the newlyopened flowers are in a state of tension. The pressure of a bee causes it to "explode," as the projections at the bases of the petals are unlocked from the corresponding depressions.

Where the stamens are monadelphous, as in tupin, broom, and gorse, pollen only is afforded. The remaining flowers named above excrete nectar on the inner side of the staminal tube, and, as the upper stamen is free, this can readily be reached from above.

Pansy (fig. 5I) recalls the heath, in that it presents a special arrangement for dusting its visitors. Here the base of the style is slender and bent, while the stigma is dilated, hollow, and provided with a receptive lip facing downwards. The anthers with their triangular appendages closely surround the style, leaving, however, a space between them and it, which receives the shed pollen. If an insect now alights on the lower petal, its proboscis, when thrust into the spur, must touch the stigma-lip, upon which it leaves pollen if other flowers have been previously visited. At the same time the insect's head will push against the head of the stigma, causing the slender style to bend and pollen to fall out. The proboscis when drawn out folds up the stigma-lip ( $c f$. iris), and any grains that happen to be on it at once adhere to the sticky fluid with which the stigma is filled. Violet is similar, but the stigma is shaped differently.

We are now in a position to understand why the posterior stamen is aborted in so many irregular flowers (cf. p. 94). The style is thus enabled to occupy the upper side of the corolla, out 
of the way, so to speak. An upper stamen would be so blocked up by it as to be of little use.
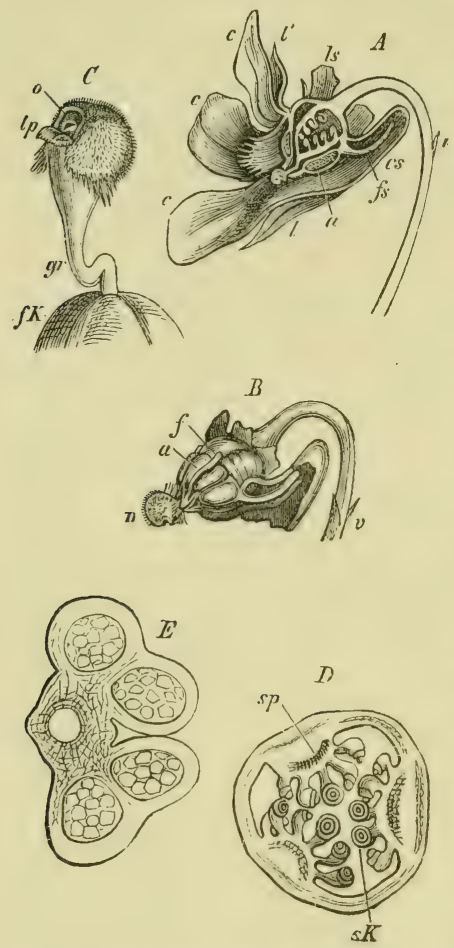

FIG, 5I, Structure of Pansy [from Sachs]. All but A. magnified. A. longitudinal section of flower. B. ovary and anthers, the former fertilized and swollen; the filaments have been broken off and the anthers carried forwards by growth of ovary. C. stigma, style, and top of ovary. D. transverse section of ovary. E. transverse section of young anther, showing two pollen-sacs in each lobe and connective uniting lobes; $v$. bracteole ; $l ; l^{\prime}$. sepals; $l s$. appendage of sepal; $c, c, c$. petals; $c s$. spur of lower petal; $a$. anthers ; $f$. filaments; $f s$. nectar-excreting appendages of lower stamens; $n$. stigma ; 0 . opening of stigma; $l p$. lip of stigma ; $g r$. style; $f K$. top of ovary ; $s p$. placentas ; $s K$. ovules. them pressed firmly down. A
visitor settling on the lower lip touches first the forked stigma, which hangs down a little, and then the anthers of the didy-
Take, for example, foxglove. The lower lip forms a landingstage from which an insect can creep into the bell. Only a large form like the humble-bee is useful, as the size of the corolla prevents others from touching the stigma and anthers. The flower is to some extent proterandrous, and, as in so many cases, the stigma projects beyond the stamens. The didynamous condition is well adapted for displaying the anther lobes, which are at first transverse, but afterwards move into a vertical position.

The personate corollas of toactflax and snapdragon can only be forced open by bees. In the latter case humble-bees are almost the sole visitors, as others are not strong enough to press down the lower lip.

Musk is particularly interesting among lipped forms, from the fact that the stigma is in the form of two flattened sensitive (especially in the large scentless musk) lobes, which close on contact. Pollen can thus be deposited in it by an arriving, but not by a departing guest.

White dead nettle presents an arrangement common in labiate flowers. The lower lip forms a convenient landing-stage; the upper one not only protects the stamens and pistil, but keeps them pressed firmly down. A
touches first the forked stigma, 
namous stamens. This flower also presents other points of interest. The corolla tube is strengthened by a backward bend just where the weight of an insect produces most strain, and the tube of the calyx is also thickened. Unbidden guests are deterred, not only by the general hairiness of the plant, but also by a weel of hairs in the corolla tube.

The allied forms thyme and wood-sage are both proterandrous. The former reminds one of the pink (p. 124), since first the four stamens project from the corolla, two at a time, diverging widely, and then the style grows rapidly, its forked end sticking right out of the flower. Wood-sage takes advantage of the rudimentary upper' lip to curve its stamens sharply back after their pollen is shed.

The two next examples, meadow-sage and orchis, show in a very striking way the reduction in number of stamens that is often associated with elaborate arrangements.

Meadow-sage (also garden-sage and a large red garden form) possesses only two fertile stamens, and these are modified ( $f$. p. 97) in a very curious way. The filaments are short, and the elongated curved connectives are loosely swung upon them. The longer upper part of each connective bears a fertile anther lobe, while the shorter lower part is united with its fellow into a curved plate. ${ }^{1}$ When undisturbed, the anther lobes are situated under the hoodlike upper lip, and the forked stigma projects beyond them, well out of the way of self-pollination. If, now, a bee lands on the lower lip of the corolla and probes the tube for nectar, its head is sure to strike against the curved plate mentioned. The result is that the anther lobes are swung downwards and forwards so as to deposit pollen on its back. Further, the sage is markedly proterandrous. The stigma of the young flower is placed too high to be touched, but when mature it bends downward and hangs in front of the flower, so that it must be touched before a bee can settle on the lower lip.

Early purple orchis (fig. 52). The flower

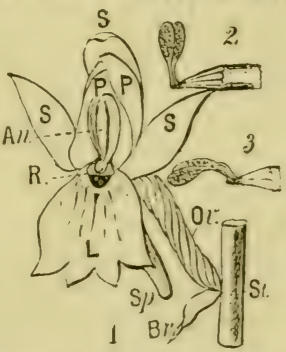

FIG. 52.-Seni-diagrammatic View of Early Purple Orchis [original]. I. St. stem; $B r$. bract; $S, S, S$. sepals; $P, P$. upper petals ; $L$. labellum, the streaks are honey-guides, directed to the opening of the spur (shaded black); $S p$. spur of labellum; $A n$. bilobed anther dehiscing by slits; $R$. rostellum, below which is the broad stigma(dotted); $O v$. inferior ovary, twisted so that posterior side of flower is below. 2. pollinia, immediately after removal by pushing end of pencil against rostellum; 3 . the same a little later.

has already been partly described (p. 88). The centre of the flower is occupied by the "column," or top of the pistil with a

1 Though two fertile stamens are present, they only produce as much pollen as one, for each has but one anther lobe. 
sessile anther upon it. Each lobe of the anther contains an agglutinated club-shaped pollen mass or pollinium. The stalks of the two pollinia slope down to a little viscid knob, the rostellum, below which is a broad sticky stigma. A bee alighting on the labellum, for the purpose of piercing the tissue of the spur and licking up the sweet sap (nectar is absent), is sure to strike the rostellum, which becomes detached, and draws with it the pollinia. The bee leaves the flower with these structures attached to its head like a pair of horns. They soon droop forwards, and are likely to strike the stigma of the next blossom visited, these remaining in whole or part.

Some American flower's are bird-pollinated, their visitors being humming-birds, and in some cases small insects are not excluded, as they attract these larger useful visitors. It is also believed that many Cape flowers, excreting as they do large quantities of nectar, are specially suited for the visits of small birds.

Self-Pollination. - The fact that the majority of flowers are bisexual leads one to suspect that this process occur's not unfrequently. Many forms which lay themselves out for cross-pollination provide for the other form as a last resort. 'Thus, in the forget-me-not, the stigma at first protrudes from the flower, but later on the corolla tube elongates, and brings its circlet of sessile anthers to the same level. Again, in Composites, the branches of the stigma, if not cross-pollinated, sometimes curl round and touch the top of the anthers with their receptive inner surfaces. This curving regularly takes place in certain small self-pollinated Composites, as groundsel.

Little specialized forms, like buttercup and rose, must often be self-pollinated, and the only perfect bars are complete dichogamy and self-steritity.

Comparison of several closely allied flowers often bring out the fact that the smaller ones are self-pollinated ( $c f . p$. I20). Compare, for instance, the large white flowers of stitchwort with the small ones of chickweed. Regularly self-pollinated flowers are characterized by inconspicuousness, partly due to their small size generally as a whole, and still more to the minuteness of the petals, which are white or pale and devoid of honey-guides. Scent and nectar are practically absent, and the stigmas are so placed that pollen can easily reach them from the anthers of the same flower. The stamens are often few in number, and produce comparatively little pollen.

All this is carried to the extreme in cleistogamous flowers, i.e., minute self-pollinating ones, which never open, and exist in addition to ordinary ones. The best example is dog-violet. In summer the ripe fruit of the cross-pollinated flowers will be found, 
and, close to these, minute bud-like structures. These are the cleistogamous flowers; their anthers are so placed that the pollen grains can send their tubes straight to the stigma. Such a flower produces, perhaps, only two hundred pollen grains, as opposed to some thousands in an ordinary blossom.

Fertilization results in changes in the egg-cell, nucellus, integuments, carpels, and frequently other parts as well. The fertilized egg-cell gives rise to an embryo, the primary root of which is directed towards the micropyle. Nutritive substances are formed in the nucellus, known as albumen. This is endosperm if produced in the embryo sac, perisperm if originated outside it. Seed-coats are developed from the integuments, while enlargement and other changes in the carpels, \&c., give us fruits.

Motility, irritability, and spontaneity have been sufficiently illustrated by the movements often performed in connection with pollination. 


\section{CHAPTER X.}

\section{SEEDS AND FRUITS.}

\section{MORPHOLOGY.}

A seed or matured ovule belongs to one of two categories: (I.) exalbuminous, (2.) albuminous, i.e., without and with albumen respectively.

A broad bean is a good example of the former sort. If previously soaked in water the examination will be facilitated. A black mark will be seen at one end. This is the scar or hilum, from which the stalk has been detached. As the ovule was inverted (p. I04) the seed must be so. The micropyle should therefore be close to the scar (fig. 49), and in squeezing the seed a drop of water will ooze out, and prove its presence. A triangular swelling on this side $^{1}$ the scar marks the position of the radicle, which is in part (cf. p. I43) the primary root of the embryo. A slight ridge, the raphe (p. I09), runs from the other side of the scar half way along the seed to what correspond with the base of the ovule, exactly opposite the micropyle. The long axis of the seed is therefore the direction of breadth. A slin or seed-coat can readily be peeled off, consisting of a thick outer and a thin inner layer, developed respectively from outer and inner integuments of the ovule. The greater part of the seed is made up of two thickened fleshy cotyledons or seed-leares, which are the first leaves of the embryo ( $c f$. figs. 2 and 5). Note also the white pointed radicle. Now separate the seed-leaves, and observe that the radicle is continuous with a minute curved plumule, or primary shoot. The space within the seed-coats is entirely occupied by the embryo, and all trace of the nucellus has disappeared. The presence of two seed-leaves characterizes dicotyledons generally. A dried pea, the kernels of almond and hazel-nut, apple and orange pips, can all be understood by comparison with bean.

A large and typical albuminous seed is that of castor-oil, obtainable from any druggist. It is oval, flattened, and mottled. At one end is a small knob, the caruncle, which marks the position of both hilum and micropyle, for the seed is a reversed one.

1 I.e., left when the bean is placed so that the scar is below and to right. 
Comparison of cross and longitudinal sections shows that we have here a straight embryo lying in the centre of the seed, with its radicle pointing towards the caruncle, and a pair of flat, beautifully veined seed-leaves closely pressed together. There is no evident plumule. Surrounding the embryo is a cheesy substance, the albumen, which fills up the space between it and the seedcoat. With care, it can be scraped away, leaving the embryo entire. The seeds of violet can be understood after examination of the preceding, but the embryo is much smaller in proportion (cf. fig. 53), while in buttercup (fig. 30) and Tarlispur most of the seed is occupied by albumen. In all these cases the nutritive matters are formed in the embryo sac, which increases in size and fills up the whole of the space within the seed-coat. Such albumen is called endosperm. In a few cases, however, the embryo sac, with its contained endosperm, is comparatively small. Most of the albumen is in this case perisperm, and belongs to the nucellus.

Examine now a grain of maize (Indian-corn). This is really a fruit, as it includes the wall of the ovary, here dry and closely adherent to the seed. A little pointed projection on the broad end of the grain is the remains of the style. The yellow

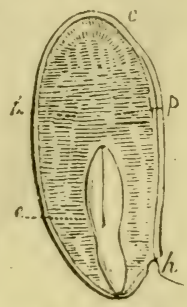

FIG. 53.--Section of Albuminous Seed, showing embryo surrounded by endosperm. part of the grain is endosperm, but on one side, near the pointed base, is a whitish patch. This is the emlryo, situaterl, as in all grasses, outside the endosperm. It can be detached from a soaked grain; and careful scrutiny will show that radicle and plumule are wrapped up in a single seert-leaf or cotyledon, part of which is closely applied to the endosperm, and receives the special name of scutellum. By cutting through a grain longitudinally, taking care to halve the embryo, the relation of parts will readily be understood, and a loose, white region of the endosperm will be seen (fig. 54). Grains of wheat, barley, and oat may usefully be compared with maize. All of them possess a single seed-leaf, which is a leading character of monocotyledons. A date-stone is a monocotyledonous seed of different type. Here the endosperm is horny, and composed of thickened cellulose cell-walls. On one side of the stone is a groove ; in the centre of the opposite side the micropyle will be found as a small depression. By cutting the seed transversely across through this, a small embryo will be found, its radicle directed towards the micropyle. The cotyledon is sheath-like, and encloses a microscopic plumule.

A huge seed belonging to the same class of plants is the cocoanut. The hard shell does not belong to the seed, the coat of 
which is a brown layer covering the edible endosperm, here forming a relatively thin layer surrounding a milk-containing cavity.

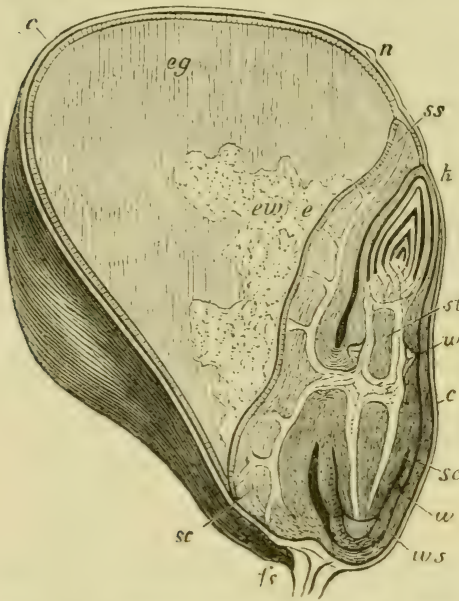

FIG. =4--Tongitulinal section of a Fruit

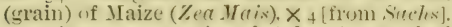
c. pericarp; $n$. remains of strle; is. attatched base of fruit: e!! dense yellow endosperm, between which and the pericarp is seen the seed-croat; ex. lnose white endusperm; sc. scutellum of embryo, its continuation can he traced round the embryo below; $x$. its apex; $e$. its epidermis (shaded like seed-coat) on endosperm side; $k$. plumule; $u$. (below) ralicle, tipmer loy root-cap; rex. its rootsheath; $v$. (above) adventitious roots arising from emhryonic stem. Vascular bundles. white (note pith in vascular cylincler of radicle, as well as in stem).

At one end of the cocoa-nut are three round marks. One of these corresponds to a soft part adjoining the micropyle of the seed. The minute embryo is to be found imbedded in the endosperm at this point.

The various parts of the seed are subject to considerable variation, as the above examples show. Straight, bent, and inverted ovules develop into similarly termed seeds (cf. p. 104). The seed-coat is of one or two layers, according to the number of integuments possessed by the ovule. It frequently happens that outgrowths from the seed-coat or funicle are present. These constitute an aril, which may consist of hairs only, as in cotton, willow-herb, and willow; or it may be a knob (castor-oil seed), ridge, crest, or complete extra covering. Examples of the last kind are seen in the red fleshy cup enclosing the solitary seed of yex, the loose orange-coloured investment of spindle-tree seeds, and "mace" which surrounds the nutmeg.

Both in albuminous and exalbuminous seeds, but especially in the latter, the embiyo may be packed away in the most various manners. The cotyledons particularly are often folded, rolled, or crumpled in an elaborate way.

Little need be said here about the minute structure of the seed. It is enough to state that reserve materials are laid up in the albumen (or cotyledons if this is absent) under three chief forms: (I) starch grains; (2) alenrone grains, which are minute masses of proteid matter, often containing crystalloids (cf. p. 26); (3) oily matter's; (4) cellulose. The date is an example of (4); and oily seeds, such as brazil-nut and castor-oil, of (3). Aleurone grains are commonest and largest in oily seeds. A thin section, 
for example, from the endosperm of castur-vil, shows them in the form of oral bodies crowding the small parenchymatous cells. Each grain contains a rystalloir? and also a rounded mass of mineral matter known as a globoid. I microscopic section through the cotyledon of a ripe pea shows that here numerous minute aleurone grains are associated with far larger oval starch grains. In wheat the external layer of enclosperm cells contains aleurone only, the internal part starch only. The preparation of flour for white bread involves the removal of this external highly nutritious layer. Hence the value of whole flour bread where it still remains (cf. p. 26).

Starch is by far the commonest reserve material in seeds, and grains differ in shape according to the kind of seed. Hence the adulteration of flour, d.c., can be detected by means of the microscope.

Fruits are seed-containing structures resulting from a growth of the ovary, and sometimes other parts, which follows fertilization. The terms superior, inferior, apocarpous, and syncarpous, are used here in the same sense as when dealing with the pistil ( $p$ p. Iо०, Іог). A distinction is made between (r.) true fruits, cleveloped from orary alone, and (2.) spurious or false frutit: ( seudocarps), which involve other structures as well.

I. Spurious Fruits.-These necessarily consist of one or more true fruits or dereloped oraries surrounded by or imbedded in other structures. An entire flower cluster sometimes gires rise to a single fruit, termed in this case multiple or collectice. Fig, pine apple, and mulberry are the commonest examples.

The flesh of a $\tilde{r g}$ (fig. 34), for instance, is the succulent common receptacle, and the "seeds" within it are the true fruits. The term "fruit" does not necessarily imply edibility, from a botanical point of view at least. Again, each of the little red swellings making up a mulberry. (fig. $55)$ is simply the calyx of a flower become juicy and surrounding a small hard fruit. The pine-apple is developed from a spike of small crowded flowers, the ovaries and floral receptacles of which have fused with bracts and axis into a fleshy mass. Each lozenge-shaped area in the outside corresponds to a single flower. Seeds are absent as a result of cultivation.

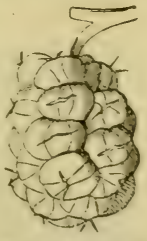

FIG. 55.-Fruit uf जilulberry.

Aggregate fruits are formed in another way in beech and sucet chextnut. Here the "nuts" are true fruits, and the prickly husk in which they are enclosed is formed by bracts which have enlarged and grown over them.

The best types of spurious fruits formed from a single flower 
are strawberry, rose-hip, apple (and pear), and acorn. The edible part of a strawberry is the dilated floral receptacle, and the "seeds" scattered over it are the true fruits. Similarly, the scarlet part of a hip, to which the sepals are still attached, is obviously the hollow receptacle of the perigynous flower. Within it will be found the true fruits. An apple presents an advance on this condition. At the end opposite the stalk will be found the withered remains of the sepals, and sometimes of the stamens. The syncarpous ovary of an apple-flower is half inferior, i.e., with its lower half fused to the receptacle. It forms the applecore (its seeds being the "pips"), while the flesh belongs to the receptacle. This kind of fruit is a pome.

Strictly speaking, all inferior ovaries develop into spurious fruits, since a part of them is receptacle ( $f \cdot$. p. IOI $)$. The union, however, between ovary and receptacle is so intimate that they are mostly classed under true fruits, e.g., gooseberry. It is just here that the distinction between the two kinds breaks down. In acorn we have a single true fruit, partly surrounded by a cup-like structure formed by the growth and union of bracts.

II. True Fruits. - These are mainly (inferior fruits) or entirely (superior fruits) formed from the developerl ovary. Their walls are termed the pericarp, and are often divisible into outer, middle, and inner layers, known as epicarp (often the epidermis), mesocurp and endocarp respectively. The subdivisions of true fruits are best shown in a tabular form.

A. Dry Fruits.-Pericarp woody or tough.

I. Indehiscent.-Pericarp encloses seeds till germination. Seed-coat thin, and often fused with pericarp.

a. One-seeded.

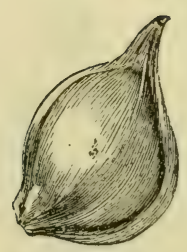

FIG. 56.-Achene of Buttercup.

(a.) Achene, of one carpel, superior, pericarp membranous, and free from seed-coat. Ex. Buttercup (fig. 56), strawberry.

(b.) Caryopsis.-Like (a), but usually of two carpels, and pericarp closely adherent to seed-coat. E.x. All grasses, as wheat, maize, oat, \&c. (fig. 54).

(c.) Cypsela.-Like (b), but inferior. Ex. All Composites, as sunflower, dandelion, \&c.

(d.) Nut, syncarpous, superior, pericarp woody, and free from seed-coat. Ex. Hazel-nut (two ovules always present in ovary. This accounts for occasional existence of two kernels.) 
b. Many-seeded.-Splitting fruits (schizocarps). Separate into one-seeded parts (mericarps), resembling nuts or achenes. Ex. Maple, parsnip, carrot, carraway (2), Indian-cress (3), forget-me-not, borage, dead nettle (4), geranium (5) (fig. 57), mallows (many). A winged mericarp, as in maple, is a samara (fig. 58).

2. Dehiscent.-Pericarp opens when ripe to liberate the seeds, which are usually numerous, and enclosed by hard or thick coats.

a. Follicle, of one carpel, superior. Dehisces along the ventral suture. $E x$. Larkspur, columbine, marsh marigold, pæony.

b. Pod or Legume - Like (a), but dehiscing dorsally as well ( $c f$. fig. 48, D). Exx. Papilionaceous flowers, as pea, bean, gorse, and broom.

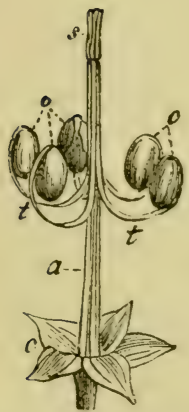

FIG. 57.-Splitting Fruit

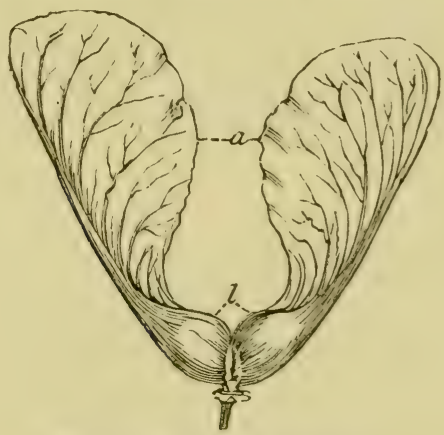

FIG. 58.-Samaras of Sycamore. of Geranium.

c. Siliqua, of two carpels, superior, cavity divided into two by a spurious dissepiment or replum ( $c f$. p. 105). Placentation parietal. Ex. Wallflower, stock, cabbage.

d. Siticula.-A short, broad siliqua. Ex. Shepherd's purse.

c. Capsule, of two or more carpels. Dehisces-

(a.) Longitudinally (fig. 59), with formation of teeth or valves for a greater or less distance from the top. If the constituent carpels separate where united, the capsule is septicidal, and when there are more than one loculus, this means splitting of the dissepiments. Ex. Gentian (one loculus), 


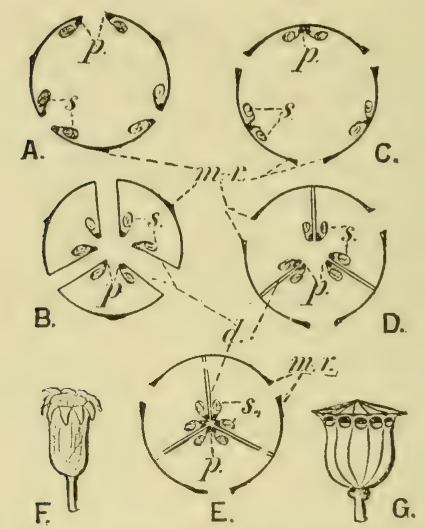

FIG. 59.-Diagrams of Capsules [origincl.] A-E. cross-sections of dehiscing capsules. A. unilocular septicidal; B. plurilocular septicidal ; C. unilocular loculicidal; D. plurilocular loculicidal ; E. septifragal ; $p$. placentas (thickened edges of carpellary leaves), split in A, B, D (cf. B with follicle); $m-r$. midrilos of carpellary leaves, split in $\mathbf{C}, \mathbf{D}, \mathbf{E}$ (cf. D with legume); $d$. dissepiments (formed by sides of adjacent carpellary leaves), split in $B ; s$. seeds, represented small for the sake of clearness, compare with fig. 48. F. capsule of primrose, dehiscing above ten teetl. G. capsule of poppy, dehiscing above by pores, beneath each of which is a valve.

foxglove (two loculi), saffron (three). Or, again, each carpel may split along its dorsal margin. The dissepiments then either separate from one another, when the capsule is loculicidal, e.g., tulip, lily, and iris, or remain united, forming a column in the centre of the fruit, when the capsule is septifragal, e.g., rhododendron. Where, as in violet, a capsule contains but one loculus, and its carpels split

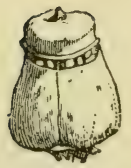

FIG. 6o.-Pyxidium of Henbane. along their midribs, this may be termed loculicidal. When the placentation is free-central, dehiscence is usually by teeth, as in primrose and pink.

(b.) Transversely (pyxidium).-Here a lid falls off. Ex. Scarlet pimpernel, plantain, henbane (fig. 60).

(c.) By pores (porouscapsule). - Ex. Snapdragon, (two pores), poppy (many). (Fig. 59, G.)

B. Succulent Fruits. - Pericarp more or less fleshy.

I. Indehiscent.--Pericarp does not burst.

a. Stone-fruit or drupe, superior, single-seeded, epicarp membranous, mesocarp succulent, endocarp 
hard and thick, forming the wall of the stone, seed-coat thin (the seed is the "kernel"). Ex. Cherry, plum, peach, \&c.

b. Berry, usually many-seeded, unilocular, epicarp tough, mesocarp and endocarp succulent, surrounding the seeds, which have firm coats.

(a.) Superior. Ex. Grape, date (with one seed and a papery endocarp).

(b.) Inferior. Ex. Gooseberry, currant, cucumber.

c. Hesperidium.-Allied to (b.) Many carpels, loculi, and seeds, superior; epicarp and mesocarp forming a rind or peel; endocarp a thin membrane, from which numerous succulent hair structures have grown out, forming a pulp by which the loculi are filled and the seeds surrounded. Ex. The term is restricted to the fruit of orange, lemon, and closely allied forms.

2. Dehiscent.-Pericarp bursts and liberates the seeds.

a. Succulent Capsule.-The pericarp splits into valves and sets free the seeds. Ex. Horse-chestnut, where the prickly green husk is pericarp (it must not be confused with the similar structure found in beech and sweet chestnut, p. I35).

b. Dehiscent Drupe.-Epicarp and mesocarp fleshy, bursting to liberate the seed, still enclosed in the hard endocarp. Ex. Walnut, the shell of which is endocarp. (N.B.-The shell of hazelnut is pericarp. Walnuts are pickled when the entire pericarp is present, and before the endocarp has hardened.)

c. Dehiscent Berry.-Resembles berry, but firm outer lnyer of pericarp bursts to liberate seeds

When an apocarpous pistil consists of more than one carpel, each of these ripens into a simple fruit, and the ripe carpels taken together form an aggregate fruit. Thus, in buttercup there is such a fruit made up of achenes, and so on. In some an aggregate fruit appears to be a simple one, as in raspberry and blackberry. These are collections of minute drupes, drupels as they may be termed. 


\section{PHYSIOLOGY.}

Protection of seets, during the early period of their growth, is largely effected by the perianth; and the calyx, especially when gamosepalous, often persists and surrounds the fruit. A protective function may also be assumed by bracts, as in siceet chestnut and beech. Seeds are also frequently provided with hard coats, and, when this is not the case, all or part of the pericarp serves the same end, e.g., in dry indehiscent and stone fruits. Succulent fruits, again, are almost inedible till ripe, when, as we shall see, they lay themselves out to be eaten, so to speak. In water plants the seeds generally remain protected in the mud at the bottom till ready to germinate. Vallisneria is a very interesting plant in this respect. The spiral stalk (cf. p. I I 5 ) of the female flower coils up after pollination, drawing it down to a place of comparative safety for the ripening seeds. Such protective movements are also known in some land plants. The stalk of $C y c l a m e n$ or sowbread coils up spirally, and the peduncle of dandelion moves so as to bring the ripening fruit close to the ground.

Distribution of fruits and seeds is brought about in a variety of ways. In comparatively few cases is there any special provision for setting the seeds close to the parent plant. Some forms, however, are heterocarpic, i.e., producing two kinds of fruit, one of which is suitable for this purpose. There is, for example, a kind of vetch which produces, in addition to the ordinary pods, small pointed ones, which grow near the ground, and are forced into it by the growth of their stalks. The capsules produced by the cleistogamous flowers of sucet violet are also situated neur the ground. As a general rule, however, there are special arrangements for dispersing the seeds and fruits to a distance. The chief agents for effecting this are-(I) the plant itself, (2) water, (3) wind, and (4) animals.

(r.) The plant itself distributes its seeds in many forms, usually as a result of the elasticity of the fruit, which in this case is either a splitting fruit or else dry and dehiscent. In geraniums we have an example of the former kind (fig. 57). The axis of the fruit is here produced into a kind of beak, at the base of which are five distinct lobes, each attached by a thin elastic rod to the beak. When the fruit is ripe these rods suddenly curl up, and the lobes (or seeds they contain) are detached and thrown to a considerable distance. The same kind of thing takes place in balsam (hence called scientifically Impatiens noli me tangere).

The legumes of some plants, such as retch and hroom, split violently open when ripe, and violently eject their seeds. A 
similar state of matters exists in some siliquas, where the valves suddenly fly up from below on the slightest touch. A good example of this is a small cruciferous ${ }^{1}$ plant with white flowers. the hairy bittercress (Cardamine hirsuta), which grows abundantly in waste places. A hand passed lightly over a patch of these plants, when the fruits are ripe, elicits a brisk discharge of seeós.

Capsules are adapted in some cases for throwing their seeds to a distance, of which the dog-violet is a very good example. Here the capsule bears three rows of seeds on parietal placentas. When ripe, it splits between these into three valves, which separate widely. The edges of each valve now curl up and press against the seeds, here extremely smooth, with the result that they are shot to some distance, just as an orange pip can be projected from between the finger and thumb.

Succulent firuits are but rarely adapted for ejecting their seeds, but this is the case with the squirting cuenmber, common in South Europe. The ripe fruit is in such a state of tension that the lightest touch separates it from the stalk and causes the contents to squirt out with much force.

(2.) Water effects the distribution of many seeds, especially such as are enclosed in a corering which is watertight and at the same time light enough to make them float. Experiments have been malle on this head, leading to the conclusion that the seeds of about one plant in ten could be floated across a sea 900 miles broad and still remain capable of germination. Earth, containing seeds, may also be carried for long distances in the crevices of drift-timber: The cocoa-nut is one of the best examples of a fruit which is safely transported by water for an immense distance without injury. Owing to this it is common on the coral islands of the Pacific.

(3.) Tind plays a very important part in the dispersal of seeds. These are sometimes suited for this by their small size, as in orchids. Such small seeds are often found in porous capsules, like those of snapdragon and poppy, and in these the pores are situated near the top. The seeds cannot, therefore, fall out, but are shaken out by the wind. Each pore in the poppy capsule is provided with a little flap on the lower side, which is said to move up and close the pore in damp weather.

Coverings or tufts of hair are often present upon seeds and fruits, materially assisting in their dispersal by wind. The commonest example is found in the "pappus" of many Composites, a sort of crown, representing the calyx, which surmounts the

1 With cross-shaped corolla ( $c f$. Appendix A), a characteristic of the group Cruciferæ, of which wallflower and stock are typical examples. 
fruit, as in dandelion, "thistledown," \&c. The dandelion is of further interest because the peduncle, which during ripening is directed along the ground, raises itself so that the fruits can readily blow away. The perianth of cotton-grass (really a sedge) consists of bristles which grow out into long hairs; a crown of hairs is found on the seeds of willow-herb, while a more general covering of hairs is present on villow and cotton seeds. The seed of storl's-bill, a near relative of the geranium, possesses a long feathery awn adapted for catching the wind. The base of the awn is also twisted, and this part when moist tends to screw the pointed seed into the ground.

Many fruits or seeds, especially those of trees, are provided with an expanded "wing," of various nature. In lime the stem of a flower cluster is provided with a large adherent bract, and in hornbeam the single fruit is in the axil of a trilobed bract. The fruits of maple, sycamore (fig. $5 \mathrm{~S}$ ), birch, ash, and elm are themselves winged, and there is a membranous margin in those of dock and parsnip. Scotch fir presents an example of wingerl seeds.

(4.) Animals help to distribute seeds and fruits in a variety of ways. Many fruits are provided with hooks, and some with sticky hairs, by which they become attached to the coats of animals. Such cases are found among plants low in stature, where alone they would be useful. The calyx of forget-me-not and fruits of burdock and cleaver are common British examples. In Plumbago the calyx with its viscid glandular hairs (p. I I 2) persists and answers the same purpose.

Succulent frivits appear to be especially adapted by their colour, scent, and edibility to attract animals, particularly birds. The well-protected seeds they contain are able to resist digestion, and are, doubtless, frequently transported to considerable distances.

Small portions of earth containing seeds must also frequently became attached to various animals.

Germination.-This simply means the development of a seerl into a young plant up to a period when it is able to obtain food from the exterior. The embryo contained in a seed is in a dormant state, and if the conditions are unfavourable, may so remain for a considerable length of time. A seed when kept damp and exposed to the air will germinate if the temperature is suitable (say about $35^{\circ}$ centigrade). Take, for example, an exalbuminous seed, like that of bean. The contained embryo first swells and bursts the seed-coat. The radicle elongates, and then the plumule, at first strongly curved, raises itself from between the cotyledons and rapidly grows. The cotyledons remain within the seed-coat, and here simply serve as stores of reserve materials, 
which are gradually converted into the soluble form, and diffuse into the young plant, forming its first nutriment. Active respiration here takes place, carbon dioxide being given off in considerable quantities. Hence the necessity for air, or rather for the free oxygen which it contains. Acorn, peu, and most forms with large cotyledons, germinate like the bean, and in nature the cotyledons remain below ground, enclosed in the seed-coat. Such germination is therefore called hypogean. It is to be noted that only a small part of the so-called radicle is really root. The region between this and the cotyledons is the base of the stem or hypocotyl (figs. 2 and 3 ). Where the cotyledons are small and comparatively poor in reserve materials, as in mustard and cress, they escape from the seed-coat by elongation of the hypocotyl, and becoming green, function as the first leaves. Such germination is epigean (fig. 3 ).

The chief point in which a germinating albuminnss seed differs from the preceding is that the cotyledons (or cotyledon) act as organs of absorption. They remain within the seed-coat, and so influence the reserve materials in the endosperm that they become transformed into the soluble state, when they can readily be absorbed. Castor-oil seeds furnish a good dicotyledonous example. Among monocotyledons grasses (maize, wheat, oat, barley, \&c.) and date may be mentioned. The scutellum ( $c f . \mathrm{P}$. I 33 ) of the former effects absorption, and the radicle and plumule elongate in opposite directions, the former having to break through a layer of tissue known as the root-sheath (fig. 54). In date the tip of the sheath-like cotyledon remains within the seed, while its base elongates considerably, thus pushing radicle and plumule (which latter it surrounds) completely out of the seed. 



\section{A.-APPENDIX ON PRACIICAL WORK.}

THE importance of practical work in Natural Science is now universally admitted, and it is therefore unnecessary to enlarge upon it here. This book is mainly written for students who are anxious to verify the leading facts of Botany, and, in accordance with this end, common plants have been used wherever possible for purposes of illustration.

Practical work in Botany may be considered under the following headings:-I. Description of Plants; II. Anatomi ; III. Histology ; IV. Physiologr.

\section{Description of Plants.}

We are here mainly concerned with the external features, and the apparatus required is of the simplest description: (I.) A sharp penknife is necessary for cutting through stems, buds, flowers, ovaries, \&c., in various directions (pp. 29, 30, 74, 84, and fig. 48). (2.) Dissecting needles, preferably three-sided glovers' needles, mounted in handles, serve for separating out the individual parts of small flowers, \&c. Pieces of fresh twig form useful handles. The blunt ends of the needles are pushed into the pith, and, after a few weeks, contraction of the wood will have fixed them firmly. (3.) A botanical lens is essential for examination of the flower. Without it the placentation (p. IO4), among other things, could not be made out in small flowers. A threefold lens, such as opticians sell for about $3 \mathrm{~s}$., is the best form. For a small sum a stand for this can be obtained, consisting of a vertical rod fixed below to a heary foot-stand. A hole is bored in the fittings of the lens just large enough to admit the rod, and allow of sliding up and down. Both hands are thus left free to dissect with needles, or otherwise, small objects placed on a sheet of white paper. The sliding action permits accurate focussing. It may not be superfluous to point out the right way of using a lens. It should be brought close to the eye, and then near the object, taking care to have a good light. Beginners frequently place the lens near the object, and then try to look through it from some distance, as if they were inspecting a photograph through it large magnifying-glass. (4.) Small pins (sold in shops as "minikins") are useful for fixing down the parts of a flower in the form of a diagram. A piece of thin deal board affords a convenient basis. (5.) A pair of small brass botanical forceps will be found extremely useful, perhaps 
indispensable, in the examination of small objects, or in arranging them on paper. The cost is about Is. (6.) A blank drawing-book (say octavo size) and an $\mathrm{F}$ or $\mathrm{HB}$ drawing-pencil are as important as any of the preceding. More real knowledge is gained by making a careful sketch than by repreated inspection only. It is not necessary to sketch whole plants, but individual parts that present any noteworthy features should be neatly outlined. From an examination point of view, answers illustrated by diagrams are far the best, for mere "cram" rarely enables a student to use these correctly and consistently.

The correct description of an ordinary flowering plant should take from half to three-quarters of an hour. Work of this kind is most valuable in training the eye and cultivating the faculty of accurate observation. Slovenliness must be aroided above all things, and, to ensure methodical work, some settled order of procedure should be adopted. The subjoined scheme may perhaps answer the purpose :-

I. HABiт.-Herb (annual, biennial, or perennial), shrub, or tree (p. 23). Size. General appearance.

II. Root :--

I. Kind (p. I3).-Whether (a.) a tap-root, and if so, relative size of primary and secondary roots; or (b.) mainly adventitious. Note in this case the places of origin. Observe also if special limels of root are present, as aërial, \&e.

2. Branching.-Amount, in I (a).

3. Form.-(a.) Fibrous, made up of numerous unthickened fibres. Chiefly seen in I (a.), e.g., in grasses. (b.) Tuberous, more or less swollen. The primary root itself may be the dilated part, as especially in biemials. The two chief shapes in this case are spindle-shaped (e.y., radish) and napiform (turnip-shaped). Or, again, there may be two or more swellings, formed from secondary or adventitions roots. Note number and shape.

4. Direction.-Which way it ehiefly extends, vertically or horizontally. Angle at which secondary branches come off from primary.

5. Texture.-Herbaceous, succulent, or woody.

6. Surface and Colour.-Smooth, wrinkled, or irregular.

III. STEM :-

I. Kind.-(a.) Aërial (pp. 24-26), or (b.) underground (p. 26). Note the particular sort in either case. Also remark the length of the internodes. If very short, the stem is condensed. Observe whether any branches are developed into runners, \&c., \&c. (p. 25). If any of the modifications described on p. 27 are present, mention them.

2. Branching.-See pp. 24 and $47-48$.

3. Form.-Cylindrical, square, \&c. (p. 23). Note if the nodes are swollen.

4. Direction.-Erect, \&e. (pp. 25-26).

5. Texture.-As for root. Also cut through longitudinally, and determine whether solid or fistular (p. 23).

6. Surface and Colour.- Smooth, ridged (in this case number and relative size of ridges), or rough. State as regards emergences and hair structures (p. 28). Form a judgment as to use of these (pp. 26, 4I). Green, brown, \&c. 


\section{Folitage Leaf :-}

I. Composition.-(a.) Stalked or sessile (p. 52). (b.) Stipulate or exstipulate (i.e., without stipules). (c.) With sheath or without. (d.) Simple or compound (in this case the kind) (pp. 59-6r).

2. Arrangement.-(a.) In the bud (chap. v.). First note distribution of the buds and then the way in which the leaves are packed in them. (b.) If radical, cauline, or both (p. 24). (c.) Horizontal, vertical, or equitant (pp. 54-55). (d.) Phyllotaxis (pp. 49-5I). Look out for bili teral arrangement (p. $5 \mathrm{I})$.

3. Petiole (and leaflet stalks in compound leaf).-(a.) Relative length. (b.) Form, whether grooved above, winged, \&c. Note whether a pulvinus is present (p. 53). (c.) Surface and colour. See Stem. (d.) Modifications (pp. 53-54).

4. Lamina.-Average specimens should be selected. Radical and cauline leaves often need separate descriptions. Treat the leaflets of compound leaves like the blades of simple leaves, noting also whether there are striking differences between the leaflets in the same compound leaf.

(a.) Size. (b.) If tubular, cylindrical, or oblique (p. 55), mention it. (c.) Venation (pp. 55-57). Note if veins project on under side. (d.) General shape (pp. 57-58). (e.) Batse; practicaliy included under (d.), as many of the terms on $\mathrm{p} .58$ are due to its modification. $(f$.$) Aper;$ the same remark is true as for base. Special terms are also used, as acute, tapering evenly to a point (fig. I8); acuminate, suddenly tapering to a point (fig. 26) ; mucronate, ending in a short hard point (Galium); obtuse, suddenly rounded off ; emarginate, with a shallow notch; retuse, with a deep notch. The last form graduates into obcordate. (g.) Murgin (pp. 58-59, footnote p. 28). Note also that the margin may be rary and spiny (both in holly). (h.) Texture (p. 62). (i.) Surface and colour (p. 62). See Stem. Note differences between upper and lower surfaces. A bluish-green colour, caused by wax-particles, is termed glancous (e.g., white poppy). (k.) Modifications (p. 6I).

5. Sheath.-(a.) Relative size. (b.) Whether forming a complete tuhe or not. (c.) Texture.

6. Stipules.-(a.) Arrangement (pp. $\left.6_{3}-64\right)$. (b.) Texture, foliaceous or membranous.

V. Scale Lieaf (p. 64):-

I. Arrangement.-(a.) On overground buds. (b.) On underground parts of stem.

2. Form.

3. Texture.

4. Surface and colour.

\section{Inflorescence and Bracts (pp. 75-8o) :-}

I. Position.-Terminal or axillary.

2. Kind and Size (including number of flowers).

3. Branching.-Its amount.

4. Direction.-Erect, spreading, pendent, \&c.

5. Peduncles and Pedicels.-Describe as stem.

6. Bracts.-Describe like foliage leaves. 
VII. The Flower :-

I. Symmetry (p. So).

2. Floral receptacle (p. 8I).

3. Relation of parts. - Shown by a floral diagram (p. \&2).

4. Calyx.

5. Corolla.

6. Androcium; and

7. Gyncecium.-Described under five headings, preferably in a table or schedule.

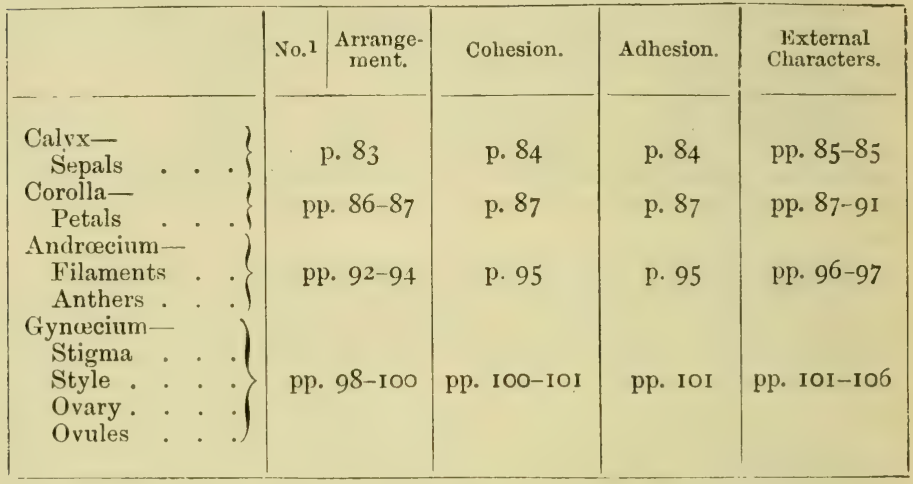

In the case of unisexual flowers two schedules will be required.

8. Nectaries.

9. Protection and Cross-Pollination.-Endeavour to make out some of the arrangements described in Chapter IX.

\section{Fruit And SeEds :-}

I. Kind of Fruit (pp. 135-139).

2. Number and Arrangement of Seeds (cf. pp. 104-106).

3. Protection and Distribution of Seeds. - Try to identify some of the methods described on Pp. I40-I 42.

iX. Classification.

Remarks on Preceding Headings.-The beginner will undoubtedly find considerable difficulty in attempting plant description. It is better to make a preliminary study of roots, stems, \&c., \&c., before trying entire plants. Above all things, never describe an absent part, about which you happen to know something. Technical terms will be gradually acquired, but in default of them use ordinary language, as tersely and clearly as possible.

I. Haвiт.-A judgment as to the kind of plant has often to be formed rom a small part of it. A woody stem points to a perennial, and if a cross-section shows annual rings (p.38), this is certain. Leathery leaves generally belong to perennial evergreens. On the other hand, an isolated

${ }^{1}$ A large number is indicated by $\infty$. 
herbaceous stem proves nothing. A rhizome (p. 26) belongs to a perennial. A dilated succulent tap-root generally indicates a biennial.

II. Rоoт.-If an underground structure possesses scale leaves, buds, or chlorophyll, it does not belong to the root at all, but to the stem.

III. StEx.-See last paragraph. In the examination of corms and bulbs, note the appearances made by cutting through them in the middle ; $(a$. ) from above downwards, $(b$. ) across. The difference (p. 26) between the two kinds of structure will readily be seen, and buds can also be detected in the typical situations. As examples of bulb, take onion, lily, and hyacinth ; for corms, examine crocus, colchicum, and cyclamen (sold as "bulbs" by florists).

\section{Foliage Leaf :-}

I. Composition.-Remember that stipules may fall off early (p. 64), and therefore do not put exstipulate unless young leaves are present. Say rather, "apparently exstipulate."

Note that there may be great variation in the foliage leaves of the same plant.

2. Arrangement.-Satisfy yourself that so-called "radical" leares really arise from a condensed lower part of the stem. Take, for example, an entire daisy plant, and halve it with a knife. The crowderl nodes can then be made out. No root possesses nodes and internodes. Remember that adventitious root-fibres are, as a rule, given off from all underground structures.

Arrangement in Bud.-Relative arrangement of leaves is seen by cutting across (footnote, p. 84). The arrangement of individual leaves (footnote, p. 49) is partly shown by the same method, partly by cutting through the bud longitudinally, and also by separating the individual leaves. The following are examples of the terms used for foliage leaves:-Imbricate, grasses and sedges; plaited, maple and currant; conduplicate, bean and oak; inflexed, tulip-tree; coincolute, cherry and apricot; involute, violet and waterlily ; revolute, sorrel and rosemary ; circinate, sundew and ferns. The remaining terms in the footnotes are used in the case of flower buds. Note if the young leaves are protected by down (p. 67).

Phyllotaxis.-To determine the divergence (p. 50) take any leaf, call it $\mathrm{I}$, and mark it. Then find the next leaf which comes inmediately above it, say the gth. 9-I=8, the number of leaves in the crcle, and denominator of the divergence fraction. Terify this by determining the number of ranks or longitudinal leaf-rows. This should be 8 . Suppose also that it is necessary to go three times round the stem in passing from I to 9 . This gives the numerator of the fraction, which is therefore $\frac{3}{8}$ (compare fig. 9).

V. Scale Leaf.-In the case of the bud, try to find the relation between the scales and young foliage leaves, and prove what region they represent (p. 64). Observe whether blastocolla is present.

In the case of underground scale-leaves, observe whether thickened as storage organs. Look for axillary buds, e.g., in a potato.

VI. Inflorescexce and Bracts.-Note the position of the youngest flowers. If these are at end (figs. 3 I and 32) or in centre (e.g., daisy and carrot), the inflorescence is centripetal, indefinite, or racemose. If 
the oldest flowers are in the above position (fig. 35), the inflorescence is centrifugal, definite, or cymose.

VII. The Flower :-

2. Receptacle.-Cut through the flower longitudinally, and determine whether the flower is hypogynous, perigynous, or epigynous (fig. 37). The receptacle is often very much shallower than in B; as, for example, in gorse and sweet-pea.

3. Relation of Parts, as shown in a floral diagram. Take fig. 38 as a model. Note position of axis, denoting back of flower. In a bilaterally symmetrical flower, rising, like a pansy, from a condensed stem, the back is above and the front below. A flower may be more or less twisted round, especially in orchids (p. 89).

Note carefully whether there is an anterior or posterior sepal (p. 82). Make a good-sized drawing (say three times as big as fig. 38 ), and do not crowd the stamens and carpels. When these last are numerous, as in buttercup, do not trouble to count them, but put a fair number of the conventional marks.

It is very useful practice to pin out the parts in the form of a diagram, marking with pencil the front, back, and planes (fig. 38). If the calyx or corolla has its elements cohering, cut it into longitudinal pieces between the lobes or teeth, and lay them out as if originally separate.

A floral formula can be made to express a great deal. Thus the diagram in fig. 38 can by represented by

$$
\mathrm{Ca}_{3}, \mathrm{Co} 3, \mathrm{An} 3+3 \text {, Gin }
$$

Ca. $=$ calyx ; Co. $=$ corolla $;$ An. = androecium ; Gn. = gynœcium. A parenthesis ( ) signifies cohering parts. In the ease of the gynœcium, a line below means superior, a line above inferior. Superposition between the whorls is indicated by $\mathbf{|}$. Thus, in primrose :-

$$
\mathrm{Ca}(5), \mathrm{Co}(5) \mid \mathrm{An} 5 \text {, Gn } \stackrel{(5)}{\text {, }}
$$

or I can be omitted if An o + 5 is inserted.

Other typical formulie are :-

Buttercup:-

$$
\begin{aligned}
& \text { Ca } 5 \text {, Co } 5 \text {, An } \sim \text {, Gn } \infty \sim \sim_{0} \\
& \text { (Here } \sim=\text { spirally arranged.) }
\end{aligned}
$$

Carrot:-

$$
\text { Ca } 5 \text {, Co } 5 \text {, An } 5+\text { o, Gn (2). }
$$

Orchis :-

Most Grasses :-

$$
\mathrm{Ca}_{3}, \mathrm{Co}_{3}, \mathrm{An} \mathrm{I}+\mathrm{o}, \mathrm{Gn}_{(\overline{3})} \text {. }
$$

$$
\mathrm{Ca} \text { o, } \mathrm{Co}_{2}, \mathrm{An}_{3}+\mathrm{o}, \mathrm{Gn}(2) \text {. }
$$

The o signifies suppression of a whorl.

4. Calyx.- $\left\{\begin{array}{c}\text { For arrangement in bud, see footnotes pp. } 49 \text { and } 84 . \\ \text { See also iv. 2. Remaining terms in footnotes : open, }\end{array}\right.$ 5. Corolla.- $\{$ petals of mignonette ; valvate, sepals of fuchsia ; obvolute, petals of fuchsia; crumpled, petals of poppy. 
6. Andracium.-When the stamens are double the number of the petals, both the typical whorls are present (p. 8z). If equal in number, the inner stamens have generally been suplyressed (see above, formulite for carrot and grasses). More rarely (see formula for primrose) the outer stamens are suppressed. It is easy to tell which whorl is left, for the outer stamens alternate with the petals, while the inner ones are superposed to them. If the stamens are fever than the petals, they usually represent part of the outer whorl (see formula for orchis).

7. Gynccium.-This is typically composed of two whorls of carpels, but do not put o to represent the usually suppressed whorl, as it is not possible in many cases to tell easily which whorl is suppressed. Thus the formula for gorse is properly (p. 103)-

$$
\mathrm{Ca}(5) \text {, Co } 5 \text {, An }(5+5) \text {, Gn } 1+0 \text {, }
$$

but it is enough to write Gn I.

Superior and Inferior.-If, as in hypogynous and perigynous flowers, the ovary is free, term it superior ; if, as in epigynous flowers, adherent to the cup-shaped receptacle, inferior.

Placentation.- In must cases a transverse cut will show this. If not, divide another specimen longitudinally. This will show erect and ascending ovules. Determine the number of orules if a few only are present. When they are very numerous, write indefinite $(\infty)$.

8. Nectaries.-These vary immensely in size, nature, and position. They may be mere points, streaks, or surfaces where nectar is excreted, but, on the other hand, may be conspicuous projections. They are so placed that the stigma, or anthers, or both, must lue touched before an insect can reach them. The chief situations are :-(a.) on receptacle (wallflower, willow, mignonette); (b.) as a spur to calyx (garden nasturtium); (c.) on corolla, as glandular spots (buttercup), or spurs (larkspur); (d.) on andracium (pansy, fig. $5 \mathrm{I})$; (e.) on ovary (dead nettle).

9. Protection and Pollination.-- Nute characteristics of wind-pollinated and insect-pollinated flowers (pp. i I 5, I IS). Do not immediately conclude that an inconspicuous flower is wind-pollinated, for it mas make up, for want of brilliancy by the possession of nectar (e.g., willow and lime) or scent (e.g., lime). If flowers are present in all stages, it is easy to determine whether proterandry or proterogrny obtains. The stamens will be dehiscing, in the former case, in rery young fiowers ; vice versu in the latter case.

VIII. Fruits And Seeds.-First master the main divisions of the table on pp. 136-139, and then attack the sub-divisions, examining for yourself as many of the examples as you can get. For dehiscence very ripe fruits are necessary.

Spurions fruits will give little trouble. All the common kinds are described on pp. 136-139.

Arrangement of seeds in the fruit is determined like that of ovules in the ovary (see above).

For the structure of seeds examine the types described on $\mathrm{pp}$. $132-134$.

IX. Classificatiox.-First determine the sub-division, class, subclass, and series, by means of the following table. Remember that here are no sharp loundary-lines in Nature, so that a plant need not 
necessarily possess all the characters of the group to which it belongs. The balance of evidence must be taken. Classify by means of what is present in your specimen.

\section{FLOWERING PLANTS}

possess seeds, and, usually, conspicuous flowers.

\section{Sub-division I.-GyMnOSPERMS.}

Ovules not enclosed in an ovary, but situated either on the axis or on open carpels. Stamens scale-like, with pollen-sacs on their under side. Perianth almost always absent. Endosperm of seed formed before fertilization.

Exs.-Yew, pine, fir, larch, cedar, araucaria, cypress, juniper.

\section{Sub-division II.-ANGIosperms.}

Ovules enclosed in an ovary. Stamens not scale-like. Perianth generally present. Endosperm formed after fertilization.

\section{CIASS I.-MONOCOTYLEDONS.}

Roots adventitious, the radicle of embryo being arrested in development. Stem with scattered closed vascular bundles. No wellmarked distinction between pith, cortex, and medullary rays. No bark. Leaves frequently possess a sheath; parallel-veined. Flower with parts in 3's or a multiple of 3. Calyx and corolla generally much alike. Seed, embryo with one cotyledon; endosperm generally abundant.

\section{Sub-class 1.-Nudifloræ.}

Perianth o or scaly. Ovary superior.

Series (I).-Spadiciflore.

Flowers generally in a spike or spadix. Series (2).-Glumiflorce.

Flowers in heads or spikelets. Bracts scaly, and known as glumes. Perianth, when present, of scales or bristles.

\section{Sub-class 2.-Petaloideæ.}

Flowers usually bisexual. Perianth always present, and generally brightly coloured.

Series (I).-Hypogyno. Ovary superior.

Series (2).-Epigyno. Ovary inferior.

\section{Class II.-DICOTYLEDONS.}

Root frequently a tap-root, i.e., with main axis formed by developed radicle of embryo. Stem, when young, with a circle of open vascular bundles, pith, medullary rays, and cortex ; when older, with annual rings of wood, formed by cambium ring, and separ- 
able bark. Leaves generally without a sheath, net-veined. Flowers with parts in 4's or 5's, or a multiple of those numbers. Calyx and corolla usually unlike. Seed, embryo with two cotyledons ; endosperm often absent.

\section{Sub-class I.-Incompletæ.}

Flowers often unisexual. Calyx inconspicuous or o. Corolla, o.

Series (I).-Hypogynce. Ovary superior.

Series (2).-Epigynce. Ovary inferior.

\section{Sub-class 2.-Polypetalæ.}

Flowers generally bisexual. Calyx and corolla both present, as a rule, the latter polypetalous, and generally bright coloured. Series (I).- Thalamifloro.

Flower hypogynous. Stamens often numerous. Series (2).-Calyciflorce.

Flower perigynous or epigynous. Calyx generally gamosepalous.

\section{Sub-class 3.-Gamopetalæ or Corollifloræ.}

Flowers generally bisexual. Calyix generally present, gamosepalous. Corolla generally present, gamopetalous, and, as a rule, brightly coloured. Gyncecium usually syncarpous.

Series (I).-Hypogynce.

Ovary superior. Stamens mostly epipetalous. Series (2).-Epigyno.

Ovary inferior.

Having determined the sub-division, class, sub-class, and series to which a plant belongs, the next step is to find its natural order or family. The following table will enable this to be effected. Details are not given of Gymnosperms, and as there are some ninety natural orders represented among British Angiosperms, only the most imiportant of these can receive notice.

\section{CLASS II.-MONOCOTYLEDONS.}

\section{Sub-class I.-Nudifloræ.}

Series (I.)-Spadiciflorce.

Order I.-Aroidaceæ.-Herbs. Leares, net-reined (N.B. exception to rule). Inflorescence, a spadix, often surrounded by a large spathe. Fruit, a berry. Exs.-Arum, arum lily (Richardia).

Order 2.-Lemnaceæ.-Minute aquatic herbs. Stem, a disc. Leaves, o. Flowers, monœcious. Stamens, I. Carpels, I. Exs.-Duckweeds (Lemna and Wolfia).

Order 3.-Typhaceæ.-Erect marsh plants. Inflorescence, spadix without a spathe. Flowers, monœcious, male inflorescences upper- 
most. Perianth, o, or of hairs or scales. Stamens, generally two or three.

Exs.-Bur-reed (Sparganium), bulrush.

Series (2).-Glumifloro.

Order 1.-Graminaceæ.--Stem, fistular, swollen at nodes. Leaves, with a split sheath, and usually a ligule; divergence $\frac{1}{2}$. F'lowers, usually bisexual. Embryo, on one side of endosperm.

Exs.-Grasses.

Order 2.-Cyperaceæ-Grass-like herbs. Stem, solid. Leaves, with a tubular sheath and no ligule; divergence ?. Embryo, enclosed in endosperm.

Exs.-Sedges.

\section{Sub-class 2.-Petaloideæ.}

Series (I).-Hypogyna.

Order I. - Liliaceæ-Mostly herbs. Flower's, regular. Floral formula, generally $\mathrm{Ca} 3$, $\mathrm{Co}_{3}$, An $3+3$, Gn (3). Placentation, axile. Fruit, a capsule or berry.

Exs.-Lily, hyacinth, tulip, onion, garlic, leek, asparagus, butcher's broom (a shrub).

Order 2.-Juncaceæ.-Grass-like herbs. Leate's, cylindrical. Flowers, inconspicuous and regular. Sepuls and petals, brown and scalelike. Floral furmula, as Liliacex. Fruit, a capsule. Exs.-Rushes.

Series (2).-Epigyna.

Order I. - Iridaceæ.-IIerbs. Stem, forming bulb, corm, or rhizome. Leaves, equitant. Floral formula, $\mathrm{Ca} 3, \mathrm{Co} 3, \mathrm{An} 3+\mathrm{o}, \mathrm{Gn}(\overline{3})$. Placentation, axile. Fruit, a 3-chambered loculicidal capsule. Exs.-Iris, crocus, gladiolus.

Order 2.-Amaryllidaceæ.-Herbs. Stem, bulbous. Flowers, usually regular. Floral formula, usually as Liliacere. but Gn (s). Placentation, axile. Fruit, generally as in Iridaceæ.

Exs.-Snowdrop, daffodil, narcissus.

Order 3.-Orchidaceæ-IIerbs. Roots, tuberous. Inflorescence, a spike or raceme. Flowers, irregular, twisted completely round. Floral formula, usually Ca 3 , Co 3 , An I + o, Gn $\frac{131}{31}$. Perianth generally spurred. Stamen, cynandrous. Placentation, parietal. Fruit, a r-chambered loculicidal capsule. Exs.-Orchids.

\section{Chass III.-DICOTYLEDONS.}

\section{Sub-class 1.-Incompletæ.}

Series (1).-Hyроgynж.

Order I.-Urticaceæ.-Herbs or shrubs, frequently covered with stinging hairs. Flowers, unisexual. Calyx, regular, with four or five divisions. Stamens, superposed to the sepals. Ovule, single, straight, erect. Exs.-Nettles. 
Order 2.-Amentaceæ.--Trees or shrubs. Leaves, scattered. Inflorescence, catkins. Flowers, unisexual. Male and female flowers arranged in different catkins. Gynœcium, syncarpous. Carpels, 2 .

Exs.-Willow, birch, alder.

Order 3.-Chenopodiaceæ.-Herlus. Leaves, exstipulate. Flowers, small, green, regular, bisexual. Calyx, 5-lobed. Stamens, superposed to sepals. Gynocium, syncarpous. Carpels, 2.

Exis.-Goosefoot (Chenopodium), spinach, beetroot.

Order 4.-Polygonaceæ.-Herbs. Stem, dilated at the nodes. Leaves, scattered, with ochreate stipules. Flowers, small, regular, generally bisexual. Sepals, 4 to 5 . Stamens, superposed to sepals Gynocium, syncarpous. Carpels, 3. Ovule, single, straight, erect. Exs.-Knotgrass, dock, sorrel, rhubarb.

Series (2).--Epigynce.

Order I.-Cupuliferæ.-Shrulss or trees. Leuves, scattered, stipulate. Flowers, small, green, unisexual. Male flowers in catkins. Female flowers surrounded by bracts. Fruit, a nut. Exs.-Oak, beech, hazel, hornbeam.

Series (I.)-Thalamiflorce.

\section{Sub-class 2.-Polypetalæ.}

Order I.-Ranunculaceæ.-Generally herbs. Learez, usually scattered. Stcmens, indefinite, spirally arranged. Gynocium, apocarpous. Carpels, generally indefinite and spirally arranged. Fruit, generally an achene or follicle.

Exs.-Clematis, anemone, buttercup, lesser celandine, Christmas rose, marsh marigold, larkspur, monk's-hood, pæony.

Order 2.-Papaveraceæ.-Herl)s with milky juice. Leures, scattered, exstipulate. Flowers, regular. Sepals, 2, usually caducous. Petals 4. Stamens, indefinite, arranged in alternating whorls. Gynocium, syncarpous. Placentation, parietal.

Exs.-Poppy, greater celandine, Californian poppy (Eschscholtria).

Order 3.-Cruciferæ.-Herhs. Leaves, scattered, exstipulate. Inflorescence, a raceme without bracts. Flovers, generally regular. Sepals, 4 , in two whorls. Corolla, cruciform. Petals, 4 , alternating with sepals, and placed obliquely (see fig. 38 ). Stamens, tetradynamous, in two whorls. Gynocium, syncarpous. Carpels, 2, lateral. Fruit, a siliqua.

Exs.-Wallflower, stock, watercress, eabbage, turnip, horseradish, radish, shepherd's purse, candytuft.

Order 4.-Violaceæ.-Herbs. Leaves, scattered, stipulate. Flowers, irregular. Floral formula, Ca 5, Co 5, An 5, Gn (3). Petals, the odd anterior (lower) one with a spur. Stamens, two lower ones with nectaries. Placentation, parietal. Fruit, a loculicidal capsule.

Exs.-Violet, pansy.

Order 5.-Caryophyllaceæ-Herbs. Stem, usually swollen at the nodes. Leares, decussate. Inflorescence, cymose. Flowers, regular, 
parts usually in 5's. Placentation, generally free-central. Fruit, usually a capsule.

Exs. - Chickweed, stitchwort, campion, ragged-robin, pink, earnation.

Order 6.-Malvaceæ.-Undershrubs or herbs. Leaves, scattered, stipulate. Flovers, regular. Calyx, frequently with epicalyx. Stamens, monadelphous, branched. Gynocium, syncarpous. Fruit, a split-fruit with numerous parts.

Exs.-Mallow, hollyhock.

Order 7.-Geraniaceæ.-Herbs. Floral formula, Ca 5, Co 5, An 5+ 5, Gn (5). Ovary, with a beak-like projection. Fruit, a split fruit. Exs.-Geranium, pelargonium.

Series (2).-Calyciflorie.

Order I.-Leguminosæ-Leaves, usually scattered, compound, and stipulate. Flowers, perigynous, and generally irregular. Sepals, 5, the odd one anterior. Corolla, usually papilionaceous. Stamens, generally ı, mon- or diadelphous. Gynocium, superior. Carpels, I, anterior. Fruit, a legume.

Exs.-Gorse, broom, lupin, laburnum, clover, bird's-foot trefoil, vetch, bean, pea.

Order 2.-Rosaceæ.-Leares, scattered, usually stipulate. Flowers, perigynous, regular. Sepals, generally 5 , the odd one posterior. Stamens indefinite. Gynocium, apocarpous, superior.

Exs.-Rose, meadow-sweet, japonica, peach, apricot, plum, cherry, laurel (cherry 1.), sloe, lady's mantle, cinquefoil, strawberry, raspberry, blackberry, hawthorn, pear, apple, mountain ash (rowan).

Order 3.-Onagraceæ-Herbs or shrubs. Leares, exstipulate. Flowers, epigynous, usually regular; parts in 4's. Calyx, often petaloid, with a long tube. Gynocium, syncarpous, superior. Placentation, axile. Fruit, a capsule or berry.

Exs.-Willow herb, evening primrose, enchanter's nightshade, fuchsia.

Order 4.-Umbelliferæ.-Herbs. Stem, generally fistular. Leaves, scattered, exstipulate, sheathing at base, generally deeply divided. Inflorescence, an umbel. Flowers, epigynous, usually regular. Floral formula, Ca 5, Co 5, An 5, Gn (2). Calyx, very small. Fruit, a splitting-fruit, dividing into two.

Exs.-Hemlock, celery, carraway, fennel, coriander, parsley, parsnip, carrot.

\section{Sub-class 3.-Gamopetalæ or Corollifloræ.}

Series (1).-Hypogynce.

Order I.-Boraginaceæ.-Hispid herbs. Leaves, scattered, entire, exstipulate. Inflorescence, cymose, helicoid. Flowers, generally regular. Floral formula, Ca 5, Co 5, An 5, Gn (2). Stamens, epipetalous. Carpels, lateral. Ovary, 4-lobed. Fruit, a splitting fruit, separating into 4.

Exs.-Bugloss, borage, comfrey, forget-me-not. 
Order 2.-Solanaceæ.-Usually herbs. Leares, exstipulate. Inflorescence, cymose. Flowers, usually regular, with parts (except gynœcium) in 5's. Stamens, epipetalous. Carpels, 2. Placentation, axile. Fruit, a berry or capsule.

Exs.-Bittersweet, potato, winter cherry, tomato, Chili pepper, deadly nightshade, tobacco-plant, petunia, thorn-apple, henbane.

Order 3.-Scrophulariaceæ.-Herbs. Flowers, more or less irregu. lar. Stamens, 4 (didynamous), 2, or (in mullein) 5 ; posterior stamen absent, except in last case. Carpels, 2. Placentation, axile. Ovules, numerous. Fruit, usually a capsule.

Eas.-Mullein, snapdragon, toad-flax, musk, calceolaria, pentastemon, foxglove, figwort (Scrophularia), speedwell, yellow rattle.

Order 4.-Labiatæ.-Herbs. Stem, square, fistular. Leares, decussate, aromatic. Inflorescence, apparently in whorls, really cymose (in verticillasters). Flowers, irregular. Calyx and Corolla, 2lipped. Stamens, 4 (didynamous), or, more rarely, 2 ; posterior stamen always absent ; epipetalous. Carpels, 2. Ovary, 4-lobed and 4-chambered. Placentation and Ovules, one erect ovule in each chamber of the ovary. Fruit, as in Boraginaceæ.

Exs.-Basil, lavender, mint, marjoram, thyme, sage, rosemary, ground ivy, dead nettle, horehound.

Order 5.-Primulaceæ.-Herbs. Leares, simple, exstipulate. Flover's, regular. Floral formula, Ca 5, Co 5 I An 5, Gn (5). Stamens, epipetalous. Placentation, free central. Fruit, a capsule.

Exs.-Primrose, cowslip, polyanthus, auricula, cyclamen, scarlet pimpernel.

Series (2.)-Epigynce.

Order I.-Dipsaceæ-Herbs. Leares, opposite, exstipulate. Inflorescence, a dense head; surrounded by an involucre. Flowers, small (florets); outer ones generally ligulate. Calyx, usually reduced to scales or bristles; surrounded by a cup-like epicalyx. Stamens, epipetalous; quite free from one another. Carpels, 2. Style, unbranched. Ovary, with one chamber. Placentation and Ovules, one suspended ovule. Fruit, a cypsela.

Exs.-Teasel, scabious.

Order 2.-Compositæ.-Herbs, often with milky juice. Leares, usually scattered; exstipulate. Inflorescence, a dense head, surrounded by an involucre. F'lowers, small (florets); outer ones often female or neuter. Calyx, when present, reduced to scales or hairs (pappus). Stamens, epipetalous, syngenesious. Carpels, 2. Style, forked. Ovary, with one chamber. Piacentation and Ovules, one erect ovule. Fruit, a cypsela.

Exs.-Colt's-foot, aster, daisy, groundsel, oxeye daisy (marguerite), chamomile, sunflower, Jerusalem artichoke, dahlia, dandelion, lettuce.

Order 3-Campanulaceæ.--Usually herbs, with milky juice. Leaves, scattered, exstipulate. Flowers, usually regular, parts (except gynocium) in 5's. Corolla, bell-shaped. Stamens, often 
united at base. Carpels, generally 3. Placentation, axile. Fruit, a capsule.

Exs.-Harebell, Canterbury bell.

II.-Anatomy.-Root (p. 14). Stem (p. 29).--Try to follow, mainly by longitudinal slicing, the course of the bundles in a piece of asparagus stem ( $c f$. fig. 5, C). Leaf.-The distribution of vascular bundles is plainly seen in most herbaceous forms, and may be rendered still more plain by bleaching in spirit, and then soaking in chloral hydrate. Compare the distribution in monocotyledons and dicotyledons.

III. Histology.-A compound microscope is necessary for this. Browning's field-microscope, shown in fig. 6I, will answer the purpose

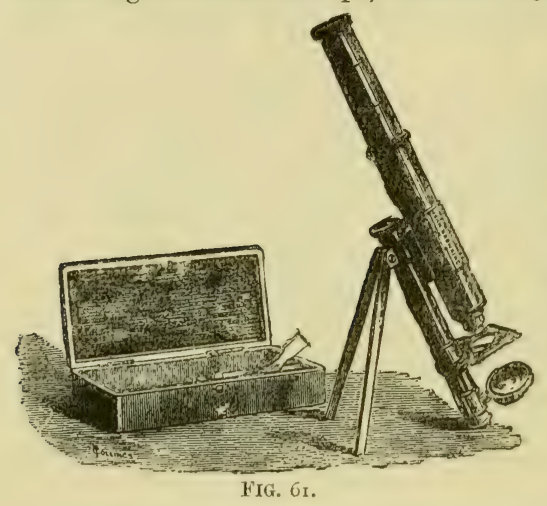
for a beginner, and even if a larger microscope is afterwards purchased, will always be useful for carrying about. It consists of a stand, eyepiece, and objectives. The stand is supported by three legs, and carries a sliding tube above, and a perforated plate or stage below, upon which the object to be examined is placed. Below the stage swings a small concave mirror, from which light ean be reflected upwards through the aperture. The eyepiece slips into the upper end of the tube, while the objective screws into the lower end. Objectives are named, according to the distance at which they must be placed from the object, two-inch, inch, half-inch, quarter-inch, \&c., \&c. Inch and half-inch objectives will be sufficient for elementary purposes, and will be called low power and high pover in the rest of this Appendix. The price of Browning's field-microscope, with one eyepiece and the two oljectives named, also with case and forceps (as in figure), is $\mathcal{L}_{2}$, Is. 6d. Suitable glass slips (say two dozen) and cover-glasses ( $\frac{1}{2} 0 \%$ of small squares) can be obtained for a small sum of the same maker. ${ }^{1}$

We may examine objects in two ways: (1) by reflected light; (2) by transmitted light. It is perhaps easier to commence with the former.

(I.) Opaque objects are best suited for viewing with reflected light. Pollen grains (preferably of mallow or hollyhock), small seeds, or that bits of leaf with hair structures are good examples. Place one of these objects on a piece of black paper on the centre of a glass slip. Screw on the low power, and pull out the inner half of the mieroscope tube till a groove upon it is seen. Put the slip under the two spring-clips of the stage, and turn the mirror so that it reflects no light through the hole. To focus, slide down the tube near to the object, apply the eye to the eyepiece, and slide up the tube till the object is seen. This sliding action is the coarse adjustment. The fine adjustment is brought into

\section{63 Strand, London, S. W.}


action by turning a screw at the back of the tube frame. A good light is, of course, necessary. Now remove the low power and follow the same course with the high one. A higher magnification can be effected by pulling out the inner part of the microscope tube further than the groove.

(2.) Objects when viewed by transmitted light require more elaborate treatment, and the following additional apparatus will be required :(a.) A rusor for section eutting. A shilling army-razor will answer perfectly well. (b.) Some pieces of elder pith. (c.) Half a dozen watchglasses. (d.) A small camel's-hair Lrush. (e.) Half a pint of methylated spirit, an 8-oz. bottle of glycerine, and the following reagents put up in I-oz. phials, through the corks of which pieces of glass rod are passed (any chemist will do this) :-Dilute glycerine (half glycerine, half water), iodine solution (dilute the liquor iodi of chemists to a dark-sherry colour), magenta solution (Judson's magenta dye diluted to port-wine colour), caustic pctash solution (five per cent.), and strong sulphuric acid.

Take, for example, a small piece of a delicate leaf treated with chloral hydrate, a daisy floret torn open, some pollen, or a bit of epidermis pulled from the lower surface of a geranium leaf. Now, with a glas: rod place a small drop of dilute giycerine in the centre of a slide, put the object in the drop, and cover with a cover-glass. One edge of this should first be made to touch the slide, and the glass then gently lowered with a mounted needle. Now proceed as before, hut, in addition, turn the mirror so as to reflect light upwards through the object. N.B.Perfect cleanliness is necessary in all microscopic work. The microscope lenses should be kept clean with a piece of new wash-leather, while rover-glasses are cleansed hr rubling them gently with a piece of old silk between the thumb and forefinger. Of course they should first be washed in water if smeared with glycerine, \&c.

Transmitted light is most useful for thin sections of root, stem, leaf, anther, ovary, \&c. These should be preserved in methylated spirit, and placed in a half and half mixture of this and glycerine for twenty-four hours before required. Small ohjects may be held in a slit in a piece of elder pith, while leaves can be rolled up. There is no roval road to section cutting, and nothing but practice will give the requisite skill. A few hints may, howerer, prove useful. Hold the object firmly in the left hand, and, grasping the middle of the razor firmly with the right, its edge uray from you, make a steady diagonal sweep from the base of the blade. Do not push or saw. The razor should be kept wet with water for fresh objects, with spirit for spirit specimens. With a sharp razor the veight of the blade should be sufficient to carry it through if a slight swing is given. Many prefer to cut torrerds them, using the first finger of the left hand as a support for the razor-blade. A number of sections should be made, and placed in a watch-glass containing dilute glycerine. From this the thinnest can be picked out with the brush and mounted as before. A piece of black paper placed beneath the watchglass will enable the sections to be seen more clearly. Do not be contented till your sections are so thin that the corer-glass will lie quite flut, and so transparent that all the details can be made out with the high power.

In many cases sections are made clearer by staining, since different elements are affected differently. This process is conveniently effected 
by placing the sections, as cut, in a watch-glass holding the reagent, transferring after a time to dilute glycerine. Reagents can also be added to a mounted section by placing a small drop on one side of the cover-glass, and drawing it under by means of a pointed fragment of blotting-paper placed on the other side. Iodine colours protoplasm and sieve-tube slime brownish yellow, cuticularized and lignified cell-walls yellow, cellulose pale yellow, and starch blue. Magenta stains generally, but colour's the protoplasm most deeply. If an object is mounted in iodine, and a drop of strong sulphuric acid run under the cover-glass, the cellulose walls will be coloured blue.

Sections can be cleared, i.e., rendered more transparent, by mounting in causti: potash solution. This method is especially useful in the case of roots.

In all the preceding cases it is essential to mount the object in a very small drop of liquid, just enough to spread out under the coverglass. If too much is taken, the inclined stage (if the field-microscope is used) will cause the cover-glass to slide off.

Students who wish to learn a little vegetable histology, but have no time to make their own sections, can obtain for ros. 63 . a set of fifteen permanent slides, illustrating the ehief points, from Mr. Arthur Shrubbs, Cambridge.

\section{Physiology.}

I. Plant Food.-Germinated beans, grains of Indian-corn, \&c., will flourish in a food solution containing the essential elements (p. Io), provided air and light have access. Such a food solution may conveniently consist of - I pint distilled water, 86 grains potassium nitrate, 43 grains sodium chloride, 43 grains calcium sulphate, 43 grains magnesium sulphate, 43 grains of finely divided calcium phosphate, and a trace of ferric chloride. The omission of any constituent will cause the plants to be sickly and stunted. The carbon dioxide in the air forms part of plant food. See p. 68.

2. Action of Chlorophyll.-Green plants grown in the dark become etiolated (p. 68). See also p. 67 Oxygen is evolved. See pp. 68-69.

3. Transpiration.-See p. 69.

4. Respiration.-The necessity for oxygen is proved by growing plants in nitrogen. They sicken and die. A large wide-mouthed bottle is one-third filled with germinating peas, and closed with a tightly-fitting stopper. After a few hours enough carbon dioxide will have collected to put out a burning candle-end lowered into the bottle.

5. Growth of Pollen-tubes.-See note on p. II 4 .

6. Germination.-Beans, \&c., can be germinated in sand or sawdust, mustard and cress on flannel. They require $(a$.$) water, (b$. $)$ access of air containing oxygen, (c.) a moderately warm temperature. They do not require light, or other food than water, since the cotyledons or endosperm contain a store of nutriment in the form of reserve materials. But when these are used up germination is completed, and food and light become essential.

The growth of shoots from bulbs, corms, and tubers may take place under the same conditions as the germination of seed. 


\section{A P PENDIX B.}

\section{- \\ EXAMINATION QUESTIONS.}

S.K.E. = South Kensington Elementary. S.K.A. = South Kensington Advanced. These questions are chiefly in Subject xv., Elementary Botany; but some are in Subject xvi., Vegetable Morphology and Physiology. L.M.=London Matriculation. L.I.=London Intermediate Science.

\section{Root.}

I. Describe the organs by which a bean-plant absorbs water, and give an account of the process of absorption. (L.I.)

2. Describe the structure, and state what are the functions, of root-hairs. By what means is a root able to absorb from the soil substances which are insoluble in water? (S.K.A.)

3. What is the use of a root? Under what circumstances may plants exist without one? (S.K.E.)

4. What is root pressure? At what period is it most conspicuous? (S.K.A.)
5. What is the chaunel by which the leaves of a plant make up for the loss of water by transpiration? Where does the water come from? (S.K.E.)

6. Explain why the root of a turnip first grows faster than the stem, aud then stops while the stem grows rapidly? (S.K.E.)

7. Describe the way in which roots grow. (S.K.E.)

8. What part of a plant's food is taken up by the roots? (S.K.E.)

\section{Stem.}

9. State the broad facts as to the development of branches. What is the difference between a sympodial and a monopodial branch system? Give illustrations of both cases from the British flora. (S.K.A.)

Io. Explain why a potato is cousidered to be a stem. (S.K.E.)

II. What is the structural difference between a prickle (as in the rose) and a spine (as in the blackthorn)? (S.K.E.)

12. What are the principal modifications of stem structure? (S.K.A.)
I3. State generally what is the composition of a vascular bundle. Describe the longitudinal course of the vascular bundles in the stem of any dicotyledon. (S.K.E.)

I4. What is the nature of the vascular bundles of endogens? (S.K.E.)

I5. Explain precisely what are meant by the terms " pith" and "medullary rays." How do these structures originate? (S.K.E.)

I6. What is the precise nature of bast? In what part of the plant is it to be met with? (S.K.E.) 
I7. What is the cause of the ringlike inarkings seen in the cross-section of a tree-trunk? (S.K.E.)

18. Describe and explain as much of the texture of a deal plank as can be made out with the naked eye. (S.K.E.)

I9. Describe, with diagrams, the primitive structure and the mode of growth in thickness of the stem of a dicotyledonous plant. Why does the stem of dicotyledonous plants usually increase in thickness? (S.K.E.)

20. Explain the modes by which stems may increase in diameter. Point out the causes of the difference between the spring and the autumn wood of dicotyledonous trees with annual growth. (S.K.A.)

21. Explain the difference in the growth of the bark of a tree and that of the wood. (S.K.E.)

22. What is the structure of the cambium; how does it originate in the stem, and to what tissues does it give rise? (S.K.A.)

23. From what source is the starch derived which is stored up in a potato tuber? By what means has it been transported thither? (S.K.E.)

24. State what is the tissue in which water travels from the root to the leaves, mentioning illustrative experiments. (S.K.E.)

\section{Foliage Leaf.}

25. Describe a bud. 'I'o what structures do the outer coverings correspond? What is the origin and use of the resinous secretion with which they are often covered? (S.K.E.)

26. How do the outer leaves of a lut generally differ from the inner? (S.K.E.)

27. What is a leaf? What is its use to the plant? (S.K.E.)

28. Of what parts is a leaf made up? What is the use of the leaf as a whole, and what are the uses of the several parts? (S.K.E.)

29. Give instinces of foliar organs in which only the part corresponding to the petiole of the leaf is developed. (S.K.A.)

3o. Describe the nature of stipules, and illustrate from British plants the forms which these organs may assume. (S.K.A.)

3r. What are stipules? Describe the stipules of the rose and of the sweetpea. (S.K.E.)

32. What is the general plan of arrangement of leaves on a stem? Why is it the most advantageous to the plant? (S.K.E.)

33. Give instances in which leaves are only imperfectly developed. What useful purposes may they serve in such cases? (S.K.E.)

34. Mention, with examples, special jurposes to which leaves are adapted in different plants. (S.K.A.)

35. Describe the structure of in onion. (S.K.E.)
36. What is the use of the leaf to an ordinary greeu plant? (L.M.)

37. What components of the atmosphere are taken from it by plants, and for what purpose? (S.K.E.)

38. From what source does a green plant obtain its carbonaceous food, and in what form and by what organs loes it absorb it? What are the conditions upon which the assimilation of the carbouaceous food depends? (S.K.K.)

39. Plants are said to "starve in the absence of light." Explain this statement. (S.K.E.)

40. State why absence of light is injurious to plants. (S.K.E.)

4I. Explain what is meant by trans. piration, and state how this process may be experimentally demonstrated. (S.K. K.)

42. What is meant by transpiration? Under what circumstances do plants transpire most? (S.K.E.)

43. Explain why it is that plants droop on a hot day, and recover their freshness in the evening. (S.K.E.)

44. Describe the structure, development, and mechanism of the stomata. What is the effect of exposure to light upon the stomata? (S.K.A.)

45. A withered branch on a tree with deciduous leaves retains its leaves in winter when the living branches have lost theirs. Explain the reason of this. (S.K. A.)

46. When a branch is cut off a plant, the leaves upon it shortly hegin to droop. Explain why this happens. (S.K.E.) 


\section{Inflorescence and Flower.}

47. Give a sketch of the different kinds of inflorescence, with examples of each. (S.K.A.)

48. Explain precisely the kinds of inflorescence to which the names spike, raceme, and panicle are given. Show in what respects they differ, and give examples from familiar plants. (S.K.E.)

49. Briefly describe, giving examples, the following forms of inflorescence, and point out the relation which exists between them: spike, spadix, raceme, head. (S.K.E.)

50. Detine raceme, spike, catkin, umbel, capitulum, corymb, and panicle, and give one or more examples of each. (S.K.E.)

5I. Describe the structure of the inflorescence in arum. (S.K.A.)

52. Describe the structure of the flower of any flowering plant. In what part of the flower is the seed formed? What events must take place before in flower "goes to seed"? (S.K.E.)

53. Describe, with examples, the structure of $\left(a_{0}\right)$ a hypogynous, $(b$.$) a$ perigynous, and (c.)an epigynous flower. (S.K.E.)

54. What is a flower? What structures compose it, and what are their use? (S.K.E.)

55. Describe the typical arrangement of the parts of a flower; how is this modified in a leguminous and labiate plint, and in an orchid and a grass? (S.K.A.)

56. Describe and compare the structure of the staminal and carpellary flowers of Pinus. (S.K.A.)

57. Give an account of the structure of the head of a daisy. (S.K.E.)

58. Describe the structure of the floret of a grass, and explain the homology of its different parts. (S.K.A.)

59. What grounds are there for regarding the parts of a flower as modified leaf organs? (S.K.A.)

6o. Explain fully the various respects in which a petal differs from a leaf. (S.K.E.)

6r. Describe the typical form of a stamen, and illustrate from British plants any remarkable deviations from it. (S.K.A.)

62. Explain, and illustrate by means of examples, the following terms relating to the stamens of flowers:-T'tradynamous, didynamous, diadelphous. syngenesious. What is the meaning of the statement that the flower of the Orchidace is gynandrous? (S.K.E.)

63. Describe the structure of the stamen of a flowering plant. What bodies are produced by it, and what happens to them after they are shed on the stigma? (S.K.E.)

64. Describe the structure and state the uses of authers. What is the evidence that a stamen may be regarded as a modification of the leaf? (S.K.E.)

65. Describe in detail the structure of an anther and of a pollen grain. (S.K.E.)

66. What is pollen? What is its use? (S. K. E.)

67. Descrihe the ordinary structure of a grain of pollen, and the change which takes place when it is applied to the stigma. (S.K.E.)

68. Describe the pistil of any flowering plant. What is the nature and what is the use of the various parts of which it is composed? State briefly the changes by which, as in the bean, a young pistil is converted into a "ripe pod." (S.K.E.)

69. What is the explanation of the origin of the syncarpous pistil? Enumerate the families in the British flora in which it occurs with a parietal placentation. (S.K.A.)

70. What is a placenta? Describe the placentation in the Cruciferre, the Leguminosæ, and the Liliaceæ. (S.K.E.)

7I. Explain the use of the stigma, and point out the mode in which its minute structure is adapted to its use. Give illustrations of modifications in its form from British plants. (S.K.A.)

72. Describe the structure and state the use of ovules. What is necessary for the final develonment of these organs? (S.K.E.)

73. In what points of structure does an ovule differ from a seed? (S.K.E.)

74. What is a "nectary"? Give examples of such a structure amongst British plants. (S.K.A.)

75. What are meant by polygamous plants? Give instances, (S.K.A.)

76. Give illustrations from British plants of contrivances to protect the floral organs from the attacks of in sects. (S.K.A.)

77. Enumerate the British plants which are wind-fertilised, and explain in what respects their flowers are adapted accordingly. (S.K. A.) 
78. Explain the way in which insects are of use to flowers, and the means by which flowers attract them. (S.K.E.)

79. Show how pollination is effected in any two of the following flowers:Foxglove, white dead nettle, broom, violet, hazel, willow. (L.M.)

8o. What is meant by diclogamy? Illustrate your answer by examples taken from the British flora. (S.K.A.)

8I. Describe the different kinds of fluwers which exist in the genus Viola, and show for what purposes and in what manner they are adapted. (S.K.A.)

82. Some English plants have one, others have two, and even three kinds of flowers. Explain how this is possible. (S.K.E.)

83. How do you explain the fact that while the leaves of most plants are green, their flowers are of some other colour? (S.K.E.)

84. Explain briefly the biological significance of $(a$.$) brightly coloured$ and $(b$.$) irregular flowers, as compared$ with $\left(c_{.}\right)$inconspicuous and $\left(d_{\text {. }}\right) \mathrm{regu}-$ lar flowers. Give examples. (L. I.)

85. What is meant by an irregular flower? Give examples and explain in each case the advantage of the modification. (S.K.E.)

86. How do you account for the formation of "spurs" from fioral organs? What is their use? Illustrate your answer by examples from native plants. (S.K.A.)

87. In some plants the style is made the instrument of distributing the pollen which it is not itself to use. Explain and illustrate this statement by examples. (S.K.A.)

88. Describe the process of fertilisation in any angiospermous phanerogam, giving a full account of the structure of the ovule at the time of fertilisation. (S.K.A.)

\section{Seed and Fruit.}

89. Explain precisely in what points of structure a seed differs from an ovule. (S.K.E.)

90. What is the botanical meaning of the term "fruit"? Describe the structure of a plum, a strawberry, a blackherry, and an apple. (S.K.E.)

9I. From what parts of the flower may the fruit be developed. Describe an achene, a follicle, and a nut, giving examples. (S.K.E.)

92. Describe a broad bean or pea, or any other large seed, and the parts of which it is composed. Describe also the changes which take place when a bean is sown and germinates. (S.K.E.)

93. Describe a ripe strawberry ; compare and contrast its structure with that of a fig. What is the use of the fleshy part? (L.M.)

94. Explain the essential differences of structure in the fruits of the strawberry and blackberry. (S.K.E.)

95. Describe the structure of a plum and of an apple. What important organ enters into the one and not into the other? (S.K.E.)

96. [ $\mathrm{n}$ what important respects does the fruit of a cruciferous plant (such as shepherd's purse) differ from that of al eguminous plant (such as a pea)? How can the differences be accounted or? (S.K.E.)

97. Describe the fruits of a buttercup and of a pink. In what respects

do they agree, and in what respects do they differ? (S.K.E.)

98. What is a berry? What is the advantage to a plant to have this kind of fruit? (S.K.E.)

99. Describe fully the structure of a grain of wheat, and explain the nature and fuuction of its several parts(S.K.A.)

I00. Describe and compare the seerls of the bean and of the wheat. (S.K.E.)

IOI. What is the structural difference between a horse-chestnut and a sweet chestnut? (S.K.A.)

I02. Describe the various modes by which seeds are disseminater, and give illustrative examples. (S.K.A.)

I03. Give a detailed account of the germination of any one of the following:-A bean, a grain of whent, an acorn, or a date. (L.M.)

I04. Why are some of our fruit trees thorny in the wild stite, but not when cultivated? (S.K.E.)

105. Describe the germination of a pea and of a grain of wheat. (S.K.E.)

I06. Give an account of the external conditions requisite for germination of a seed and growth of the embryo, and explain how these conditions operate. (L.I.)

I07. The seeds of mustard and cress will germinate on flannel soaked with rain-water. Will they go on growing under these circumstances, and if not, why not? (S.K.E.) 


\section{Classification.}

I08. Describe the male flower of any Conifer you please, and state the structural differences which distinguish the flower of gymnosperms from that of other phinerogams. (S.K.A.)

Ic9. Give the essential characters of Orchideæ. (S.K.A.)

IIO. Contrast the character of grasses and Cyperacer. (S.K.A.)

III. Give a precise account of the structure of the flower of any Crucifer, and draw a diagram showing the arrangement of the different parts. (S.K.E.)
I12. Describe the typical strueture of a stamen. State the peculiaritie. characteristic of those of a Crucifer, it Composite, a Labiate, and a Grits.. (S.K.E.)

II3. Give the principal characters of Rosaceæ. (S.K.E.)

II4. Draw a diagram showing the arrangement of the parts of the flower of a leguminous plant as seen in transverse section. Point out in what respects it differs from the arrangement typical of flowers generally. (S.K.E.)

\section{General, Comparative, and Miscellaneous.}

II5. State what is meant by annual, biennial, and perennial plants, giving examples. (S.K.E.)

II6. Give examples of different kinds of climbing plants, briefly describing the mode of climbing in each case. (S.K.E.)

II7. What are the chief differences between a root and a stem? (S.K.E.)

II8. Suppose a piece of the axis of some flowering plant were shown to you, what appearances would enable you to decide whether it was part of a root or of a stem? (S.K.E.)

IIg. Compare the structure of the rnot of any flowering plant with that of its stem. Mention and briefly describe cases in which $(\alpha$.$) the stem and$ (b.) the root has become modified to serve as a depository of reserve materials. (S.K.E.)

I20. Give a botanical description of the part, in each of the following plants, which is commonly used as food: the potato, the onion, the turnip, and the carrot. (S.K.E.)

I2I. What are tendrils? Of what organs may they be modifications? Give examples. (S.K.E.)

I22. Give examples of plants which climb by means of tendrils, and explain how a tendril acts. (S.K.E.)

I23. Describe the structure of a living parenchymatous plant-cell. What chemical elements enter into the composition $\left(a_{\text {. }}\right)$ of the cell-wall, $(b$.$) of the$ protoplasm? (S.K.E.)

124. What is a "growing-point"? What is the difference between the growing-points of stems and those of roots? (S.K.E.)
125. State what are the general characteristics of the epidermal tissue of the sub-aërial parts of plants. (S.K.A.)

126. What are fibro-vascularbundles? Of what are they formed? What purposes do they serve? (S.K.E.)

127. What is a sieve-tube? What is its structure? What is its position in a dicotyledon? What is its probable function? (L.I.)

128. What is meant by a vessel? How is it formed, and what is its use? (S.K.E.)

129. What are the differences between the vessels of the wood and those of the bast? (S.K.E.)

r30. Why can a tree be transplanted more safely in the winter than in the summer? (S.K.E.)

I3I. Why will a plant grown in a dwelling-room be less vigorous than one grown in the open air? (S.K.E.)

I32. Write an account of the functions performed by the epidermal tissue. (L.I.)

I33. Why does heaping earth round celery cause the stalks to be white? (S.K.E.)

I34. What remarkable change do plants show when they are grown in the dark? (S.K.E.)

I35. When any vegetable material is burned, what constituents go off as gas? What are left behind? (S.K.E.)

I36. Describe the method by which the importance of the various mineral constituents of a plant's food has been most satisfactorily ascertained. (S.K.E.)

I37. What parts of a green plant are 
green and what are not? What gives the greenuess to the green parts? What is the great difference in function between the parts which are not green and those which are? (S.K.E.)

${ }_{3} 8$. What is the nature of and composition of chlorophyll? Where is it found, and how is it formed? (S.K.E.)

I39. What constituents of sunlight are most effective in producing the chemical changes on which the nutrition of plants depeuds? (S.K.E.)

I4O. What is the nature of starch? How is it formed, and what is its use? (S.K.E.)

I4I. Why do plants require nitrogen, and in what form do they take it in? (S.K.E.)

142. From what source and in what forms do plants usually absorb their nitrogenous food? Mention cases in which the nitrogenous food is absorbed from other sources and in other forms. (S.K. E.)

I43. Give a brief account of the genus Drosera, and describe its insectivorous mechanism. (S.K.A.)

I44. Give an account of the movement of water in the plant, and state the tissues, that take part in it. (S.K.A.)
I45. Trace the course of the sap from the root to the leaves. (S.K.E.)

I46. What is meant by respiration? Describe an experiment for showing that plants respire. (S.K.E.)

I47. What are stomata? Where are they found in the plant, and what is their use? (S.K.E.)

148. What is the difference in the physiological action of green and coloured leaves? (S.K.A.)

I49. Explain precisely how a tendril acts. (S.K.E.)

I 50. What is the cause which enables a plant to climb round a support? (S.K.E.)

I5I. Describe an experiment by which it can be shown that the upward growth of a stem and the downward growth of a rost is in each case to be attributed to the action of gravity. (S.K.A.)

152. Explain why it is that, when a seed germinates, the stem grows upwards and the root downwards? (S. K.E.)

I53. Describe the processes which lead to the conversion of an ovule into a seed, and state which is the difference between albuminous and exalbuminous seeds, giving examples. (S.K.E.) 


\section{INDEX.}

A.

ABORTED, 97, 99, 127 .

Absorntion, of food, $9,17-18,69,143,160$.

Acacia, 53, 54; false a. (see Robinia).

Accretion, 6.

Achene, 136, 137, 155 .

Acid ; carbonic a. (see Carbon dioxide); formic a., 72 ; sulphuric a., $159,160$.

Acorn, 136,143 .

Acropetal succession, 16, 23, 46, 7x.

Actinomorphic, 8o.

Acuminate, $\mathrm{I}_{47}$.

Acute, 147 .

Acyclic, $8 \mathrm{x}, 83,86,92,98$.

Addition of reagents, 160 .

Adhesion, 83 ; of sepals, $84-85, x_{4} 8$; of petals, 87,148 ; of stamens, 95,148 ; of earpels, 95,148 .

Adjustment, ${ }_{15} 8$.

Adnate, 56,96 .

Estivation (see Præfloration).

Aggregate, $x_{35}, 1_{39}$.

Air, $3,4,17,34,35,40,47,70,142$, I 43,160 ; air-bladder, 98, 116 ; air-cavity, 30, 43 66

Alæ, 88.

Albumen (of seeds), I3r, I32, 133 .

Albuminous, I32, I34, I 43 .

Alburnum, 38,42 .

Alder, 50, II6, 155 .

Aleurone grains, 134. 135.

Almond, $1 I_{3}, 132$.

Aloc, 62, 70 .

Alternate; a. whorls, 83 , I5 ; a. leaves (see Scattered).

Amaryllidacea, $I_{54}$.

Amentacer, $r=5$.

Amentum (see C'atkin).

America, North, 43, 55, II6.

Ammonia, ro.

A moeba, 5 .

Amorphous, 5 .

Amplexicaul, 58 .

Anacharis, 43 .

Analogous, 7 .

Analogue, 7 .

Analog 5,7 .

Analysis, Io.

Aluatumy, I; of root, I4, I58; of stem. 29-30, I58; of foliage leaf, $64-66, x 58$.

Anatropous (see Inverted).

Ancestors, 102 .
Androcium, 74, 81, 83, 92-98, I5c, $151,1_{52}$ $153,154,155,156,157$ (sce Siamen).

Anemone, 87, 106, 155 .

Anemophilous (ste Wind-pollinated).

Angiosperms, 2I, 10I, I09, II4, I $52-I_{5} 8$.

Angular distance, 50 .

Auimals, how differing from plants, 2-4; breathing of a., II ; digestion of a., 71 ; browsing a., 4I, III ; creeping a., 4I ; soft-bodied a., $4 \mathrm{I}$; relation to flowers, I I-I3O; relation to seeds and fruits, 142.

Aunuals, I4, 23, 44, I46.

Annual rings, $38,39,40,152$.

Anterior, $82,94,103,150,155$.

Antero-posterior, 52, 82 .

Anther, 74, 95, 96, I14, 118, I23, 124, 126,

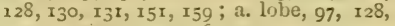
I29; $\mathrm{i}$. ring, I24, I26, I27.

Ants, 7I, IIr.

Apex; of foliage leaf, $58, I_{47}$; of ovule, 107 , Iog, $\mathrm{II}_{4}$.

Aposarpous, 100, 101, 102, 103, 135, I39, I55.

Aposepalous, 84 .

Apparatus, I45-146, I58-159.

Appendages; of stamens, 96, I27; of seeds and fruits, I4I, I 42 .

Appendix; on practical work, I.45 ; exami. nation questions, $x 6 \mathrm{r}$.

Apple, 51, 56, 123, I32, I36, I56.

Apricot, $149, x_{5} 6$.

A pril, 88.

Aril, 134 .

Aroidacer, $x_{53}$.

Aromatic, 157

Arrangement; of foliage leaves, 46-5I, I10, $147, x_{49}$; of stipules, $63-64, I_{4} ;$; of scale-leaves, 147 ; of flowers, $75^{-80}$, I 47 , I 49-150; of sepals, $83-84$, I $_{4} 8$; of petals, $86-87$, I48; of stamens, $92-94$, I 48 ; of carpels, $98-100, r_{4} 8$; of seeds, $104-106,148$.

Arrow-shaped, 58 .

Artichoke (sce Jerusalem a.)

Articulation, 59.

Arum, 2 I $56,76,78,98,99$, II $_{3}$, II $_{4}, 120$, $125,153$.

Ascending, 25.

Ascidians, 4 .

Ash, 59, 60, 6r, 99, 100, I42.

Asparagus, $27,29,30,36, x 58$.

Aspen, 50, 53 . 
Assimilation, ro, 67 (see Nutrition).

Aster, 157 .

Atonis, 4 .

Auricula, 157 .

Australia, 53, 55 .

Autumn, $38,42,48$.

$A$ wn, $117, x_{42}$.

Axial, 106.

Axil, 22, 26, 27, 44, 47, 64, 75, 76, 100, 109, IIO.

Axile, 104, 106, I54. 157, 158.

Axillary, 22, 63, 149 .

Axis ; of root, $1_{3}, 1_{52}$; of stem, $1_{3}, 21$; of inflorescence, $77,78,79,80,82,1_{35}, x_{50}$; of flower, 74, 81, 92, 152 .

B.

BACK; of leaf, 52 ; of flower, 150.

Balsam, I40.

Bamboo, 23.

Banana, 56.

Barberry, 60, 6r, 77, 86, 97, 124.

Bark, $37,40,41,42,44,47,152,153$.

Barley, II 7, I33, I43.

Basal, 103

Basal-veined, 56, 57 .

Base; of foliage leal', 58 , 147 ; of ovule, ro7, 109, 132.

Basifixed, 96

Basil, 157 .

Bast, 3I, 34, 40, 4I, 66; hard b., 3I, 32, 34 ; primary b., 36 ; secondary b., 37 ; soft b., 31, 33, 34, 36; b. fibres, 31, 32, 34 ; b. parencuyma, 3r, 33, 34; b. vessels (see Sieve-tube).

Beak, 103, 140, 156 .

Bean, $\mathrm{I}_{3}, \mathrm{I}_{4}, 3 \mathrm{O}, 6_{3}, 68,88,95, \mathrm{II}_{3}, \mathrm{I}_{27}, \mathrm{I}_{32}$, $I_{42}, I_{43}, I_{49}, I_{5} 5, I_{60}$

Beech, 24, 47, 48, 50, 51, 54, 56, 64, 116, 135, $139,140,155$.

Bees, II3, I17, I20, I21, 122, I24, 126, 127 , I29.

Beetles, xig.

Beet-root, 18, 155 .

Begronia, 49, 55 .

Bellis (see Daisy).

Bell-jar, 68, 60.

Bell-shaped, 86, 89, I28, 57 .

Bent, rog.

Berry, 139, I53, 154, 156, 157 .

Bidden guests, III.

Biennials, I4, 23, I46, I49.

Bifacial, 65, 73 .

Bilateril, 5 $5,54,64,80,85,86,87, \mathrm{r}_{47}$.

Biology, 2.

Birch, 48, II6, I42, I55.

Bird-pollinated, $x_{3} 0$.

Birds, III, I15, I30, 142 .

Bird's-foot tretoil, 95, 127, 156 .

Bird's-nest, 64 .

Bisexual, 98. 99, 100, 1 I $_{5}$, I $17_{7}$, I $_{52}$, I $_{53}$, I $_{55}$.

Bistort (iee Knot-grass).

Bittercress, I4I.

Bittersweet, I57.

Blackberry, 28, 103, 122, 123, I39, 156.

Black-currant, 123.

Bladder-campion, 95, II3.

Bladderwort, 62, 112 .

Blade (see Limina).

Blastocolla (see Bud-glue).

Bleeding of vines, 18.
Blossom (see Flower).

Blue, $85,90,91,119,120,124,160$.

Boat-shaped, 88.

Borage, 28, $105,1_{37}, 1_{56 .}$

Boraginaceæ, $1_{56}, 1_{57}$.

Botany, I; scope and subdivisions, I-2; descriptive, I ; econonic, 2 ; fossil, 2 ; geographical, 2 ; systematic, $I-2$.

Bract, $51,74,76,78,99$, $100, x_{1}, x_{12}, x_{3}$,

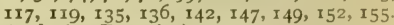

Bracteole (see Bractlet).

Bractlet, $76,83,85$, 117 .

Bramble (see Blackberry)

Branches; of root, 13,146 ; of stem, 21, 25 , $26,27,39,43,75^{-80}, 147$; b. spines, 27 , $6 \mathrm{r}$.

Branching; of root, $12,16,146$; of stem, $24,46,75-80,146$; of stamens, $94,{ }_{5} 6$.

Brazil-nut, 134 .

Bread, 135 .

Breathing, ro (see Respiration).

Bristles, 62, 73, 118, 152 .

Brookweed, 93, 97.

Broom, 127, $137,1_{40}, I_{5} 6$.

Broom-rape, 64,71 .

Browning, 158 .

Browsing animals, $4 \mathrm{I}$.

Bryonia (see Bryony, white).

Bryony, black b., 56 ; white b.. 45 .

Brush, of hairs, 126 .

Bud, 26, I45; accessory b., 48 ; adventitious b., 49 ; apical or terminal b., 46 , 48 ; axillary b., 47, 48; ciormant b., 47 ; flower b., $49,75,84$, IIO, II 7, I 49 ; leaf b., $7,36,44,46-50,64,67,75,147$, I 49 ; b. glue, $7,64,67$, I I $_{4}$, г49.

Budding, 44 .

Bugle, 90.

Bugloss, I 56 .

Bulb, 26, 44, 48, 64, 149, 160.

Bulbil (see Bulblet).

Bulblet, $44,48,64$.

Bulrush, I $_{54}$.

Bundles, viscular; of ront, $14-16$; of stem, $29,30,31,36,152,158$; of foliage leaf. $47,56,65,66,67,158$; of petal, $9 x$; of stamen, 98 ; of carpel, IO7; of ovule, ro7; closed b., 36 ; common b., 30 , open b., 32 ; primary b., 36 ; b. sheath, 32 .

Burdock, 142 .

Bur-reed, ${ }_{54}$.

Butcher's broom, 27, I54.

Buttercup, 21, 24, 3r, 36. 57, 62, 74, 81, 83, $84,85,86,92,93,96,98,100,103,122$, 126, 130, 136, $_{3} 39$, I $_{5}$ I, I $_{55}$.

Butterfies, 120,122 .

Butterfly-shaped, 88, 98, $114,126,{ }_{5} 6$.

Butterwort, i12.

$$
\text { C. }
$$

CABBAGE, 25, I37, I 55 .

Uitetus, 27, 71, 83 .

Caducous, 84, 86, 155.

Calceolaria, 157 .

Calcium, ro, 160.

Californian poppy (see Eschscholtzia).

Calycitloræ, $153,156$.

Calystegia, $12 \mathbf{r}$.

Calyx, $74,78,80,8 \mathrm{r}, 83-86,89$, 100, то2, I13, I17, 120, 123, I29, I35, I40, I4I, $\mathrm{I}_{42}, \mathrm{I}_{4} \mathrm{~S}, \mathrm{I}_{50}, \mathrm{I}_{5} \mathrm{I}, \mathrm{I}_{52}, \mathrm{I}_{53}, \mathrm{I}_{54}, \mathrm{x}_{55}$, I56, I57; (see Sepal); c. tube, $84-8.5$. 
Cambium, $17,31,34,36,37,38,39,40,44$, 66 ; fascicular c., 37 ; interfascicular c. 37 ; cork c., 40 ; c. ring, $37,39,40$.

Camel's-hair brush, 159.

Campanulaceæ, 157 .

Campanulate (sce Bell-shaped).

Campion, 79, 87, 109, 156 (see Bladder c.).

Campylotropous (see Bent).

Canal, 43 (see Pollen-canal).

Candy-tuft, 155.

Canes, 25

Cimescent, 28.

Canterbury bell, $84,89,1_{3}, 1_{26}, 3_{5} 8$.

Cape, I30. $_{3}$

Capitulum (see Head).

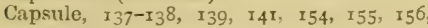
I 57,158 .

Carbun, 3, 5, 10 ; c. dioxide, 3, 9, 10, II, I7, $18,19,42,67,68,71,114,143,160$.

Carbonic acid (see Cirbon dioxide).

Cardamine, I4 1 .

Carina (see Keel).

Carnation, I00, I56.

Carolina, North, 6r.

Carpel, 75, 82, 92, 95, 98-109, I10, I13, 136 , $I_{37}, I_{3} 8, I_{50}, I_{5} I_{1} I_{53}, I_{54}, I_{55}, I_{5} 6$, $157,158$.

Carraway, $137,1_{5} 6$.

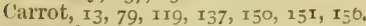

Citruncle, I32, I33.

Caryophyllacere, I 55 .

Caryopsis, 136.

Castor-oil seed, I32, I34, I35, I43.

Caterpillar, III.

Catkin, 78, 99 100, I16, 155.

Cits, I2I.

Cittle, IrI.

Cituline, 147

Caustic potash, 68, I59, I6o.

Cedar, 152 .

Celandine, ${ }_{55}$.

Celer5, 68, 156 .

Cell, 5, 8; antipodal c., Iog; artificial c., 9 ; co-operating c., I09, II4; egg-c. (sre Egg-cell); eudosperm c. (see Endosperm); guard c., 66,70 ; c. derivate, $8, \mathbf{6}, 17,32,33,34$; c. fusion, 33,34 ; c. nucleus (see Nucleus); c. protoplasm (see Protoplasm); c. sa!), 8, I6, 18, 19, $3 x, 65,72$; c. wall, $8,16,17,18,30,31$, $32,33,34,35,38,65,67,70$, (see Tissue). Cellular, 45 .

Cellulose, 3, 4, 10, I r, ז6, 30, 3r, 32, 33, 65 , $\mathrm{x} 34, \mathrm{x} 60$.

Central (see Free central).

Centric, 66.

Centrifugal, 79, $x_{50 .}$

Centripetal, 77, 124, 149 .

Ceylon, 62.

Chalaza (see Base of ovule).

Chamomile, 157 .

Chenopodiacere, I55.

Chenopodium, 155 .

Cherry, 51, 77, xxo, I39, I49, 156; c. laurel, I 56 .

Chestunt, 135, 139, 140; (see Horse-chestnut).

Chevaux-de-rive, 125 .

Chickweed, ${ }_{5} 6$.

Chili pepper, 157 .

Chinese prinirose, 125.

Chloral hydrate, $67,158$.

Chlorides, ro, 160.
Chlorophyll, 4, 8, I0, I I, 40, 42, 67, 68, 7 1, I49, I60 ; c. granules or corpuscles, 8 , $3 \mathbf{I}, 6 \Xi, 67,70,7 \mathrm{r}$.

Christmas ruse, 155 .

Ciliate, 28 .

Cinquefoil, I $_{3}$, I $_{5} 6$.

Circinate, 49, 149.

Circular, 57 .

Circulation; of gases, 19, 43 ; of liquids, I8.

Circumnutation, 44 .

Cladode, 27.

Cladophyll, 27.

Class, $21, I_{5} I_{1} I_{52}, I_{53}, I_{54}$.

Classification, $I, 2 I, I 48,15 x-158,165$.

Claw, 87, 88, 124 .

Cleanliness, 159 .

Clearing, of sections, 160

Cleaver (see Goosegrass).

Cleft, 59 .

Cleistogamous, $\mathrm{r}_{30-\mathrm{r}} \mathrm{r}, \mathrm{I} 40$.

Clematis, ${ }_{55}$.

Climate, dry, 27, 62 .

Climbers, 25-26, 53 .

Clover, 59, 60, 78, 88, I21, 127, 156.

Cluỏ-moss, 92.

Club-shaped, 99 .

Coats, of animals, 142 ; of ovule (see Integument); of seed (see Seed-coat).

Cocoa-nut, $x_{33}, x_{34}, x_{4} x$.

Cohesion, 83 ; of sepals, 84 , $x_{4} 8$; of petals, 87,148 ; of stamens, $95, x_{48}$; of carpels, IOO-IOI, 148 .

Cohort, 2 I.

Colchicum, I 49

Collar, II2.

Collective, $x_{35}$.

Collenchym:1, 31, 41, 67 .

Colleter, 64 .

Colour; of root, r8, r46; of stem, r46; of petiole, 147 ; of lamina, 62,147 ; of scale-lenf, I47; of flower; II5, II 8, I $_{52}$; of calyx, 86; of corolla, 9I, 153 ; of stamen, 97 ; c. body, 9 I.

Coltsfoot, $\mathrm{r}_{57}$.

Columbine, 88, 100, 102, 104, 107, 137.

Column, 129.

Comfrey, 156.

Common bundles, 30 .

Compartment (see Loculus).

Compass plant, 55 .

Compositæ, 78, 80, 84, 95: I19, 126, 130, 136, I 4 I, $x_{57}$.

Composition, of foliage leaf, $x_{47}, x_{49}$.

Compound, 59, 79, 147, 156; c. microscope (see Microscope).

Condensed, $I_{4} 6, x_{49}, I_{5}$.

Conducting tissue (see Tissue, conducting).

Conduplicate, 49, I 49 .

Cone, 92, 98, 99, 101, I16.

Conical, $8 \mathrm{r}$.

Connate, 58, 112.

Connective, 96, 129.

Conspicuousness, II9-120.

Contact, 19, 20, 45, 73, 128 .

Convolute, 49 , 149 .

Convolvulıs, 8, 25, 89, 93, 121 .

Coral islands, $x+1$.

Core, of apple, ${ }_{3} 6$.

Coriander, 156 .

Cork, I7, 40, 4I, 43, 67; c. cambium, 40.

Corm, 26, 42, 44, 48, 149, 154, 160 .

Corolla, $74,78,81,83,86-9 x$, 101, $112, x_{3}$, 
I17, I18, I20, 122, I25, I27, 129, I48, I50, $x_{51}, I_{52}, I_{53}, x_{54}, I_{55}, 1_{56}, x_{57}$, (see Petal)

Corolliflor:e, $153,15^{6-158 . ~}$

Corona, 88, I12.

Cortex; of root, $\mathbf{4} 4$; of stem, $28,30,3 \mathbf{r}, 36$, $38,40,4 \mathrm{I}, \mathrm{I} 52$.

Corydal, to5.

Corymb, 77, 79 .

Costal-veined, 56 .

Cotton, $3, x_{34}, 1_{42}$.

Cotton-grass; 142 .

Cotyledon, 50, I32, I33, I34, I35, I42, I43, r52, 153,160 .

Cover-glasses, $158,159,160$.

Cow-parsnip, rrg.

Cowslip, 125,157 .

Uram, I46.

Crane's-bill (see Geranium).

Creeping, 25, 43, 54.

Cress, $50,143,160$.

Crocus, 26, 149, 154 .

Cross-fertilization, I $I_{5}$

Cross-pollination, $\mathrm{II}_{5}^{-1} 30$, $14^{8}$.

Cross-shaped, 88, I4I, I55.

Crozier, 49.

Cruciferæ, I4I, 155.

Cruciferous (see Cross-shaped).

Crumpled, 49, 134, I50.

Cryptogams, 2.

Crystal, 5. 6.

Crystalloid, 26, 42, 134,135

Cucumber, 25, 36, 95, 139; squirting c., I4I.

Culm, 23, 25

Cultivation, 135 .

Cupuliferæ, 155 .

Currant, 77, 123, 139, 149.

Cuticle, 30, 65, 69.

Cuticularized, $65,70, x 60$.

Cutin, 30, 40.

Cutting, of sections, 159

Cuttings, 13,43 .

Cyclamen, 26, 140, I49, 157 .

Cycle, 50, $51,81,83$, 149 .

(yclic, $81,82,83,86,93,98$.

Cylinder, vascular (see Vascular c.).

Cylindrical, 23, 29,52, 103, 146, 147 .

Cyme, 79. 80, 100.

Cymose, 24, 75, 79, I50, 155, 156, 157.

Cypress, 21, I52.

Cypripedium, 94 .

Cyjolis, 136, ז57.

J).

I) $A F F O D I L, x 54$.

Dahlia, 14, 19, 95, $157^{\circ}$

Daisy, $21,24,78,93,95,106,119,126,149$, $157,159$.

Daudelion, 19, 24, 78, 95, 106, 136, 140, 142, I5I.

Dark, 160 .

Darwin, 44, 45, 121.

Date, $\mathbf{I}_{33}, \mathrm{I}_{34}, \mathrm{I}_{39}, \mathrm{I}_{43}$

Deadly nightshade, $80, x 57$.

Dead-nettle, 21, 49.80, 86, 89, 90, 93, 95, 96, Deal, 39. $97,100,105,106, I_{3}, 128,137$ : 151, 157

1) eciduous, $62,64,86$.

Decompound, $6 \pi$.

Decumbent, 25 .
Decurrent, 58 .

Decussate, $49,80,82, I_{55}, I_{57}$.

Definite (see C'ymose).

Dehiscence; of anther, I14, 126; of fruit, $I_{37-13} 8, I_{39}, I_{40-14}, I_{5}$ I.

Description of plants, $145-158$.

Desmodium, 73 .

Development, 7, 27 (see Germination)

DeW, 4I, I 3 .

Diadelphous, $95,103,156$.

Diagonal (see Oblique).

Diagrams, $x_{4} 6$; of anatomy of vegetative organs, 29 ; of capsules, 138 ; of dicotyledon, 15 ; of epigynous flower, $8 \mathrm{x}$; of hypogrynous flower, $8 x$; of monocotyledon, 22 ; of ovules, 104 ; of perigynous flower, 81 ; of secondary thickening, 37 ; of simple flower, ro8; of unicellular plant, 9; f. diagrams, $82,148,{ }_{50}$.

Dichogamous, Ir 5 .

Dichogamy, I 15, I 30 .

Dichotomous, 79 .

Dichotomy, false d., 24, 47, 79 .

Dicotyledons, $21,24,30,32,34,35,36,3^{8}$, $50,51,52,56,57,66,83,86,98,107,1_{52-}$ ${ }_{53}, I_{54^{-1}} 5^{8}$; diagram of, $x_{5}$.

Didynamous, $94, x_{2} 8,157$.

Dielytra (Dicentra), I05.

Differences between plants and animals, 2-4; between living and non-living matter, 4-6.

Differentiation, 12 .

Diffusion, 9 (see 0 :mosis).

Digestive excretion, 71,73 , $1 x_{4}$.

Dimorphism, 125.

Dicecious, 99 .

Dipsacere, 157 .

Direction ; of growth, 24,23 ; of root, 146 ; of stem, 146; of influrescence, 147 ; of ovules, 106

Disc, xo6.

Disk, $78,95,126$.

Dissecting needles, 145 .

Dissection of plants, $145,149,150,158$.

Dissepiment, ro4, ro5, false or spurious d., $105,137$.

Distasteful substances, 67, II I.

Distilled water, 160 .

Distribution; of plants, 2 ; of fruits and seeds, $\mathrm{I}_{40} \mathrm{O} \mathrm{I}_{4} 2, \mathrm{I}_{4} 8$.

Ditches, 62 .

Dittany, ro4.

Divergence, 50, 51, 83, 149, 154 .

Divergent, 85 .

Division, 21 ; of cells, I I, I6 ; of labour, 12.

Dock, 56, 64, 106, 109, 117, 142, 155 .

Dodder, 3, II, 23, 7I.

Dog-rose (see Rose).

Dog-violet, $\mathrm{x}_{3} \mathrm{O}$, I4I.

Dorsal margin, 102, $1_{3} 8$.

Double flowers, 1 Io.

Dove's-foot geranium, Izo.

Drawing, 146 ; d. book, 146 .

Dried flowers, IIr.

Drift-timber, I4I.

Drugs, 2.

Drupe, I39

Drupel, I39.

Dry fruits, $136-138,140$.

Duckweed, 21, 27, 98, 153 .

Durimen, 38, 42 .

Duration of life, $14,23$. 
Dusk, 119 .

Dwarf mallow, $\mathrm{x}=0$.

Dyes, 2.

E.

EARTH, 3, I9 ( $\mathrm{sec}$ Soil).

Earthworm, ig.

Edge (see Margin).

Egg-apparatus, Iog.

Egg-cell, $109, x_{15}, 1_{31}$.

Eight-rauked, $5 \mathrm{I}$.

Elder, $40,59,80$, II 9 , I59.

Elements ; chemical, 4 ; essential, 9, 160.

Wilm, 24, 36, 48, 50, 51, 54, 55, 80, 1 42 .

Eludea, 43 .

Emarginate, 147 .

Jimbryo, I3I, $1_{33}, I_{34}, 1_{42}, 1_{52}, 1_{53}, 1_{54}$.

Embrjo-sac, Iog, 133 .

Emergences, 28, 54, 61, 63, 71, 72 .

Enchanter's nightshade, 86, 156 .

Indocarp, 136, 139.

Endodermis (see Bundle-sheath).

lindogenous, I4, 39 .

Endogens, 38, 39 .

Endoparasites, 4 .

Endosmosis, 9 .

Endosperm, I3I, I33, I34, I52, I53, I54, $x \in 0$.

Energy, Ir ; kinetic, 5, ro ; potential, 5, ro.

Entire, 58, 156 .

Entomophilous (see Insect-pollinated).

Epipetalous, 95, I1 8, I53, I56, 157 .

Epicalyx, $3_{5}$, 156, $_{57}$.

Epicarp, 136, 139.

Epidermis, 7, 17; of root, 14 ; of stem, 28 , $29,30,3 \mathrm{I}, 36,40,4 \mathrm{I}$; of leaf, $64,65,67$; of petal, $9 \mathrm{r}$; of stamen, 98 ; of carpel, I07; of fruit, 136.

Epigean, 143 .

Epigynæ, I52, I53, I 54, I $_{55}$, I $_{57}$.

Epigynous, 81, 84, 85, 87, 95, 101, 124, 150, $15 x, 153,156$.

Epilobium (see Willow herb).

Epiphytes, I3.

liquitant, 55, 154.

Erect, 24, 4I, I46, I53, I 57 .

Eschscholtzia, ror, 155 .

Essential floral leaves (see Essential organs).

Essential organs, $92-r_{3}$.

Etiolated, 68, 160.

Etiolin, 68; e. granules, 68.

Eucalyptus, 53 .

Europe, South, I4t.

Evaporation, $4 \mathrm{I}$.

Evening primrose, 93, 107, ${ }_{5} 6$.

livergreens, 62,67 .

liverlasting pea, 127

Exalbuminous, $\mathrm{I}_{32}, \mathrm{I}_{4} 2$.

Examinations, 146 ; exim. questions, $161-$ I66.

Excreted, II

Excretion, II, 7I, 73, 74, II2, II4, I2I, I22, 123.

Exogenous, 39 .

lixogens, 33, 39

Exosmosis, 9 .

Explosion of flower: 127 .

Exserted, 96.

Exstipulate, $I_{49}, I_{55}, 1_{5} 6, I_{57}$.

External characters ; of calyx, $85-86, x_{4} 8$; of corolla, 87-91, I48: of stamens, 9697,148 ; of carpels, 101-106, 148 .
Extine, 98.

Extra-axillary, 49.

Extra-floral necturies, Iro, $x \leq 3$.

Extrorse, 96, 97.

Eyepiece, 158

Eyes, 26, 48, 64 .

F.

Fadisg, 9, 69.

Fall, of the leaf, 42 .

False; dichotomy (see Dichotomy, false); dissepiment (see Dissepiment, false); fruit (see Pseudocarp).

Family, 21, 106.

Fian, 49 .

Fan-palms, 56.

Fascicle, 80.

Feéding, 9 (see Nutritiou).

Female ; spore-leaf, 92 ; catkin, 99,100, I 53 ; cone, 92, 99, х16 ; flower, 92, 94, 99, 100. 101, I09, x1 $5,117,119,121,125,140,155$, I 57 .

Fennel, 156 .

Ferns, 92, 149.

Ferric chloride, 160 .

Fertilization, Ix 5 , I3I, I52 ; cross-fertilization, II5.

Fertilized, I $_{5}$.

Fibre, 2, 146, 149.

Fibrous, 146.

Fibro-vascular, 34.

Field-microscope, 158 .

Field-mouse, 122.

Fig, 135 .

Figwort, I57.

Filament, 74, 95, 96, 98, 100, $\mathbf{I I}_{3}, \mathrm{II}_{7}, \mathbf{1}_{1} 8$, I29.

Fir, 21, 24, 30, 35, 36, 39, 64, 84, 92, 93, 98, 09, I01, I16, I42, 152 .

Fission, $\mathrm{Ir}$.

Fistular, 23, 154 .

Five, $83,86,87,89,91,93.94,96,97,102$, $I_{0}, I_{0}, I_{7}, x_{53}, x_{55}, 1_{5} 6, I_{57}$.

Five-ranked, $5 \mathrm{x}$.

Flaccidity, 9 .

Flag, 1 I9.

Flannel, 160 .

Flattened, 23, 104, 132.

Fleshy, 56, 76, 78, 103, 106, 123, 135, 139.

Flexible, I12, II4.

Flies, 3, 120.

Floral diagram (see Diagram, floral).

Floral formula, I $_{50}$, $1_{5} \mathrm{I}_{1} \mathrm{I}_{54}, \mathrm{x}_{55}$. I $_{56}, \mathrm{I}_{57}$.

Floral leaves, 74, 75, 8I, 131 (see Flower).

Floral receptacle, $74,8 I, 84$, IoI, I09, I2I ; description of, $148, \mathbf{1} 50, \mathbf{1} 5 \mathbf{I}$.

Floret, $78,89,91 ; 93,95$, хо6, х19, 126, $x_{57}$. 189 .

Flour, 135 .

Flower, 2, 21, 24, 4r, 69, 74 ; flower-cluster (see Inflorescence), description of, 148 , I50-15I; examination questions on, $163-164$; morphology of, 74-110, 152, I $53,1_{54}, x_{55}, x_{56}, 1_{57}, 1_{58}$; physiology of, III-131 ; flower-stalk, 25, 28, 76, II

Flower-bud (see Bud, flower).

Flowering ash, roo.

Flowering glume, II 7 .

Flowering plants, $12,92,1_{4} 6$; classification of, $15 x-15^{8}$. 
Flowering rush, 98.

Fly-trap, 6r, 73 .

Focussing, 145.

Foetid, 120.

Folded, 49.

Foliaceous, 63

Foliage leaf, 5 I, $52-73,76,83,85,102$, II 6 , $I_{52}, I_{53}, I_{54}, I_{55}, I_{56}, I_{57}$; arrangement of, I10, I12; assimilation by, $66-$ 69; blade of (see Lamina); descriotion of, I47; examination questions on, 162 ; irritability of, 73 ; kinds of, 59 ; morphology of, 52-66; motility of, $7 x^{-}$ 72 ; parts of, 52 ; physiology of, 6673 ; protection of, 67 ; reproduction by, $7 \mathbf{x}$; respiration of, $7 \mathbf{I}$; spontineity of, 73 ; stalk of (see Petiole); structure of, $64-66,86, \mathbf{1 0 7}, \mathbf{x} 5$, 159; support of, $66-67$; transpiration of, $69-71$; venation of, $55-57$ (see also Sheath and Stipule).

Follicle, 137,155 .

Food, 6 ; of plants and animals, 3 ; reception of, 9 (see Nutrition); nature of, 9 ; food solution, 9, 10, 17, 68, 69, 160.

Forceps, 145.

Forget-me-not, 80, 89, 93, 105, I30, I37, 142, 186.

Forking (see Dichotomy).

Form; of plints $v$. animals, $3,4,5$; of $n \circ n-$ living matter, 5; of simplest plants, 8 ; of root, $\mathrm{I}_{3}-14, \mathrm{I}_{4} 6$; of stem, $23-27$, r46; of lamina, $57-62,147$; of petiole, 53,147 ; of scale-leaf, 64,147 ; of hairs, 28 (see External characters).

Formic acid, 72 .

Four, $83,87,93,94,97,100,104,105,124$, $x_{53}, 1_{55}, 1_{5} 6,1_{57}$

Four-lobed, ro5.

Four-rased, 80.

Four-sided (see Square).

Foxglove, $77,89,90,94,95,97,98$, 104, I19, $122,128,138,157$.

Fragrance, $114,118,120$, 121 .

Fragrant substances, 28, 66.

Fraxinus, 6r.

Free, $84,87,88$, ror, ${ }_{5}$ r.

Free central, 106, 138,156 .

Frightening of insects, 124 .

Frogbit, 98.

Front, 106, 150

Fruit, 42, 75, 102, 103, 132-143; description of, $\mathrm{x}_{4} 8, \mathrm{I}_{51}$; distribution of, $140-142$; examination questions on, 164 .

Fuchsia, 81, 93, 101, 102, 107, 123, 150, 160.

Funnel-shaped, 86, 89 .

Funicle, 107, 108.

\section{G.}

Galeate, go.

Galium (see Goose-grass).

Gamopetalæ, $x_{53}$, I $_{56-158 .}$

Gamopetalous, 87, 89-90, 94, I07, $\mathrm{II}_{2}, \mathrm{II}_{3}$, I53.

Gamosepalous, $84,85-86$, r26, I $_{53}$.

Gaping, 90.

Gardening, 42, 43, 44, 68, 95, xxo.

Garden-sage, 129 .

Garlic, 154 .

Gases, I9, 3 I.

Gastric juice, 7 r.
Genealogy, 2, 2r.

General exam. questions, 165-166.

Genetic spiral, 50.

Gentian, 112, I37.

Genus, 2 r.

Geotropism, 19, 20, 44, 73 .

Geranium, 21, 52, 53, 56, 98, 120, 124, 137 , I $40, I_{42}, I_{5} 6, I_{50}$

Germination, 68, $x_{3} 6, x_{4} 0, x_{42}-143,160$.

Glabrous, 28, 30, 54, 62, 91, I12.

Gladiolus, 154 .

Gland, 6r.

Glandular, 6I, 7x, 100, II2, I5I.

Glaucous, 147 .

Globoid, I35.

Globular, 27, ro4.

Glomerulus, 80 .

Glossy, 67 .

Glovers' needles, I45.

Glume, II7, I52.

Glumifloræ, 152, 154 .

Glycerine, 159, 160 .

Gonseberry, 112, 123, 136.

Goosefoot, $x_{55}$.

Goosegrass, 26, 28, 142,147 .

Gorse, 2r, 61, 86, 88, 95, 100, II 3, х19, 127, I37, I5O, I5 I, I56.

Grafting, 43 .

Grains, pollen (see Pollen).

Graminaceæ, I54.

Granules; chlorophyll, (see Chlorophyll g.) ; etiolin (see Etiolin g.).

Grape, I39.

Grasses, $x_{3}, 21,30,36,50,52,56,63,66,67$, $79,96,100, x_{7}, 120, x_{3} 6,1_{43}, x_{4} 6,149$, I $50, I_{5}$ I, $I_{54}$

Grass-pea, 63 .

Gravity, 19, 20, 44, 73 .

Groater celandine, 155 .

Grooved, 28, 53 .

Ground-ivy, 157 .

Groundsel, 53, 78, 95, 130, I 57 .

Ground-tissue (see I'issue, ground).

Group, 2r.

Growing-point, $16,34,47,66$.

Growth; of cell, 8; of inorganic matter, 6 ; in length, $16,32,45,47,66$; of organic matter, 6 ; of plants, 42,71 ; of pollen-tube, II4, 160 ; in thickness, I6, 23, 24, 36, 152; definite R., 48; direction of $\mathrm{g} ., 19,20,24,44$; indefinite $\mathrm{g} ., 48$.

Guald-cell, 66, 70

Guelder rose, rrg.

Guests ; bidden g., I I I, I18-130; unbidden g., III-II3, IIG.

Gymnosperms, 21, 24, 30, 32, 35, 36, 38, 98, IOI, I02, 107, I09, II $4, \mathrm{I}_{52}, \mathrm{I}_{53}$

Gynandrous, 96, ror. 154 .

Gynœeium, 75 (see Pistil).

\section{H.}

НАBIT, I46, I48-I49.

Hair, 3, 7, 8, 16, 17, 2x, 28, 29, 3I, 4I, 44, $54,62,65,67,72,73,86,90,98,99,107$, I12 I1 3, I16, 126, I27, I29, I41, 142 ; br:mched h., 62 ; glandular h., $28,4 \mathrm{r}$, $62,71, x 12$; sensitive h., 62, 73 ; stinging h., $6_{2}, 72, \mathrm{I} 54$

Hair-structure (see Hiir).

Hairy, 28, 62, х1 $3, x_{26}, x_{27}$, 29. 
Hair's bitter cress, I4I.

Half-anther, 97.

Handles, for dissecting needles, 145 .

Harebell, 89, 113, 126, 158 .

Hawthorn, 28, 77, 122, 123, 156.

Hay, III.

Hazel, 9, 48, 78, 116, 155 ; h. nut, $\mathbf{x}_{32}, \mathbf{x}_{3} 6$, I 30.

Humble-bee, II 3, I21, I22, I28.

Humming-bird, 130 .

Husk, I35, 139.

He:rd, $78,80, I_{57}$; of bee, 129,130 .

Hear:wood, 38,42 .

Heat, 69,160 .

Heath, 89, 97, I13, 123, I27.

Henther, $89,123$.

Helianthus tuberosus (see Jerusalem artichoke).

Helicoid cyme, 80, $x_{5} 6$.

Heliotropism, 20, 45, 73 .

Helmet-shaped, 90.

Hemicyclic, 8r, 83, 86, 93, 98.

Hemlock, 79, 106, I19, 156.

Henbane, $1_{3} 8,{ }_{157}$.

Herb, $23,48,57,1_{53}, 1_{54}, 1_{55}, 1_{56}, 1_{57}$.

Herbaceous, 62, 69, 70, 146 , I49, I58.

Herkogamy, II 5 .

Hesperidium, $x_{39}$.

Heteromorphism, I24.

Heterostyly, I24.

Hidden-veined, 56 .

High power, 158 , I59.

Hilum, 132 .

Hip, 136.

Hirsute, 28.

Hispid, 28.

Histology, I, I45; of root, $\mathrm{I}_{4}-16$; of stem, $30-4 \mathrm{I}$; of foliage leaf, $64-66$; of flower, $86,91,97-98$, 107-109; practical h., $158-160$.

Hoary, 28.

Hollow (see Fistular).

Holly, 5x, 6r, 65, I47.

Hollshock, I56, 158 .

Homologue, 7 .

Homology, 7, 27 .

Honey, 121 (see Nectar).

Honey-gland (see Nectary).

Honcy-guide, I22, I23, 130.

Honeysuckle, 90.

Hood, 85.

Hoodlike, I29.

Hook, 26, I.42 ; h. climber, 26.

Hop, 8, 25, 28, 44, 99, 100.

Horehound, 157 .

Horizontal, 54,6 , 106, 147 .

Iformbeam, Ir6, 142, 355 .

Horse-chest nut, 7, $46,47,49,59,64, \mathbf{I} 39$.

Horse-radish, I 55 .

IIot-water jug, 62 .

House-leek, 24. 25, 57 .

II jacintl, 77, 86, 107, 109, I23, I49, I54.

Hydrangea, II9.

Hydrogen, 3, 5, to.

II ydrotropism, 20.

Ifypocotyl, r43.

Hypocratet iform, 89 .

I1 ypoge:m, 143 .

Hypogyna, I52, I $53, \mathbf{I}_{54}, \mathrm{I}_{5} 6$.

Hypogynous, $81,87,95$, I0I, 150, 151 , 153.
I

ILLUMINATION, 68.

Imbricate, 84,149 .

Impatiens, 143 .

Incompletae, 153,154

Inconspicuousness, 116, 121, 130, 151, 154 .

Increase (see Growth).

Indefinite, I48, I5I, I55 (see Racemose).

Indehiscent fruits, $1_{36}, 1_{37}, 1_{39}$.

Indian, 73 .

Indian-corn, $\mathrm{r}_{33}, \mathrm{I} 36, \mathrm{r}_{43}, \mathrm{x} 6 \mathrm{0}$

Indian-cress, 86, 91, 126, $137, \mathrm{~J} 5 \mathrm{r}$.

Indian, E:st, 62.

Inferior, 85, 10r, 105, 106, 123, 136, 139, 153, 157 .

Inflated, 86, 89, II3.

Inflexed, $49, x_{49}$.

Inflorescence, 24, 25, 27, 75-80, 100, I13. $I_{4}, I_{17}, \mathrm{II} 9, \mathrm{I} 25, \mathrm{I} 53, \mathrm{I} 54, \mathrm{I} 55, \mathrm{I} 56$, I57; female, 99; male, 99, I53 ; description, I47-149, I 50 ; exanination questions $011, \mathbf{1} 6_{3}$.

Innate, 96.

Insectivorous plants (see Plants, ins ctivorous).

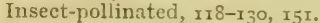

Insects, 4I, 7I; digestion of (see Plants, insectivorous); as pollinating agreuts, II5, II 8 , I30; as unbidden guests, IIIII 3 .

Insertion, of leaf, 43 .

Integument, 107, 108, 13r.

Int ercellular spaces, $19,41,43,65,66,70$.

Interfoliar, 64 .

Internode, 22, 23, 24, 26, 29, 46, 47, 49, 55, $74,76,78,109,146,149$.

Intine, 98 .

Introrse, 06.

Intussusception, 6 .

Inverness-shire, 116 .

Inverted, 109, I32, 134 .

Involucre, 78, 79: III, I 22.

Involute, $49,149$.

lodine, $67,159,160$.

Ireland, 43 .

Iridace?, 154

Iris, $21,26,55,56,123,127,138, x_{54}$.

Iron, Io.

Irregular, $79,80,88,89,118,120,126,146$, $154,156,157$.

Irregularity, $121-122$.

Irritability, II-I2 ; of flower, $x_{31}$; of $\mathrm{reO}^{*}$, I9; of stamens, 124 ; of stem, $44^{-45}$.

Isomerous, 87.

Ivy, 8, I3, 26, 54, 56, 78 .

\section{J.}

JA PONICA, ${ }_{5} 6$.

Jerusalem artichoke, 26, 49, 157 .

Jessamine, 59 .

Joint, 59, 60 .

Jointed, 27.

Judson's dye, r59.

Juice, $x_{55}, x_{57}$.

Jume, 88, 92 , 116 .

Juniper, 2I, 35, 84, 152 .

K.

RATABOLISI, I1, I2.

lieel, 88. 
Kernel, 136, 139.

Kerner, rig.

Kidney-shaped, $58,65,97$.

Kinds ; of foliage leaf, I 47 ; of fruit, I48 ; of inflorescence, 147 ; of root, 146 ; of stem, 146 .

\section{Knife, 29.}

$\mathrm{Knob}, \mathrm{II}_{3}, \mathrm{II}_{4}$, I34.

Knot-grass, $64, \times 55$.

Knots, 39.

\section{L.}

LABELlum, 88, 89, 130 .

Labiatæ, 157

Tabiate, 86, 89, 90, 12 r, 122.

Laburnum, 156.

Ladies' slipper, 94.

Lady's mantle, 156 .

Iambs' tiils, iा6.

Lamella, middle, $3^{2}$.

Lamina, 52, 54, 62; apex of, 58 ; base of, 58 ; colour of, 62 ; description of, 147 ; form of, 57-58; margin of, 58-59; modifications of, $6 \mathrm{r}-62$; position, $54-55$; structure of, $64-66$; support of, 67 ; surface of, $62-63$; symmetry of, 55 ; texture of, 62 ; venation of, $55-57$.

Lanceolate, 57 .

Landing stage, I21, 123, 126, I28.

Larch, 2I, I52.

Larkspur, 85, 86, 88, 91, 100, $102, \mathrm{IO}_{3}, \mathrm{IO}_{7}$, $109,122,126, x_{33}, x_{37}, x_{51}, 1_{55}$.

Lateral, $56,75,76,=82,85,88,90,94, \mathrm{IO}_{3}$, 105.

Lathyrus, 63 .

Laurel, $x_{3}, x_{5} 6$.

Lavender, 62, 157 .

Layering, 43.

Leaf, I0, II, I9, 20, 45, 47, 54, 55, 67, 68, I59, I6́ ; arrangement of, $46-50$; cataphyllary 1. (see Scale leaf); euphyllary 1. (sce Foliage leaf); floral 1. (sce Floral leaf); foliage 1. (sce Foliage leaf); hypsophyllary 1. (see Bract); kinds of, $5 \mathrm{I}$; scale 1. (see Scale leaf); seed 1. (see Cotyledon) ; 1. climber, 26, 53,$61 ; 1$. insertion, 50, 53, 64; 1 . margin (see Nargin); 1. scar, 43, 47, 48 ; 1. spine, 6 I ; 1. stalk (see Petiole); 1. tendril, 61,73 .

Leaflet, 59, 60, 61, 63, 72, 73, 83, r47.

Leathery, $62,65,67,69$, 148 .

Leek, 154 .

Legume, I37, I40, I56.

Leguminosere, 156 .

Lemna, 153 .

Lemnacex, 153 .

Lemon, 139.

Length of stem, 23 .

Lens, 29, 65, 145 .

Lenticel, 4I, 43 .

Lesser celandine, 155 .

Lettuce, I 57 .

Life, 2, 5; physical basis of, 4; under simple conditions, 8-10.

Life history, 6.

Ligulate, 90, 157 .

Ligule, 63,88 , ${ }_{54}$.

Lilac, $47,56,64,80$, 100.

Liliaceæ, 154 .

Lily, 2r, 39, 86, 93, 94, 98, 104, 107, 109,
I20, I38, I49, I54; tiger $1 .$, I, $44 ; 1$. ol the valley, 56 ; white $1 ., 65,96$, Ioo.

Limb, 85, 87, 89, 123.

Lime, 50, 116, 117, 121, 151.

Limited growth, 66 .

Linear, 97.

Lip, 86, 89, 90, I27, I28, I29.

Lipped (see Labiate).

Liquor iodi, 159.

Lobe, 55, 58, 59, 6r, 62, 86, 89, 90, 93, 96, 97. 118, 124, 128, 129.

Jobed, $58,59,118$.

l.obelia, 9o, 95 .

Locomotion if plants and animals, 3,4 .

Loculicidal, $\mathrm{I}_{3} 8, \mathrm{I}_{54}, \mathrm{x}_{55}$.

Loculus, 100, 104, 105, 106, 107, 137, 138. I39.

Iodicule, II 7 .

Log. $3^{8}$

Londen pride, roo.

Long-styled, I25.

Loosestrife, 124, 125 .

Low power, $x_{5} 8, x 59$.

Lubbock, 120.

Lupin, $127,156$.

I.ycopodium, 92.

\section{II.}

MACE, I34.

Madagascar, 62 .

Magenta, 159. I60.

Magnesium, Io, I60.

Mahonia, 60.

Maize, 98, 133, 136, 143, 160.

Male; catkin, 99, II6, I55; cone, 92, 99 ; flower, $92,95,98,99,100,115,125,155$ inflorescence, $99, \mathbf{x} 53$.

Mallow, 94, 95. 97, 120, $1_{37}, \mathrm{I}_{5} 6, \mathrm{I}_{5} 8$.

Malva (see Millow).

Malvacere, 156 .

Many-seeded, 137 .

Maple, 137, I $_{42}, 1_{4} 9$.

Marble, I8.

March, 99.

Margin; of lamina, 56, 58-59; of carpel, 102, 104, 105; dorsal m., 102, 105.

Marginal, I02.

Marguerite, 157 .

Marjor:an, 96, 157 .

Marsh, 6r; m. mallow, 85 ; m. marigold, $87,102, r_{37}, r_{55} ; m$. pea, 63 .

Masked, 90.

Matter, 4-6.

Meadow; m. geranium, $124 ; \mathrm{m}$. pea, 63 ; m. sige, 96, 129

Meadow-sweet, ${ }_{5} 6$.

Medium-styled, 125 .

Medulla (see Pith).

Medullary ray, 29, 30, 32, 38, 39. I52 ; primary or large m. r., 36 ; seconclury or short m. $r ., 37$.

Menuber, $7,8$.

Membrane, 3 .

Membranous, 55, 63, 64, 76, 86, 139 .

Mericarp, i 37 .

Meristem (sce Tissue, fornutive).

Mesocarp, 136, I39.

Mesophyll, 64, 65, 66, 67, 71.

Metamorphosis, rxo.

Methylated spirit, I59.

Nicropyle, 107, 109, II4, I15, х31, 132, г 33 . 
Microscope, 29. 44, 72, 158, 159, 160; use of, x $58-160$.

Middle lamella, 32 .

Midrib, 56, 57, 59, 62, 63, 86, 89, 102, 104.

Mignonette, 102, 12 r, I50, 15x.

Milky, I 55, I 57 .

Millefoil, 59, 1x9.

Minikins, 145 .

Mint, 26, 157 .

Mirror, 158, 159 .

Miscellaneous examination questions, 165 , 166.

Mistletoe, 18, 24, 47, 79 .

Mixed inflorescences, 80.

Modification; of stem, 27 ; of petiole, 53: 54 ; of lamina, $6 r-62, \mathbf{r} 47$.

Moisture, 19, 20, 3r, 69, Ir2 (sce Water).

Molecule, 4 .

Monadelphous, 95, 120, 156 .

Monkshood, $85,87,88$.

Monocarpellary, ror.

II inocotyledon, 21, 24, 30, 36, 38, 50, 52, 53 , $55,56,57,66,83,86,93,98,107,120$ $133,152,153-154,158$; diagram of, 22.

Monoeciots, 99, 100, 116, I53.

Monopodial, $14,24,75$.

Monosymmetrical, 80 (see Irregular).

Monotropa, 64 .

Monstrosities, I 10 .

Morphology, I ; elementary, 7-8: of root, $\mathrm{r}_{3-\mathrm{I}} 7$; of stem, $2 \mathrm{I}-4 \mathrm{I}$; of buds, $46-50$; of foliage leaf, 52-66; of scale leaf, 64 ; of bracts and inflorescence, $74-80$; of flower, 80-110.

Moth, 120.

Motility, I2; of root, I9; of stem, 44; of foliage leaf, $7^{1-73}$; of peduncle, 140 ; of flower, $13 \mathrm{r}$; of stamen, 124 ; of stvle, r24; of stigma, 128 .

Mottled, 62 .

Mountain; m. ash, 156; m. geranium, I20.

Mounting of microsenpic objects, r59.

Movement (sce Motility).

Mucronate, 147 .

Mulberr5, 135.

Mullein, 94, 97, 157 .

Multicellulitr, 8,28 .

Multiple, r35.

Mushroom-slianed, $\mathbf{1 2 .}$

Musk, 128, 157 .

Mustard, 18,50 .

Myrtle, 55, 66 .

\section{N.}

NAMES, scientific, 2 r.

Napiform, I 46.

Narcissus, 76 , I54.

Nectar, 85, I1 1 , II2, II3, II4, II6, II7, I18, I19, I21, 122, I23, I24, 125, 126, 129, 130

Nectary, 74, 85, 100, 106, 110, I17, 123, 124, $148,15 I, 155$.

Needles, 30 .

Nepenthes, 62 .

Nerves, 3 .

Nerrous system, 3,4 .

Nest, $1_{35}, x_{36 .}$

Nettle, 63, 65, 72, 99, 100, 109, II7.

Net-veined, 56,153 .

Network of veins, 56 .
Neuter, 94, 98, rrg.

Night, $x 1,70$.

Night-flying insects, rro, 12x.

Nightshade (see Deadly nightshade, Enchanter's nightshade).

Nine, 95.

Nitrates, 10, 160.

Nitrogen, 5, 6, 10, 160 .

Nitrogenous organic matter, 10.

Node, 22, 23, 29, 30, 43. 48, 149, $154,1_{55}$.

Non-nitrogenous organic matter, ro.

North, 55.

North America, 55, II 6.

North Carolina, 6r.

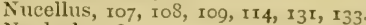

Nucleolus, 8.

Nucleus, 8, Ir, 16; of embryo sac, rog.

Nudiflor:, $x_{52}, I_{53}-I_{54}$.

Number, 83 ; of carpels, $78-100, I_{4} 8$; of seeds, r48; of sepals, 83, I48; of stamens, 92-94, 148 ; of petals, 86-87, 148.

Nutrition, II, 17-18, 41-42, 63, 67-7 r, Ir 4 .

\section{O.}

OAK, 38, 42, 5I, II6, I 49, I 55 .

Oat, $x_{33}, x_{3} 6, x_{45}$.

Objective, 158.

Oblanceolate, 58 .

Oblique, $82,88,94$, I47, I55.

Oblong, 57 .

Ohovate, 58

Obvolute, 84 , 150.

Ochreate, 64, I55.

Odour, т16, І17, 118, т20-12 r.

Offset, 25 .

Ogle, $x 10$.

Oil, $28,62,66,68$, III, I34. $_{3}$.

Onagracere, 156.

One, $84,86,94,97,98,99$, roo, ror, ro6.

Onion, 21, 55, 76, 154.

Opaque objects, 188 .

Open, 32, 84, 150 .

Opposite, 49, 54, 63.

Orange, 8, I04, I32, I49, I4I.

Oringe-coloured, 91, 96, IOI.

Orchids, $\mathbf{r}_{3}, 86,94,95,97,98, \mathbf{1}_{20}, \mathbf{I}_{4} \mathbf{1}, \mathbf{x}_{54}$.

Orchidaceæ, 154 .

Orchis, $88,89,105,122,129-130$, I50, I57.

Order (see Fanily).

Organic matter, 10, $42,67,7$ r, II4.

Organs, $7-8$; essential, 92 ; reproductive 43,92 ; vegetative, $17,29,4 \mathrm{I}, 43$.

Origin of roots, 14 ; of stems, 22.

Orobanche, 64 .

Orthostichy (see Rank).

Orthotropous (see Straight).

Osmosis, 9, I7, 18, 4I, 67 .

Outline (see Form).

Oval, 57, 97.

Ovary, 100, xо1, 102, 103, 104, 106, 107, 117 , $123, I_{45}, \mathrm{I}_{52}, \mathrm{I}_{53}, \mathrm{I}_{56}, \mathrm{I}_{57}, \mathrm{x}_{59}$; description of, $\mathrm{r}_{4} 8, \mathrm{r}_{5} \mathrm{r}$.

Orate, 57.

Oroid; 144 .

Orule, 75, 92, 101, 102, 104, 105, 106, 107I09, I14, 132, 136, ז52, 154, 155, I57; description of, 148,157 .

Ovum (see Egg-cell).

Ox-eye daisy, I57.

Oxidation, Ir. 
Ox-lip, 125 .

Oxygen, 3, 5, 10, II, x9, 71, 143, x6o.

Osster, 4.

\section{P.}

PACIFIC, I4I.

P:xony, I37, I55.

Palate, go.

Pale, II 7 .

Palm, 21, 56 .

Palmate, 59.60.

Pulm itely; p. cleft, 59 ; p. divided, 59 ; p. lobed, $59 ;$ p. parted, 59 .

Panicle, 79, 80, 100, II 7 .

Pansy, 63, 75, 76, 88, 96, 98, I04, I21, I27, I5O, I5I.

Papaveracex, I55.

Papilla, ro7.

Pappus, I4I, I57.

Parallel-veined, 56,152 .

Parasite, 3, 64, 7I.

Parenchyma, $14,19,31,36,41,42,67,98$, 135 ; palisade p., $65,66,68$; spongy p., $66,67,9$.

Parietal, I05, 137, I54, r55; p. layer, 32.

Parsley, I56.

Parsnip, 79, 106, I19, I42, ${ }_{5} 6$.

Parted, 59.

Partial; p. involucre, 79 ; p. peduncle, 76 .

Passiflora (see Passion-flower).

Passion-flower, 27, 45 .

Patchouli, 62.

Path-pointer, 122.

Pei, 61, 82, 88, 95, 100, I01, 102, 106, II4, I27, $\mathrm{r}_{35}, \mathrm{I}_{37}, \mathrm{I}_{43}, \mathrm{I}_{50}, \mathrm{I}_{56}$.

Peach, II 3, I39, $_{5} 6$.

Pea-flower family (see Leguminosex).

Peitr, 136,156 .

Pedicel, 76, 78, I1 7, I47.

Peduncle, $74,76,85, I_{02}, I_{2}$, II5, I40, I42, 147.

Peel, 139

Peeling; of potatoes, 26 ; of tivigs, 40.

Pelargonium, 28, 85, 156.

Peltate, 58.

Pendent, 99, 123, r47.

Pendulous, 77, I06, II3, II6, I23.

Penknife, 74, 145.

Pentastemon, 94, 97, I57.

Pepper-castor, $3 \mathbf{I}$.

Perennials, $14,23,41,42,48, I 46, I 48, I 49$.

Perfoliate, 58.

Perianth, 74, 8I, 83-9I, 92, 99, II 3 , II5, II6, II7, II8, II9, I26, I40, I42.

Pericarp, $136,1_{37}, I_{39}, 1_{40}$.

Perigynous, $8 \mathbf{1}, 84,85,87,95$, IOI, II3, I36, I59, I5I, I53, 156 .

Perisperm, I3I, I33.

Periwinkle, 54 .

Permanent slides, 160.

Persistent, 86.

Personate, 90, II 3 .

Petal, 74, 75, 76, 82, 83, 85, 86-9r, 93, 94, 95, I03, IIO, I13, I22, 123, I27, I50, I5I, $I_{54}, x_{55}, 1_{56}, x_{57}$.

Petaloid, 76, 86, 87, 88, I20, I25, I26, I56.

Petaloider, I52, 154 .

Petiole, $52,53-54,56,59,60,61,63,64,66$; description of, 147 .

Petunia, 157.

Phanerogams (see Flowering plints).
Phloëm (see Bast).

Phosphates, 10, 160.

Phosphorus, 5, 10.

Phylloclade, 27, 42.

Phyllode, 53, 54, 63, 70 .

Phyllotaxis, 49-5 I, $83,147,149$.

Physiology; elementary, 8-1o; of root, I 7-20; of stem, $4 \mathrm{I}-45$; of foliage leaf, 66-73; of flower, III-r3I ; of seeds and fruits, $\mathrm{I}_{40-143}$; practical, 160.

Pigment, 9r.

Pilose, 28.

Pimpernel (see Scarlet p., Water p.)

Pine, 21, 116, 152.

Pineapple, 135 .

Pink, 2r, 49, 87, 100, 105, 124, 129, 138, 156.

Pinnate, $59,60,6 \mathrm{r}, 63$.

Pinnately; p. cleft, 59 ; p. divided, 59 ; p. lobed, 59 ; p. parted, 59,62 ; p. veined, $56,57,59$.

Pins, 145.

Pinus (see Fir).

Pip, 132, 136, r4.

Pistil, 81, 83, 85, 92, II5, I22, 124, I28, I29, $152,153, I_{54}, 1_{55}, x_{56}, 1_{57}, 1_{58}$; description of, $\mathrm{I}_{4} 8, \mathrm{I} 5 \mathrm{I}$.

Pistillate, 94.

Pit, 32, 33, 55 ; bordered pit, 35; p. mem. brane, 32,33 .

Pitcher-plants, 4, 54, 62, 7 I.

Pith, 29, 30, 34, 38, 39, 40, 42, I52, I59.

Placenta, 101, 102, 104, 106, 107.

Placentation, 102, 104, 105, 106, I37, 154. I55, I56, I57, I58; description of, $\mathbf{I}_{5} \mathbf{x}$.

Plaited, 49.

Plane, antero-posterior p. (see Median); lateral $p_{0}, 82$; median p., 52,82 ; oblique p., 82 .

Plank, 39.

Plantago (sce Plantain).

Plantain, 57, 78, 93, I17, $118, x_{3} 8$.

Plants, how differing from animals, $2-4$; aquatic p., II, $18,19,23,43,68$, II2, II5, I 40 ; climbing p., 8, 2.t; creeping p., 24; flowering p., 2, 12, 21, 33; Howerless p., 2 ; green p., II ; insectivorous or carnivorous p., $3,54,6 \mathbf{I}-62$, $7 \mathrm{I}, 73$, II2, II 4 ; land p., I7, т9, 43, 69, 70 ; marsh p., 23 ; multicellulitr p., 8 , I2: unicellular p., 8.

Pluin, 42, 139, 156.

Plumbago, 84 , I12, 142.

Plumule, $\mathrm{r}_{32}, \mathrm{I}_{33}, \mathrm{I}_{42}, \mathrm{I}_{43}$.

Pod, 102, 137, 140.

Point, growing (sce Growing-point).

Pollen, 74, 75, 92, 96, 97, 99, I Ir, I $44-131$; p. canal, ro7, I14; p. grain, 98, rog, $114,116,118,123,131,158$; 1). sac, 98 , I09, I52; $\mathrm{p}$ tube, II4, II5, 125 .

Pollination, II4, 140, I5I; by birds, I30; cross, II $5^{-1} 30$; by insects, II8-130; self, II5, I30-I3I; by water, II $5 ;$ by wind, II 5-1 18,120 .

Pollinium, 97, 130 .

Polyadelphous, 95.

Polyanthus, 125, 157 .

Polycarpellary, ror.

Polygamous, 99.

Polygonaceæ, 155.

Polygonum amphibium, 1 I2.

Polypetalae, I $_{53}, \mathbf{I}_{55}, \mathbf{I}_{5} 6$.

Polypetalous, 87, 88, I 4 , 53 . 
Polysepalous, 84,85 .

Poly'synmetrical, 80 (see Regular).

Pome, 136.

Ponds, E2.

Poplar, Ir6.

Poppy, 21, 62, 84, 87, ror, xо3, 105, 122, ${ }_{13}^{8}, 141,150,155$.

Porc, 97, $123,124,1_{3} 8$.

Porous capsule, 138, I41.

Position, relative, 7,27 .

Posterior, 85, 86, 89, 94, 95, 103, 105, 127 , 156.

Potassium, Io, 160.

Potato, $5,17,26,44,45,59,64,89,93,97$, r $49,157$.

Potentilla, 62 .

Power (of microscope), high p., 3I; low p., $3 \mathrm{r}$.

Practical work, 6 .

Pratloration, 84,87 .

Prefoliation, 84, 149.

Prickle, 28, 4I, 65, 86, III.

Primary, $\mathrm{r}_{32}, \mathrm{I}_{4} 6$; leaflet, $6 \mathrm{r}$.

Primine, ro8.

Primrose, 76, 84, 87, 89, 93, 95, 96, 97, ror, I06, $124,125,138,151,157$.

Primulacer, 157 .

Prismatic, 27.

Privet, 100.

Procumbent, 25.

Prosenchymatous, 32 .

Prostrate, 25.

Protection; of buds, 47 ; of flower, III-II4, $\mathrm{I} 48, \mathrm{I} 5 \mathrm{I}$; of foliage leaf, $6 \mathrm{I}$; of lamina, 54 ; of root, I7 ; of seeds, I40, 148 ; of shoot, 27, 40, 6r.

Proteids, $5,26,42,67,71$.

Proterandry, II5, II7, I20, I22, I23, I24, I28, I29, 151 .

Proterogyny, I15, 117, I18, 121, 123, 151.

Protoplasm, 4, 5, 8, I0, II, I7, 28, 3I, 32, 33 , $34,35,40,42,43,65,7 x, 72,73$, т 14, I 15 $x 60$; composition of, 5 ; structure, 5 .

Protoxylem, 34, 36, 37 .

Pruning, 18.

Pseudaxis (see Synpodium).

Pseudocarp, I35-136, I5 I.

Pubescent, 28.

Pulp, 8, x 39.

Pulvinus, 53, 147.

Purple, 88, 89, 119, 124.

Purple loosestrife, I24, 125

Purple orchis (see Orchis).

Pyxidium, $x_{3} 8$.

Q.

QuiLled dahlia, 95.

Quincuncial, 51 .

R.

RACEME, 77, 78, 79, 117, 154, $x_{55}$.

Racemose, 24, 46, 75, 76, 80, 149 .

Radial, 30 .

Radical, $24,57, x_{47}, x_{49}$.

Radicle, $132,133,142,143,152$.

Radish, 13, I4, I55.

Ragged-robin; 87, 556 .

Rain, Ir3.

Rank, 83. 149.

Ranunculaceæ, $\times 55$.
Ranunculus (see Buttercup).

Raphe, rog, 132 .

Raspberry, 25, $x_{3}, 1_{23}, x_{39}, x_{5} 6$.

Razor, 29, 159 .

Ray, 78 ; ray floret (see Floret).

Reagents, I59, 160 .

Receptacle, 78, r2I; for water, I12.

Recumbent, 25 .

Red, 9r.

Reddish brown, I19.

Reduction, 84, 94, 96, 129.

Reflected light, $15^{8}$.

Reflexed, 85, 88, 90, Ii3, I25.

Regular, 80, 88, 80, 123-126, 154, I55, 156 , 157.

Relation of floral leaves, $82,1_{4} 8$, r $_{50}$ (see Floral diagram).

Relationships (of plants), 2.

Renewal of organisms, 6.

Reniform, 58.

Replum, $x_{37}$.

Reproduction, 12 ; true, $1_{1} 4^{-1} 31$; vegeta. tive, $19,43,44,71, \mathbf{1} 4$.

Reproductive, 19 .

Re-erve materials, $14,18,24,25,26,42,64$, $67,68, \mathbf{x}_{34}, \mathbf{x}_{42}, \mathbf{x}_{43}, \mathbf{1 6 0 .}$

Respiration, II, $x_{2}$; of flower, $\mathrm{x}_{4}$; of foliage leaf, $7 \mathbf{I}$; of germinating seed, I4.3 ; of root, $18-19$; of simpie plint, is ; of stem, 43 .

Respiratory cavity, 66.

Reticulated, 56 .

Revolute, I 49 .

Rhizome, 26, 42, x 54 .

Rhododendron, $97,{ }^{3} 3$.

Ribbed, 23.

Richardia, 153 .

Ridged, $28,29,49,53, x 46$.

Ringent, go.

Ringing, 42.

Rings, annual, 38,39 .

Ripening, of seed, 86, 99.

Robinia, 19, 53, 64.

Room, plants in, 7 o.

Root, 7, 8; adventitious, r3, r4, I9, 21, 22, $26,43,49$; air, 13 ; 1 . cap, $16,17,34 ; r$. climbers, 26; description of, 146,149 ; development of, 14, 39 ; examination questions in, $r 6 r$; 1 . fibre, 149 ; $r$. hairs, $I_{4}, 18,28$; morphology, I3, I7, 21, I43, 152 ; parasitic, 13, 18 ; physio$\operatorname{logy}, 1_{7}-20,42,44,45,67,69$; r. pres. sure, 18; primary, ${ }_{13}, I_{4}, 1_{9}, 20,2 \pi$; secondary, $x_{3}, 1_{4}, x_{9} ; x$. sheath, $x_{43}$; structure of, $x_{4}-15,3 x, 66, x_{59}$; tap, $x_{3}$, I4, 21, I46, 152; r. tips, 19, 20; r. tubers, 14, 19; underground, $\mathbf{1}_{3}$; water, $\mathrm{I}_{3}, \mathrm{I} 8$.

Rootstock, 24

Rosacere, $\mathbf{x}_{5} 6$.

Rose, 21, 25, 28, 48, 51, 59, 63, 8x, 83, 84, 8 , 103, 106, 110, 123, 130, 156 .

liose-bay willow-herb, 120, 124.

Rosemary, 149, 157 .

Rosettes of lettves, I9, 24, 6I, II2.

Rostellum, זзо.

Rotate, 89 .

Rounded, 57.

Round-leaved sundew, II.

Rowan, 156.

Rows of cells, $3^{I-32}, 33,40$.

Rudiment, 94, 96. 
Rue, 66.

Runner, $25, x_{4} 6$.

Rupture, 30 .

Rupture, of tissues, 23.

Ruscus (see Butcher's bioom).

Rush, 55, 93, 117, 120, 154.

\section{S.}

SaCCATE, 85,88

Saffron, 138 .

Sage, 86, 96, 97, 100, 105, 157 .

Sagittate, 58.

St. John's wort, 66, 94 .

Salts, 3, 4, 9, 10, 71, 160.

Salver-shaped, 89, 118,125 .

Samura, 137 .

Sand, r6o.

Saprophyie, 3, 64, 7x.

Sap, 8, 38, rзo; ascending or crude, 4r, 42, 67,71 ; course of, $4 \mathrm{I}-42$; elaborated, 42,67 (see Cell-say)).

Sap-wood, 38, 42 .

Sarracenia, 54, 7 I.

Saucer-shaped, 89 .

Sawdust, r6o.

Saxifrage, roo.

Scabious, 157 .

Sctule, 28, 64, 98, 99, ror, I52, ${ }_{54}$ (see Scaleleaf).

Scale-leaf, 46, 6r, 64, 67; description of, I $47,149$.

Scalpel, 29, 74 .

Scaly, 78, 86, 152 .

Scape, 76, II2.

Scar, 132 (see Leaf-scar).

Scarlet pimpernel, 138,157 .

Scarlet runner, $25,53,59,64,72,127$.

Scattered, 48, 49, I12, I55, I56, 157 .

Schizocarp, 137 .

Selerenchyma, $33,34,36,4 \pi, 66$.

Scorpioid cyme, 8o.

Scotch fir (see Fir).

Scrophularia, 157 .

Scrophulariacere, I57.

Scutellum, r33, I43.

Sea-squirt, 4 .

Secondary ; bast, 37 ; leaflet, $6 r$; lobe, 59 ; root, 13 ; sten, $2 x$; wood, 37 .

Secretion, 66

Secretory reservoir, 66.

Section ; cross-s. (see Transverse s.); longitudinal s., 30, 107, 149 ; preparation of, $159-160$; radial s., $30,32,33,38$; tangential s., 30, 38 ; transverse s., 30, 3I, $38,40,98,106,149$.

Section-cutting, 159 .

Secundine, ro8.

Sedges, 21, 26, 50, 53, I17, I18, 1 20, 142, 149, I 54 .

Seed, $7,67,68,75,86$, 102, I09, II5, 136, 137, $1_{39}, x_{52}, x_{53}, x_{54}, x_{58}, x_{60}$; description of, 148 , 151 ; distribution of, $140-142$; examination questions on, I64; germination of, $142-143$; morphology of,

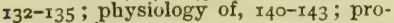
tection of, 140 .

Secd-coat, $1_{32}, 1_{34}, x_{3} 6,1_{37}, 1_{39}, I_{40}, 1_{42}$, I43.

Seedling, r9-20, 44, 50, 54, 6r, 68.

Segmented, 58.

Self-pollination, $11_{5}, 1_{20}, x_{25}, 1_{26}, 1_{27}, x_{29}$ I3 $x$.

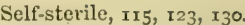

Sensitiveness, 3 (see Irritability).

Sensitive plant, $3,53,72$.

Sepal, 74, 75, 82, 83-86, 87, 88, 103, $\mathbf{1} \mathbf{1 0}, \mathbf{r} \mathbf{8}$, I25, 126.

Septicidal, $137, \mathbf{1}_{3} 8$.

Septifragal, ${ }_{3} 8$.

Series, 21, I5 I, I52, I53, I54, I55, I56, I57 ; linear s., 2.

Serrate, $5^{8}$.

Sessile, 52, 58, 59, 63, 96, 103, I1 7, 122, 147 .

Setose, 28.

Seven, 6r.

Shadow, 54

Shape (see Form).

Sheath, $53,63,64,76, x_{52}, 1_{53}$; description of, 147 .

Sheathing, $55,63,84,{ }_{5} 6$.

Shepherd's purse, $28,76,83,85,105$, 109, I37, 155 .

Shoot, 19, 22, 25, 26, 40, 4r, 42, 43, 44, 46, $54,61,68,70,71,74,75,76,80,92,99$, ro9, 132,160 .

Shortening, of root, 19.

Short-styled, 125.

Shrub, 23, 48, 146, I54, 155.

Sieve-plate, 3I, 33 .

Sieve-tube, $31,33,34,35,36,67$.

Silica, 67 .

Silicula, I37. $_{37}$

Siliqua, 137, 141, 155 .

Silky, 28.

Silphium, 55.

Silver grain, 38 .

Silverweed, 62 .

Simple, 59, 76, 78, 79 .

Six, 82, 93, 94, 98, 99, $117,123$.

Size, of plants, 23 , 146 .

Skeleton leaves, 8.

Sleep, of plants, 72 .

Sleeping-room, Ix.

Slides, $15^{8-160 .}$

Slit, 124 .

Sloe, 28, 156 .

Slugs, 4 I.

Small-flowered geranium, 120.

Smooth, I46 (see Glabrous).

Snails, 4I, IIr.

Snapdragon, $77,87,90,94: 95,96,97, x r_{3}$, $128,1_{3} 8,1_{57}$

Snowberry, 104.

Snowdrop, 21, 76, 83, 86, 93, 94, 98, ror, $105,1_{13}, 1_{23}, 1_{54}$.

Sodium, 160.

Soft-bodied insects, $1 \mathrm{x}$.

Soil, I7, I9, 45, I4I, I42.

Solid, 23,146 .

Solomon's seal, 26 .

Solution, of food, 10, 17, 18, 69 ; how to prepare, 160

Sorrel, 64, 117, 155 .

South, 55 .

Sowbread (see Cyclamen).

Spadicifloræ, $\mathbf{I}_{52}, \mathbf{I}_{53}-\mathbf{1} 54$.

Spadix, 78, 99, 120, 125, I52, 153 .

Spanish chestnut (see Chestnut).

Sparganium, 154 .

Spathe, 76, 120, 125, 153 .

Species, 2x.

Speedwell; 89, 94, 9.5, 157.

Spike, $77,78, x_{7}, x_{18}, 1_{52}, x_{54}$.

Spikelet, $117,152$. 
Spinach, I55.

Spindle-shaped, 14,28

Spindle-tree, $x_{34}$.

Spine, 27, 28, 4I, 6r, 64, II I.

Spiny, 147.

Spiral, 25, 74, 75, 80, 81, 83, 92, 110, т15, I40, 155 ; genetic s., 50 .

Spirit, 159.

Splitting fruit, $x_{37}, x_{5} 6, x_{57}$.

Spontaneity, Ix, I2; of root, 19 ; of stem, $44^{-45}$; of foliage leaf, 73 ; of flower, $13 x$.

Sporangium, 92, rog.

Spore, 92, 109, II4 ; s. case, Iog.

Spore-leaf, female (see Carpel); male (see Stamen).

Sporophyll, female (see Carpel); male (see Stamen).

Spotted, 62, 90, 122 .

Spreading, $85,88,118,123,124,147$.

Spring, 18, 19, 38, 46, 47, 116 .

Spring-clip, 158 .

Spring-water, 69 .

Spur, 85, 90, I2I, I30, I5I, I55.

Spurious fruit (see Pseudocarp).

Spurred, 85,88 , go.

Square, 23, 30, 52, I46, $_{57}$.

Squirting cucumber, I4I.

Stage, $158,160$.

Staining, of sections, 159-160.

Stalactite, 6.

Stalk (see Funicle, Pedicel, Peduncle, Petiole).

Stalked, 52, 59, 60, 69, 77, 147 .

Stamen, 74, 75, 82, 85, 86, 87, 88, 92-98, 100,

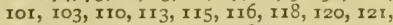
$122,123,124,125,127,128,129,130, I_{52}$, $153, x_{54}, 1_{55}, I_{5} 6, x_{57}$; description of, 148, I 5 .

Staminode, 97.

Stand, 158 .

Standard, I $\mathbf{I}_{3}$.

Standard rose, 25

Starch, 3, 10, 18, 25, 42, 67, 134, I35.

Stellate, 89 .

Stom, 2I-45; adventitious s., 22; aerial, 23, 24-25; climbing s., $25-26,44,45$; creeping S., 25,43 ; description of, 146 , I49; examination questions on, $16 \mathrm{I}$ 162 ; external form of, 23-27; kinds of, $24-27$; length of, 23 ; modified s., 27 ; morphology of, $7,2 \mathrm{I}-4 \mathrm{I}, 46,52,99$ : overground s. (see Aerial s.); parasitic s., 23; physiology of, 8, 20, $4 \mathrm{I}-45,67$, $7 \mathrm{I}$, III ; primary S., I3, $2 \mathrm{I}$; structure of, $29-41,64,66,159$; surface of, 28 ; secondary s., 2 I (see Branch); subter. ranean s., $23,24,26-27,43,64,146$; thickness of, 24 ; underground $\mathrm{s}$. (see Subterranean s.); water s., 23; s, tendril, 27,73 .

Stereome, 41, 67.

Sticky substances, 28, 4I, 46, 6r, 64, 107, $112,114,116,117,118,142$.

Stigma, 100, 102, 103, 104, 107, II4, I15, I16, I17, I18, I20, I $21,122,123,127$, I28, 129, 130, 13x; description of, 148 .

Stimuli, II, 19, 73 .

Stinging hairs, $62,65,72,154$.

Stipel, 64.

Stipule, 53, 63-64, 85, I12, II3 ; description of, 147 ; kinds of, $63-64,84,155$; sur. face of, 64 ; texture, $64 ;$ s. spine, 64 ;

s. tendril, 64 .

Stitchwort, 79, 156 .

Stock, 28, 83, 123, I37, 141, 155.

Stolon, 25, 43 .

Stoma, -ta, 3r, 4r, 43, 65, 66, 69, 70, 98, ro7.

Stomach, 4, 7x.

Stone-crop, 66.

stone-fruit, 139,140 .

Storage ; of ieserve materials, $18,24,25,26$, $42,64,67,1_{34}, 1_{42}, 160$; of nectar, 121 .

Stork's-bill, I42.

Straight, I08.

Strain, r29.

Strap-shaped, go.

Straw, 23.

$\left[\mathrm{I}_{3} 6, \mathrm{I} 56\right.$

Strawberry, 25, 43, 59, 85, 103, 122, 123, Streaked, 122,

Streaming, of protoplasm, II, 44, $7 x, 72$.

Striking, of cuttings, $r_{3}$.

Structure, $x, 8,8_{3}$; of root, $x_{4-17}$; of stem, $29-41$; of follage leaf, $64-66$; of sepal, 86 ; of petal, $9 \mathrm{r}$; of stamen, $97-98$; ot pistil, 107-rog; of seed, I34-I35.

Stumps, 23 .

Style, 100, хог, 102, 103, 106, 107, II4, II7, $123,124,126,127, x_{57}$; description of, 148 .

Subclass, $x_{51}, x_{52}, x_{53}, x_{54}, x_{55}, x_{5} 6$.

Subdivision, $15 x, x_{52}$.

Suberin, 40.

Submerged, 65,68 .

Succulent, 62 , 146 .

Succulent capsule, $\mathbf{I}_{39}$.

Succulent fruits, I39, 140, 142

Sucker, 23, 25, 43 .

Sugar, 9, 18, 67, 71 .

Sulphates, xо, 160.

Sulphur, 5, I0.

Sulphuric acid, $\mathrm{r}_{59}, \mathrm{I} 60$.

Sulphur showers, II6.

Summer, 47,48 , ror.

Sun, 55, 67 .

Sundew, 6r, 73 .

Sunflower, $13,29,30,34,36,37,56,69,78$, 95, 106, х19, 126, 136, 157.

Sunlight (see Light).

Superficial, ro5.

Superior, 85, I01, I1 7, 135, 136, I51, 152, 153 . Superposed, $83,93,97,1_{54}, 1_{55}$.

Support, I7, 24, 25, 4I, 44, 45, 66-67, II I.

Suppression, 78 , 103, 109, 151 .

Surface; of root, $x_{4} 6$; of stem, $28,1_{4} 6$; of petiole, $54, \mathrm{I}_{47}$; of lamina, $62, \mathrm{I}_{47}$; of stipule, 64 ; of scale-leaf, 147 ; of calyx, 86 ; of corolla, $9 \mathrm{x}$; of ovary, 104.

Suspended, 106.

Suture (see Ventral suture).

Sweet-briar, 62 .

Sweet-chestnut (see Chestnut).

Sweet-pea (see Pea).

Swollen, 85 .

Sycamore, 56, I42.

Symmetry, $4_{48}$; bilateral s., $52,55,80,85$, 86,87 , 106; radial s., $52,55,66,80,81$ 86,87, 106.

Sympodium, 24, 27, 48, 79, 8 o.

Synantherous (see Syngenesious).

Syncarpous, 100, 101, 102, 103, 105, 107, II7, $124, x_{35}, 1_{36}, 1_{53}, 1_{54}, 1_{55}, 1_{56}, 1_{57}$.

Syngenesious, 95, 126 .

Synpetalous, 87 .

Synsepalous, 84 . 
T.

'TAIL, I24.

Tangential, 30.

'Tapeworm, 4.

Taproot (see Root).

Tare, 6.

Teasel, I12, 157.

'Teeth, 58, 59, 86, 89, 90, 137, $3_{38 .}$

'Telegraph plaut, 73 .

Ten, 93, 95, хоз.

Tendril, 25-26, 27, 45, 6r, 62, 64; t. climbers, $25-26,43,61$.

Tension, 40, 127 .

I'entacle, 6x, 73 .

'T'erminal, r47.

'Ternite, 6r.

'iermately-parted, 63 .

Tertiary, leatlet, $6 x$.

'Test-tube, 69 .

Tetradynamous, \$4, 123, 155 .

Texture; of corolla, 91 ; of lamina, 62, I 47 ; of root, I 46 ; of scale-leaf, 147 ; of sepal, 86 ; of sheath, 147 ; of stem, 41 , I 46 ; of stipule, 64,147 ; of wood, 38 .

Thalamifloræ, $153, \times 55^{-156 . ~}$

Thickening (see Growth in thickness).

Thickness; of root, $1_{3}, r_{4}$; of stem, 24.

Thirteen-ranked, $5 \mathrm{I}$.

Thistle, 46, 78, 89, 95, III, I22, 14 ?.

Thorn, 27, 28, 4r, 67, I1 1 .

Thorn-apple, I57.

Three, 83, 86, 88, 93, 94, 98, го0, 104, х17. I26, $138,{ }_{5} 2$.

'Three-sided (see Triangular).

'T'bree-ranked, 50.

'Three-rayed, 80.

'Thrift, ro6.

Throat, 89 .

'Thyme, 129, 157 .

'Thyrsus, 80 .

'T'imber, 38 .

Tissues, 8 ; classification of, $x 7$; conducting t., I07, Ir4; formative t., I7, 32 (see also Cambium and Growing point); fundamental (see Ground tissue); ground t., $14, x 7,28,29,30,31,36,40$, $43,64,65,66,98,107$; mechanical or supporting t., 4I; permanent $t ., I_{7}$; vascular t., $16,17,18,19,28,29,30,36$, $41,66,91,98,107$, IIr, 152 .

Toadflax, 90, I22, I28, 157 .

Tobacco plant, I57.

'T'omato, I 57.

Tomentose, 28.

Torus (see Floral receptacle).

Trachex, 35, 43.

Tracheide, 35, 4x, 66 .

Trailing, 54.

'Transmitted light, 159

Transpiration, 69-7x, 16o. [tropism, 73.

Transverse, I28; geotropism, 73; helio-

Tree, 23, 25, 37, 38, 41, 46, 49, 54, 64, 68, I 6,149 , I 55 .

Trefoil (see Bird's-foot trefoil).

'Triadelphous, 95.

'Triangular, $23,52$.

Trichomes (sce Hairs).

Trifurcation, 6r.

Trimorphic, 125 .

I'ripinnate, $6 r$.

Triternate, $6 \mathrm{r}$.

Tropieal, 88.
'I'rue fruits, $x_{35}, x_{3} 6-x_{39}$

I'runk, 23, 25, 38, 42, 49 .

'lube, $84,85,87,89,95,127$; of microscope, $158,159$.

Tuber, 26, 44, r6o; root tubers, I4, 19.

T'uberous, $146, \mathbf{x}_{54}$.

Tubular, 55, 84, 85, 89, 147 .

Tulip, 21, 75, 76, 86, 98, 104, 120, 130ิ.

Tulip-tree, I 49 .

Turgid, 9.

'Turgidity, 9, 32, 69, 70.

'Turnip, 13, 14, I55.

Turnip-shaptd, 146 .

Twig, 40, 46, 54 .

Twining, 25, 44 .

Twisted, 55, 89, 154 .

Two, 6i, 84, 86, 87, 88, 93, 94, 96, 97, 98, $100,104,106,124,136,137, x_{3} 8$.

Two-ranked, 50, 55 .

'I'wo-rayed, 79.

U.

UMBEL, $78,79, \mathbf{I}_{5} 6$.

Umbelliferæ, $79,119,156$.

Umbrella, 67, 78 .

Unbidden guests, III-II3, I19, 129.

Undershrubs, 23,156 .

Undifferentiated, 55 .

Uniaxial, 75 .

Unicellular, 8, 28, 72 .

Unilocular, 104, 105, 106, 139.

Union ; of foliage-leaf margin, 55 ; of lobes, 58 (see Adhesion and Cohesion).

Unisexual, 98, 99, 115, 116, х18, I21, I54, $x 55$.

Units of structure, 5 .

Unsymmetrical, 55 .

Urceolate, 89, 123.

Urn-shaped, 89

Urticacexe, ${ }_{54}$.

Utricularia, 62 .

V.

VACUOLE, 8, 32, 72.

Vacuolized, 32.

Vallisucria, 71, 115 .

Valvate, 84 , 150.

Valve, 62, I37.

Valvular, 97.

Vapour, 60 .

Variegated, 62 .

Vascular, I6.

Vascular cylinder (of root), $\mathbf{1 4}, \mathbf{x} 6$.

Vegetable marrow, 25, 28, 36, 95, 101 .

Vegetative, 17, 7 1, 74.

Veinlet, 56.

Veins, 55-57, 63, 65, 91, 104.

Venation, 55-57, 147 .

Ventral, 103, 107.

Ventral suture, I02, I04, I06, 107, I37.

Venus' fly-trap, 6r, 73 .

Verbena, 93 .

Vernation (see Prefoliation).

Versatile, $96,117,118$.

Vertical, $54,55,68,70,128,146,147$.

Verticillaster, $\tau_{57}, 180$.

Vessel, $x 6,33-34,41$ (see Tissue, vascular); annular v., $34 ; 36$; pitted v., 34 ; spiral v., 34,36 .

Vetch, $6 x_{1}, x_{3}, x_{4} 0, x_{5} 6$. 
Vicia faba (sce Bean).

Villous, 28.

Vinca, 54.

Vine, $18,25,27$.

Violacea, 155 .

Violet, $21,49,76,88,93,96$, 104, I07, I2I, $127,1_{3}^{8}, 1_{4} 0,14 x, 149$

Virginian ereeper, 25,45 .

Viscid (sce Sticky).

\section{W.}

WALL, 45 .

Wallflower, $21,28,62,77,83,84,85,87,88$, $94,98,1_{23}, I_{37}, I_{4} I_{1} I_{5}$, I 55 .

Walnut, r 39 .

Wash-leatier, 159 .

Wasp, rig, I2I.

Waste of organisms, 6 .

Waste products, II.

Watch, 44.

Watch-glasses, I59, I60.

Water, 3,4 , I0, II, I9, 4I, 42, 67, 68, 69, 70, 7I, II I I I 5, I40, I4I, I60 (see Moisture); conduction of water, 42 ; free W., 17 ; hygroscopic w., 17 ; of soil, 17 .

Water-cress, 155 .

Water-lily, 21, 86, 92, 96, 105, 149.

Water-pimpernel, 93,97 .

W:ater-pollinated, i1 5 .

Water-thyme, 43 .

Wary, 147 .

Wax, 4I, 62, II2.

Weather, protection from, $4^{\mathrm{I}}, 47,67, \mathrm{II}_{3}-$ II 4 ; sunny w., 70; wet w., 70.

Weel, II2, 129 .

Wet (see Weather).

Wheat, $78, x_{1} 7,1_{33}, x_{35}, x_{3} 6, x_{43}$.

Wheel-shiped, 89 .

White, 76,83 , I19, ז4I; w. bread, I35; w. lily (see Lily).

Whole flour, 135 .

Whorl, 8x, 82, 83, 85, 87, 93, 94, 97, x 10, 155 , I57.
Whorled, 49 .

Wind, $45,53, \mathrm{Ir}_{3}, \mathrm{Ir}_{4}, \mathrm{Ir}_{5}-\mathrm{II} 8, \mathrm{I}_{4} \mathrm{O}, \mathrm{I}_{4} \mathrm{I-}$ 142 .

Window, 45.

Wind-pollinated, $115-1 \times 8,120$.

Wing, $58,63,126,127,142$.

Winged, 23, 46, 52, 6r, 63, 142 .

Wingless insects, $4 \mathrm{I}, \mathrm{III}, \mathrm{II}_{3}$.

Wild pea, 63 .

Willow, 41, 51, 78, 84, 87, 99, 100, 1 16, 12 I, I5I, 155 .

Willow-herb, 93, 120, 124, 142, 156.

Winter cherry, 157 .

Winter, 25.

Wisteria, 88.

Wolffia, 21, 153 .

Wood, $3 \mathrm{I}, 34,37,40,4 \mathrm{I}, 42,66,67,152$; $\mathbf{w}$. fibre, 31, 32, 34 : heart w., 38 ; w. parenchyma, $3 \mathrm{r}, 32,34$; primary $\mathrm{w}$., $36 ; \operatorname{sap} w ., 38 ;$ secondary w., 37 ; w. ressels, $3 \mathrm{I}, 32,34,36,66$.

Wood-sage, 90, 129.

Wood-sorrel, 72, 117 .

Woody, 36.

Woolly, 28, 67 .

Wrinkled, $\mathrm{I}+6$.

$\mathrm{x}$.

Xrlear (see Wood)

Y.

YARROW, 59 .

Yellow, 60, 74, 75, 78, 90, 9 $1,97,99$, 105. I19, I22, I60; Y. bird's nest, $64 ; \bar{y}$. pea, 63 ; y. rattle, 157 .

Yew, 2r, 54, 84, r34, I52.

Z.

ZOOLOGT, 2.

Zygomorphic, 80 (see Irregular).

THE END. 



\section{A SELECTION}

nom

\section{TME PUBLICATIONS}

OF

\section{CHARLES GRIFFIN \& COMPANY, \\ LI IM ITED.}

MESSRS. CHARLES GRIFFIN d COMPANY'S PUBLICATIONS may be obtained through any Bookseller in the United Kingdom, or will be sent Post-free on receipt of remittance to cover published price. To prevent delay, Orders should be accompanied by a Remittance. Cheques and Postal Orders to be crossed "Sirith, Payne \& Smiths."

General, Medical, and Technical Catalogues sent Post-free on Application. 


\section{NDFX.}

Early Christian Literature, . . . . . . ${ }^{\text {PAGR }} 3$

Prof. Eadie's Biblical Works, . . . . . . 4

The Emerald Series of Poets, including the "Eton" Gray, 6

Illustrated Classics, . $\quad$. $\quad$. $\quad$. $\quad$. 8

Histories of Literature, . . . . . 3, 9, 10, 14

Classical Antiquities, . . . . . . . . $\quad$ 12, 13, 16

Prehistoric Antiquities, . . . . . . . 15

Profs. Fleming \& Calderwood's Vocabulary of Philosophy, . 11 Griffin's Introductory Science Series, . . . . . 18

Mr. Southgate's Works, . . . . . . 5, 20 


\title{
A SELECTION FROM
}

\section{CHARLES GRIFFIN \& CO.'S}

\section{P U B L I C A T I O N S.}

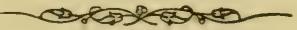

Now Ready, in Two Vols, Large 8vo, Handsome Cloth, 21 s.

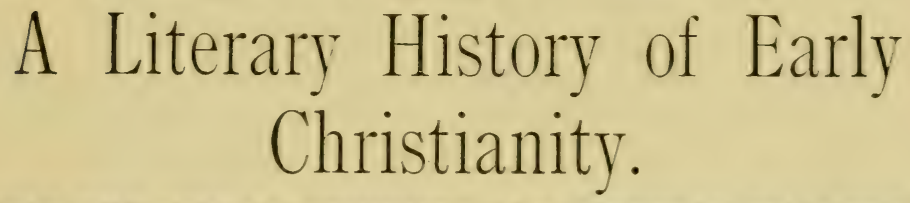

FOR THE USE OF STUDENTS AND GENERAL READERS.

BY

\author{
CHARLES THOMAS CRUTTIVELL, M.A., \\ Formerly Fellow of Merton College, Oxford; Author of "A History of Roman \\ Literature," \&c.
}

\begin{abstract}
"Mr Cruttwell has accomplished his task with Rentarkable success. His History is BMINENTLY READABLE. - It abounds in eloquent passages on subjects which have a deep interest for men of all times "-Athencum.

"The Author has accomplished his task ADMIRABLY. I do not know how more could be offered to the general reader than is contained in these 650 pages."-Professor A. Harnack in the Theologische Literaturzeitung.

"It cannot be doubted that Mr. Cruttwell's method, though somewhat novel in English theological literature, is well adapted to harmonise with the dominant tendencies of moden religious thought." - Times.

"A Most interesting account of the literature of the Ante-Nicene age, written in a free and agreeable style, with admirable and lucid descriptions of each Author, evincing accomplished scholarship, great literary ability, and historical acumen."-Church Times.

"The Sections on the Apostolic Fathers, the Apologists, and the Alexandrian writers are VERY SUCCESSFUL and full of instruction. The translations which enrich the workthe Didache, the Letter from the Churches of Lyon and Vienne, and the extracts from the lately discovered "Gospel of Peter - will certainly be heartily welcomed by many readers "Theologisches Literaturblatt.

"Precisely such a guide as is needed. . . . Admirably lucid and painstaking."English Churchman.

"Mr. Cruttwell's success-in making Early Christian Literature INTERESTING to the general reader of to-day-is great." - Scotsman.

"Mr. Cruttwell's work betrays everywhere the heart and hand of the earnest admirer and scholarly student. ... We have interesting sketches and admirable translations of interesting documents--and could wish there were more."-HIanchester Guardian.
\end{abstract}

LONDON : EXETER STREET, STRAND. 


\title{
STANDARD BIBLICAL WORKS
}

\author{
BY \\ THE REV. JOHN EADIE, D.D., LL.D., \\ Late a Member of the New Testament Revision Company.
}

This SERIEs has been prepared to afford sound and necessary aid to the Reader of Holy Scripture. The Volumes comprised in it form in themselves a Complete LiBRARY OF REFERENCE. The number of Copies already issued greatly exceeds A QUARTER OF A MILLION.

I. EADIE (Rev. Prof.): BIBLICAL CYCLO. PÆDIA (A); or, Dictionary of Eastern Antiquities, Geography, and Natural History, illustrative of the Old and New Testaments. With Maps, many Engravings, and Lithographed Fac-simile of the Moabite Stone. Large post 8vo, 700 pages. Handsome cloth, 7/6. Trenty-sixt/ Edition.

II. EADIE (Rev. Prof.) : CRUDEN'S CONCORDANCE TO THE HOLY SCRIPTURES. With Portrait on Steel, and Introduction by the Rev. Dr. King. Post 8vo. Fifty-fourth Edition. Handsome cloth, $3 / 6$.

** Dr. EAdie's has long and deservedly borne the reputation of being the COMPLETEST and BEST CONCORDANCE extant.

III. EADIE (Rev. Prof.): CLASSIFIED BIBLE (The). An Analytical Concordance. Illustrated by Maps. Large Post 8vo. Sixth Edition. Handsome cloth, 8/6.

"We have only to add our unqualified commendation of a work of real excellence to every Biblical student."-Christian Times.

IV. EADIE (Rev. Prof.): ECCLESIASTICAL CYCLOPADIA (The). A Dictionary of Christian Antiquities, and of the History of the Christian Church. By the Rev. Professor EADIB, assisted by numerous Contributors. Iarge Post 8vo. Sixth Edition.

Handsome cloth, . . . . 8/6.

"The ECCLESIASTICAL Cyclopedia will prove acceptable both to the clergy and laity of Great Britain: A great body of useful information will be found in it."-Athenaum.

V. EADIE (Rev. Prof.) : DICTIONARY OF THE HOLY BIBLE (A); for the use of Young People. With Map and Illustrations. Small 8vo. Thirty-eighth Thousand. Cloth, elegant, . . . . $2 / 6$. 


\title{
MR. SOUTHGATE'S WORKS.
}

\author{
(See also p. 20.)
}

"No one who is in the habit of writing and speaking much on a variety of subjects can afford to dispense with Mr. SouthGate's Works."-Glasgow Nerws.

THIRD EDITION.

\section{SUGGESTIVE THOUGHTS ON RELIGIOUS SUBJECTS:}

A Dictionary of Quotations and Selected Passages from nearly I, of the best Writers, Ancient and Modern.

Compiled and Analytically Arranged

\section{B Y H E N R Y SOU T H G A T E.}

In Square 8vo, elegantly printed on toned paper.

Presentation Edition, Cloth Elegant, .

Library Edition, Roxburghe,

Ditto, Morocco Antique, .

The treated of are as wide as our Christianity itself : the writers quoted are from every Section of the one Catholic Church of JESUS CHRIST."-Author's Preface.

"Mr. Southgate's work has been compiled with a great deal of judgment, and it will, I trust, be extensively useful."-Kev. Canon Liddon, D.D., D.C.L.

"A casket of gems."-English Churchman.

"This is another of Mr. Southgate's most valuable volumes. . . . The mission which the Author is so successfully prosecuting in literature is not only highly beneficial, but necessary in this age. . . . If men are to make any acquaintance at all with the great minds of the world, they can only do so with the means which our Author supplies." - Homilist.

"Many a busy Christian teacher will be thankful to Mr. Southgate for having unearthed so many rich gems of thought ; while many outside the ministerial circle will obtain stimulus, encouragement, consolation, and counsel, within the pages of this handsome volume."Nonconformist.

"Mr. Southgate is an indefatigable labourer in a field which he has made peculiarly his own. . . The labour expended on 'Suggestive Thoughts' must have been immense, and the result is as nearly perfect as human fallibility can make it. . . . Apart from the selections it contains, the book is of value as an index to theological writings. As a model of judicious, logical, and suggestive treatment of a subject, we may refer our readers to the manner in which the subject 'Jesus CHRIST' is arranged and illustrated in 'Suggestive Thoughts." "-Glasgow News.

\section{"Every day is a little life."-Bishop HALL.

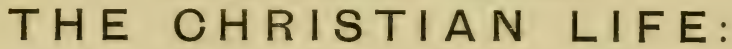

Thoughts in Prose and Verse from 500 of the Best Writers of all Ages.

Selected and Arranged for Every Day in the Year.

By MRS. H. SOUTHGATE.

Small 8vo. With Red Lines and unique Initial Letters on each page.

Cloth Elegant, 5/. Second Edition.

"A volume as handsome as it is intrinsically valuable."-Scotsman.

"The Readings are excellent."-Record.

"A library in itself."-Northern Whig. 


\section{ANECDOTES (Cyclop midia OF Religious AND}

Moral). With an Introductory Essay by the Rev. George CHeEver, D.D. Thirty-sixth Thousand. Crown 8vo. Cloth, 3/6.

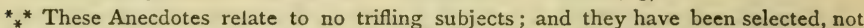
for amusement, but for instruction. By those engaged in the tuition of the young, they will be found highly useful.

The Large-Type Bunyan.

\section{BUNYAN'S PILGRIM'S PROGRESS. With}

Life and Notes, Experimental and Practical, by William MASON. Printed in large type, and Illustrated with full-page Woodcuts. Twelfth Thousand. Crown 8vo. Bevelled boards, gilt, and gilt edges, $3 / 6$.

\section{CHRISTIAN YEAR (The): With Memoir of the} Rev. John KeBle, by W. Temple, Portrait, and Eight Engravings on Steel, after eminent Masters. Nerw Edition. Small 8vo, toned paper. Cloth gilt, $5 \%$

** The above is the only issue of the "Christian Year" with Memoir and Portrait of the Author.

\section{THE EMERALD SERIES OF POETS.}

Illustrated by Engravings on Steel, after Stothard, LESLIE, David Roberts, Stanfield, Sir Thomas Lawrence, Cattermole, \&c. Fcap 8vo. Cloth, gilt.

Particular attention is requested to this very beautiful series. The delicacy of the engravings, the excellence of the typography, and the quaint antique head and tail pieces, render them the most beautiful volumes ever issued from the press of this country, and now, unquestionably, the cheapest of their class.
BYRON, 3/.
Camplell, $3 /$.
Chatterton, $3 /$.
GRAY (Eton Edition, with
KEBLE, 5/.
the Latin Poems), 5/.
Goldsmith, 3/.
POE, 3/.

FOSTER (Charles): THE STORY OF THE BIBLE, FROM GENESIS TO REVELATION. Including the Historical Connection between the Old and New Testaments. Told in Simple Language. With Maps and over 250 Engravings (many of them Full-page, after the drawings of Professor Carl Schönherr and others), Illustrative of the Bible Narrative, and of Eastern Manners and Customs. FifTH and Greatly Improved Edition. In large 8vo. Cloth Elegant, 6/-; Gilt and Gilt Edges, 7/6.

"A book which, once taken up, is not easily laid down. When the volume is opened, we are fairly caught. Not to speak of the well-executed wood engravings, which will each tell its story, we find a simple version of the main portions of the Bible, all that may most profitably be included in a work intended at once to instruct and charm the young -a version couched in the simplest, purest, most idiomatic English, and executed throughout with good taste, and in the most reverential spirit. The work needs only to be known to make its way into families."-Scotsman. 


\title{
MIND IN MATTER:
}

\section{A SHORT ARGUMIFINT ON THEISM.}

BY THE

REV. JAMES TAIT.

Third Edition. Demy Svo. Handsome Cloth, 6\%.

General Contents.-Evolution in Nature and Mind-Mr. Darwin and Mr. Herbert Spencer-Inspiration, Natural and Supernatural-Deductions.

${ }^{*}{ }^{*}$ Special attention has in this, the Third Edition, been directed to Embryology and later Darwinism.

"An able and original contribution to Theistic literature. . . . The style is pointed, concise, and telling to a degree."-Glasgoze Herald.

"Mr. TAIT advances many new and striking arguments . . highly suggestive and fresh."-Brit. Quarterly Reviezv.

\section{THE MASSES:}

\section{HOW SHALL WE REACH THEM?}

Some Hindrances in the way, set forth from the standpoint of the People, with Comments and Suggestions.

\section{BY \\ AN OLD LAY HELPER. \\ Cloth, 2s. 6d. Second Edition.}

\begin{abstract}
** An attempt to set forth some deficiencies in our present methods of reaching the poor, in the language of the People themselves.

"So full of suggestiveness that we should reprint a tithe of the book if we were to transcribe all the extracts we should like to make." - Church Bells.

"'Hindrances in the way' exactly describes the subject-matter of the Book Any one contemplating Missionary work in a large town would be helped by studying it." - Guardias.

" "The Masses' is a book to be well pondered over and acted upon."-Church Work.

"A very useful book, well worth reading."-Church Times.

"A most interesting book. - . Contains a graphic description of work among the masses."-English Churchman.
\end{abstract}

\section{WORDS AND WORKS OF OUR BLESSED LORD:}

AND THEIR LESSONS FOR DAILY LIFE.

Two Vols. in One. Foolscap 8vo. Cloth, gilt edges, 6/. 


\section{EDUCATIONAL PUBLICATIONS.}

\section{Standard I/lustrated Classics.}

\section{BRYCE (Archibald Hamilton, D.C.L., LL.D.,}

Senior Classical Moderator in the University of Dublin) :

THE WORKS OF VIRGIL. Text from Heyne and Wagner. English Notes, original, and selected from the leading German and English Commentators. Illustrations from the antique. Complete in One Volume. Fourteenth Edition. Fcap 8vo. Cloth, 6\%

Or, in Three Parts :

Part I. Bucolics and Georgics, . . $2 / 6$.

Part II. The ANEID, Books I.-VI., . $2 / 6$.

Part III. The ÆNEID, Books VII.-XII.,. 2/6.

"Contains the pith of what has been written by the best scholars on the subject. - The notes comprise everything that the student can want."-A thenaum.

"The most complete, as well as elegant and correct edition of Virgil ever published in this country."-Educational Times.

"The best commentary on Virgil which a student can obtain."-Scotsman.

\section{URR I E (Joseph, formerly Head Classical} Master of Glasgow Academy):

THE WORKS OF HORACE: Text from ORELlius. English Notes, original, and selected from the best Commentators. Illustrations from the antique. Complete in One Volume. Fcap 8vo. Cloth, 5/.

Or in Two Parts :

Part I.-Carmina, • • • . • $3 /$.

Part II.-Satires And Epistles, - . $3 /$.

"The notes are excellent and exhaustive."-Quarterly Foumal of Education. 
COBBETT (William): ENGLISH GRAMMAR.

With an additional chapter on Pronunciation, by the Author's Son, JAMES PAUL COBBETT. The only correct and authorised Edition. Cioth, $\mathbf{I} / 6$.

\section{COBBETT (William): FRENCH GRAMMAR.} Fifteenth Edition. Fcap 8vo. Cloth, 3/6.

“Cobbett's 'French Grammar' comes out with perennial freshness. There are few grammars equal to it for those who are learning, or desirous of learning, French without a teacher."-School Board Chronicle.

COBBIN'S MANGNALL: MANGNALL'S HISTORICAL AND MISCELLANEOUS QUESTIONS, for the use of Young People. By Richmal Mangnall. Greatly enlarged and corrected, and continued to the present time, by Ingram CoBbin, M.A, Fifty-fourth Thousand. New Illustrated Edition. 12mo. Cloth, 4/.

COLERIDGE (Samuel Taylor): A DISSERTATION ON THE SCIENCE OF METHOD. (Encyclopadia Metropolitana.) With a Synopsis. Ninth Edition. Cr. 8vo. Cloth, 2/.

\section{CRAIK'S ENGLISH LITERATURE.}

\section{A COMPENDIOUS HISTORY OF}

ENGLISH LITERATURE AND OF THE ENGLISH LANGUAGE FROM THE NORMAN CONQUEST. With numerous Specimens. By George Lillie Craik, LL.D., late Professor of History and English Literature, Queen's College, Belfast. New Edition. In two vols. Royal 8vo. Handsomely bound in cloth, 25\%

"Professor Craik has succeeded in making a book more than usually agreeable." The Times.

Crown 8vo. Cloth, 7/6. TENTH EDitron.

A MANUAL OF ENGLISH LITERATURE, for the use of Colleges, Schools, and Civil Service Examinations. Selected from the larger work, by Dr. CraIK. Tenth Edition. With an Additional Section on Recent Literature, by HeNRy Craik, M.A., Author of "A Life of Swift."

\footnotetext{
"A Manual of English Literature from so experienced a scholar as Professor Craik needs no other recommendation than the mention of its existence."- Spectator.
}

LONDON: EXETER STREET, STRAND. 


\section{WORKS BY REV. C. T. CRUTTWELL, M.A.,}

Late Fellow of Merton College, Oxford.

\section{A HISTORY OF ROMAN LITERATURE:}

\section{From the Earliest Period to the Times of the Antonines.}

Fifth Edition. Crown 8vo. Cloth, 8/6.

"Mr. Cruttwell has done a real service to all Students of the Latin Language and Literature. . . . Full of good scholarship and good criticism."-A thenaum.

"A most serviceable-indeed, indispensable-guide for the Student. . . . The 'general reader'- will be both charmed and instructed."-Saturday Revieve.

"The Author undertakes to make Latin Literature interesting, and he has succeeded. There is not a dull page in the volume.'-Academy.

"The great merit of the work is its fulness and accuracy."-Guardian.

\section{SPECIMENS OF ROMAN LITERATURE:}

\section{Prose Writers and Poets.}

From the Earliest Period to the Times of the Antonines.

Part I.-Roman Thought : Religion, Philosophy, Art, 6/.

Part II._Roman Style: Descriptive, Rhetorical, Humorous, 5/.

Or in One Volume complete, Io/6. SECOND EDITION.

Edited by C. T. Cruttwell, M.A., Merton College, Oxford; and Peake Banton, M.A., some time Scholar of Jesus College, Oxford.

"Marks a new era in the study of Latin."-English Churchman.

"A work which is not only useful but necessary. The sound judgment exercised in plan and selection calls for hearty commendation."-Saturday Review.

* * KEY to Part II., Period II., by Thos. Johnston, M.A., may now be had (by Tutors and Schoolmasters only) on application to the Publishers, Price $2 / 6$.

\section{A HISTORY OF EARLY CHRISTIAN LITERATURE}

\section{For the use of Students and General Readers.}

In Two Vols. 8vo, Handsome Cloth.

[See page 3. 


\section{HELLAS: An Introduction to Greek Antiquities,}

Comprising the Geography, Religion and Myths, History, Art and Culture of old Greece.

On the Basis of the German Work by E. DOERING, With Additions by ELLIOTT GRÆME.

In Large 8vo, with Map and Illustrations.

\section{P A R T I.}

The Land and the People: the Religion and Myths of Old Greece

* In the English version of Mr. Doering's work, the simple and interesting style of the original-written for young Students-has been retained; but, throughout, such additions and emendations have been made as render the work suitable for more advanced Students, and for all who desire to obtain, within moderate compass, more than a superficial acquaintance with the great People whose genius and culture have so largely influenced our own. The results of the latest researches by Dr. Schliemann, MM. FouQue, CARAPANos, and others, are incorporated.

[Shortly.

\section{D'ORSEY (Rev. Alex. J. D., B.D., Corpus}

Christi Coll., Cambridge, Lecturer at King's College, London) :

SPELLING BY DICTATION: Progressive Exercises in English Orthography, for Schools and Civil Service Examinations. Sixteenth Thousand. I8mo. Cloth, I/.

Fifth Edition. Now Ready. Ios. 6d.

\section{THE VOCABULARY OF PHILOSOPHY;}

OR, STUDENT'S BOOK OF REFERENCE

ON THE BASIS OF PROF. FLEMING'S VOCABULARY.

Reconstructed AND ALMost Entirely Rewritten by

H. CALDERWOOD, LL.D.,

Professor of Moral Philosophy in the University of Edinburgh.

"The additions by the Editor bear in their clear, concise, vigorous expression, the stamp of his powerful intellect, and thorough command of our language. '-Weekly Reviez. . 
By Prof. GARDNER and F. B. JEVONS, M.A.

\section{A MANUAL OF GREEK ANTIQUITIES. \\ For the Use of Students and General Readers.}

PERCY GARDNER,

M.A., LITT. I.,

Prof. of Class. Archæology and Art in the University of Oxford ;
BY

AND
F. B. JEVONS,

M.A., LITT.D., Classical Tutor in the University of Durham.

In Large Crown 8ro. IVith Illustrations. Price I8s.

\section{GENERAL CONTENTS.}

Books I.-V. by Dr. Gardener-Books VI,-IX, by Dr. Jevons.

Book I.-THE SURROUNDINGS OF GREEK LIFE: The Land and PeopleThe Cities: Arrangement and Plan-The Homeric House-Private Houses: Historical Times-The Dress of Men and Women.

BooK II.-RELIGION AND MYTHOLOGY : National and Borrowed Elements in Religion-Classification of Mythis-Formation of the Pantheon-The Homeric and Hesiodic Pantheon-The Pantheon of Historic Times.

Book III.-CULTUS : Sacred Precincts and Temples-Temple Property-Organisation of Religious Societies-Orgiastic Cults-Temple Ritual-Sacrifice-Divination and Oracles - The Public Games-The Mysteries-The Attic Calendar.

BooK IV.-THE COURSE OF LIFE : Childhood and Education-Physical Training -Daily Life of Men - Travelling-Position and Employments of Women-Treatment of Disease-Burial and 'Tombs.

Book V.-COMMERCE : Agriculture and Pasturage-Manufactures and Professions - Commerce and Trade-Routes-The Money-Market and Coins.

Book VI.-CONSTITUTIONAL AND LEGAL ANTIQUITIES : The Homeric State -The Spartan Constitution-Crete-The Constitutional History of AthensAthens: Metics, Citizens, Demes, Tribes: The Magistrates; The Boulê and the Areopagus; The Ecclesia; Finance-T: e Government of Athens-Attic Law : Protection of Life and of the Person; the Law of Property ; of Inheritance; Marriage Laws-Offences against the State-The Laws of Gortyna-The Judicial System and Legal Procedure in Athens-Greek States in their Relations to each other.

Book VII.-SLAVERY: The Sources of the Slave Supply-Employment and Treatment of Slaves-Emancipation and Price of Slaves-The Effects of Slavery.

Book VIII.-WAR : Armour and Drill-Army Organisation-The Army in the Field-Siege Warfart and Fortifications-The Trireme-Naval Warfare.

Book IX.-THE THEATRE: Origin of the Drama-The Buildings-SceneryActors and their Costumes-Production and Performance of a P'lay.

** The present work is an attempt to compress into a single volume, for the use of students, in a logical and readable form, an Introduction to all the Main Branches of HELLENIC ANTIQUITIES-Social, Religious, and Political.

LONDON : EXETER STREET, STRAND. 


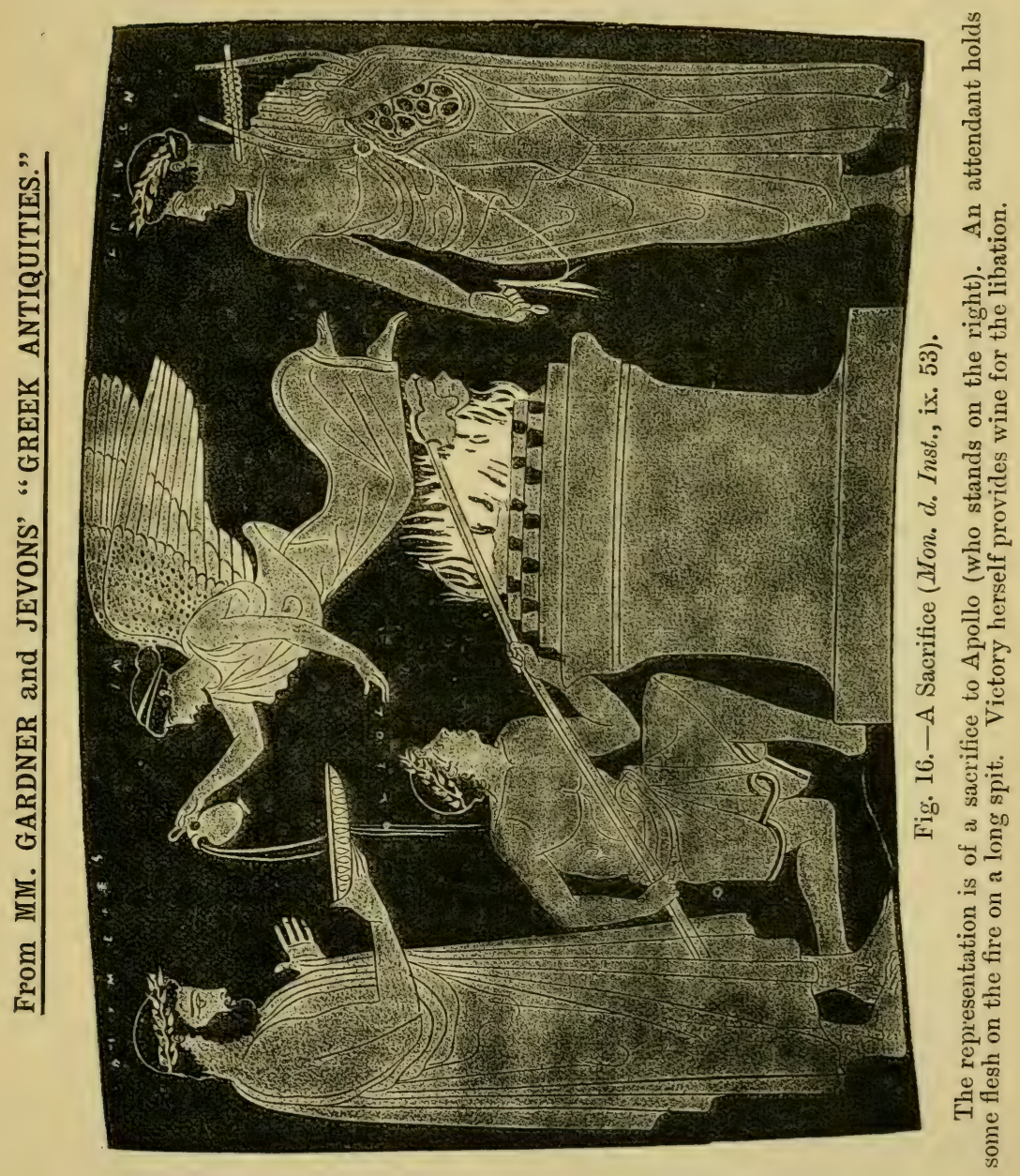

LONDON : EXETER STREET, STRAND. 


\section{WORKS BY F. B. JEVONS, M.A., Litt.D.}

Second Edition, Revised. Crown 8vo, Cloth, 8s. 6d.

\section{A HISTORY OF GREEK LITERATURE。}

From the Earliest Period to the Death of Demosthenes.

By FRANK BYRON JEVONS, M.A., Litt.D., Classical Tutor in the University of Durham.

Part I.-Epic, Lyric, and the Drama.

Part II.-History, Oratory, and Philosophy.

Second Edition. With Appendix on The Present State of the Homeric Question.

"It is beyond all question the BEST HISTORY of Greek literature that has hitherto been published."-Spectator.

"An admirable text-book."-Westminster Review.

"Mr. Jevons' work supplies a real want."-Contemporary Revierw.

"Mr. Jevons' work is distinguished by the Author's THOROUGH ACQUAINTANCE with THE OLD WRITERS, and his DISCRIMINATING USE Of the MODERN LITERATURE bearing upon the subject. . . His great merit lies in his EXCELLENT EXPOSITION of the POLITICAL AND SOCIAL CAUSES concerned in the development of the Literature of Greece."-Berlin Philologische Wochenschrift.

"As a Text-Book, Mr. Jevons' work from its excellence deserves to SERVE AS A MODEL." -Deutsche Litteraturzeitung.

\section{THE DEVELOPMENT OF THE ATHENIAN DEMOCRACY.} Crown 8vo, Is.

\section{A MANUAL OF GREEK ANTIQUITIES FOR THE USE OF STUDENTS.}

[See under Gardner and Jevons.

\section{PREHISTORIC ANTIOUITIES OF THE ARYAN PEOPLES,}

Translated from the German of PROF. SCHRADER by DR. JEVONS. (See next page.) 
In Large 8vo, Handsome Cloth, Gilt Top, 21s.

\title{
PREHISTORIC ANTIQUITIES OF THE ARYAN PEOPLES:
}

\author{
By Prof. O. SCHRADER of Jena. \\ Translated from the Second Germax Edition by \\ F. B. JEVONS, M.A., Litt.D.
}

In Dr. Schrader's great work is presented to the reader a most able and judicious summary of all recent researches into the Origin and History of those Peoples, Ancient and Modern, to whom has been mainly entrusted the civilisation and culture of the world.

Dr. Schrader's pictures of the Primeval Indo-European Period:-The Animal Kingdom, Cattle, The Plant-World, Agriculture, Computation of Time, Food and Drink, Clothing, Dwellings, Traffic and Trade, The Culture of the Indo-Europeans, and The Prehistoric Monuments of Europe (especially the Swiss Lake-Dwellings), Family and State, Religion, The Original Home-will be found not only of exceeding interest in themselves, but of great value to the Student of History, as throwing light upon later developments.

$$
\begin{aligned}
& \text { Part I.-History of Lixguistic Palfontology. } \\
& \text { Part II.-Research by means of Language and History. } \\
& \text { Part III.-The First Appearance of the Metals. } \\
& \text { Part IV.-The Primeval Period. }
\end{aligned}
$$

"Dr. SChrader's Great' Work."-Times.

"Mr. Jevons has done his work excellently, and Dr. Schrader's book is a model of industry, erudition, patience, and, what is rarest of all in these obscure studies, of moderation and common sense." - Saturday Review.

"INTERESTING FROM BEGINNING TO END."-Manchester Guardian.

"A work in every respect of CONSPICUOUS EXCELLENCE." - $\boldsymbol{B}(r u) g m(a n n)-$ Litterar. Centralbl.

"I must confess that, for long, I have read no work which has roused in me so lively an interest as Dr. SCHRADER'S. Here all is FRESH, LIVING INSIGHT, AND SOLID WELL-BALANCED REASONING."-Wilh. Geiger-Deutsche Litteraturzeitung.

"A MOST REMARKABLE BOOK." - St(einthal)-Zeitschrift für Vülkerpsycholngie und Sprachwissenschaft.

"Every one who, for any reason whatsoever, is interested in the beginnings of European Civilisation and Indo-European Antiquity, will be obliged to place Dr. SCHRADER's book on his library shelves."-Gustav Jfeyer-Philologische Woehenschrift.

LONDON : EXETER STREET, STRAND. 


\section{WORKS BY WILLIAM RAMSAY, M.A.,}

Trinity College, Cambridge, late Professor of Humanity in the University of Glasgow.

By Profs. RAMSAY and LANCIANI.

\section{ROII A N ANTIQUITIES (A Manual of).}

By WILLIAM RAMSAY, M.A.

Fifteenth Edition, Revised by

Prof. RODOLFO LANCIANI, D.C.L.Oxon., LL.D., F.S.A.,

Assisted by Prof. E. DE RUGGERO,

Both of the University of Rome.

In Large Crown 8vo, with Two Photogravures. Ios. 6 d.

***The Fifteenth Edition includes a New Map and Plans prepared by Prof. Lancians to illustrate the most recent discoveries relative to the Topography of Ancient Rome.

"The chief interest in the New Edition centres in the chapter on Roman Topography, which has been entirely revised and partly rewritten by Prof. LANCIANI, the greatest living authority on this subject. We recommend this most heartily to all who have been to Rome. or intend to go there. In Rome . . . it is THE BEST and HANDIEST guide yet produced."Athencenm.

RAMSAY'S ELEMENTARY MANUAL OF ROMAN ANTIQUITIES. Adapted for Junior Classes. With numerous. Illustrations, Eighth Edition. Crown 8vo. Cloth, 4/.

\section{RAMSAY'S MANUAL OF LATIN PROSODY,} Illustrated by Copious Examples and Critical Remarks. For the use of Advanced Students. Seventh Edition. Crown 8vo. Cloth, 5/.

"There is no other work on the subject worthy to compete with it."-Athenaum.

RAMSAY'S ELEMENTARY MANUAL OF LATIN PROSODY. Adapted for Junior Classes. Crown 8vo. Cloth, 2s. 


\section{McBURNEY (Isaiah, LL.D.,) : EXTRACTS} FROM OVID'S METAMORPHOSES. With Notes, Vocabulary, \&c. Adapted for Young Scholars. Third Edition. $18 \mathrm{mo}$. Cloth, $\mathrm{I} / 6$.

\section{MENTAL SCIENCE: S. T. COLERIDGE'S} celebrated Essay on METHOD; Archbishop Whately's Treatises on LOGIC and RHETORIC. Tenth Edition. Crown 8vo. Cloth, 5/.

\section{MILLER (W. Galbraith, M.A., LL.B., Lecturer} on Public Law, including Jurisprudence and International Law, in the University of Glasgow) :

THE PHILOSOPHY OF LAW, LECTURES ON. Designed mainly as an Introduction to the Study of International Law. In 8vo. Handsome Cloth, 12/.

"Mr. Miller's 'Philosophy of Law' bears upon it the stamp of a wide culture and of an easy acquaintanceship with what is best in modern continental speculation. . . Interesting and valuable, because suggestive."-Fournal of furisprudence.

SENIOR (Nassau William, M.A., late Professor of Political Economy in the University of Oxford):

A TREATISE ON POLITICAL ECONOMY. Sixth Edition. Crown 8vo. Cloth. (Encyclopadia Metropolitana), 4/.

THOMSON (James): THE SEASONS. With an Introduction and Notes by ROBERT BeLl. Fourth Edition. Cloth, I/6.

WHATELY (Archbishop): LOGIC-A Treatise on. With Synopsis and Index. (Encyclopadia Metropolitana), 3/.

RHETORIC-A Treatise on. With Synopsis and Index. (Encyclopaciia Metropolitana), 3/6. 


\section{GRIFFIN'S INTRODUCTORY SCIENCE SERIES.}

\section{FuLLY ILLUSTRATED.}

BOTANY.

CHEIMISTRY.

GEOLOGY.

ENGINEERING DRAWING.

THE FLOWERING PLANT. By Ainsworth Davis, Professor of Biology, University College, Aberystwyth. SECoNn EDition, . . . .

THE THRESHOLD OF SCIENCE. Easy and Amusing Expériments. By C. R. Alder Wright, D.Sc., F.R.S., SECOND EDITION,

OPEN AIR STUDIES. By Grenville Cole, F.G.S., M.R.I.A., Professor of Geology, Royal College of Science for Ireland. (Now Ready), . . . . $s / 6$

I. PRACTICAL GEOMETRY, PLANE AND SOLID,

By Sidney H. Wells, A.M.Inst. $\dot{C} . E$.

MAGNETISM \& AN INTHODUCTORY MANUAL. ELECTRICITY. By Prof. JAMIEsox, Glasgow and West of Scotland Technical College. THIRD

MECHANICS. AN INTRODUUTORY MANUAL. By Prof. Jamieson. Second Edition, . $3 / 6$

THE STEAII ENGINE. PHYSICS.

(Heat, Light, Photography, \&e.)
AN INTRODUCTORY MANUAL. By Prof. Jamieson. Fourth Edition, .

THE THRESHOLD OF SCIENCE.

By Dr. Alder Wright, F.R.S. Easy and Amusing Experiments. (Ste above. The Chemical and Physical Experiments are contained in the same volume), . .

** For full details of the above, see Griffin's Catalogue of SCIENTIFIC and Technical Works. 


\title{
A BOOK NO FAMILY SHOULD BE WITHOUT.
}

Thirtieth Edition. Royal 8vo, Handsome Cloth, ios. 6\%.

\section{A DICTIONARY OF \\ DOMESTIC MEDICINE AND HOUSEHOLD SURGERY,}

BY

\author{
SPENCER THOMSON, M.D., EDIN., L.R.C.S.,
} REVISED, AND IN PART RE-WRITTEN, BY THE AUTHOR.

BY

JOHN CHARLES STEELE, M.D., Late of GuY's Hospital,

AND BY

GE O. RE I D, M.D., D.P.H., Med. Officke, Stafrs. County Councin.

With Appendix on the Management of the Slok-room, and many Hints for the Dlet and Comfort of Invallds.

In its New Form, Dr. Spencer Thomson's "Dictionary of Domrstic Mrdicine" fully sustains its reputation as the "Representative Book of the Medical Knowledge and Practice of the Day" applied to Domestic Requirements.

The most recent IMPROVEMENTS in the TRRATMENT OF THE SICK-in APPLIANCrs for the RELIRF OF PAIN-and in all matters connected with SANITATION, HYgIRNR, and the Maintrnance of the Grneral Hralth-will be found in the New Issue in clear and full detail; the experience of the Editors in the Spheres of Private Practice, of Hospital Treatment, and of Sanitary Supervision respectively, combining to render the Dictionary perhaps the most thoroughly practical work of the kind in the English Language. Many new Engravings have been introduced-improved Diagrams of different parts of the Human Body, and Illustrations of the newest Medical, Surgical, and Sanitary Apparatus.

" All Directions gruen in such a form as to be readily and safely followed.

\section{FROM THE AUTHOR'S PREFATORY ADDRESS.}

" Without entering upon that difficult ground which correct professional knowledge and educated judgment can alone permit to be safely trodden, there is 2 wide and extensive field for exertion, and for usefulness, open to the unprofessional, in the kindly offices of 2 true DOMESTIC MEDICINE, the timely help and solace of a simple HOUSEHOLD SURGERY, or, better still, in the watchful care more generally known as 'SANITARY PRECAUTION,' which tends rather to preserve health than to cure disease. "The touch of a gentle hand ' will not be less gentle because guided by knowledge, nor will the safe domestic remedies be less anxiously or carefully administered. Life may be saved, suffering may always be alleviated. Even to the resident in the midst of civilization, the 'KNOWLEDGE IS POWER,' to do good ; to the settler and emigrat it is INVALUABLE."

". Dr. Thomson has fully succeeded in convoying to the public a vast amount of useful proiessional knowledge. "-Dwblin Fowrnal of Medical Scionce.

"The amount of useful knowledge conveyed in this Work is surprising." -Medical Tisus axd Gasette.

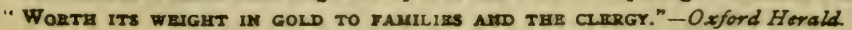




\section{FIRST SERIES-THIRTY-SIXTH EDITION. SECOND SERIES-TENTH EDITION.}

\section{MANY THOUGHTS OF MANY MINDS:}

\section{A Treasury of Reference, consisting of Selections from the Writings of the most Celebrated Authors. FIRST AND SECOND SERIES.}

COMPILED AND ANALYTICALLX ARRANGED

\section{By HENRY SOUTHGATE.}

Each Series is complete in itself, and sold separately.

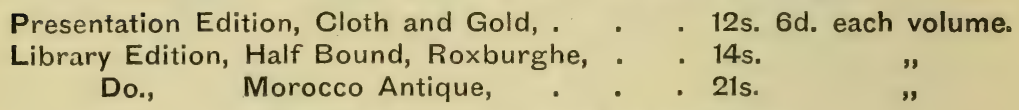

In Square $8 v 0$, elegantly printed on toned paper.

“'Manx Thodghts,' \&c., are evidently the produce of years of research." - Examiner.

"Many beautíful examples of thought and style are to be found among the selections."-Leader.

"There can be little doubt that it is destined to take a high place among books of this class."Notes and Queries.

"A treasure to every reader who may be fortunate enough to possess it. Its perusal is like inhaling essences: we have the cream only of the great authors quoted. Here all are seeds or gems." - English Journal of Education.

"Mr. Southgate's reading will be found to extend over nearly the whole known field of literature, ancieut and modern." - Gentleman's Magazine.

"We have no hesitation in pronouncing it one of the most important books of the season. Credit is due to the publishers for the elegance with which the. work is got up, and for the extreme beauty and correctness of the typography." - Horning Chronicle.

"Of the numerous volumes of the kind, we do not remember having met with one in which the selection was more judicious, or the accumulation of treasures so truly wonderful."-Morning Herald.

"The selection of the extracts has been made with taste, judgment, and critical nicety."-MIorning Post.

"This is a wondrous book, and contains a great many gems of thought."-Daily News.

"As a work of reference, it will be an acquisition to any man's library."-Publishers' Circular.

"This volume contains more gems of thought, refined sentiments, noble axioms, and extractable sentences, than have ever before been brought together in our language."-The Field.

"All that the poet has described of the beautiful in nature and art, all the axioms of experience, the collected wisdom of philosopher and sage, are garnered into one heap of useful and well-arranged instruction and amusement."-The kira.

"The collection will prove a mine rich and inexhaustible, to those in search of a quotation."Art Journal.
"Will be found to be worth its weight in gold by literary men." - T'he Builder.

"Every page is laden with the wealth of profoundest thought, and all aglow with the loftiest inspirations of genius." - Star.

"The work of Mr. Southgate far outstrips all others of its kind. To the clergymen, the author, the artist, and the essayist, "Many Thoughts of Many Minds cannot fail to render almost incalculable service."-Edinburgh Mercury.

"We have no hesitation whatever in describing Mr. Southgate's as the very best book of the class. There is positively nothing of the kind in the language that will bear a moment's comparison with it."-Manchester Weekly Advertiser.

"There is no mood in which we can take it up without deriving from it instruction, consolation, and amusement. We heartily thank Mr. Southgate for a book which we shall regard as one of our best friends and companions."-Cambridge Chronicle.

"I'his work possesses the merit of being a MAGNIFICENT GIFT-BOOK, appropriate to all times and seasons; $a$ book calculated to be of use to the scholar, the divine, and the public man."Freemason's Magazine.

"It is not so much a book as a library of quotations."-Patriot.

"The quotations abound in that thought which is the mainspring of mental exercise."-Liverpool Courier.

"For purposes of apposite quotation, it cannot be surpassed."-Bristol Times.

"It is impossible to pick out a single passage in the work which does not, upon the face of it, justify its selection by its intrinsic merit."-Dorset Chronicle.

"We are not surprised that a SECOND Skries of this work shuuld have been called for. Mr. Southgate has the catholic tastes desirable in a good Editor. Preachers and public speakers will find that it has special uses for them."-Edinburgh Daily Review.

"The SECoND SERIES fully sustains the deserved reputation of the FiRsT."-John Bull. 




\section{New York Botanical Garden Library}

QK45.A38 1892

gen

Ainsworth-Davis, Ja/The flowering plant:

||||||||||||||||||||||||||||||||||||||||||||||||||

35185001003985 
